Frauke Kraas

Regine Spohner

Aye Aye Myint
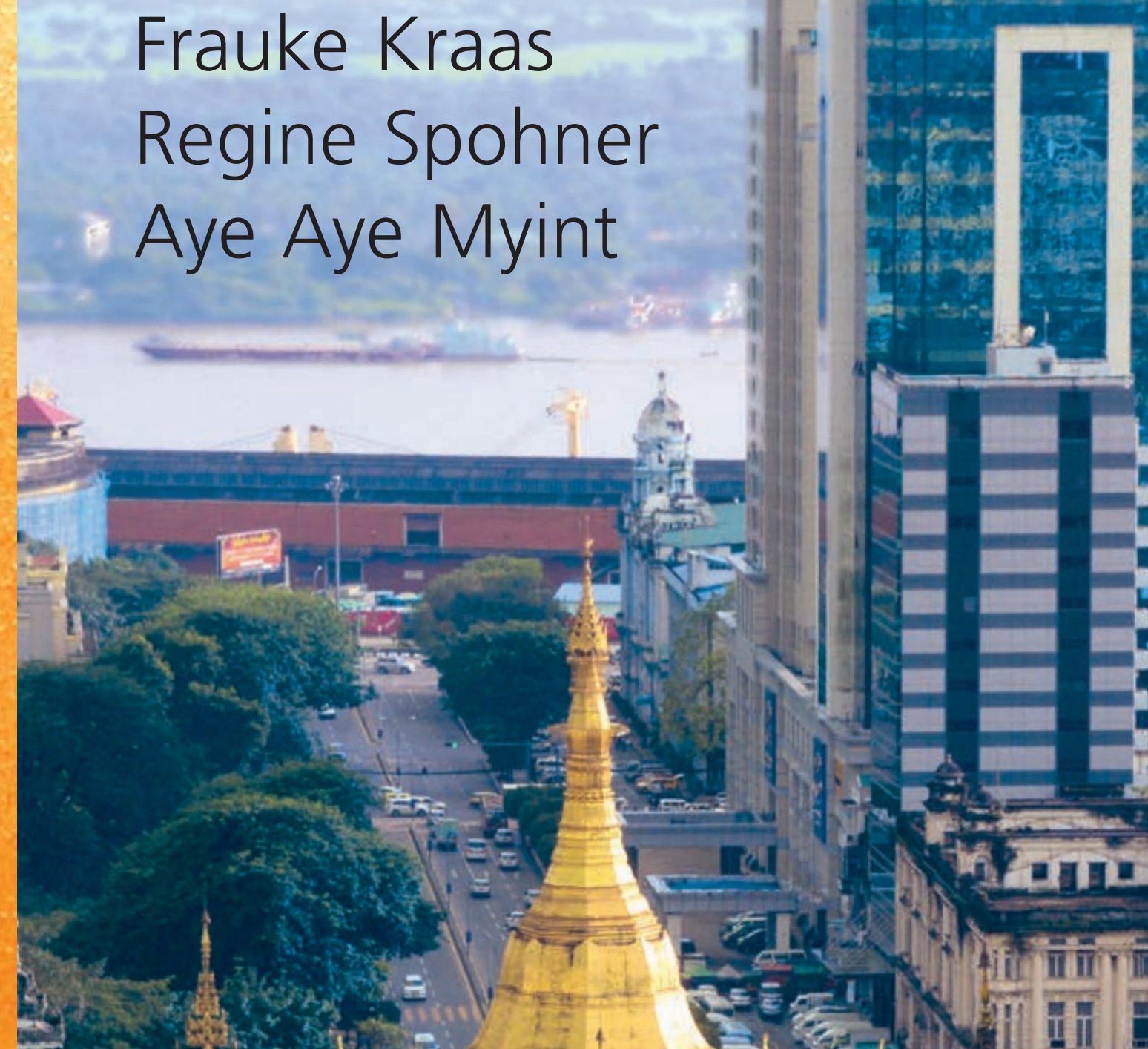
3 ind be

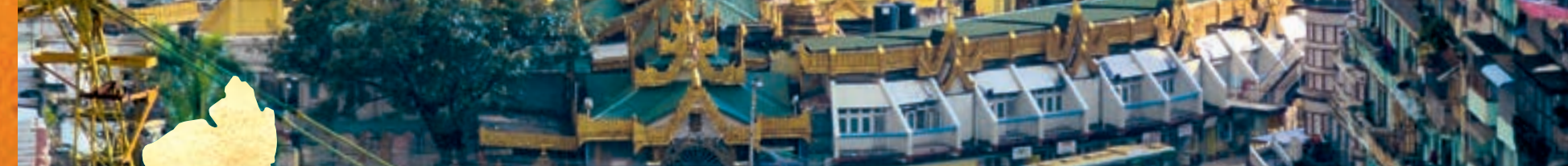
IN

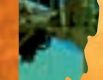
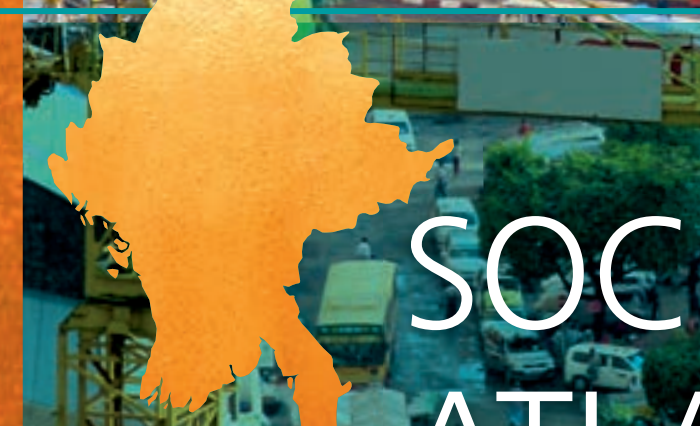

1. $0^{13}-A T$ - $y$. Exs at mixile 


\section{SOCIO-ECONOMIC ATLAS OF MYANMAR}

(7) Franz Steiner Verlag 


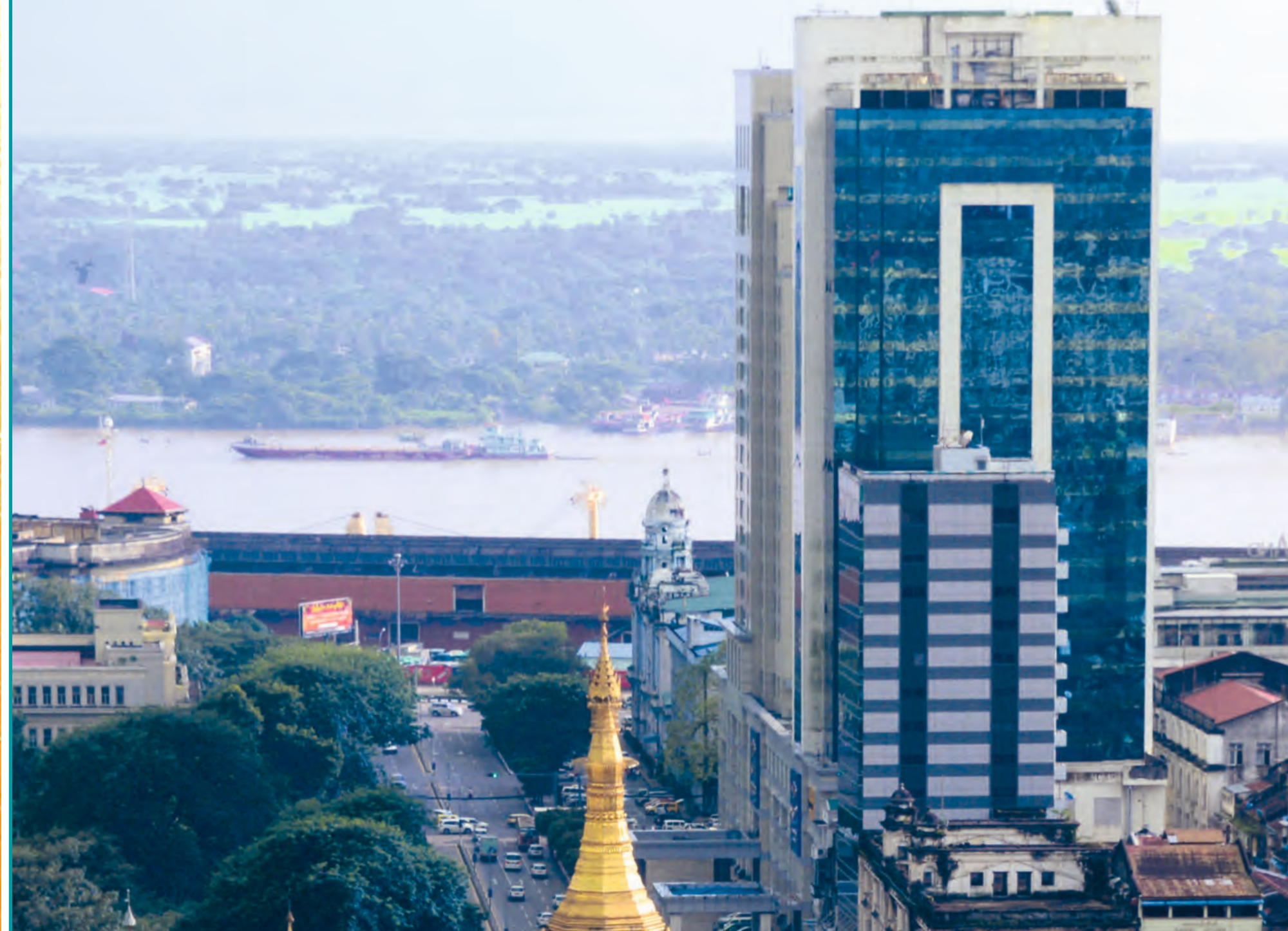

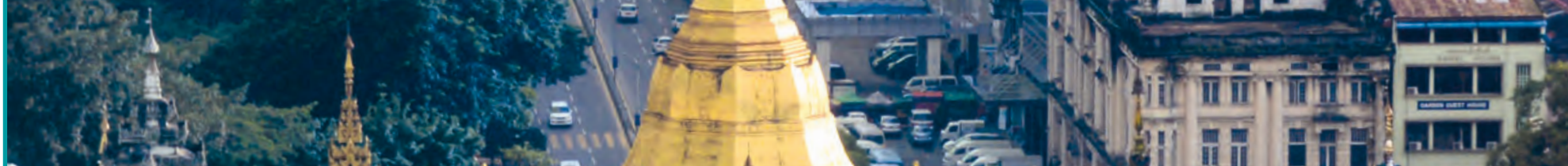

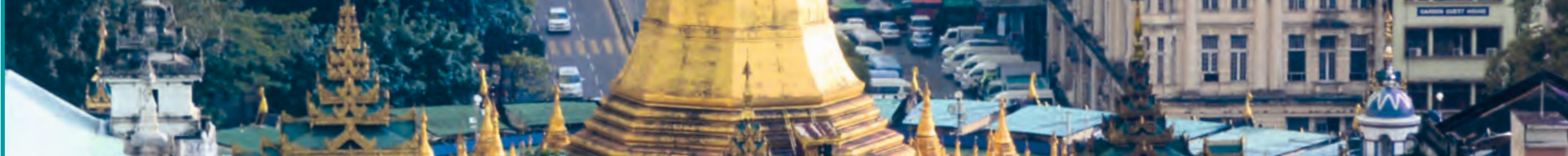

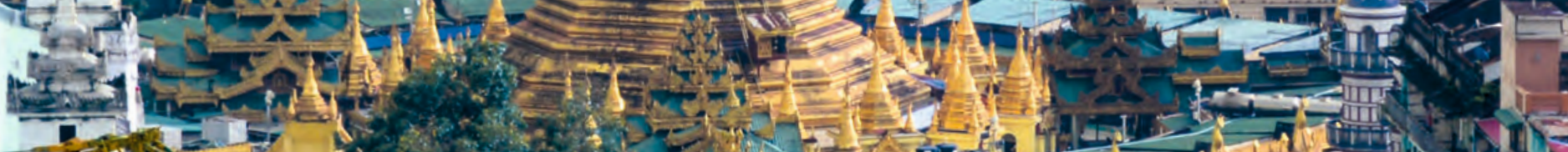

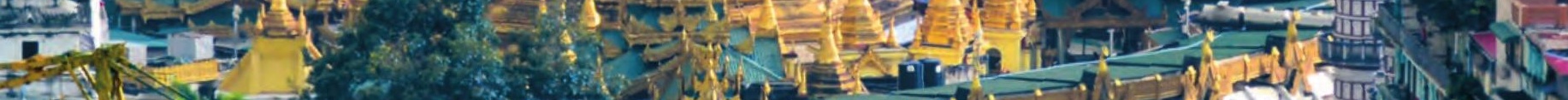

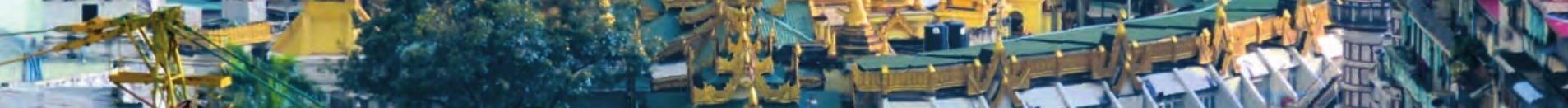

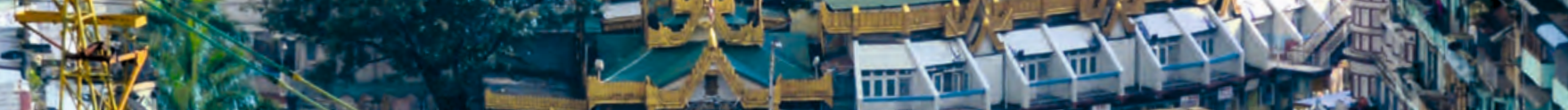

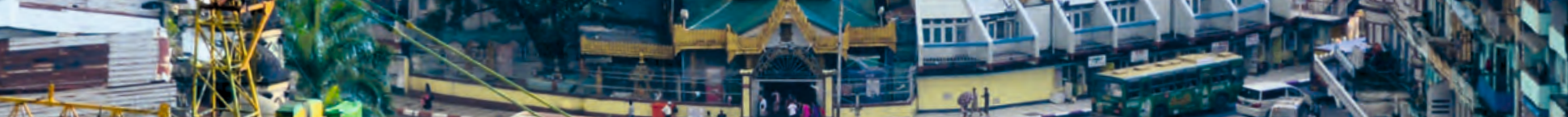

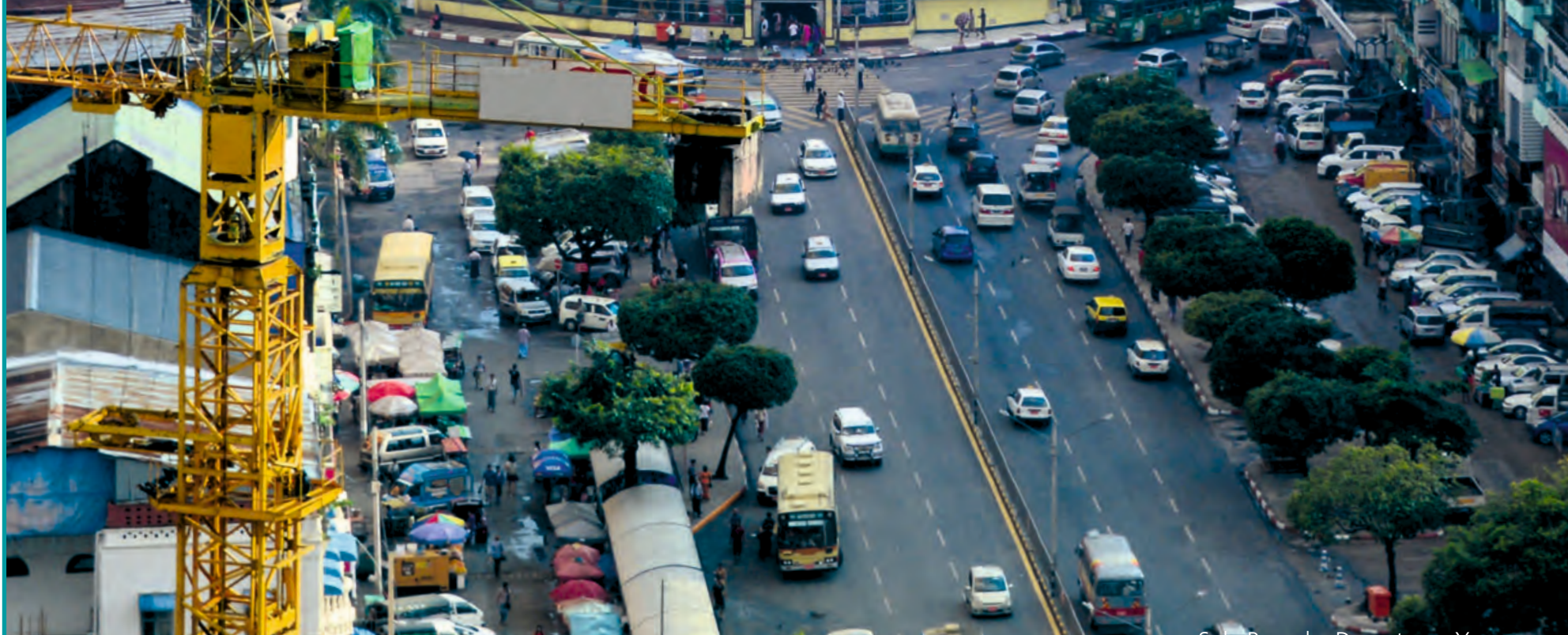
int $x=2$

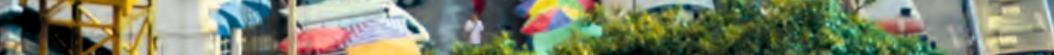


Frauke Kraas

Regine Spohner

Aye Aye Myint

Aung Kyaw, Hlaing Maw Oo,

Htun Ko, Khin Khin Han,

Khin Khin Soe, Myint Naing,

Nay Win Oo, Nilar Aung,

Saw Yu May, Than Than Thwe,

Win Maung, Zin Mar Than,

Zin Nwe Myint

\section{SOCIO-ECONOMIC ATLAS OF MYANMAR}


Diese Publikation wurde mit finanzieller Unterstützung der Deutschen Gesellschaft für Internationale Zusammenarbeit (GIZ) GmbH, der Universität zu Köln sowie der Deutschen Forschungsgemeinschaft (DFG) gedruckt.

This publication was printed with the financial support of the Deutsche Gesellschaft für Internationale Zusammenarbeit (GIZ) GmbH, the University of Cologne and the German Research Foundation (DFG).

Umschlagabbildung/Cover illustration:

Sule Pagoda, Downtown Yangon, Myanmar. @ Frauke Kraas

Taunggyi, Shan State, Myanmar. @ Frauke Kraas

Open Access

Wo nicht anders festgehalten, ist diese Publikation lizensiert unter der Creative Commons Lizenz CC-BY-NC-ND 4.0.

This book is distributed under the terms of the Creative Commons Attribution CC-BY-NC-ND NonCommercial-NoDerivatives 4.0.

Bibliographische Informationen der Deutschen Nationalbibliothek:

Die Deutsche Nationalbibliothek verzeichnet diese Publikation in der Deutschen Nationalbibliographie; detaillierte bibliographische Daten sind im Internet über <http://dnb.d-nb.de> abrufbar.

Bibliographic information published by the German National Library:

The German National Library lists this publication in the Deutsche Nationalbibliografie; detailed bibliographic information is available at $<$ http://dnb.d-nb.de $>$.

Dieses Werk einschließlich aller seiner Teile ist urheberrechtlich geschützt. Jede Verwertung außerhalb der engen Grenzen des Urheberrechtsgesetzes ist unzulässig und strafbar.

This publication and all parts thereof are protected by copyright. Any usage beyond the narrow limits of the Copyright Act is not permissible and liable to prosecution.

Layout: Stefanie Naumann (Lübbeke Naumann Thoben, Cologne)

Photos: Frauke Kraas, Regine Spohner

(๑) Franz Steiner Verlag, Stuttgart 2017

Druck/Print: Hubert \& Co., Göttingen

Gedruckt auf säurefreiem, alterungsbeständigem Papier. Printed on acid-free and age-resistant paper.

Printed in Germany.

ISBN 978-3-515-11623-7 (Print)

ISBN 978-3-515-11625-1 (E-Book) 


\section{CONTENTS}

\section{ACKNOWLEDGEMENTS}

1. CONCEPT AND DATA OF THE ATLAS

CONCEPT OF THE ATLAS

DATA AND MAPS

THE NATIONAL CENSUS 2014

2. ADMINISTRATIVE AND SPATIAL ORGANISATION

STATES AND REGIONS

ADMINISTRATIVE BOUNDARIES

3. ENVIRONMENT AND NATURAL RESOURCES

TOPOGRAPHY AND NATURAL LANDSCAPES

THE VIEW FROM THE SATELLITE

LAND COVER

CLIMATE: TEMPERATURE AND PRECIPITATION

NATURAL HAZARDS AND RISKS

NATURAL HAZARDS: EARTHQUAKES AND FAULT LINES, SEISMIC ZONES

ENVIRONMENTAL PROTECTION

MINERAL RESOURCES

$\begin{array}{ll}\text { FUEL MINERALS } & 57\end{array}$

METALLIC MINERALS

PRECIOUS METALS AND STONES, RARE EARTHS AND RADIOACTIVE METALS 61

4. POPULATION, SETTLEMENTS AND URBANISATION 63

POPULATION

TOTAL POPULATION AND SEX RATIO

POPULATION DENSITY BY TOWNSHIP

POPULATION DENSITY - POPULATION DISTRIBUTION MODEL 69

URBAN AND RURAL POPULATION

URBANISATION PROCESSES AND THE URBAN SYSTEM 72

RANKING AND LOCATION OF CITIES/TOWNS

5. INFRASTRUCTURE

ROADS, RAILROADS, AIRPORTS, PORTS $\quad 84$

ENERGY SUPPLY $\quad 92$

HYDROPOWER AND THERMAL POWER PLANT PROJECTS 93

$\begin{array}{ll}\text { TELECOMMUNICATIONS } & 94\end{array}$

INFORMATION AND COMMUNICATION TECHNOLOGY I MPT TOWERS 95

INFORMATION AND COMMUNICATION TECHNOLOGY I OOREDOO AND TELENOR TOWERS 97 
6. ECONOMIC DEVELOPMENT

GROSS DOMESTIC PRODUCT

DOMINATING ECONOMIC SECTORS' SHARES

GROSS DOMESTIC PRODUCT: DOMINATING ECONOMIC SECTORS' SHARES

AGRICULTURAL DEVELOPMENT

RAIN PADDY PRODUCTION

SUMMER PADDY PRODUCTION

CHANGE OF PADDY YIELD

AGRICULTURAL REGIONS

GROSS DOMESTIC PRODUCT: SHARE OF PRIMARY SECTOR

SHARE OF PRIMARY SECTOR IN TOTAL GDP 117

AQUACULTURE

SECONDARY SECTOR DEVELOPMENT AND INDUSTRIALISATION 122

SHARE OF SECONDARY SECTOR IN TOTAL GDP 123

CRAFTS

GARMENT INDUSTRY IN YANGON

THE TERTIARY SECTOR: ADMINISTRATION, TRADE, TRANSPORTATION AND TOURISM 130

GROSS DOMESTIC PRODUCT: SHARE OF TERTIARY SECTOR 131

TOURISM CENTRES AND REGIONS

7. SOCIAL DEVELOPMENT: HOUSEHOLD INFRASTRUCTURE, EDUCATION AND HEALTH

HOUSEHOLD INFRASTRUCTURE

MAIN SOURCE OF LIGHTING AND AVAILABILITY OF MOBILE PHONES

EDUCATION AND EDUCATION SYSTEM

PROPORTION OF PERSONS WITH EDUCATION

NUMBER OF PERSONS WITH EDUCATION

EDUCATION LEVEL

HIGHER EDUCATION: UNIVERSITIES, DEGREE COLLEGES, COLLEGES

HIGHER EDUCATION: SUBJECTS AND NUMBER OF STUDENTS

SUBJECTS, NUMBERS OF STUDENTS AND STUDENT-TEACHER RATIO

HEALTH AND HEALTH SYSTEM

REGIONAL HEALTH CENTRES

SUBREGIONAL HEALTH CENTRES

HOSPITALS AND DOCTORS 


\section{ACKNOWLEDGEMENTS}

Since Myanmar gained its independence on 4 January 1948, it has passed through several highly distinct phases of development: decades of isolation, at first self-imposed and later the result of sanctions, then the introduction of a market economy in the late 1980s, with various watershed moments in the country's politics, ushering in a period of transition which has recently gathered pace. This has been accompanied by radical political and economic changes, mainly at the national level but also in the international context as the country has opened up to the outside world. In Myanmar itself, at the level of the Union Territory of Nay Pyi Taw, the 14 states and regions and the 330 townships, dramatic changes are taking place: the massive expansion of infrastructure, the intensive development of formerly peripheral areas of the country, much of which has been driven by resource extraction, and stronger links with neighbouring countries, all of which are focusing interest on the nature and pace of, and potential for, development in individual regions. In this setting, the purpose of this 'Socio-Economic Atlas of Myanmar' is to provide, for the first time, a geographical overview and analysis of the country's development progress and the spatial characteristics and disparities in its socio-economic transition using maps and texts.

The idea for the Atlas evolved over the last 21 years, since February 1996, as a result of the increasingly intensive cooperation between the Departments of Geography at the University of Yangon, Myanmar, and the University of Cologne, Germany. The signing of the Memorandum of Understanding between the Universities on 23 August 2003 - highly unusual at the time - led to even more intensive cooperation in the fields of research and teaching. In 2011, the Centre of Excellence (CoE) for Urban and Regional Development was established as a partnership between the University of Yangon and the University of Cologne. Following various joint workshops between Germany and Myanmar, a partnership was also established with the then Department of Human Settlement and Housing Development (DHSHD), now the Department for Urban and Housing Development (DUHD) at the Ministry of Construction. Here too, many years of positive and increasingly intensive cooperation culminated in the signing of a Memorandum of Understanding on 13 June 2012 and the founding of the Myanmar German Research Centre for Urban and Regional Development (MGRC). The results of a joint research project - 'The 81+ urban network system of Myanmar' - were also incorporated into the Socio-Economic Atlas.

Since 2011, an intensive partnership has also developed with the Deutsche Gesellschaft für Internationale Zusammenarbeit (GIZ) GmbH, which is a German federal enterprise and supports the German Government in international cooperation for sustainable development via technical advice and capacity building. GIZ operates in more than 130 countries and employs approximately 17,000 staff worldwide. On behalf of the Federal German Ministry for Economic Cooperation and Development (BMZ), GIZ resumed its activities in Myanmar in 2012 in the area of sustainable economic development. The GIZ Private Sector Development Project (PSD) in Myanmar aims to strengthen capacities for sustainable private sector development with the focus on improved framework conditions for small and medium enterprises (SMEs) in Myanmar.

All parts of this atlas, from the single maps to the texts, have been created and written with the utmost diligence and care. However, the maps in particular are based on information and statistical data which sometimes may contain errors and uncertainties. They reflect and visualise the current state of knowledge. Any errors and shortcomings in data other than that provided to us by other 
institutions remain our own. In order to contribute to the further improvement of knowledge about the country and the current socio-economic transformation processes, we encourage the readers of the Atlas to notify and discuss with us any errors which may come to their attention.

This atlas could not have been produced without the trustful and fruitful collaboration and constant support of countless dedicated individuals in numerous institutions in Myanmar and Germany. The authors are indebted to their many colleagues, department heads, officials, staff members and other individuals who, with great kindness and patience, provided information, data and advice, shared knowledge, experience and passion, and listened and encouraged over many years and in many areas of Myanmar.

First and foremost, we would like to express our profound thanks to the Ministry of Construction, particularly the Department of Urban and Housing Development, and the University of Yangon under the Ministry of Education for their trust, confidence and invaluable support over many years in which the Atlas gained shape.

At the Ministry of Construction, H. E. the Minister of Construction, U Win Khaing, H. E. the former Minister of Construction, U Kyaw Lwin, Permanent Secretary U Kyaw Linn, Director General U Min Htein, former Deputy Director General U Win Myint and former Director U Win Zaw provided invaluable support for which we are sincerely grateful. Several staff members of the Ministry of Construction are co-authors of the Atlas, others contributed indirectly.

In the Ministry of Education, we are deeply grateful to H. E. the Minister of Education, Professor Dr Myo Thein Gyi, H. E. the former Minister of Education, Professor Dr Khin San Yee, H. E. Chairman of the National Education Policy Commission Professor Dr Myo Myint, H. E. and the former Vice Minister of Science and Technology, Professor Dr Ba Shwe. We would like to thank the Rector of the University of Yangon, Professor Dr Pho Kaung, his predecessors Professor Dr Aung Thu, Professor Dr Tin Tun and Professor Dr Soe Yin, and Pro-Rectors Professor Dr Kyaw Naing and Professor Dr Omar Kyaw for their excellent personal support and strong encouragement. Several heads of the Department of Geography at the University of Yangon have done much to strengthen the growing collaboration since 1996. The members of the Centre of Excellence (CoE) for Urban and Regional Development at the University of Yangon, established in 2011 as research institution and think tank, were very supportive in respect to the generation of regional knowledge. Several members of various universities in Myanmar under the Ministry of Education are co-authors of this atlas, others contributed indirectly.

We are sincerely grateful to the German Federal Ministry for Economic Cooperation and Development (BMZ) and the Deutsche Gesellschaft für Internationale Zusammenarbeit (GIZ) GmbH for the excellent collaboration and their generous financial support for parts of the cartographic work and the publication of this atlas. Our thanks are also due to Irina Scheffmann, Cho Myat Nwe Tun and Dominik Weidert for the trustful cooperation and creative exchange over recent years. We also thank GIZ's institutional partners, the Directorate of Investment and Company Administration (DICA), especially Director General U Aung Naing Oo, Deputy Director General U San Myint, Director Dr Marlar Myo Nyunt, Assistant Director Daw Aye Aye and Deputy Staff Officer Daw Yin Yin Mar. 
We are most grateful to numerous ministries and departments which contributed valuable information and data for the generation of the maps, namely the former Ministry of Agriculture and Irrigation, Ministry of Commerce, Ministry of Communications and Information Technology, Ministry of Cooperatives, Ministry of Electric Power, Ministry of Energy, Ministry of Environmental Conservation and Forestry, Ministry of Finance, Ministry of Health, Ministry of Home Affairs, Ministry of Hotels and Tourism, Ministry of Immigration and Population, Ministry of Industry, Ministry of Information, Ministry of Labour, Employment and Social Security, Ministry of Livestock, Fisheries and Rural Development, Ministry of Mines, Ministry of National Planning and Economic Development, Ministry of Rail Transportation, Ministry of Science and Technology, Ministry of Social Welfare and Ministry of Transport. Our sincere thanks also go to the Nay Pyi Taw City Development Committee, Yangon City Development Committee and Mandalay City Development Committee, the Myanmar Computer Federation and Myanmar Garment Manufacturers Association (MGMA).

The German Academic Exchange Service (DAAD) supported a two-year Visiting Professorship (2012-2014) and several short-term stays at the University of Yangon. The German Research Foundation generously supported the research project 'The urban system of Myanmar in the transformation process' (KR 1764/19-1) and provided a substitute professorship grant (2012-2014; KR 1764/23-1). Sincere thanks go to the Rectorate, the Faculty of Science and the Institute of Geography of the University of Cologne for their support.

Sincere thanks are due to all our co-authors and contributors to the atlas, namely YCDC Secretary Daw Hlaing Maw Oo, Pro-Rector Professor Dr Aung Kyaw, Pro-Rector (retir.) Professor Dr Win Maung, Deputy Director General Professor Dr Nay Win Oo, Deputy Director General U Myint Naing, Director Dr Than Than Thwe, Professor Dr Htun Ko, Professor Dr Khin Khin Han, Professor Dr Nilar Aung, Associate Professor Dr Khin Khin Soe, Associate Professor Dr Saw Yu May, Associate Professor Dr Zin Nwe Myint and Dr Zin Mar Than, for their commitment to the book's joint endeavour, namely to provide an up-to-date overview of a rapidly evolving development process.

We owe special thanks to Stefanie Naumann for the excellent layout and Christopher Hay, Ulli Huber, Dr Edel Sheridan-Quantz and Katharine Thomas for the thorough translation and English correction.

Finally, we would like to thank our families and friends in Myanmar and Germany for sharing their love and passion and for strengthening the bridge between our cultures.

This book is dedicated to our teacher, friend and sister Sayama Gyi Professor Dr Mi Mi Kyi, without whom none of this would have been possible.

Frauke Kraas, Regine Spohner and Aye Aye Myint

Cologne and Nay Pyi Taw, April 2017 


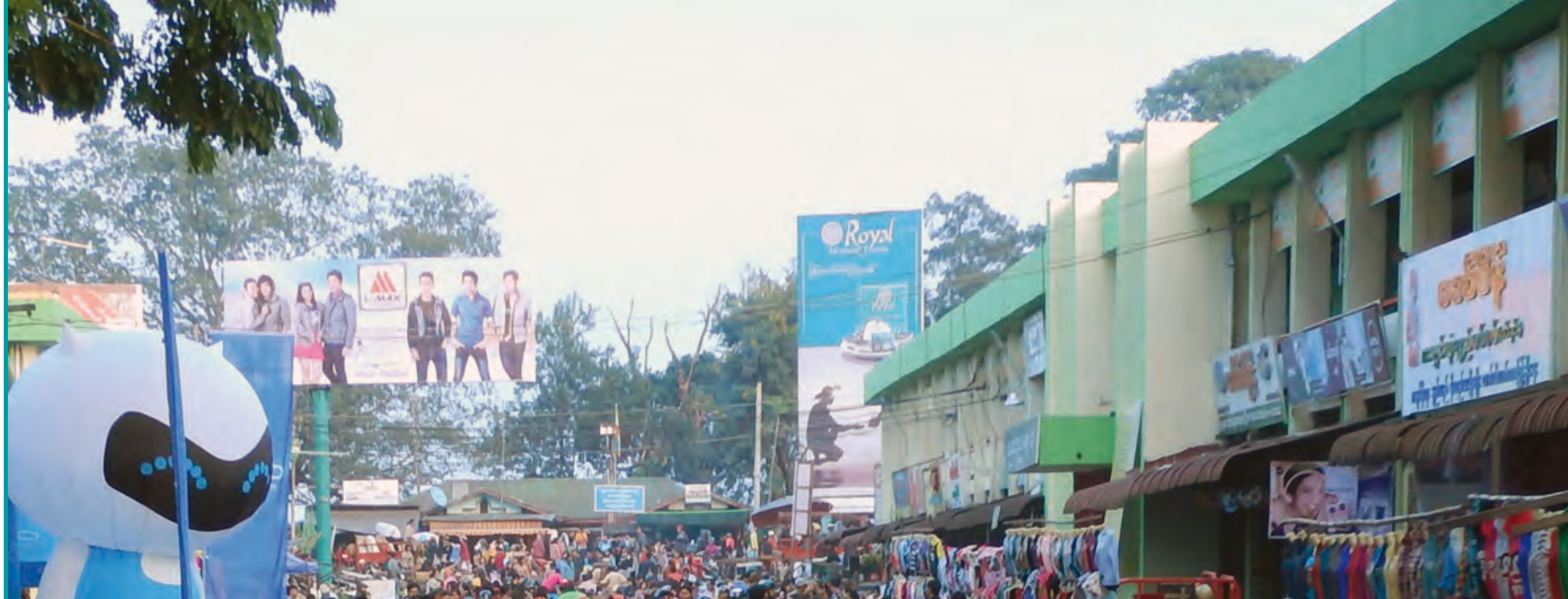

5 (1)

T. 1 (1)

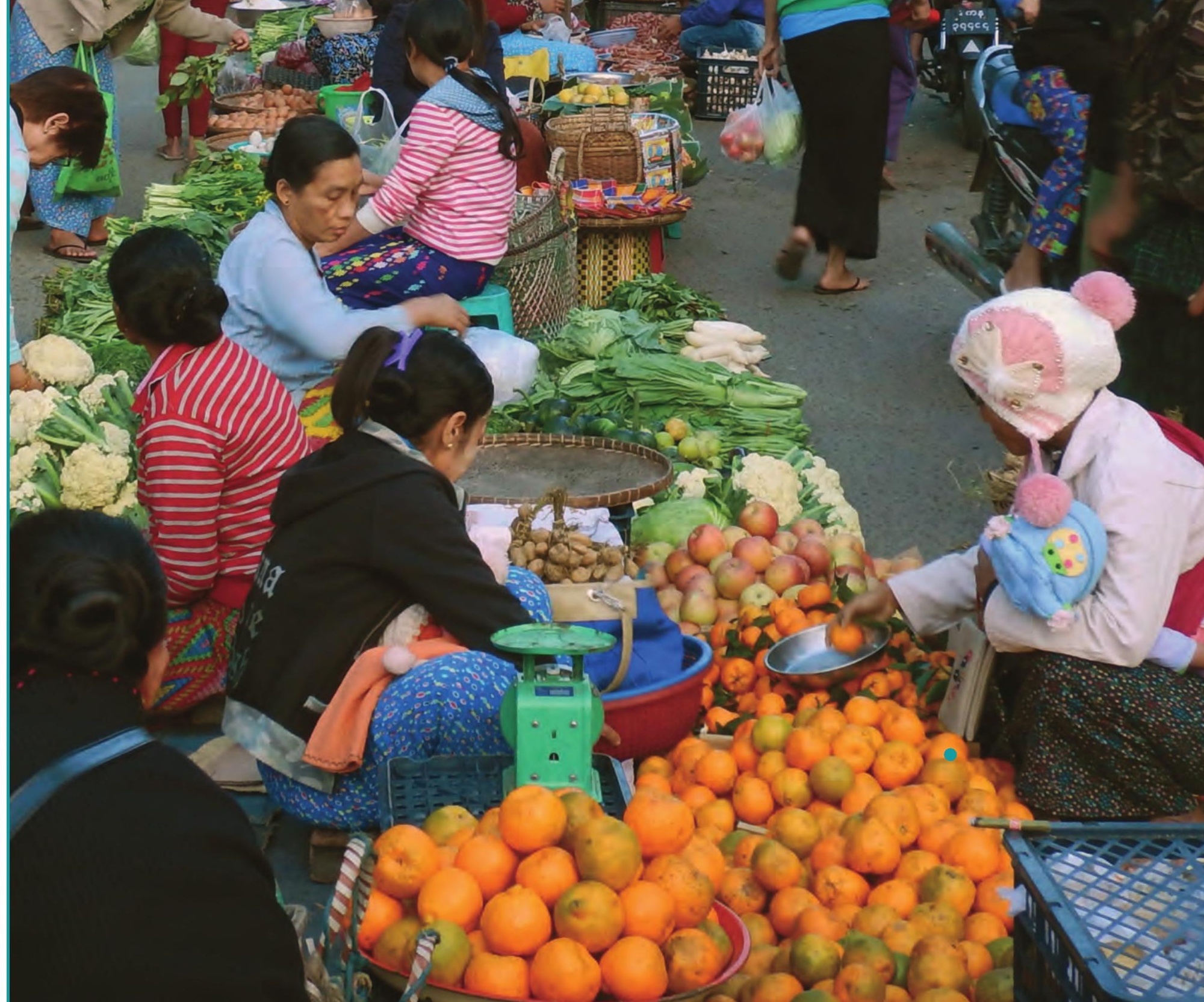




\section{CONCEPT AND DATA OF THE ATLAS}

12 CONCEPT OF THE ATLAS

16 DATA AND MAPS

22 THE NATIONAL CENSUS 2014 


\section{CONCEPT OF THE ATLAS}

\section{DEVELOPING}

\section{THE SOCIO-ECONOMIC ATLAS}

The Socio-Economic Atlas of Myanmar emerged through many years of trusted cooperation between German and Myanmar colleagues. The work involved experts from academics, government and planning practice from the natural and social sciences including diverse disciplines such as physical and human geography, architecture and landscape planning, civil engineering and zoology.

The Atlas aims to present and evaluate key spatial developments in the current transformation process of Myanmar. The focus is on social-economic developments and their uneven manifestation in the states and regions of the country. These development processes are observed in relationship to administrative structures and their dependence on the characteristics of the landscape, natural resources and existing infrastructure. The meticulous spatial analyses aim to increase the state of knowledge about Myanmar both within the country and abroad, and to support decision-making on spatial development policy. In order to ensure wide accessibility the Socio-Economic Atlas is published in print and as an open-access document.

In international publications and media reports it is often said that little is known about Myanmar. Although this may appear true from an outside perspective, it requires qualification if not revision when the situation within the country is considered. In Myanmar there is a significant body of scarcely tapped knowledge that has attracted very little international attention. In the universities and administrations, especially on the local and regional levels, there is a great deal of knowledge - historical, regional, ecological and social - about
Myanmar, its sub-regions and local, ethnic and religious communities. Numerous $\mathrm{PhD}$ and Master theses (albeit of varying quality, originality and depth of analysis) represent a notable body of knowledge, even if it is scattered over local libraries and hard to access, particularly as some of the work is written in the Myanmar language. Many unpublished investigations, reports and research papers have been bound by the institutes concerned and are not generally known of or catalogued. Furthermore, there is an enormous body of reflected, usually unwritten knowledge and experience. This large pool of different forms of knowledge is practically unknown or is not regarded as a serious resource, especially abroad but also domestically where it has not been systematically compiled and is not discussed among experts and decision-makers. Academic exchange with Myanmar colleagues makes clear that in the concrete social context of Myanmar apparently 'objective' knowledge is very differently assessed, weighted and judged from different 'internal' perspectives. The use of mixed teams of authors for the joint analyses and interpretations of the Atlas was a targeted attempt to take this into account.

\section{THE CURRENT PROCESS OF TRANS- FORMATION IN MYANMAR}

References to the numerous basic publications in the academic literature on Myanmar are provided here with no further detailed discussion. The historical and political processes of the last two decades are the focus of the indepth analyses by Carey (1997), Steinberg (2001), Thant Myint-U (2001, 2011), Kyaw Yin Hlaing/Taylor/Tin Maung Maung Than (2005), Charney (2009), Taylor (2009), Steinberg (2010), Than Tun (2010), Holliday (2011), Aung- 
Thwin/Aung-Thwin (2012), Keck (2015), Rogers (2016) and Mullen (2016). More recent economic development processes are discussed in the work by Mya Than/Tan 1990, Myat Thein (2004), Mya Than (2005), Perry (2007), von Hauff (2007), Okamoto (2008), Fujita/Mieno/ Okamoto (2009), Myint (2010), Findlay/Park/ Verbiest (2015) and Odaka (2016). Social changes and ethnicity issues are at the heart of the work by Skidmore (2005), James (2006), Gravers (2007), Ganesan/Kyaw Yin Hlaing (2007) and Walaiporn/Pritchard (2016). The transformation processes currently affecting Myanmar are the focus of several edited volumes, in particular Cheesman/Skidmore/Wilson (2010 and 2012), Gravers/Ytzen (2014), Egreteau/Robinne (2016) and Lall (2016). They are also subject to comprehensive analysis in a series of international reports by global development organisations and consultants (ADB 2012a, Chhor et al. 2013, Nixon et al. 2013, Rieffel/Fox 2013, OECD 2014a and 2014b, World Bank 2014).

The reports focus on the central challenges related to the transformation process and possible development approaches. They largely agree on the development characteristics and problems of the country but vary in their policy recommendations, development approaches and proposed solutions.

The major challenges for the country can be summarised as follows. To date the rich potential of the landscape and natural resources has only been partially tapped. Agriculture provides employment and thus the economic basis for a large proportion of the population. The many political and economic reforms passed after 1988 and particularly after 2010 aim to improve countrywide infrastructure, promote the private sector and attract direct foreign investment. They promote decentralisation of the administration and institutional transformation, the eradication of price controls and subsidies, the modernisation of the tax and customs system, the diversification of the export sector, the improvement of import and export procedures, and the restructuring of wages and prices. They also provide increased freedom of choice for farmers in terms of the crops they cultivate and the processing, transport and trading of those products (MNPED 1995: 33, Mya Than/Tan 1990). However, these measures have not yet overcome state capitalism to a significant extent.

The greatest obstacles to the mobilisation of direct foreign investment are related to the ongoing problems of macro-economic stability, extensive bureaucracy, widespread infrastructural deficits, economic diversification, the ensuring of long-term guarantees, a lack of openness of the financial sector to foreign competition, and restrictions on the transfer of foreign capital and profits. However, the privatisation measures of recent years have led to the emergence of numerous manufacturing, trading and services companies that supplement the large, efficient, state-owned enterprises with their export trade. In addition to growing numbers of companies involved in textile, garment and food production there are more and more service enterprises (especially in the tourism sector). Foreign investment is particularly over-concentrated in the metropolitan areas of Yangon and Mandalay.

\section{THEMATIC FOCUSES OF THE ATLAS}

Against the background of the far-reaching socio-economic changes of recent years and the frequently heard call for decision-making to correct inequalities in regional development, the Socio-Economic Atlas focuses on the analysis and evaluation of current regional differences in geographical conditions, infrastructure and socio-economic development. Neither historical developments nor Myanmar's international relationships - for instance within the ASEAN or with neighbouring countries - have been included so as to keep the subject manageable.

Considerable conceptual input was drawn from the existing thematic atlases of neighbouring countries. Thus the Atlas of Cambodia (SCW 2006) focuses on natural resources and issues of poverty, while the impressive thematic atlases of Vietnam (Vu/Taillard 1993), Laos (Bounthavy/Taillard 2000 and Messerli et 
al. 2008) and Thailand (Kermel-Torrès 2004) concentrate particularly on socio-economic developments.

For Myanmar itself, the Ministry of Forestry in cooperation with the Department of Geography of the University of Yangon has produced topographic maps displaying the states and divisions of the country (MoF 2004). Insights into resources and agriculture are provided by the Atlas of the Mineral Regions of the ESCAP Region, which analyses the geology and mineral resources of Myanmar (UN 1996), and the Agricultural Atlas of the Union of Myanmar (FAO 2005). Numerous thematic maps of Myanmar are included in the KTAM Report (1953) and the comprehensive fundamental work produced by Hla Tun Aung (2003). Overviews of infrastructure and socio-economic developments are found in the maps included in the regional study by Storz (1967). However, none of these maps are georeferenced and many are either too generalised or not up-todate.

A number of possible maps could not be produced because of a lack of reliable, consistent or plausible data:

- Thus despite the enormous relevance of questions of ethnicity, especially in the process of national reconciliation (for in-depth analysis see Skidmore 2005, James 2006, Gravers 2007, Ganesan/Kyaw Yin Hlaing 2007, Kipgen 2015), it was not possible to include a map of the regional distribution of ethnic or ethnolinguistic population groups. There are a number of spatial representations of the distribution of ethnic or ethnolinguistic groups, at least of the groups most dominant in the individual areas (e.g. Smith 1993, Smith/Allsebrook 1994: 51, Lintner 1994: 77, Steinberg 2001: xvii, Gravers 2007: xx, South 2008: xii, Gravers/Ytzen 2014: 156). However, there is a lack of detailed regional data and no spatially differentiated cartographical representation of the great ethnic/ethnolinguistic diversity of Myanmar. The most accurate mapping to date is the large-scale key map by Moseley/Asher (1994: Map 49), but even here, for example, only four of the many ethnic and ethnolinguistic groups found in Chin State (Min Naing 2000) have been recorded. In the absence of more accurate data, cartographic representations are often copied from one another with minimal changes; several display the title 'main ethnic groups' but then inconsistently mix ethnic and religious groups in the actual maps (e.g. Smith/Allsebrook 1994: 51).

- On the controversial issue of regional concentrations of foreign population groups (particularly Chinese, Indian, Nepalese/ Gurkha and 'western' foreigners) there are practically no detailed regional data and few studies (Cernea 2007, Chang 2014, Maung Aung Myoe 2014).

- Due to political sensitivity, detailed data from the 2014 census concerning the various religious and belief groups - Buddhists, Christians, Moslems, Hindus, Animists etc - have only been released on a national scale and the scale of the states and regions (MoLIP 2016c). Regional and local developments and the interfaith-networks of the religious groups have been subject to little investigation. Research has focused particularly on the development of individual religious groups (see e.g.: Chakravarti 1971, Yegar 1972, Berlie 2008), different perspectives on the religious problems (Gravers 2013, Charles Maung Bo 2015, David Thang Moe 2017) and current issues of reconciliation (Schissler/Walton/Phyu Phyu Thi 2017, Chit Win/Kean 2017).

- Interpretations and statistics on the highly charged and controversial so-called Rohingya issue vary greatly (Leider 2012 and 2014, Kipgen 2013, Gibson/James/Falvey 2016, Ibrahim 2016); it is impossible to produce reliable cartographic representations of this topic.

- Even for less controversial issues, cartographic representations of regional differences in distributions or developments are either impossible or unhelpful. Thus the mapping of numbers of tourists is presently unadvisable due to the unreliability and inconsistency of data - the published tourism 
statistics include the numerous business travellers and people who are visiting relatives, leading to the recorded numbers of tourists entering the country being greatly inflated (Kraas/Häusler 2016). A cartographic representation of numbers of alleged tourists would be correspondingly misleading and could result in false conclusions being drawn.

\section{DATA SOURCES AND CARTOGRAPHY}

Drawing on topographical maps and satellite data, a Geographical Information System was created as a basis for the cartography, and linked to the statistical data and thematic contents. Great care was taken to ensure precise cartographical representations and meticulous checking of all the cartographic and data sources.

There are undoubtedly severe problems with the availability, quality and reliability of data, especially of statistics: 'Under decades of authoritarian rule, data sensitivity was a political culture ... it is now time for Myanmar to move towards improving the quality, accuracy, credibility, timeliness and availability of economic and social statistical data and information as a first step in building a modern developed nation' (Myint 2010, quoted in Than Tun Sein et al. 2014: 185). Against a background of very varied data quality and reliability, the temptation to create visualisations without quality control was resisted and a number of maps have not been produced that may otherwise have been possible.

The findings of the 2014 census and data from various ministries were vital sources for the Atlas. Many of the themes also drew on a synthesis of different academic sources, even when numerous very different sources had to be brought together and much work was necessary to accurately localise non-georeferenced information. Regionally detailed findings from the 2014 census have been published on population development, agriculture, education and health, allowing good and very accurate presentations of these topics. There are, in contrast, as yet limited data on industrialisation and flows of transport, trade and finance. The information on GDP, for instance, is incomplete simply because the informal sector is not included due to an understandable lack of data. There are to date no data available on the richly diverse crafts, the importance of which has scarcely been addressed, either in terms of cultural heritage or as a traditional source of local income.

Frauke Kraas, Aye Aye Myint and Regine Spohner

Agriculture between Lashio and Pyin Oo Lwin

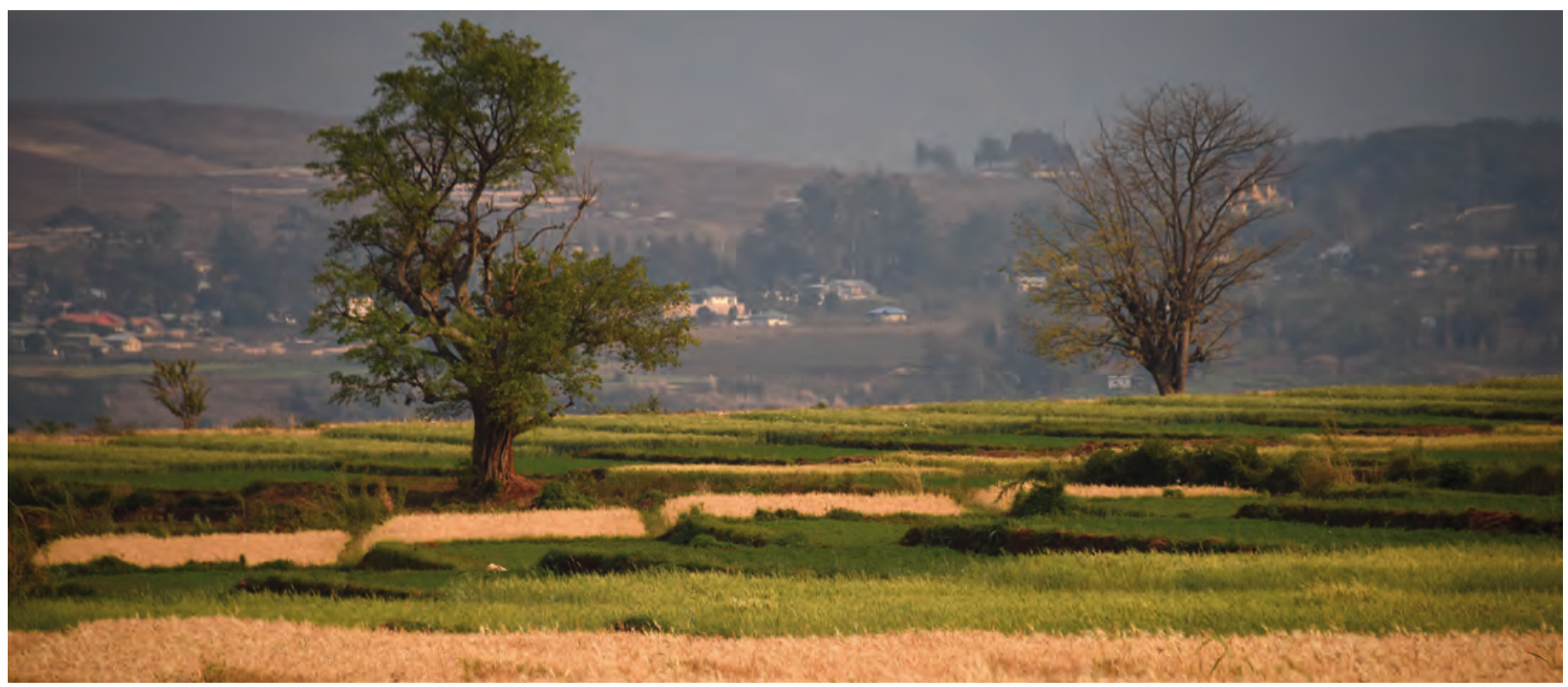




\section{DATA AND MAPS}

The core idea of producing a reliable and spatially detailed Socio-Economic Atlas of Myanmar could only be realized in a targeted manner with the help of a Geographic Information System (GIS) and the available source data. Visualisation of most of the thematic contents is carried out on the basis of the 330 townships, the administrative units of Level 3. All point and line elements of the Atlas geo-database were recorded with great positional accuracy and stored at an appropriate level of generalisation for the mapping scale of 1:7,850,000 in an A4 print format. The accuracy of contents and the consistency of the data, some of which were drawn from many different sources, were ensured by an elaborate plausibility assessment. A combination of close communication with Myanmar colleagues and knowledge of the country enabled the meticulous examination of outliers and spatial anomalies and thus the administration of a reliable database.

The geo-database was compiled using administrative and topographic vector data or remote sensing raster data with the help of the Geographical Information System ArcGIS 10.2. The satellite data provided the basis for recording new or correcting existing geo-data and were processed using ENVI5.0. The final cartographic design of the maps was produced in Adobe Illustrator (Adobe CC 2015/2016). The add-on MaPublisher 9.6 (Avenza) installed in Illustrator proved to be indispensible when operationalizing the workflow between GISbased data processing and cartographic visualisation in Illustrator. This software allowed the spatially fixed and to-scale import of the GIS data layers and their further attributebased graphic processing. The combination of Illustrator and MaPublisher permitted the optimal construction of the maps through the establishment of the spatial data layers from the GIS. It furthermore allowed the use of very elaborate cartographic symbols and visualisations of the diverse topics, something that would not have been possible in GIS due to its considerably more limited graphical sophistication. In cooperation with the designers Luebbeke Naumann Thoben (Cologne), the ambitious overall layout was achieved using Adobe Indesign.

The fundamental coordinate system for the national data is a geographical coordinate system (GCS_WGS_1984 / Date: D_WGS_1984). For the regional maps of the urban area of Yangon the Universal Transvers Mercator-System was selected (UTM Zone 47 / WGS84). There was a lack of standards in the various source statistics/data in terms of the coding of the 330 administrative units and the Romanisation of the township names. This meant that the 330 spatial units were only linked after the adjustment of the township names in the statistics in line with the naming convention from MIMU (Myanmar Information Management Unit).

When preparing the thematic maps various steps were required, as follows:

- The basic topographic data were produced using a digital ground model (Shuttle Radar Topography Mission, SRTM 90m vers. 4.1) in combination with Landsat 8 OLI archive data (USGS, Earthexplorer). For Myanmar, a regularly updated archive of Landsat 8 OLI scenes is available to the project. An image sharpening process is used to calculate the Landsat 8 RGB images (channel combination $4,3,2$ ) at $15 \mathrm{~m}$; these images serve as the spatial base reference for both the national key maps and the regional maps. The rich objective image data and the accuracy of the 'objects' visible in the images is higher in the Landsat data 
than in the available topographic maps. Landsat 8 was used as a basis for the digitalisation of the water network, the updating and correction of the street network and railway lines, the localisation of hydropower plants and the updating of the position of towns. VHR-satellite data serve as the spatial reference for Yangon (WorldView2, GeoEye), supplemented by time periods from Google Earth image data. The topographic names and toponyms for landscapes, mountainous areas, rivers and mountains are derived from the topographic maps of Myanmar at the scale of 1:250,000 and 1:50,000, from the literature and from internet research.

- The relevant dataset of the geo-data made available by MIMU (Myanmar Information Management Unit) was used as the administrative base data (download in August 2014). The data were digitized by MIMU on the basis of the topographic map 1:250,000. As this dataset includes flawed polygon data (gaps and sliver) and for certain regions is too generalized or too roughly digitized, the MIMU dataset was considerably reworked and refined in the Institute of Geography of the University of Cologne with the help of topographic maps and, especially, on the basis of the Landsat 8 image data. This applies particularly to the adjustment of borders where they follow the course of rivers, mountain ridges or roads. Furthermore, in Cologne a line and polygon dataset was created for the geo-database of the Atlas using the administrative codes and assigned names from the MIMU dataset (PCode-list, MIMU/GAUL/DCW and translation of the GAD names). The very differing Romanisation of the township names by the different authorities or ministries represented a major problem, especially as the statistics and geo-data provided had to be linked to these names. A correct 'fit' could only be achieved by very elaborate linking procedures and checking the assignment of every individual data sequence to each township. All datasets in the Atlas are affected by this problem.
The individual thematic maps were subject to further conceptual deliberation, as described in the following. The workflow of GIS-based data processing in ArcGIS and cartographic finalisation in Illustrator applied to all maps.

- Topography and topographic profiles: For this map freely accessible datasets of heights were available (SRTM vers. 4.1). However, a water-network based on the Landsat 8 data and adjusted to the scale of the map was newly created. The corrected MIMU dataset was used as administrative data. Representative cross-sections were selected and calculated in ArcGIS.

- Land use / land cover: For the map the freely accessible datasets from NASA WorldView, MODIS and GlobCover 2009 v2.3 were straightforwardly transferred to ArcGIS, the exemplary districts were representatively selected and were fed into the final cartographic process (Photoshop and Illustrator).

- Population: Data from the 2014 Census were used for total population, population density, sex ratio and urban-rural population. The census statistics were prepared so as to match the GIS dataset of the townships. In light of the problems concerning the Romanisation of the census data it was necessary to ensure the fitting of the data.

- Modeled population density: The modeled Myanmar dataset of the licensed LandScan 2013 data was procured for the spatial visualisation of population density.

- Climate: The precipitation and temperature data were derived from the 'Agricultural Atlas of Myanmar' (FAO 2006); new digitisation of the map of precipitation and temperature distributions allowed for adjustments appropriate to the design of this Atlas. The base data of the diagrams of the selected regional locations come from the 'Climate Change Knowledge Portal' of the World Bank Group; they were consistently re-visualized in Illustrator in graphic form.

- Natural Risks: This map is a compilation of freely available digital data. Firstly, the time 
series of all earthquake events with magnitudes over 4.0 of the last 200 years were drawn from the web archive of the USGSNational Earthquake Information Center. Secondly, the ground model data from SRTM 4.1 for the land and from ETOPO1 for the seabed were used. These data were overlaid with the modeled population (LandScan 2013) and supplemented with the fault lines and seismic zones from the literature (tectonic map of Myanmar www.sagaingfault.info).

- National conservation area: The map was created on the basis of a content comparison of a combination of four primary sources (see sources listed in the map). The spatial assignment was mainly based on Beffasti/Galanti (2011), as here detailed maps showing the extent of the protected areas are available. The visualisation was completed using the Ministry map. The classification of the protected areas is based on the usual IUCN categories.

- Fuel minerals, metallic minerals, precious stones etc.: The Ministry of Mines provided data for these maps. Due to positional errors, omissions and inconsistencies the data needed to be supplemented. An accurate basis was provided by a publication with geological maps of Myanmar (UN 1996). Extensive research was necessary to create the basis for the supplementary contents included in the map on fuel minerals; the presentation of the coal basins and the oil and gas blocks was drawn from various scientific sources (sources cited in the map).

- Urban system of Myanmar: A list made available by the Ministry of Construction provided the basis for identifying the towns and cities. This shows the towns and cities in 2015, categorized in five classes according to urban population (Census 2014) and administrative status. The position of the towns was in some cases corrected using Landsat 8 images.

- Road network, railway lines, towns, harbours and airports (transportation networks and towns) - detailed overviews in four parts: The basis of the maps was pro- vided by comprehensive maps of each state or region from the Ministry of Construction. In some cases no accurate information was available on the year in which the individual road sections were constructed. The course of the roads was sometimes very generalized or visualized as a simple link between towns, so that the exact course of the road could not be determined from the maps. The data provided by MIMU are in some cases more accurate, but the positions and connections of roads are also often incorrect. It was therefore necessary to refer to the current Landsat 8 image data as a basis for interpreting the exact course of roads; additional information from Google Earth images was used for more narrow roads or the course of roads through wooded areas. Interpretation was aided by maps from the Myanmar Transportation Masterplan. A comparison with detailed GIS maps (such as those that exist for the eastern Shan State) was not possible. New road links, for instance between Paletwa and Matupi via Samee, were added based on Landsat images and newspaper reports on the opening of the streets. All the streets were first captured in GIS and later combined with the other map layers in the overall layout of the infrastructure maps. The data on the railway network was provided by the Ministry of Rail Transportation in the form of network plans showing all stops but not their accurate positions. The railway network was also checked using Landsat 8 data and, as far as visible, 'sections under construction' were also digitized. The aim of the infrastructure map is to visualize all 367 towns as connected with the street network. This goal was not fully achieved as the network of paths linking very remote small towns was not accurately visible in either the Landsat 8 or the Google Earth images. The information on airports came primarily from the UNECE platform. Local interview partners and media reports augmented the information on the operational status of the airport, for instance whether it is used seasonally. In addition, research of Google Earth images was help- 
ful in recognizing whether the airport was actually in operation: some of the airports listed as 'domestic' by MIMU or UNECE (with the note: no detailed information) could be excluded from the mapping (sometimes a defunct runway could be recognized). The ports were mapped with the help of information from the DLCA platform, which allowed a distinction to be made between 'international exporting sea port' and 'sea port with domestic coastal traffic'. Presentations from the Ministry of Construction, and information from newspaper reports served for the designation of planned or already implemented Deep Sea Port projects. The background data on topography and vegetation (generalized) are freely available.

- Power plants: This map required some of the most extensive research of all the mapping projects of the Atlas. First, all the hydropower plants shown in the MoEP map (2015a, in addition 2015b) had to be pinpointed in their correct positions in GIS here the Landsat 8 images and Google Earth or Google Earth time series were consulted. They were given attribute data (status, installed/proposed capacity). This literature-based information (especially Snider 2012) on the 'Hydropower Plant' and 'Thermal Power Plant' locations and attributes was compared with information on the status of the projects from burmariversnetwork.org, internationalrivers.org and newspaper reports. Capacity, type and status of the power plants were precisely cartographically visualized. The catchment areas of the large rivers were included as additional information. Furthermore, a summarized visualisation of the total capacities per Region/State according to type and status is included as a bar graph.

- Telecommunication: Data on the location of the towers (MPT, Ooredoo and Telenor) were transferred from the Excel tables to GIS point data. The number of towers was linked with data on availability of mobile phones per household per township from the individual Region/State data tables of the Census. The visualisation takes the percentage shares into consideration. This allowed a content-rich map to be produced.

- GDP main and per sector, economic classification of townships based on GDP 2015: Very good raw data was available for this map. Information on the main sectors and their sub-sectors was provided in the form of a table for each of the 330 townships. These tables were then manually reprocessed in a meticulous and time-consuming procedure to produce a GIS-compatible table. The attributes of each township were originally arranged in rows in 330 separate tables and had to be transferred to columns to enable linking. After the overall table had been produced with information on volumes of GDP in Kyat per sector/sub-sector and their percentages for each township, an additional link to the population was created in order to calculate GDP per capita. In the overall table the percentages per sector/sub-sector were then classified in $25 \%$ steps, an 'outlier-category' was identified and the result was visualized in four maps (1: \% of the three main sectors, $2-4: \%$ of the sub-sectors in the three main sectors). The visualisation of the percentages could only be undertaken semi-automatically. The workflow from the GIS-based data processing could be carried out specifically for the complicated semi-automatic assignment of the graphic attributes in Illustrator. The townships were classified according to their percentage share of the main sectors and their resulting position in a ternary plot. 16 categories with information on the percentage distribution of the sectors and the number of townships per category reflect the economic structure of Myanmar. Overall, the data preparation and semi-automatic visualisation were thus very complex and time-consuming. However, the depiction has decided advantages over a classic proportional circle map or a mono-thematic choropleth map, as the interaction of the main sectors/sub-sectors is effectively presented.

- Rain and summer paddy: The Ministry for Agriculture and Irrigation provided de- 
tailed data for this map, in some cases in temporal resolution for harvested area (ha) and yields (Tinn). From this data the distribution maps for rain paddy (absolute production, annual yield and change over time of both) and summer paddy (absolute production and annual yield, without time series data) were produced. The combination of absolute production and proportion of rain or summer paddy was depicted in color-graded classified symbols, allowing both variables to be effectively portrayed (as already used in the presentation of the percentage share of urban population in the total population of a township, and later again applied to the topics of health and the availability of mobile phones).

- Agricultural regions: The map represents a substantive combination of the regional distribution of the geographical characteristics of topography, climatic conditions and land cover/land use. It was decided not to carry out automatised GIS analyses, for instance according to threshold values on the individual data layers. Instead the eight agricultural regions were identified as a synthesis of the factors considered (on the basis of freely available data layers).

- Aquaculture: The map is based on, consistent datasets from the Ministry of Livestock and Fishery (MoLF). Both the datasets on shrimp and fish farming could be summarized in one map. It should be noted that data were missing from the dataset for many townships, e.g. in Shan State (although there are fish farming projects).

- Yangon garment factories: The map is based on two very detailed datasets from the Myanmar Garment Manufacturers Association (MGMA) that include almost 300 locations of garment-industry enterprises, primarily situated in Yangon, with information on addresses, investment type, type of factory, number of workers and product specifications. The pinpointing of the location of the almost 300 enterprises was undertaken by hand using the addresses of the individual industrial zones in the separate townships in Yangon (designation of the in- dustrial zones according to information from Myanmar Industries Association, YCDC 2009, Tractus 2015b). Enterprises outside the industrial zones were grouped per township or per zone outside Yangon. The enterprise-specific data were transformed into township-summarized data that could then be processed in GIS and transferred to Illustrator for cartographic visualisation. The complex cartography visualizes the number of employees in proportional circles and the proportions of types of enterprise and investment. The current built area of Yangon, the industrial zones and the administrative structure are added as background information.

- Tourism map: in this map elements of tourism infrastructure (street/railway network, airports, selected towns and cities of the urban system of Myanmar) and tourism potential (protected area, world heritage sites) are visualized from existing data layers of the Atlas geo-database and combined with a classification in primary and emerging travel destinations.

- Electricity for lighting, availability of mobile phones: The map is based on data from the 2014 Census. It contains a combination of the variables 'Number of households per township' and the percentage share of 'Township-households with mobile phones'. Color-graded symbols of different sizes were again selected. The proportion of households per township with access to electricity for lighting was added as background information. The preparation of the census statistics for the GIS dataset of the townships was subject to the problems of Romanisation.

- Health (regional health centers, sub-regional health centers; doctors, hospitals, midwives): The data were available in pdf format and contained comprehensive information on the number of hospitals, regional health centers, sub-regional health centers (all three variables: Ministry of Health, May 2015) and the number of hospitals, doctors, nurses and midwives (all 
four variables: Ministry of National Planning and Economic Development MNPED, Aug. 2015). After the initial conversion/adjustment/linking process to the township object data in GIS the dataset could be directly used for the visualisation process. The Ministry of Health datasets also contain information on the number of beds per hospital and township, although these deviate strongly from the MNPED data (Ministry of Health: total number of hospitals in Myanmar: 1,083; MNPED: total number of hospitals in Myanmar: 1,001); in some townships the data concur, in others they vary widely. For the map the MNPED data on the number of doctors per hospital per township were used as these data were available in a coherent dataset. It is, however, unclear whether these data are more reliable. The datasets could not be mixed, which prevented information on hospital beds per 1,000 persons being provided. The three variables are presented using a color graduation in symbols classified according to size. The size classification was selected in order to permit a better visualisation of the 330 object data; the proportion of urban population was added as background information. The development of an operational workflow between GIS and the Desktop Publishing System was necessary for this so as to guarantee the error-free assignment of the color classes to each symbol - the aim was to minimize errors in the manual submitting of the graphic attributes; the graphic attributes were assigned through layer management.

- Education level: The three education maps are drawn from data from the 2014 Census. In all three maps the percentage share of over 25 year olds with a school qualification (primary to higher education) is related to a) the absolute number of over 25 year olds with a school qualification, b) the percentage share of 25 year olds with the highest school qualification in the township population, c) the percentage share of the school level of all those with a school qualification over 25 years old (classed in primary, mid- dle and high School). The preparation of the census statistics for the GIS dataset of the townships was, as usual, complicated (Romanisation problem).

- Higher education, location and students: The three maps are based on data from the Ministry of Education on the 169 (as of 2016) locations of institutes of higher education in Myanmar; this includes universities, degree colleges and colleges. Interviews with colleagues helped in assigning the institutes to disciplinary categories. The locational data was linked to the towns in GIS. The resulting maps show a) the locations of the higher education institutions with their subject area classified by city, b) the number of students per city plus the proportion of students in each discipline. Furthermore, c) the number of students in each higher education institution and subject area is linked with the student-teacher ratio and recorded in a comprehensive list of higher education locations.

Overall, the automatic processing of the maps in GIS was hindered by the problems caused by the very varied Romanisation of the Myanmar names, which prevented automatic linking. This necessitated the very complex and timeconsuming preparation of the statistical data for the 330 townships. Many of the datasets made available (maps and statistics) are characterized by inaccuracies and incoherency; in some cases they are incomplete. Little can be said about data reliability, as few verification or plausibility investigations have been documented, even in the academic literature. Experience from fieldwork shows that data from the lowest administrative levels are the most precise and reliable; the village-tract and wardlevel data and data from the individual institutions are usually the most accurate. Often data were only available on the district level and were thus not suitable for use at the scale of the administrative basis of the 330 townships.

Regine Spohner and Frauke Kraas 


\section{THE NATIONAL CENSUS 2014}

For the first time in thirty years, a national census was conducted in Myanmar from 29 March to 10 April 2014. Preliminary results were available from 30 August 2014, the first official findings were published on 29 May 2015.

The census was conducted by the Myanmar Ministry of Immigration and Population (MoIP) in accordance with international standards and with technical support from the United Nations Population Fund (UNFPA) and financial aid from international donor institutions. In total, the census cost about 58.5 million USD, the Myanmar government provided more than 15 million dollars (UNFPA 2013).

More than 100,000 specially trained enumerators - mostly administrative personnel and teachers - visited almost 11 million households in the 15 states and regions of the country,

\begin{tabular}{rr|r|} 
& TOTAL POPULATION & $\begin{array}{r}\text { POPULATION DENSITY } \\
\left.\text { (people per } \mathbf{k m}^{2}\right)\end{array}$ \\
\hline UNION OF MYANMAR & $\mathbf{5 1 , 4 8 6 , 2 5 3}$ & $\mathbf{7 6}$ \\
\hline KACHIN STATE & $\mathbf{1 , 6 8 9 , 4 4 1}$ & 19 \\
\hline KAYAH STATE & 286,627 & 24 \\
\hline KAYIN STATE & $1,574,079$ & 52 \\
\hline CHIN STATE & 478,801 & 13 \\
\hline SAGAING REGION & $5,325,347$ & 57 \\
\hline TANINTHARYI REGION & $1,408,401$ & 32 \\
\hline BAGO REGION & $4,867,373$ & 124 \\
\hline MAGWAY REGION & $3,917,055$ & 87 \\
\hline MANDALAY REGION & $6,165,723$ & 200 \\
\hline MON STATE & $2,054,393$ & 167 \\
\hline RAKHINE STATE & $3,188,807$ & 87 \\
\hline YANGON REGION & $7,360,703$ & 716 \\
\hline SHAN STATE & $5,824,432$ & 37 \\
\hline AYEYAIWADY REGION & $6,184,829$ & 177 \\
\hline NAY PYI TAW & $1,160,242$ & 164 \\
\hline & & \\
\hline
\end{tabular}

Population by Region and State (MNPED 2015:17) reaching almost $98 \%$ of the total population. The official "census night" was the night of 29 March 2014, i.e. every person was counted in the place where they spent that night. Effectively however, as is usual with censuses elsewhere, the count period extended over two weeks. This was especially necessary because of the inaccessibility of villages in the countryside and mountain regions. Every individual was counted, regardless of nationality, religion or age. Not included were an estimated 1.2 million people in the regions of Rakhine, Kachin and Kayin State affected by ethnic conflict, which were not surveyed for security reasons (UNFPA 2015).

The households were visited personally by the enumerators between 7 a.m. and 6 p.m. As well as normal family households the population in institutions - e.g. hotels, monasteries and military barracks - as well as special groups (e.g. construction and port workers in provisional housing or people living on the streets) were counted. All persons present, i.e. not just those on the official Household Registration List, were counted.

The population had been thoroughly well informed of the reason for the census - the collection of statistics to plan the reform process -, the process of enumeration, the census questions and the extent of data collection, via television, radio, posters, flyers and the internet. The information material was available in Myanmar and English as well as numerous ethnic languages (e.g. Kachin or Chin-Laizo).

A Census Law passed in July 2013 protects the confidentiality of the personal data collected. Furthermore, there was explicit reassurance that the census information would not be used for the purpose of taxation, registrations, verification or detention (the latter in the context 
of the requirement that de jure every individual on the Household Registration List has to register; but migrant workers in particular often fail to meet this requirement).

Demographic and socio-economic data were collected, including: age, sex, family composition, marital status, religion, ethnic identity, migration status, education, employment, births, deaths and handicaps as well as housing standards (house type, ownership status, electricity and water supply, communications, sanitary facilities, building materials and the means of transport available).

\section{PREVIOUS CENSUSES AND POPULA- TION ESTIMATES}

Since 1872 twelve censuses have been carried out in Myanmar: in 1872 and 1881 (both only in Lower Myanmar), 1891, 1901, 1911, 1921, 1931, 1941, 1953-55 (in three incomplete enumerations), 1973, 1983 and 2014. The total population of Myanmar grew from 22.9 million (1963) through 28.9 million (1973) to 35.3 million in 1983 (the second most recent census; MoHRA 1984, Than Than Thwe 2004, Spoorenberg 2013: 310, Kraas/Spohner 2015). In 1997, the country's population was about 46.4 million.

Before the census of 2014, Myanmar's population was estimated at about 60.5 or 60.98 million on the basis of growth projections. The census of 2014 recorded the considerably lower - but not really surprising - figure of 51.5 million inhabitants. The miscalculation was due to the use of too high a growth factor of about 2.0\% (Spoorenberg 2013: 310 and 2014), based on the forward projection of earlier fertility rates and an assumed increase in life expectancy from 60.4 to 66.8 years (1983 to 2003). Also, international migration was not taken into account (Spoorenberg 2013: 312).

While migration occurred from the late 1980s due to civil war, famine, landlessness and unemployment as well as in response to political persecution, labour migration rates rose in the last ten years, particularly because of the possibility of achieving higher earnings in the neighbouring states of Thailand and Malaysia. As well as about one million labour migrants, more than 400,000 refugees fled the country in 2009, so that the number of Myanmar citizens living abroad was estimated at up to 1.5 million (2010).

\section{RESULTS OF THE 2014 CENSUS}

The most important results of the census can be summarised as follows (MoIP 2015a, MoIP 2015b, UNFPA 2015, Kraas/Spohner 2015, MoLIP 2016a, band c):

- The total population figure of 51,486,253 includes estimated (not enumerated) figures of 1.09 million in Rakhine State, 69,753 in Kayin State and 46.600 in Kachin State.

- In rural regions the natural growth rates are often twice as high as the national average, with simultaneously increasing migration rates.

- Overall Myanmar, with an average population growth rate of $0.89 \%$, is demographically relatively stable compared to other developing countries. In comparison with the 1970s the population growth rate has more than halved.

- About $50 \%$ of the population is under 27 years of age, although the proportion of children is falling.

- Nationwide there are 100 women to 93 men, reflecting men's lower life expectancy and the markedly higher foreign migration rate for male workers. Currently, life expectancy is 60.2 years for males and 69.3 years for females (MoLIP 2016a: xii).

- "Some States/Regions had far lower fertility than others; Chin State had the highest TFR (5.0 births per woman), which was no less than 3.2 births higher than in Yangon Region. The level of fertility is also influenced by the high proportion of females who remain never married: some 12 per cent of women aged 50-54 have never married. The 2014 Census showed that the marital status of a woman is closely related to her educational attainment. The higher a 
woman's level of education, the higher the probability of her remaining never married. However, while there is a clear correlation between fertility and women's level of education, education is not the single cause of low fertility in the country, there are other contributing factors. It is important to state that education for women is essential for the future development of Myanmar." (MoLIP 2016a: xi).

- Particularly in urban regions, falling fertility rates (births per woman) are slowing down natural increase: the average number of births per woman has fallen from 4.7 (1983) to 2.3 (2014), which is equivalent to stabilising the current population figures.

- Life expectancy at birth has risen to an average of 66.8 years (men: 63.9, women: 69.9 years) and is among the lowest in Southeast Asia. Average life expectancy in urban regions is 72.1 , in rural areas it is 65.5 years.

- Child mortality (under 5 years) and infant mortality at $62 \%$ and $72 \%$ respectively per 1000 live births is almost twice as high as the average for Southeast Asia. "The lifetime risk of maternal death is 7.3 per 1,000 women, which means that one in every 137 women dies as a result of pregnancy or childbirth. Maternal mortality is the most preventable of all causes of death for women and is determined by the social and economic status of the mother" (MoLIP 2016a: xi-xii).

- The number of households has risen to 10.87 million, with the highest increases since 1983 in Shan State (119\%), Kayin State (116\%) and the Yangon Region (108\%).

- Household size has fallen to an average of 4.4 persons per household. $70.2 \%$ of households have between two and five members; the largest average household sizes are to be found in Kachin State (5.1 persons/household), the lowest in the Ayeyarwady Region, Magway Region and Nay Pyi Taw (4.1 persons/household).

- In addition to Nay Pyi Taw, "there are other States/Regions in which high levels of re- cent in-migration were reported; these include Kachin, Kayah and Kayin. These States are all located on the border with Thailand or China and appear to have an economic dynamism that comes from the large amount of cross-border trade that occurs through these States. Policies designed to increase the number of cross-border entry points will likely provide increased opportunities for employment, and therefore migration" (MoLIP 2016b: xii-xiii).

- Detailed information on the migration of Myanmar citizens to other countries had not previously been published. The 2014 census results cite an overall figure of 2.02 million Myanmar citizens living abroad, $61 \%$ of whom are men and ca. $83 \%$ between 15 and 39 years of age. Most of the migrants come from Mon State $(427,000)$, Kayin State $(323,000)$ and Shan State $(236,000$ individuals). $70 \%$ work in Thailand, $15 \%$ in Malaysia. "Through backward projection methods, the current study estimates that in 2014, a total of 4.25 million persons who were born in Myanmar were living abroad at the time of the Census. International migration is clearly dominated by men. The sex ratio among such migrants is 156.3 men per 100 women" (MoLIP 2016: xii).

- In total, 58,859 foreigners reside in Myanmar in 2014, among them 23,812 Chinese, 23,903 Indians, 2,286 Pakistanis, 755 Bangladeshis and 8,103 others.

- In $2014,89.8 \%(87.9 \%)$ of the population were Buddhists, $6.3 \%$ (6.2\%) Christians, 2.3\% (4.3\%) Moslems, 0.5\% (0.5\%) Hindus

\begin{tabular}{|r|r|}
\hline TOTAL & $\mathbf{2 , 0 2 1 , 9 1 0}$ \\
\hline THAILAND & $\mathbf{1 , 4 1 8 , 4 7 2}$ \\
\hline MALAYSIA & 303,996 \\
\hline SINGAPORE & $\mathbf{7 9 , 6 5 9}$ \\
\hline CHINA & 92,263 \\
\hline JAPAN & 7,597 \\
\hline KOREA & 14,592 \\
\hline INDIA & 17,975 \\
\hline USA & 37,577 \\
\hline OTHERS & 49,775 \\
\hline
\end{tabular}

Former conventional household members living abroad (MoPF 2016: 20, based on 2014 Myanmar Population and Housing Census) 


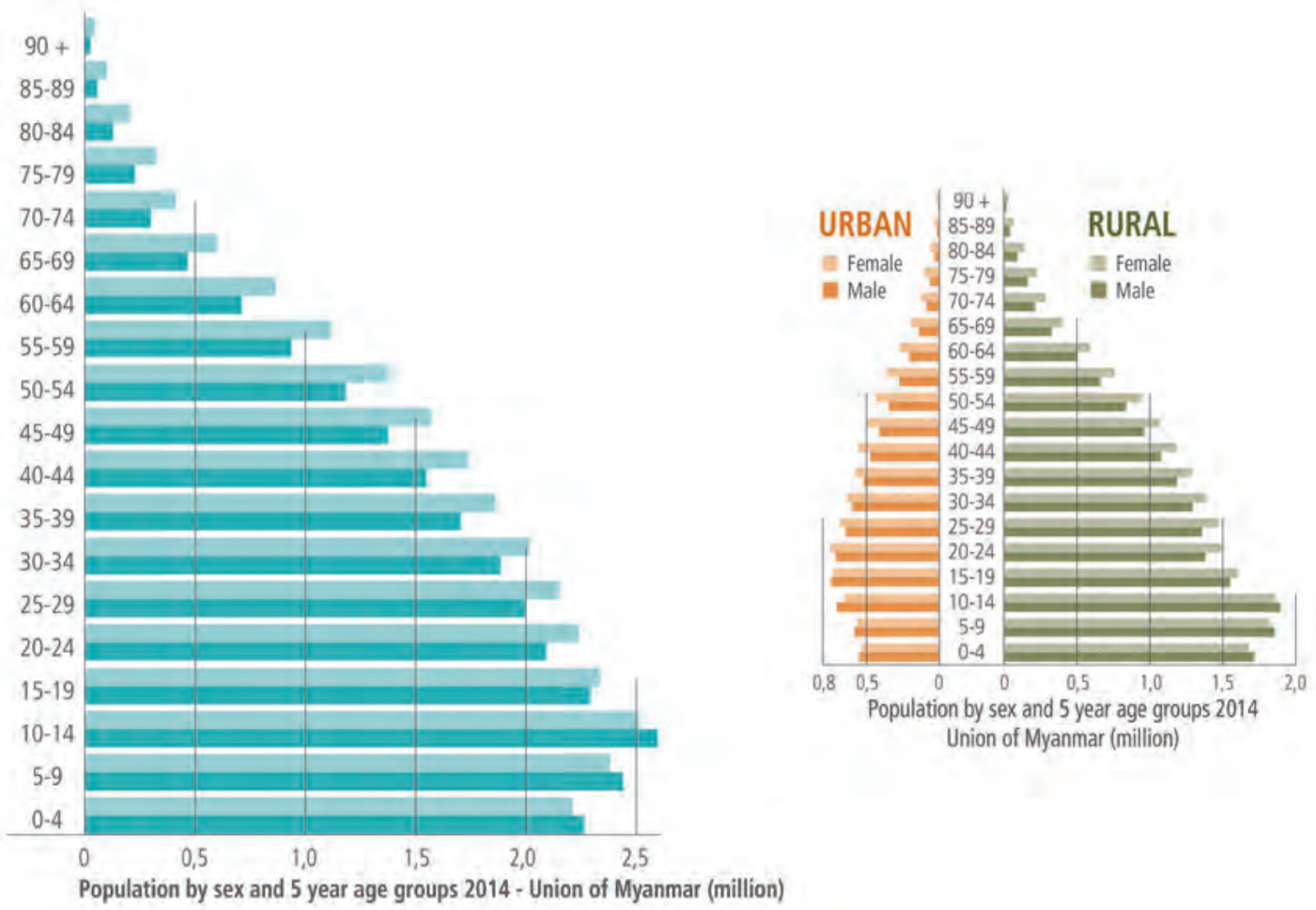

Population pyramid of the Union of Myanmar - total, urban, rural (MoIP 2015a)

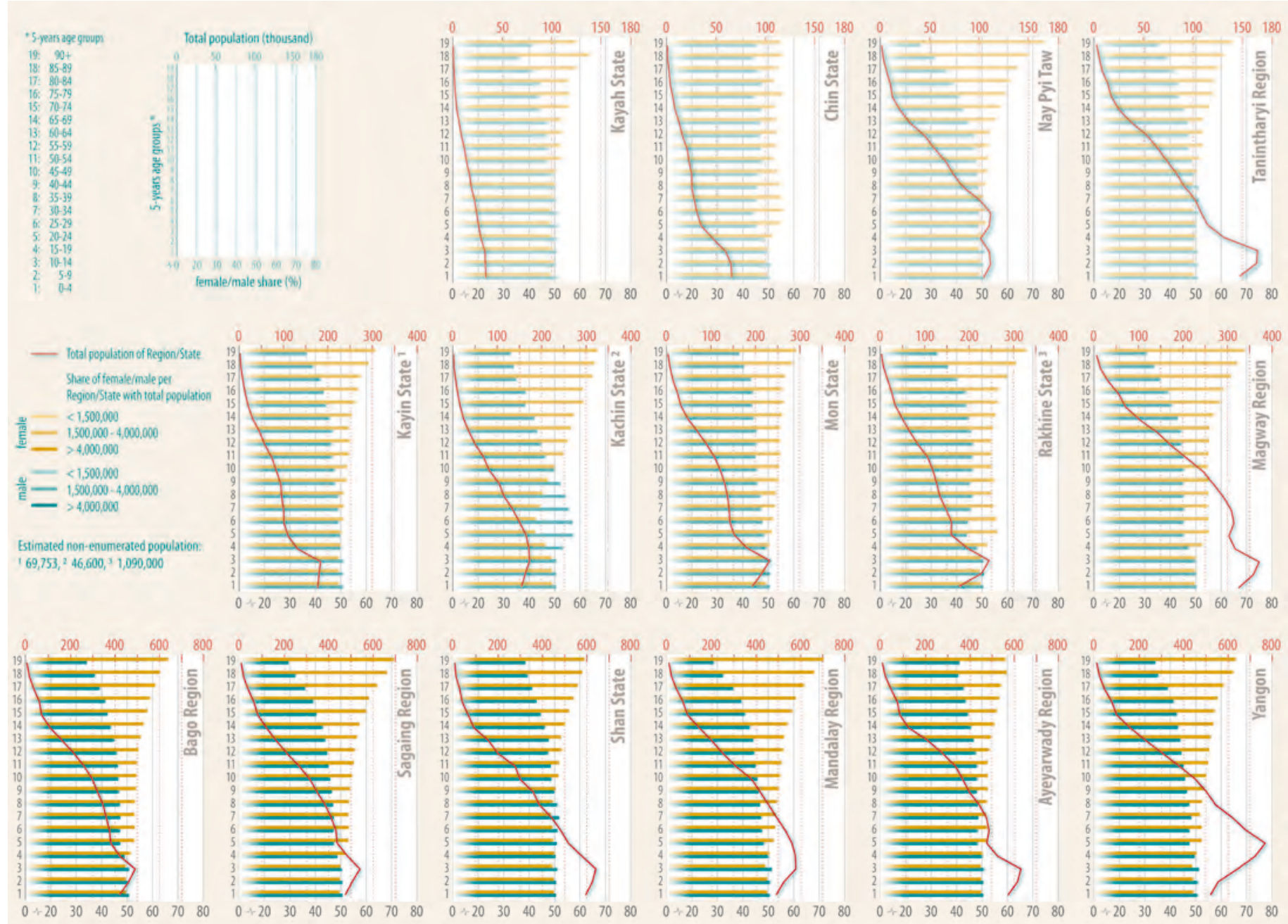

Population pyramids of regions and states with total population (thousands) and female/male share (\%) (MolP 2015a) 


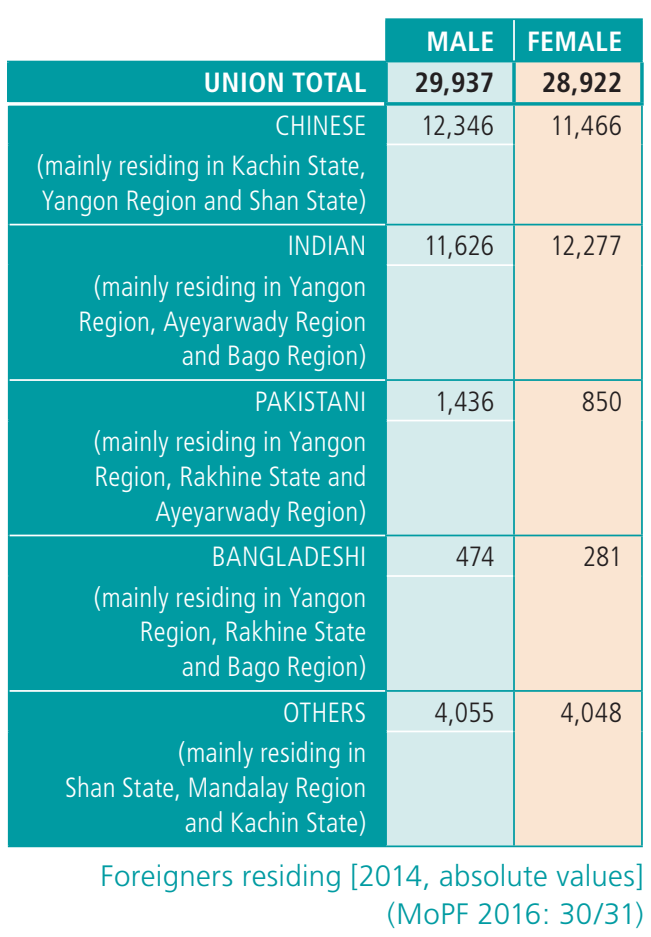

and $0.8 \%(0.8 \%)$ Animists; $0.2 \%(0.2 \%)$ were of other religions and $0.1 \%(0.1 \%)$ mentioned no religion (MoPF 2016: 22).

- Almost 90\% of adults countrywide are literate, but in some regions the figures are considerably lower (e.g. 64.6\% in Shan State). Male literacy rates are slightly higher than female rates; the greatest divergence between the sexes is $16.6 \%$ difference (in Chin State).

- The demographic transition has "changed the position of women, as it gives them an opportunity to play a more active role in the labour market and in community life. In Myanmar, female education has improved impressively over the last three decades. Inequality no longer exists between young males and females in terms of illiteracy. In fact, more females than males now hold higher diplomas" (MoLIP 2016a: xiii).

- $85.2 \%$ of adult males but only $50.5 \%$ of women are in gainful employment; $4 \%$ were registered as unemployed. The unemployment rate among 15-29-year-olds is almost twice as high at $7.7 \%$.

- The population projection shows that "because of the demographic momentum up until 2050, many more young people will enter the labour market than old people will leave. In 2020, some 265,000 new jobs will be needed, a further 188,000 in 2035 and 57,000 in 2050" (MoLIP 2016a: xiv).

- More than $86 \%$ of households own their home, $7 \%$ rent, and $3 \%$ of homes are provided by the government. $79 \%$ of houses are built of wood or bamboo.

- A third of households (32.4\%) have electric light. 'However, there is a huge difference between urban (77.5\%) and rural areas (14.9\%) in the use of electricity as the main source of lighting. The proportion of households using battery, generator and solar systems as the main source of lighting is considerable' (MoIP 2015c: 33).

- A third of households have mobile phones: $31.9 \%$ in the Union, 63.5 in urban and 21.0 in rural areas (MoIP 2015c: 35). Half of households have a television: $49.5 \%$ in the Union, $75.8 \%$ in urban and $39.2 \%$ in rural areas (MoIP 2015c: 35).

- $86 \%$ of rural households use firewood for cooking, even in urban areas $52 \%$ of households cook with firewood or charcoal.

- Drinking water for $31 \%$ of households comes from wells, $18.9 \%$ from springs and $9 \%$ of households have piped water. $31 \%$ of urban households use water purifiers or buy bottled drinking water.

- Countrywide more than $70 \%$ of households have improved water supplies and sanitary facilities; regional values are often lower. Only $14.4 \%$ of households have no toilet facilities.

- $38.7 \%$ of households own a motorbike and $36 \%$ a bicycle $-70 \%$ of all rural households - and $3.1 \%$ have a motor car, a van or a truck.

At township level, regional developmental differences and disparities are very pronounced. Such disparities are to be found between rural and urban regions, and between the central lowlands and the frequently mountainous periphery. There are also marked differences in development potential associated with the ex- 


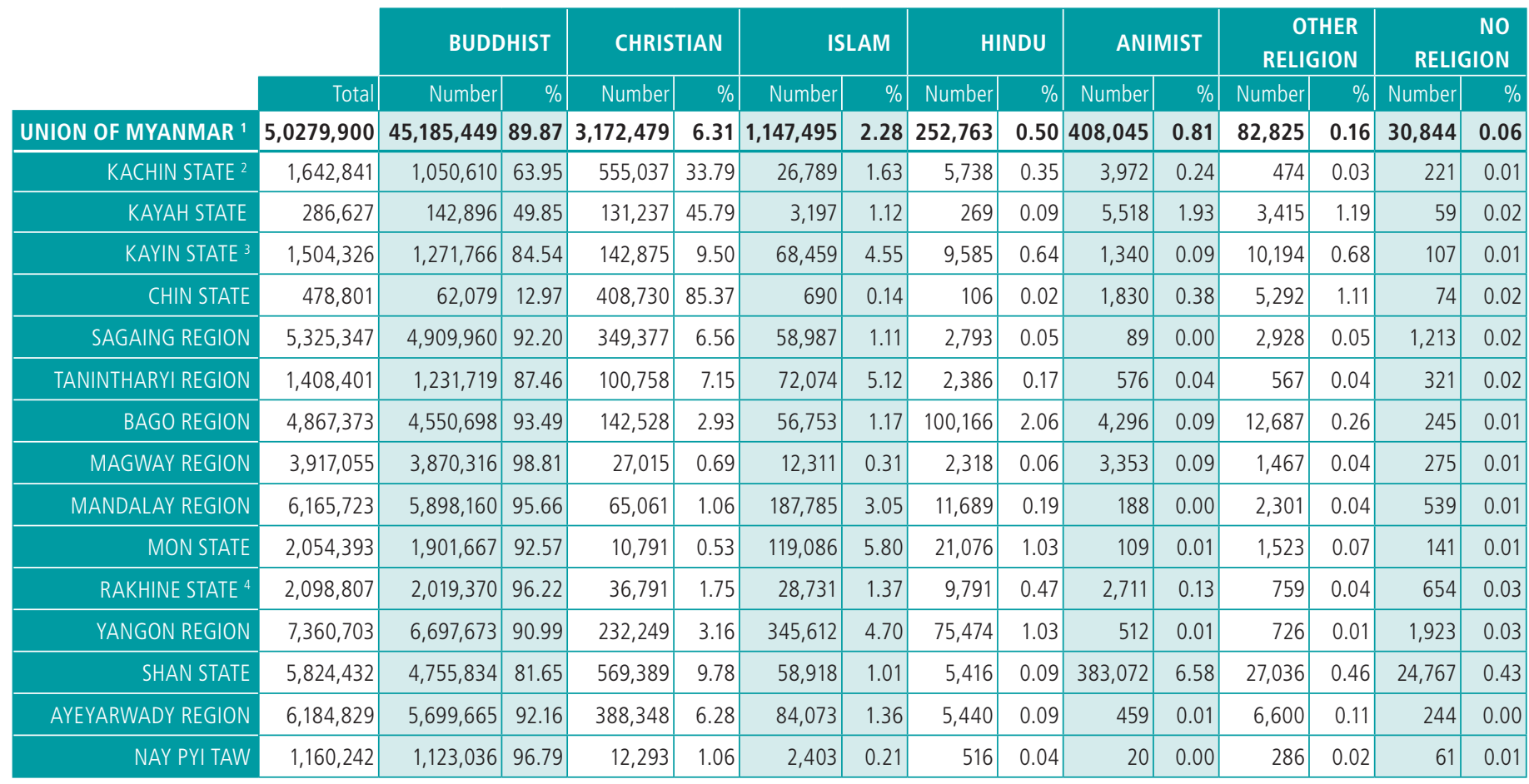

Number and percentage of persons by religion (MoPF 2016: 21, based on the 2014 Myanmar Population and Housing Census) Estimated non-enumerated population: ${ }^{1}$ 1,206,353, ${ }^{2} 46,600,{ }^{3} 69,753,{ }^{4} 1,090,000$

ploitation of resources in the primary sector as well as disparate historically determined patterns.

The census data now published are available at an important point in time: The transformation processes in Myanmar, which have been increasingly consolidating and accelerating since the elections in 2010, require reliable data. These are now available for important development parameters in a regionally differentiated form (aggregated for 15 states and regions and 330 townships). So far, data have been published at national, state/regional, district and township levels, also in the internet; a small amount of data will be published at ward or village level. The publication of the findings on employment, migration, maternal mortality and ethnic and religious identity, which are complex to evaluate and in some cases politically sensitive, might be expected for the future. The initial published findings make it possible to implement specific infrastructural and socio-economic measures, especially in hitherto undersupplied regions. This can help to counteract the intensification of regional socio-economic disparities, which was previously disregarded and difficult to prove.
Furthermore, 'two population groups can, for different reasons, play an important role in harnessing a demographic dividend in Myanmar: women and international migrants. ... International emigrants can play a key role in obtaining a demographic dividend. As they most often draw from the unemployed, their departure leads to a decrease in the proportion of the group of economically dependent. If properly used for savings and investment, the remittances sent by migrants may be an important input for economic growth. ... The second dividend will be determined largely by the way elderly persons are supported in the future. The chance for Myanmar to reap a second demographic dividend will depend on how the active population can accumulate assets and have savings by the time they retire. Government policies to assist middle-aged workers to save for their retirement, individually or through pension funds, will help generate the conditions for a second demographic dividend' (MoIP 2015c: 109).

Frauke Kraas, Regine Spohner and Aye Aye Myint 


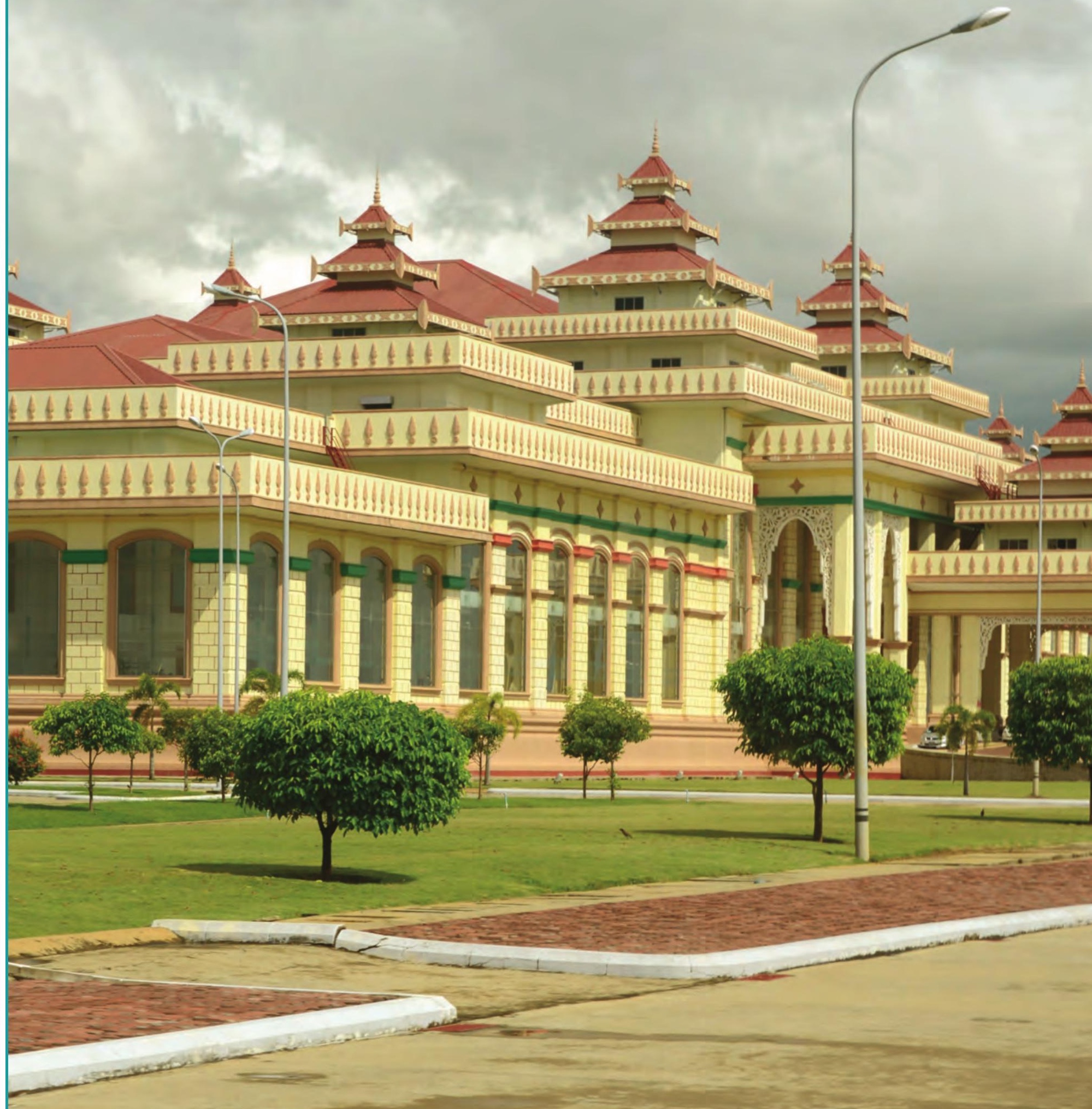

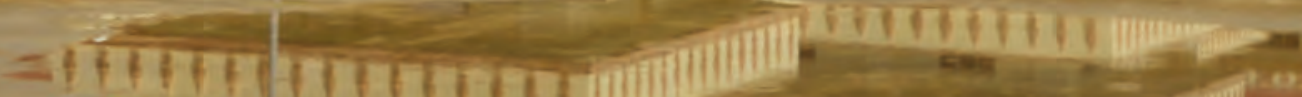




\section{ADMINISTRATIVE AND SPATIAL ORGANISATION}

30 STATES AND REGIONS OF MYANMAR

32 ADMINISTRATIVE BOUNDARIES 


\section{STATES AND REGIONS}

Covering 676,553 $\mathrm{km}^{2}$, the Republic of the Union of Myanmar is the second largest state of Southeast Asia in terms of surface area. The country spans $2,056 \mathrm{~km}$ from north to south and $933 \mathrm{~km}$ from east to west - between $9^{\circ} 32^{\prime}$ $\mathrm{N}$ and $28^{\circ} 31^{\prime} \mathrm{N}$ latitude and $92^{\circ} 10^{\prime} \mathrm{E}$ and $101^{\circ}$ 11' E longitude; the Tropic of Cancer passes through Myanmar near Tiddim, Tagaung, Mabein and Kutkai (Hla Tun Aung 2003: 1). Scarcely developed border mountains and uplands separate Myanmar from the neighbouring states of Bangladesh (271.92 km common border), India (1,452.93 km), China $(2,226.85$ $\mathrm{km})$, Laos (234.91 km) and Thailand (2,098.14 $\mathrm{km}$ ); the full length of the border of Myanmar is $6,284.75 \mathrm{~km}$ (Hla Tun Aung 2003: 1-2). The coastline extends over $2,228.47 \mathrm{~km}$ from the mouth of the Naaf River in the west to Bayintnaung Point (called Victoria Point in the colo- nial period) in Kawthaung; Rakhine State has $712.79 \mathrm{~km}$ of the coastline, the Ayeyarwady Delta $437.65 \mathrm{~km}$ and Mon State with Tanintharyi Region 1,078.03 km (Hla Tun Aung 2003: 14-15).

The territory of the Republic of the Union of Myanmar is made up administratively of Nay Pyi Taw Union Territory, 14 Regions and States, which in turn comprise 74 districts, 330 townships, 442 towns, 3,301 wards, 13,588 village tracts and 63,798 villages (MNPED 2016: 13). The Regions and States differ widely in surface area (the largest are Shan State, Sagaing Region and Kachin State; the ones with the smallest area are Nay Pyi Taw Union Territory, Yangon Region and Kayah State).

Frauke Kraas and Aye Aye Myint

\begin{tabular}{|c|c|c|c|c|c|c|c|}
\hline & AREA (km2) & DISTRICT & TOWNSHIP & TOWN & WARD & VILLAGE TRACT & VILLAGE \\
\hline UNION OF MYANMAR & $676,552.70$ & 74 & 330 & 442 & 3,301 & 13,588 & 63,798 \\
\hline KACHIN STATE & $89,038.58$ & 4 & 18 & 30 & 160 & 596 & 2,547 \\
\hline KAYAH STATE & $11,731.10$ & 2 & 7 & 8 & 37 & 74 & 56 \\
\hline KAYIN STATE & $30,381.67$ & 4 & 7 & 18 & 86 & 376 & 2,097 \\
\hline CHIN STATE & $36,017.58$ & 3 & 9 & 15 & 46 & 469 & 1,363 \\
\hline SAGAING REGION & $94,621.07$ & 10 & 37 & 46 & 238 & 1,754 & 6,000 \\
\hline TANINTHARYI REGION & $43,343.34$ & 3 & 10 & 17 & 87 & 264 & 1,228 \\
\hline BAGO REGION & $39,403.00$ & 4 & 28 & 51 & 325 & 1,410 & 6,441 \\
\hline MAGWAY REGION & $44,818.96$ & 5 & 25 & 30 & 184 & 1,535 & 4,781 \\
\hline MANDALAY REGION & $29,954.33$ & 7 & 28 & 28 & 271 & 1,415 & 4,779 \\
\hline MON STATE & $12,296.19$ & 2 & 10 & 16 & 100 & 368 & 1,153 \\
\hline RAKHINE STATE & $36,776.72$ & 5 & 17 & 26 & 170 & 1,035 & 3,738 \\
\hline YANGON REGION & $10,170.89$ & 4 & 45 & 21 & 743 & 619 & 2,126 \\
\hline SHAN STATE & $155,795.72$ & 13 & 55 & 85 & 505 & 1,566 & 14,334 \\
\hline AYEYARWADY REGION & $35,136.05$ & 6 & 26 & 43 & 292 & 1,920 & 11,910 \\
\hline NAY PYI TAW & $7,067.50$ & 2 & 8 & 8 & 57 & 187 & 795 \\
\hline
\end{tabular}




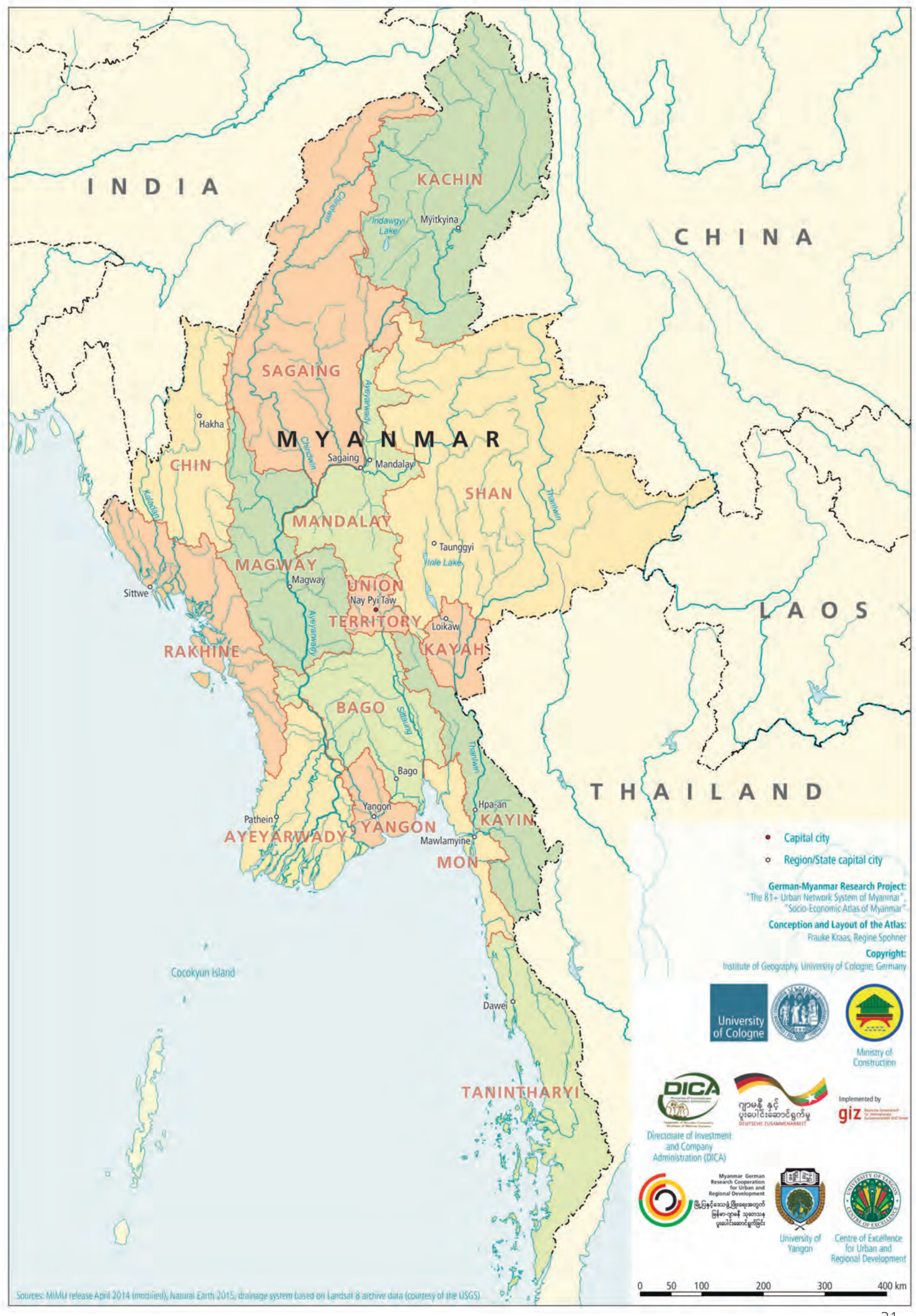




\section{ADMINISTRATIVE BOUNDARIES}

The system of tiered administrative boundaries in Myanmar is based in principle on a hierarchical structure of territorial units of different sizes. The 14 states and regions plus Nay Pyi Taw Union Territory are structured in 74 districts which in turn comprise 330 townships. Townships with a large surface area essentially have low population numbers and densities; in the cities, the surface areas of townships are small and their population numbers and densities are high. The townships with the largest surface areas are in the mountain and peripheral regions; those with the smallest areas are in the inner city of Yangon.

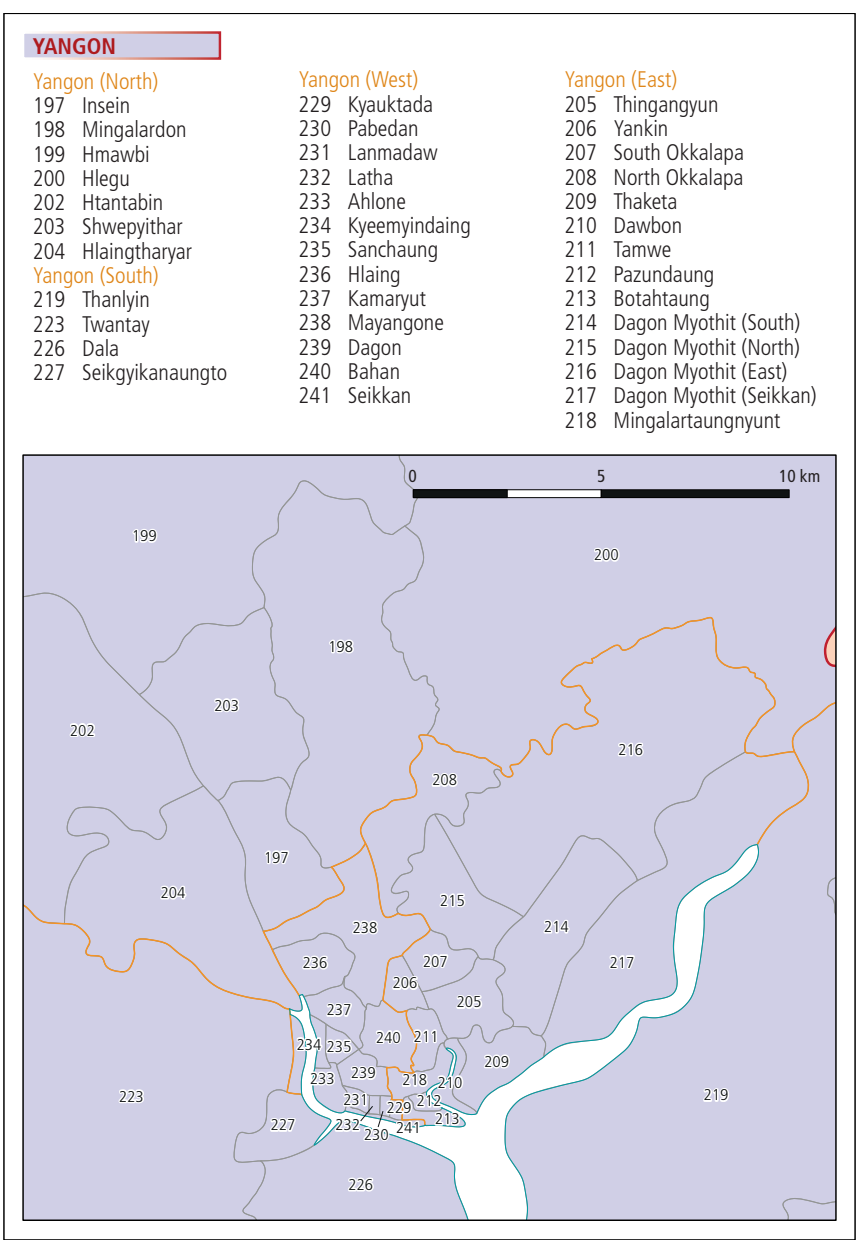

At country level the number of townships is very steady over longer periods. In contrast, the areas and boundaries of the towns and wards - in urban regions - and of village tracts and villages - in rural regions - are often adjusted to population numbers. This usually involves the partitioning of areas or the administrative conversion of rural areas into urban ones. The number of administrative territorial units below township level thus changes continuously. For instance, between 2015 and 2016 the number of towns rose within one year from 422 to 442 , while over the same period the number of wards across Myanmar was reduced from 3,183 to 3,301 and that of villages from 63,860 to 63,798 (MNPED 2015: 10, MoPF 2016: 13). The boundaries of these territorial units are recorded descriptively by specialised administrative personnel and are registered precisely.

\section{Frauke Kraas and Aye Aye Myint}

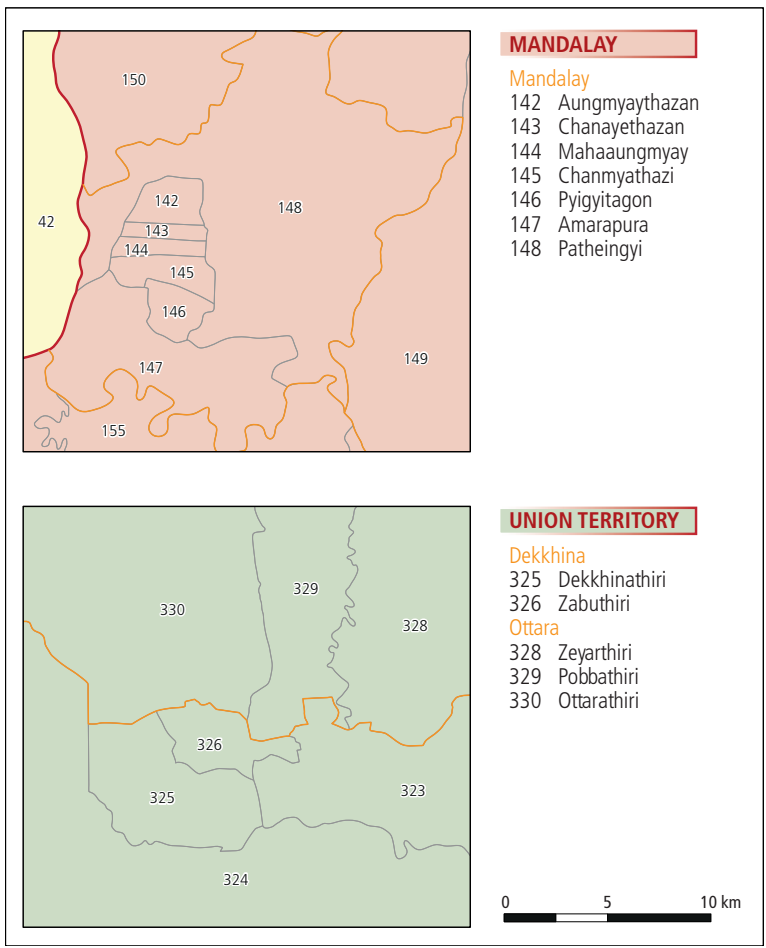




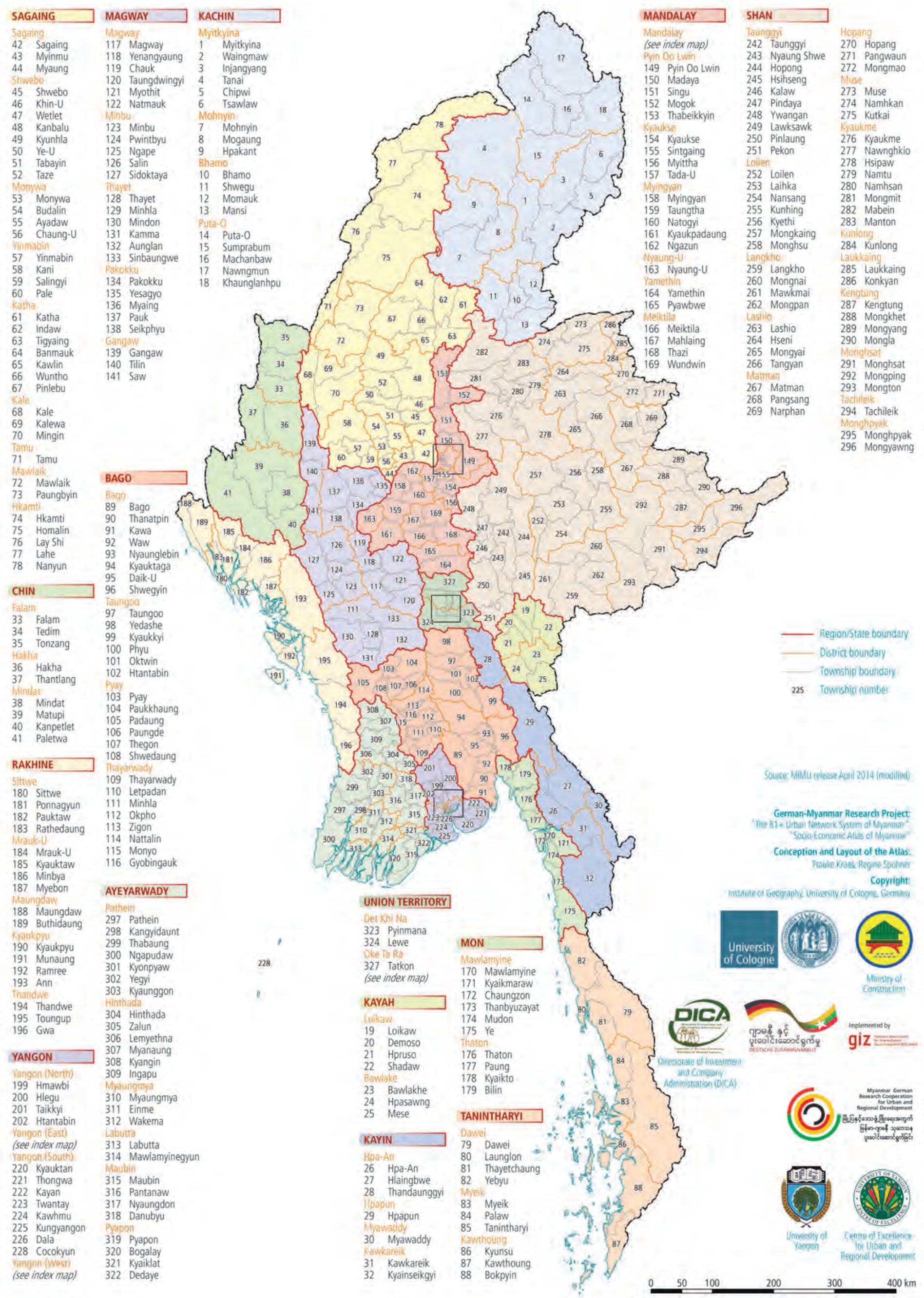




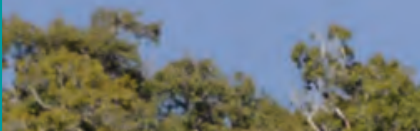

(2)

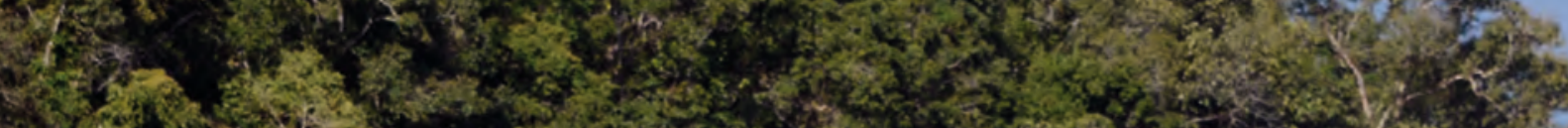

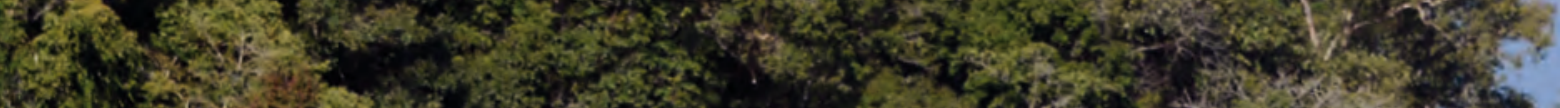

Why

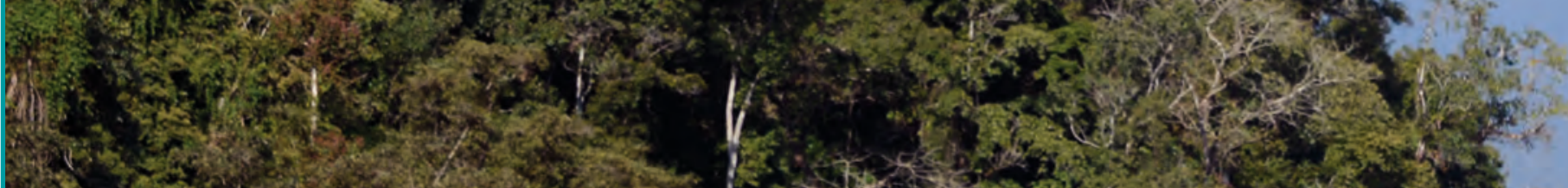

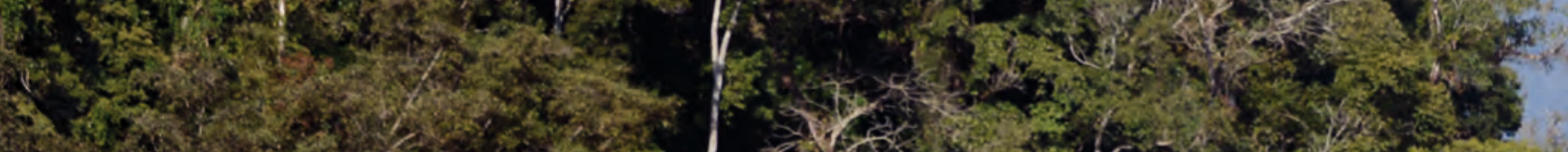

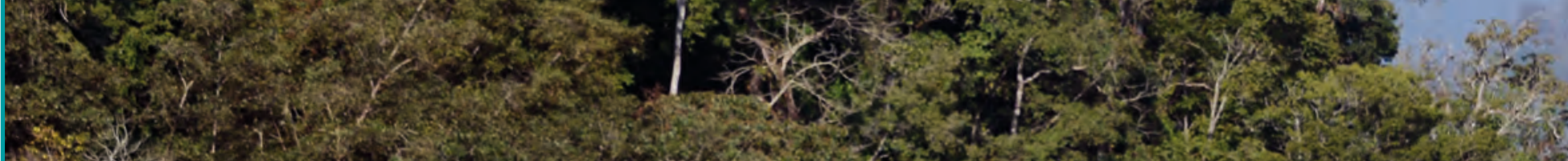

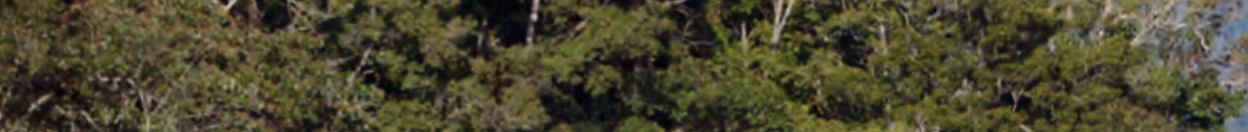

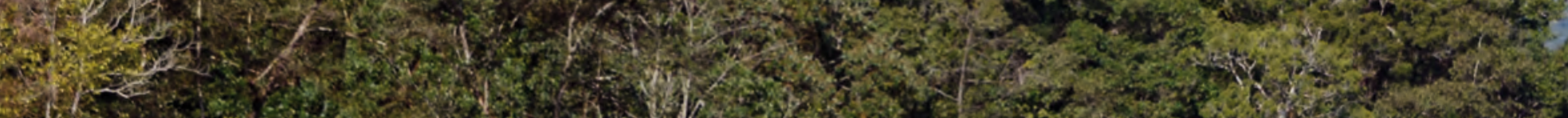

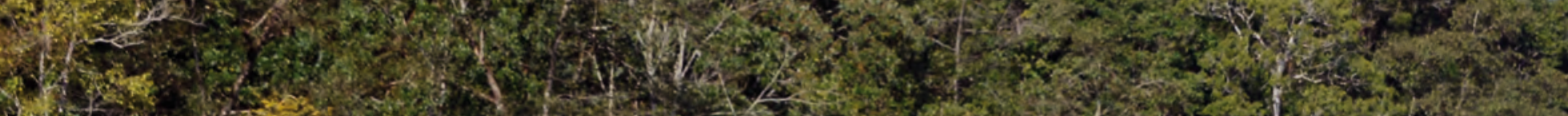

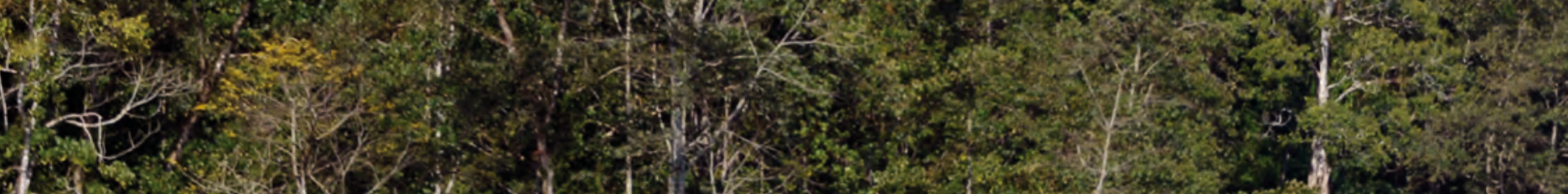
1.1. 2.

(1)

W.

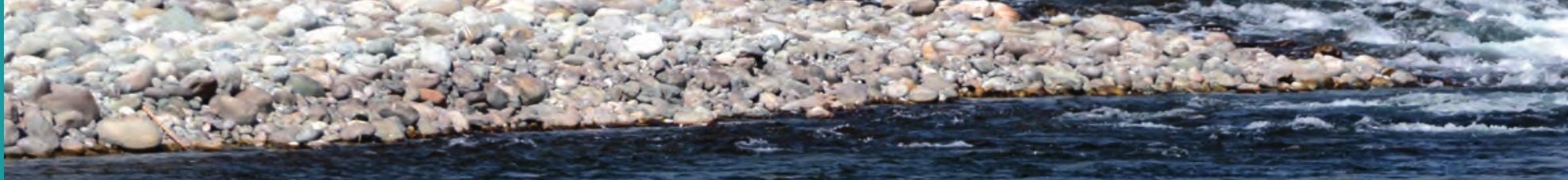




\section{ENVIRONMENT AND NATURAL RESOURCES}

36 TOPOGRAPHY AND NATURAL LANDSCAPES

38 THE VIEW FROM THE SATELLITE

40 LAND COVER

44 CLIMATE: TEMPERATURE AND PRECIPITATION

48 NATURAL HAZARDS AND RISKS

49 NATURAL HAZARDS: EARTHQUAKES AND FAULT LINES, SEISMIC ZONES

52 ENVIRONMENTAL PROTECTION

56 MINERAL RESOURCES

57 FUEL MINERALS

59 METALLIC MINERALS

61 PRECIOUS METALS AND STONES, RARE EARTHS AND

RADIOACTIVE METALS 


\section{TOPOGRAPHY AND NATURAL LANDSCAPES}

Long coasts and beaches, extensive lowlands with fertile deltas and partly relatively untouched mangrove forests, dry regions in the interior, and partly undeveloped hills and mountains along the state borders divide Myanmar into different natural landscapes, which can be classified in seven tropical-subtropical natural regions.

1 The narrow strip of the Rakhine coast in 1 the west is separated from the rest of Myanmar by the Rakhine Mountains. The rolling hills are traversed by short, rapidly flowing rivers, cliffs fall steeply to the sea, countless islands lie offshore. The tropical rainforests, bamboo groves and the long narrow mangrove woods along the coast are little developed.

2 The Thanintharyi coast, a long coastal strip along the Thai border in southeast Myanmar, has similar features. As part of the Malayan Peninsula with humid tropical conditions and high precipitation, the natural mountain forests, coastal habitats (including the reefs and sandy beaches), mudflats and mangrove swamps are experiencing increasing pressure from human activities, mainly in the form of rubber and oil palm plantations.

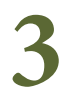

The Shan Hills at an altitude between 1,000 and $2,000 \mathrm{~m}$ consist of mountain ranges, mostly formed by limestone and granite, and basins. Partly excessive deforestation and intensive agriculture, including fruit and vegetable plantations, coffee and tea cultivation, as well as underused secondary vegetation and grasslands are characteristic of the region.
4 Myanmar's northernmost region, where alayas reaches up to $5,881 \mathrm{~m}$ around the highest peak of Hkakabo Razi, is very inaccessible. The dense mountain rainforests with oaks, chestnuts, tree ferns and bamboos have been cleared in the valley bottoms to make way for rice and vegetable cultivation.

5 The northwestern mountain area with 5 numerous peaks between 2,000 and $4,000 \mathrm{~m}$ contains several parallel mountain chains running north-south. They are extensively covered by rainforests with some precious wood, but mostly oak and pine forests. The area is sparsely populated and mostly cultivated by Taungya and subsistence agriculture.

6 To the southeast lies the central dry zone. At its centre is the almost $1,500 \mathrm{~m}$ high volcanic massif of Mount Popa. Because of the low precipitation in this region, dwarf shrubs and succulents as well as various types of acacia thrive here.

7 To the south of this region is the densely populated and intensely used lower Ayeyarwady basin and delta with the most intensively extensive cultivated areas in the country, the "rice bowl" of Myanmar. Only in the nature conservation areas of the Bago Mountains have teak and bamboo forests survived, and the extreme south of the delta region is bounded by mangrove forests.

Frauke Kraas and Nay Win Oo 

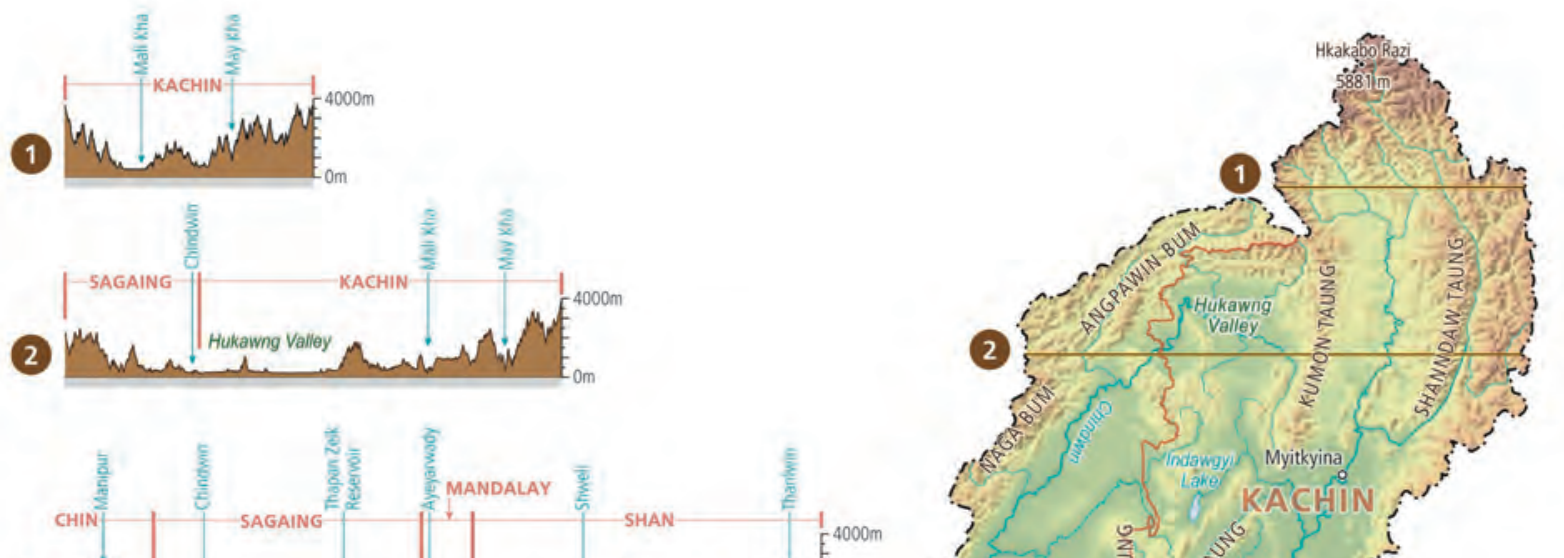

\section{(3)}

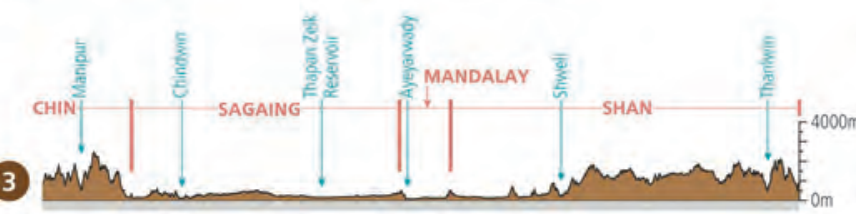

Elevation:
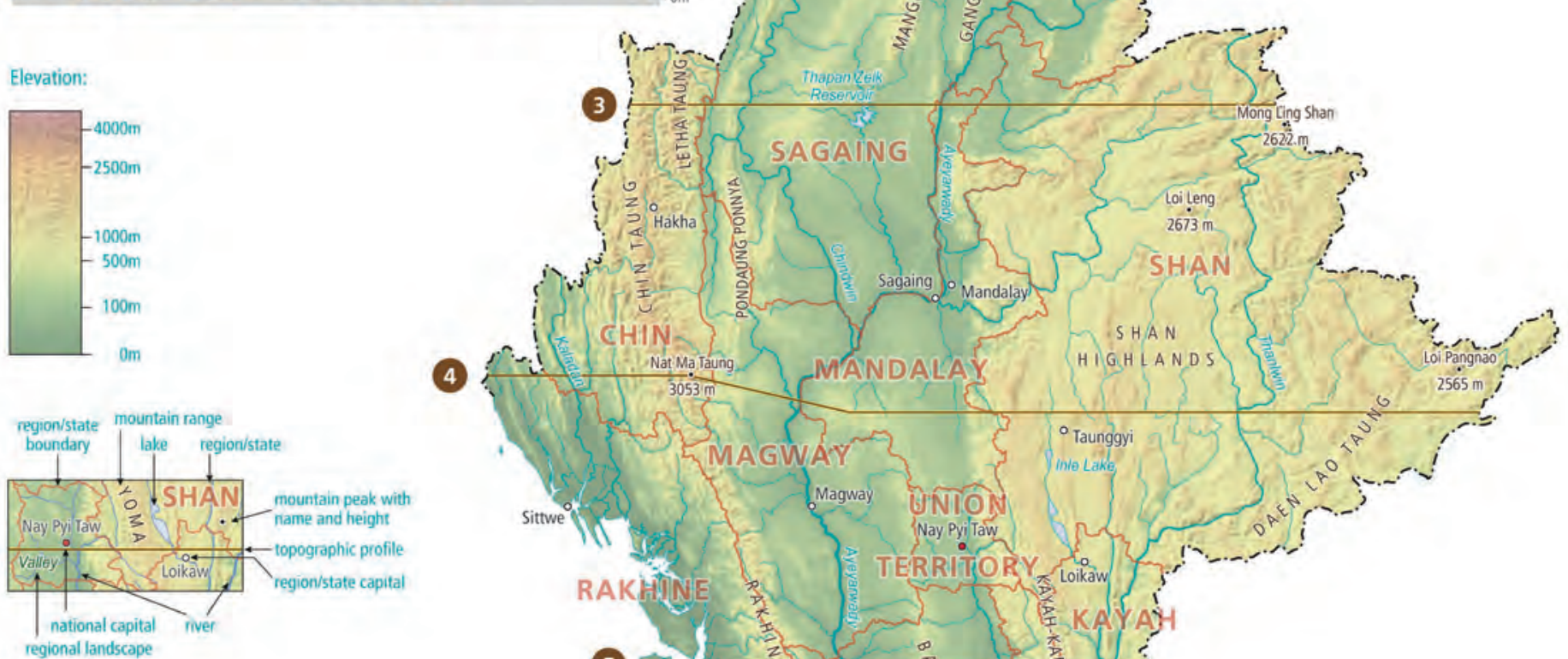

Sources: MiMuU release Apri 2014 (modifien) Hila Tum Aung 2003, Jarvis et al. 2008

German-Myanmar Research Project: "The 81+ Urtan Network System of Myanmar" "Socio-Economic Attas of Myanmai" Conception and Layout of the Atlas: Frauke Kras, Regine Spohnes

Copyright:

instifute of Geogroghy, University of Cologne, German
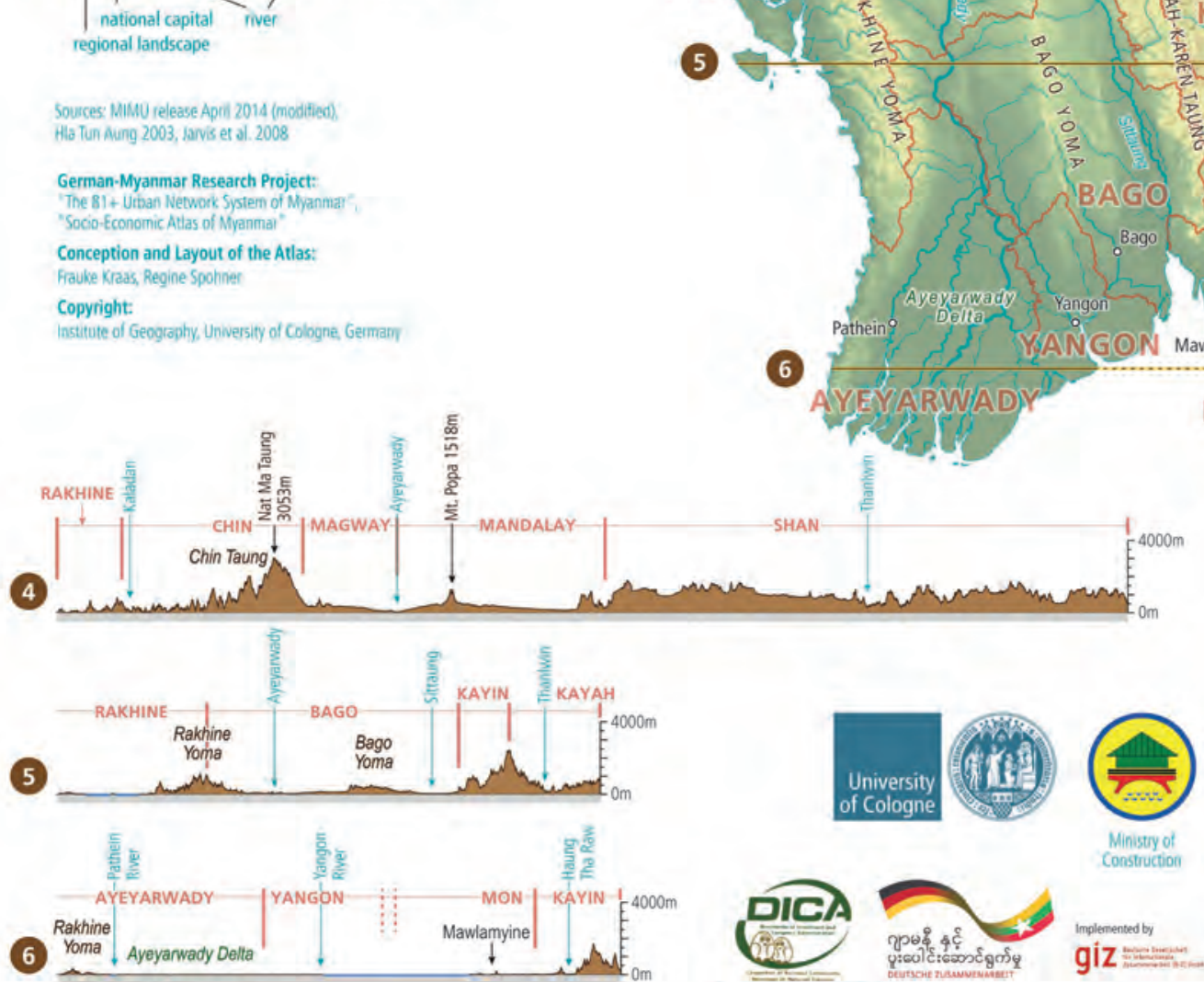

6 Roma , Ayeyarwady Della
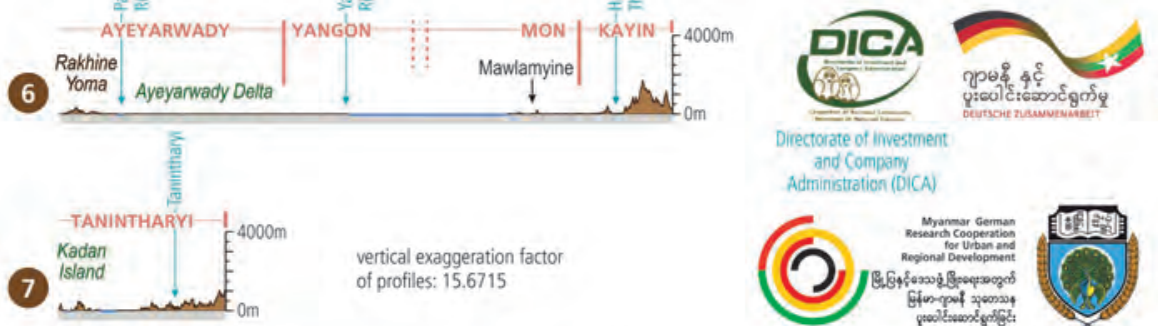

\section{(C) 놀}

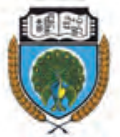




\section{THE VIEW FROM THE SATELLITE}

Myanmar, with an area of $676,552 \mathrm{~km}^{2}$ the second-largest state in Southeast Asia, extends 2,056 $\mathrm{km}$ from north to south and $933 \mathrm{~km}$ from east to west, covering 20 parallels of latitude ranging from the tropics and subtropics to north of the Tropic of Cancer. Rather inaccessible mountain and hill regions separate Myanmar from the neighbouring states of Bangladesh, India, China, Laos and Thailand.

The satellite image shows the obvious differences in respect to the vegetation cover. On the one hand, the central Myanmar basin of the Ayeyarwady River and its wide plains are the agricultural heartland of the country. Smaller in extension but similarly intensely cultivated is the area around Sittaung River east of the Bago Mountain range, stretching north-southward in the southeast of the central lowland. To the west, the Rakhine Mountains bound the central plains, running almost parallel to the coast. On the other hand, the contrast of the predominantly forest-covered mountain areas becomes obvious. Apart from the Shan Highland in which larger basins have been settled and cultivated, particularly in recent decades, the mountain ranges at the borders in the west, north, southeast and south of the country are yet left in a comparatively natural condition.

While the coastal lowlands and delta regions are at sea level or only a little above it, the high mountains in the north of Kachin State (in the satellite image mostly snow-covered) reach heights of almost $6,000 \mathrm{~m}$; the highest mountain is Hkakabo Razi at 5,881 $\mathrm{m}$. The mountain chains and major valleys mostly run in a north-south direction, determined by their tectonic origins (Hla Tun Aung 2003). The $1,571 \mathrm{~km}$ long Ayeyarwady River, the largest in the country, crosses Myanmar from the foothills of the Himalayas in the north where it emerges north of Myitkyina, at Myitsone with the confluence of N'Mai Hka and Mali Hka
Rivers - to its more than $150 \mathrm{~km}$ wide delta on the Indian Ocean in the south. Here, in the southernmost coastal zones, larger mangrove areas are still protecting the delta.

To traverse the heart of the country from east to west, it is necessary to cross numerous mountain chains, especially in the mountainous regions of Kachin State, Sagaing Region, Shan State and Chin State. In the east, the Thanlwin River transects the Shan Hills and the south-eastern coastal provinces. Underlying rocks, topography, soil evolution and vegetation cover, erosion and accumulation (especially along the coast of the Ayeyarwady Delta; Gupta 1996) together with other geofactors create many challenges to human access to and exploitation of the country's natural regions (Gupta 2005): Steep, sometimes instable slopes, as well as geological fault zones with a high incidence of earthquakes inhibit the development of infrastructure.

Frauke Kraas, Aung Kyaw and Nay Win Oo 
Kachin State: high mountain area

2 Kachin State, Sagaing Region: mountain area (Indawgyi Lake area, forest area, mining area of U Yu River area [Hpakant])

3 Chin State: mountain area of Chin Hills

4 Sagaing and Mandalay Region: transition from cultivation area of Central Myanmar to mountain area of Shan North

5 Shan State (North): valley of mountain area [Hsipaw]

6 Rakhine State: coastal area from Sittwe to Mrauk-U

7 Mandalay Region: Mt. Popa and cultivation area of Central Myanmar [Bagan area]

8 Shan State (South): mountain area with basins and valleys of Kalaw, Taunggyi and Inle Lake

Shan State (East): mountain area with Tachileik and surroundings

10 Rakhine State: mountain area of Rakhine Yoma

11 Bago Region: mountain area of central Bago Yoma, Sittaung Valley

12 Ayeyarwady Region: coastal area with the delta region of Ayeyarwady River

13 Yangon Region: urban fringe of Yangon City and southern foothills of Bago Yoma

14 Mon and Kayin State: low land of Thanlwin River east/northeast of Mawlamyine and karst landscape of Hpa-an

15 Tanintharyi Region: Myeik Archipelago and transition from coastal to mountain area of Bilauk Taung
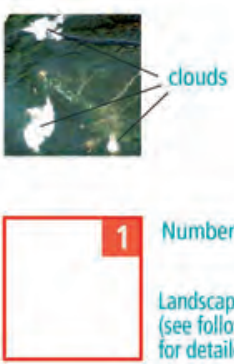

Number of the area used as an example

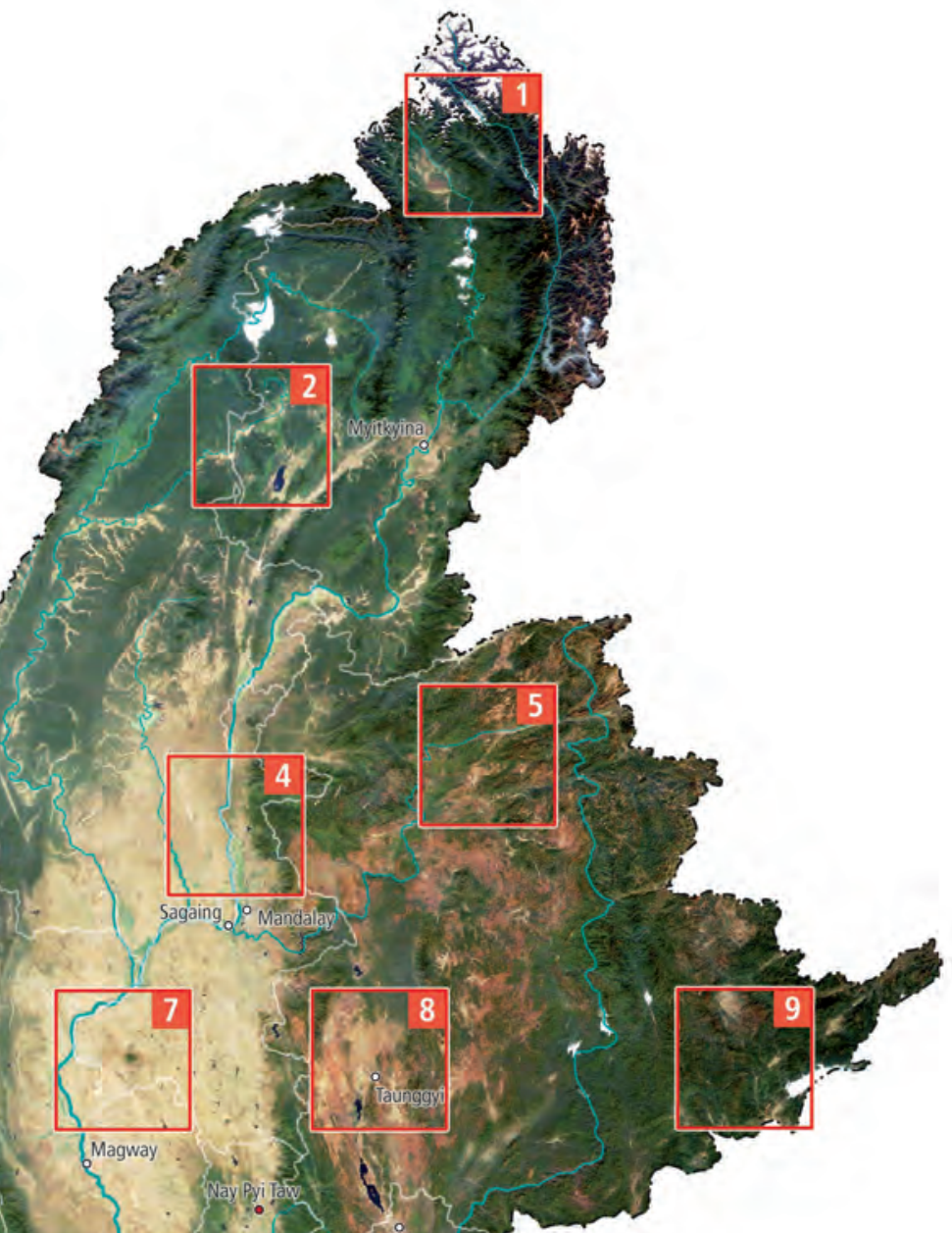




\section{LAND COVER}

Out of Myanmar's 167,186,000 acres of land area, $43,871,000$ acres were classed as reserved forests $(26.24 \% ; 2014 / 2015)$ and $36,409,000$ acres as other woodland (21.78\%); 29,617,000 acres consisted of net area sown (17.72\%), 13,014,000 acres of cultivable waste other than fallows (7.78\%) and the rest of other forms of land use, including village land (1,216,000 acres), 638,000 acres of irrigation systems (canals, reservoirs, tanks and embankments), transport (740,000 acres) and settlements (490,000 acres; all figures: MNPED 2015: 206208).

Myanmar's extremely species-rich forests have been studied and described in detail (e.g. Stamp 1924, Davis 1960, Blower et al. 1991). Broadly speaking, they contain evergreen and deciduous trees and may be divided into the following forest types: tropical (under 3,500 feet), subtropical (between 3,500 and 7,500 feet, mainly in Shan and Kachin State) and temperate (above 6,000 feet in northern Myanmar) (Bryant 1997: 226, Corlett 2005). The key commercial species for centuries are teak (Tectona grandis; in Myanmar: kyun) und iron-wood (Xylia dolabriformis; pyinkado); however, padauk (Pterocarpus macrocarpus), in (Dipterocarpus tuberculatus), kanyin (Dipterocarpus spp.), thitka (Pentace burmanica), thitkado (Cedrela toona), thingan (Hopea odorata), thitsi (Melanorrhoea usitata, tapped for lacquerware) and various species of pine (Pinus spp.; tinya) and fir (Abies spp.) are also in demand (Bryant 1997: 226).

Figures on Myanmar's forest cover vary: according to MNPED (2015: 277), forest cover area has decreased from 51.54\% (of total land area $=$ 134,626 square miles, $2000-2001$ ) to $45.04 \%$ (= 117,655 square miles, 2014-2015). Figures from the FAO indicate that forest cover area has decreased from $57.9 \%$ (1990) to $51.1 \%$ (2000) and then $47.6 \%$ (2005) (FAO 2009), with a loss of around 446,000 ha of forest between 2000 and 2005 (FAO 2006) and a simultaneous increase in the proportion of reserved forests from $15 \%$ (1990) to $23 \%$ (2005; Khin Htun 2009: 13). Leimgruber et al. (2005) refer to an estimated $0.3 \%$ of annual forest loss. A total figure of $44.2 \%$ is on record for 2015 (FAO 2015: 6), with annual loss of forest cover between 1990 and 2015 amounting to $1.2 \%$ (FAO 2015: 12). The largest percentage of forest losses (based on total land area) per year were recorded for Kayah State and the Ayeyarwady and Yangon Regions (2000-2005; Liu et al. 2015: 8) and are mainly attributed to forest clearance for road building and to anthropogenic and wild fires (Liu et al. 2015: 13-16).

The spatial analysis of MODIS Land Cover data (based on the IGBP Land Cover Classification Scheme) shows the predominant land cover types: $39.39 \%$ of the country - mainly in mountain regions - consists of evergreen broadleaf forest, while $23.96 \%$ is classed as woody savannas and $13.78 \%$ as cropland/natural vegetation mosaic. A further $9.12 \%$ is classed as mixed forest; these contiguous areas are located in the far northeast of Kachin, where there are also areas of snow and ice. Croplands account for $8.52 \%$ and are mainly located in the agricultural areas of Central Myanmar, the Ayeyarwady Delta, along the Ayeyarwady, Sittaung, Kaladan and Thanlwin Rivers and in coastal regions. Water and permanent wetlands, the latter mainly along the coasts and around the islands, account for $0.45 \%$ /1.15\%, respectively (Davies/Sebastian/Chan 2004). Grasslands (0.89\%) and savannas (0.59\%) are also of relevance. Urban and built-up areas cover just $0.22 \%$ of national territory at present.

Frauke Kraas, Win Maung, Htun Ko and Saw Yu May 
Kachin State: high mountain area

2 Kachin State, Sagaing Region: mountain area (Indawgyi Lake area, forest area, mining area of U Yu River area [Hpakant])

3 Chin State: mountain area of Chin Hills

4 Sagaing and Mandalay Region: transition from cultivation area of Central Myanmar to mountain area of Shan North

5 Shan State (North): valley of mountain area [Hsipaw]

6 Rakhine State: coastal area from Sittwe to Mrauk-UV

7 Mandalay Region: Mt. Popa ar cultivation area of Central Myanmar [Bagan area]

8 Shan State (South): mountain area with basins and valleys of Kalaw, Taunggy and Inle Lake

V051 MODIS Land Cover classification types and share of land cover type of total area [IGBP Land Cover Classification Scheme]

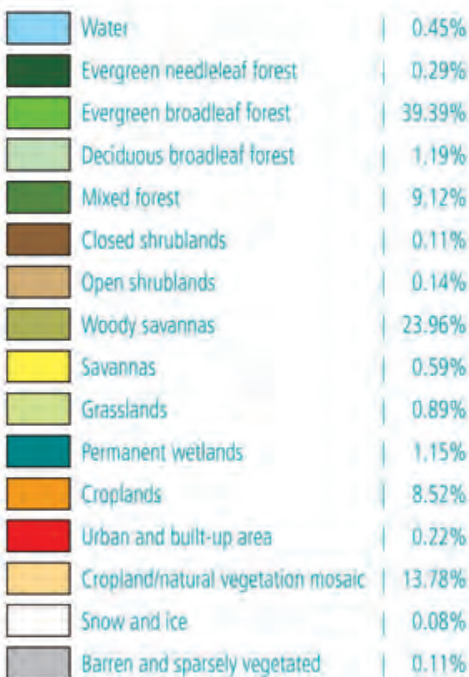

9 Shan State (East): mountain area with Tachileik and surroundings

10 Rakhine State: mountain area of Rakhine Yoma

11 Bago Region: mountain area of central Bago Yoma, Sittaung Valley

12 Ayeyarwady Region: coastal area with the delta region of Ayeyarwady River

13 Yangon Region: urban fringe of Yangon City and southern foothills of Bago Yoma

14 Mon and Kayin State: low land of Thanlwin River east/northeast of Mawlamyine and karst landscape of Hpa-an

15 Tanintharyi Region: Myeik Archipelago and transition from coastal to mountain area of Bilauk Taung

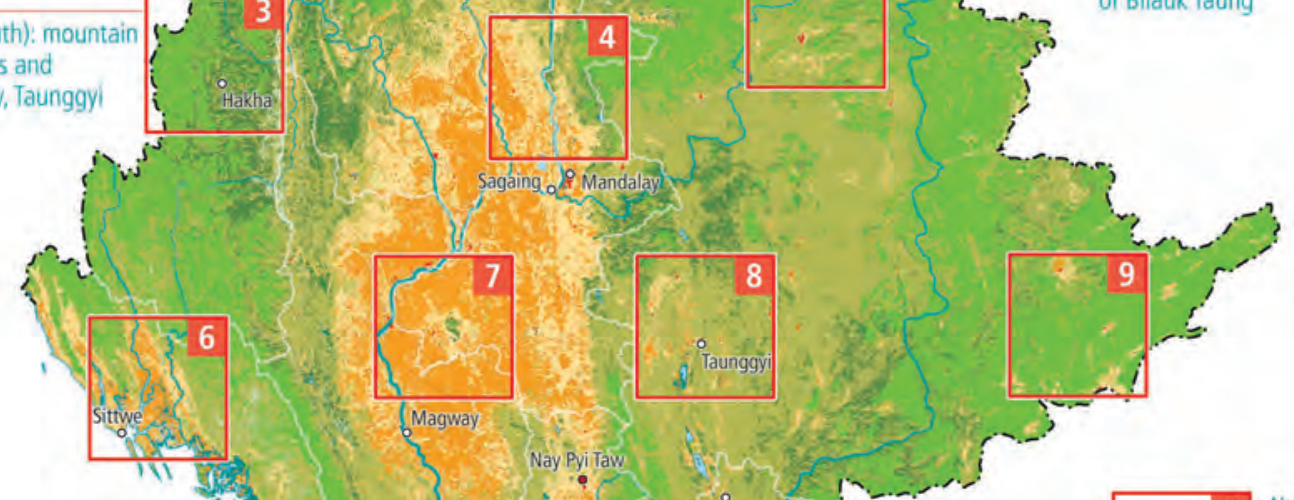

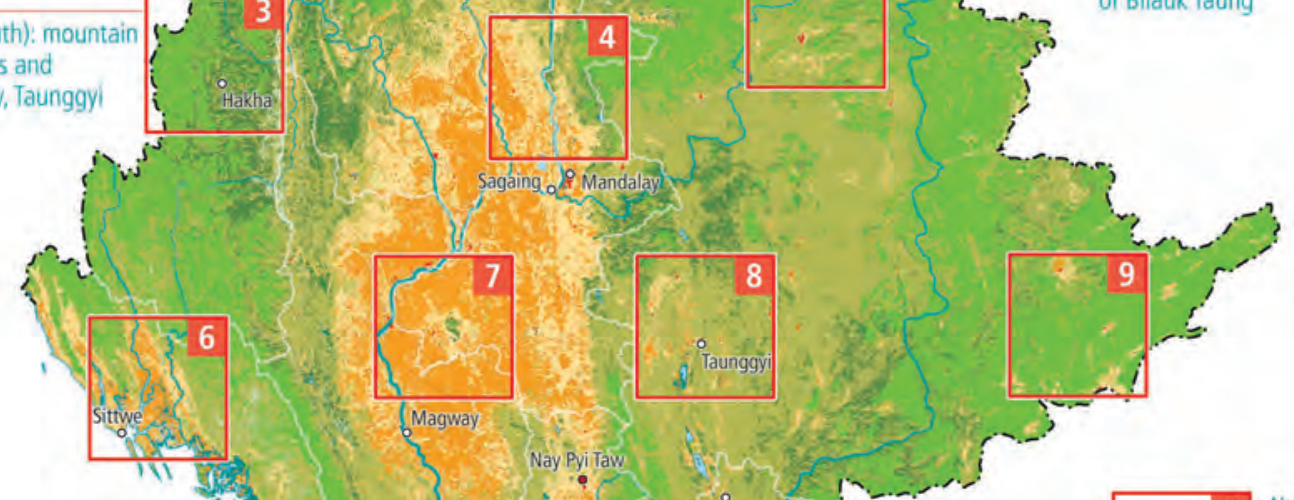

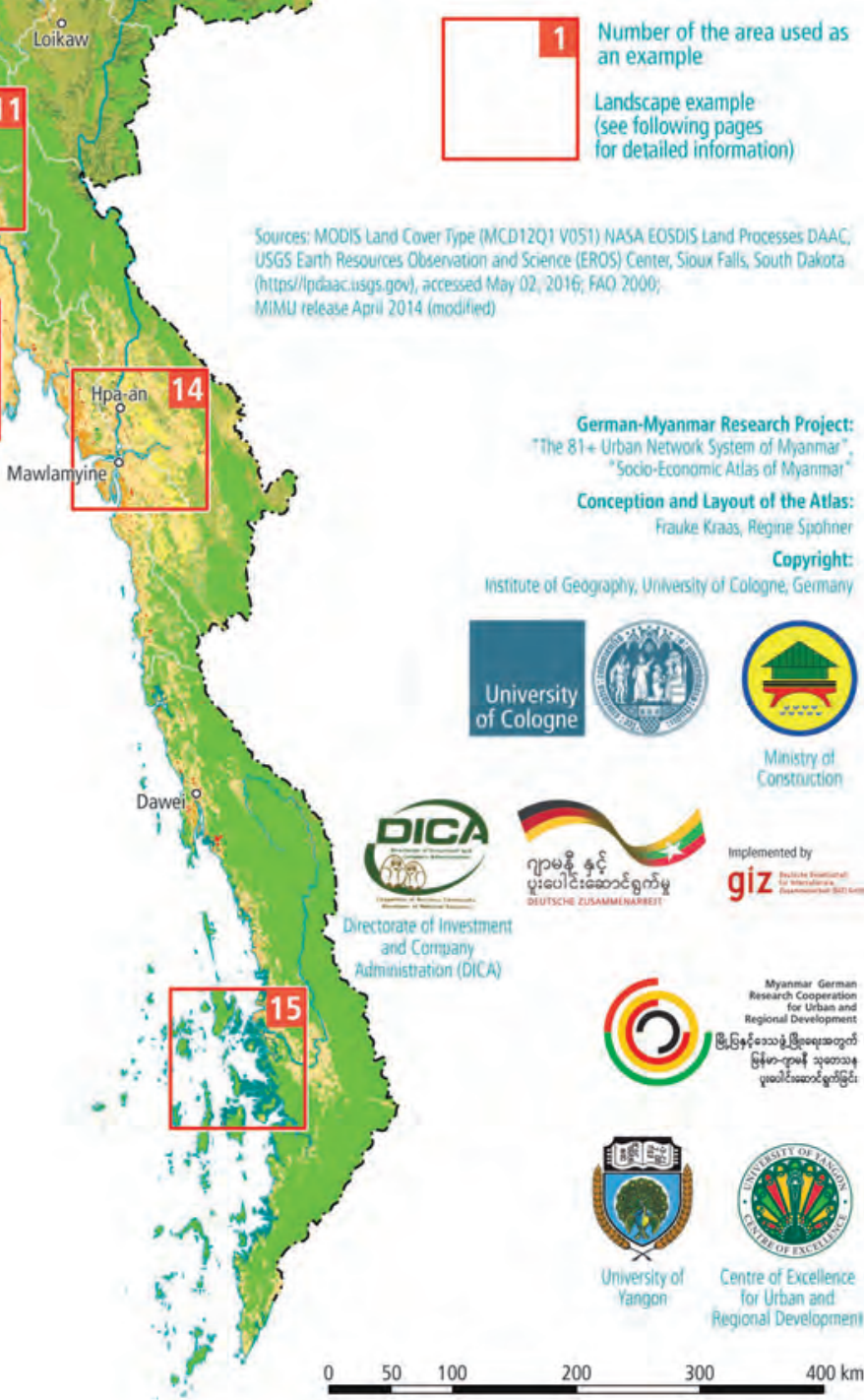

Number of the area used as an example Landscape example (see following pages for detailed information 

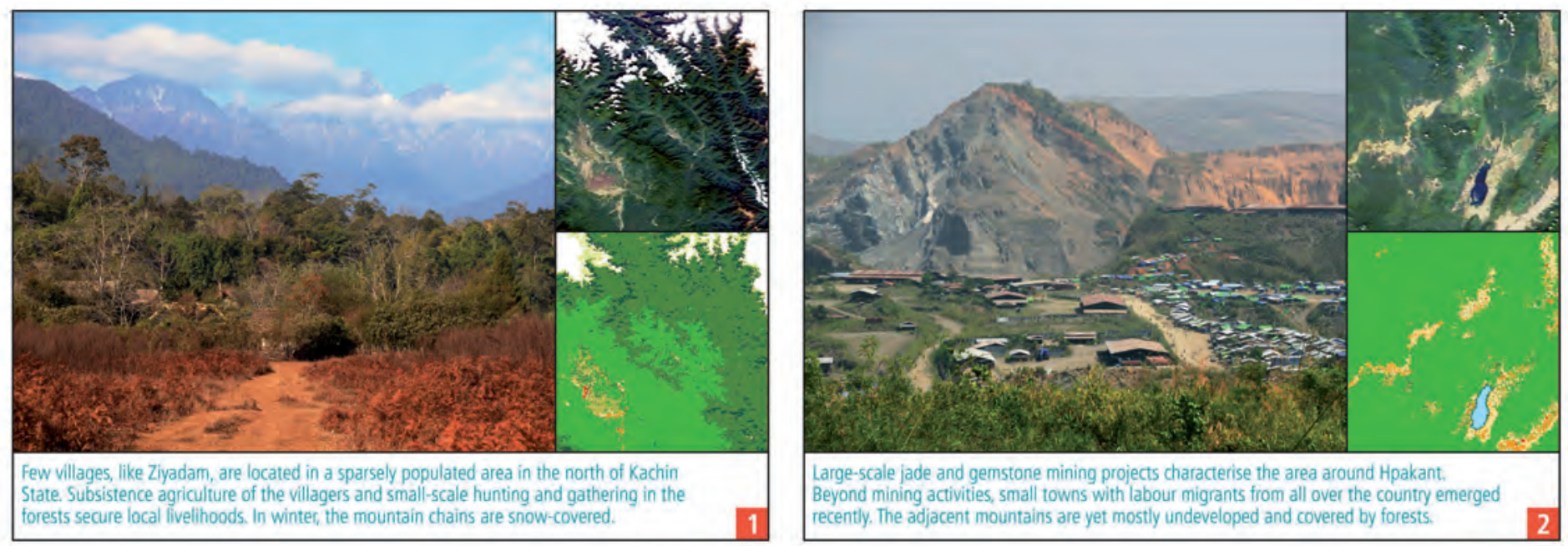

Large-scale jade and gemstone mining projects characterise the area around Hpakant. Beyond mining activities, small towns with labour migrants from all over the country emerged recently. The adjacent mountains are yet mostly undeveloped and covered by forests.

2
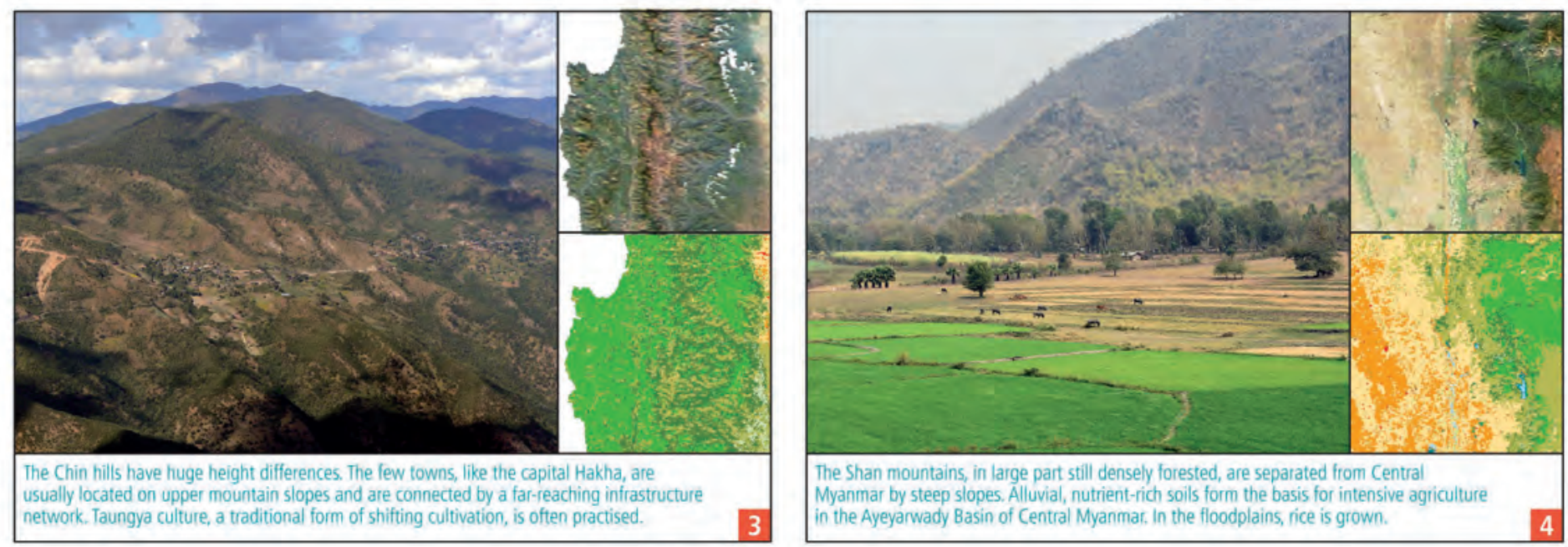

The Shan mountains, in large part still densely forested, are separated from Central Myanmar by steep slopes. Alluvial, nutrient-rich soils form the basis for intensive agriculture in the Ayeyarwady Basin of Central Myanmar, In the floodplains, rice is grown.
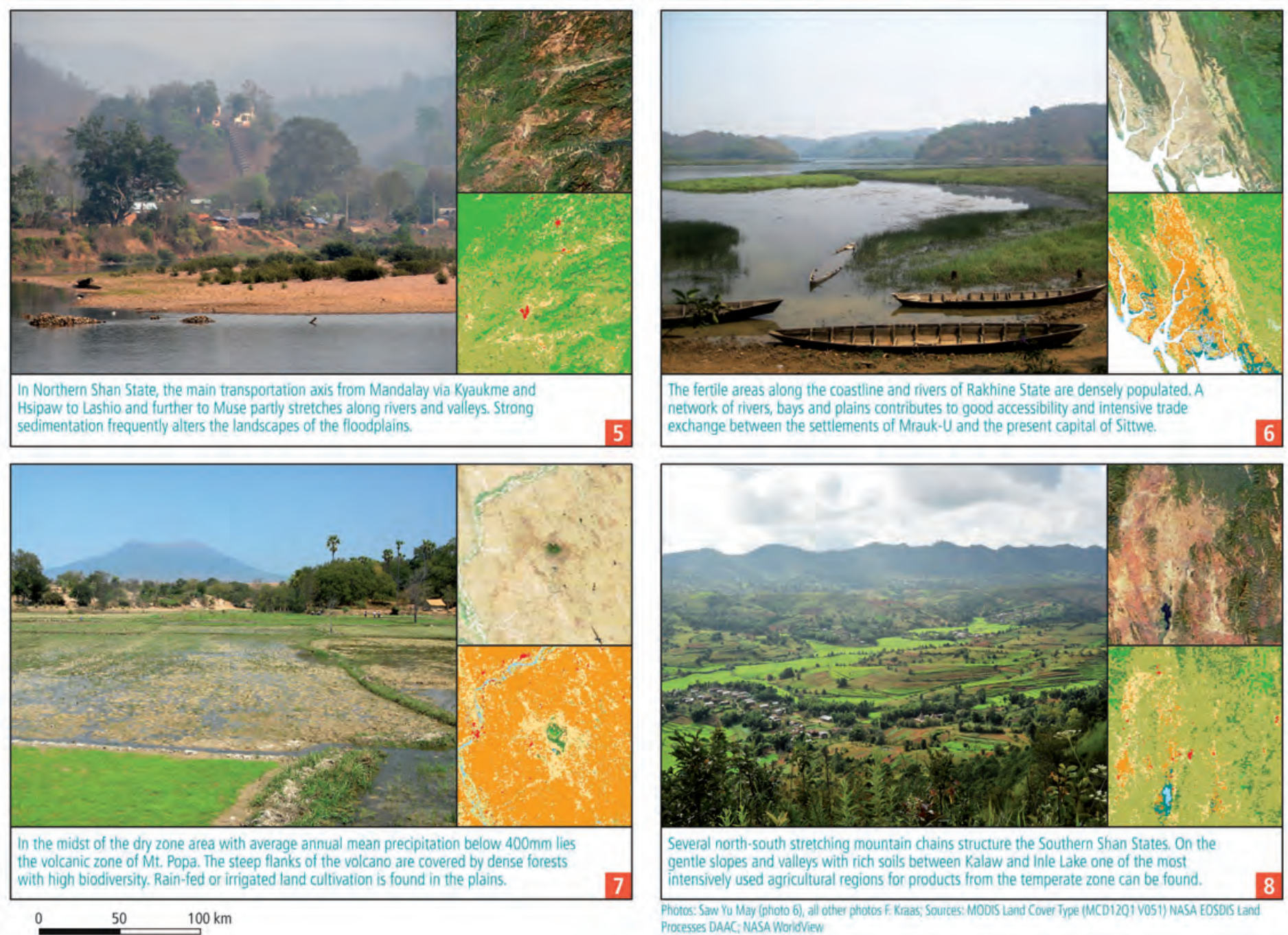

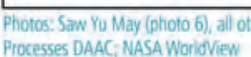




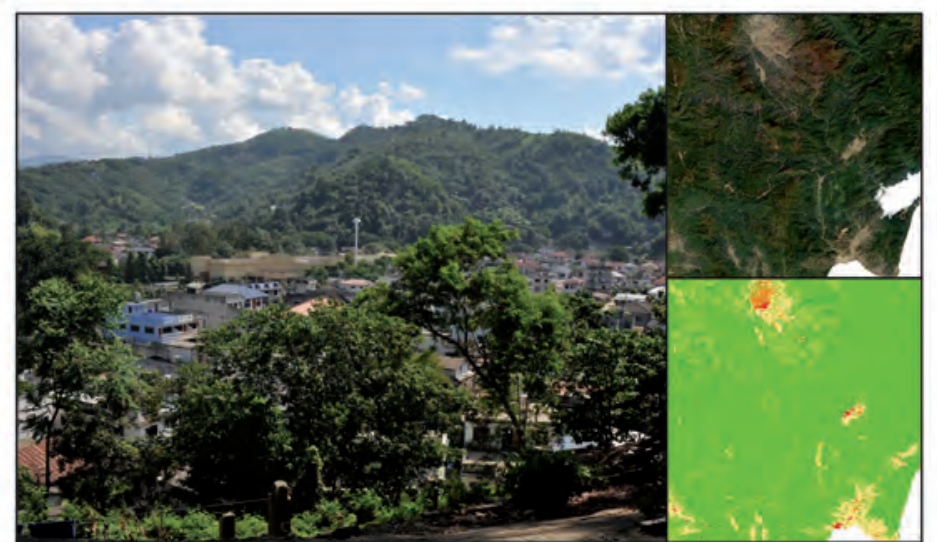

The mountains of Eastem Shan State are difficult to access and develop due to their high elevation, steep slopes and sparsely settled surroundings. An economic development corridor started to emerge recently from Kengtung to Tachileik on the border to Thailand.
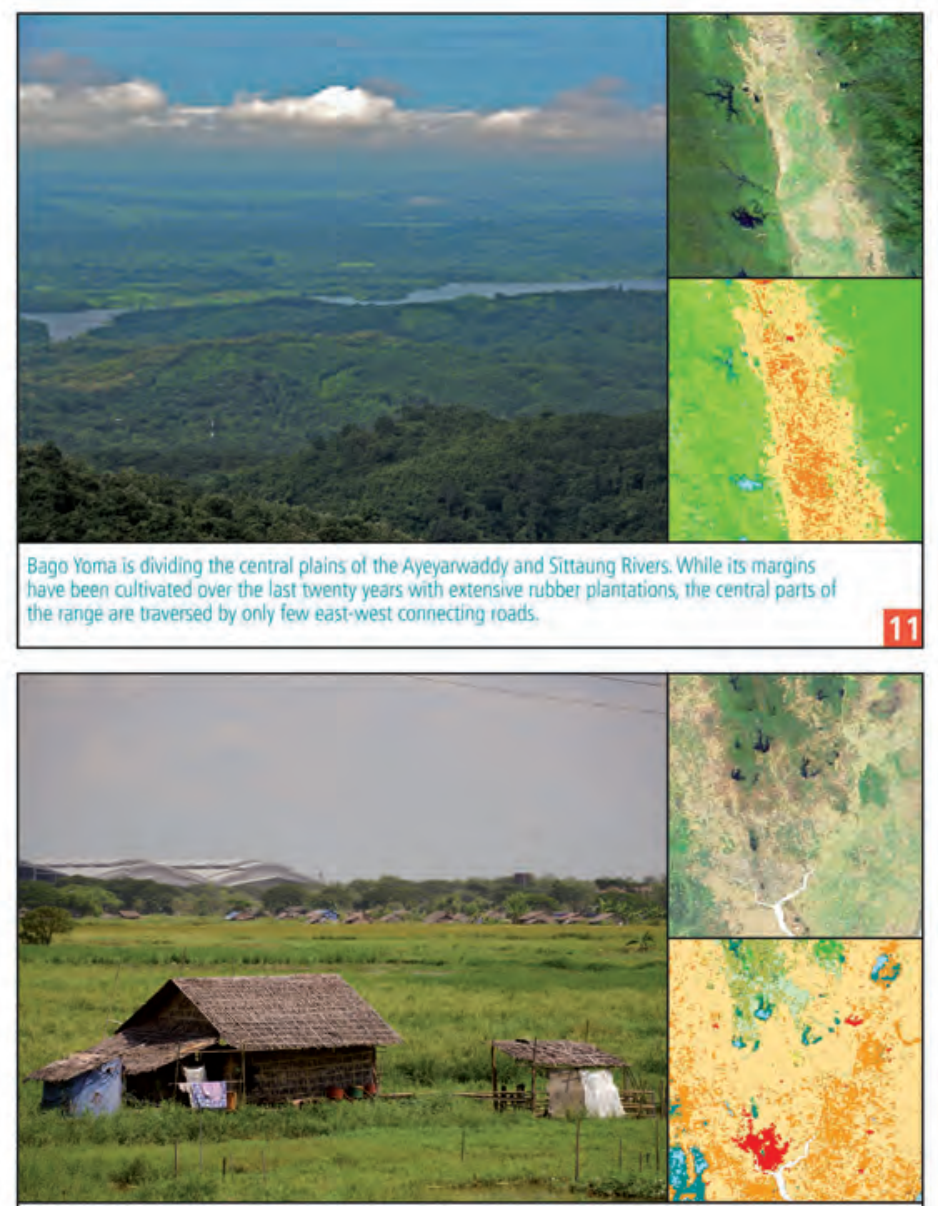

Around Yangon City, in the urban fringe areas, the sharp contrast berween the previously redominant agricultural usage and the current urbanisation and industriallisation is among the most visible testimonies to the current transformation processes.

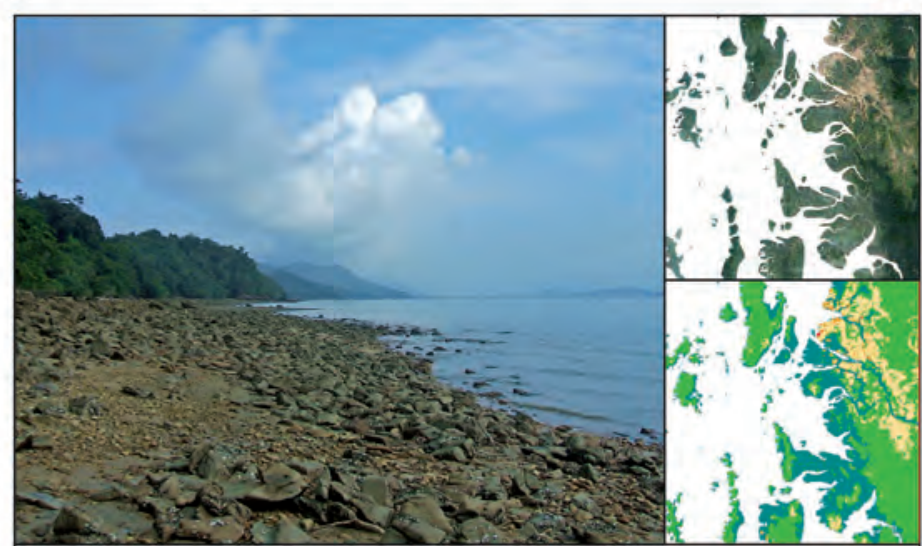

In the southernmost part of Myanmar, the Tanintharyi Region with its large Myeik. Archipelago is among the prime future tourism destinations, though competing strongly with attempts to conserve one of the largest and most pristine marine heritage sites of the world.

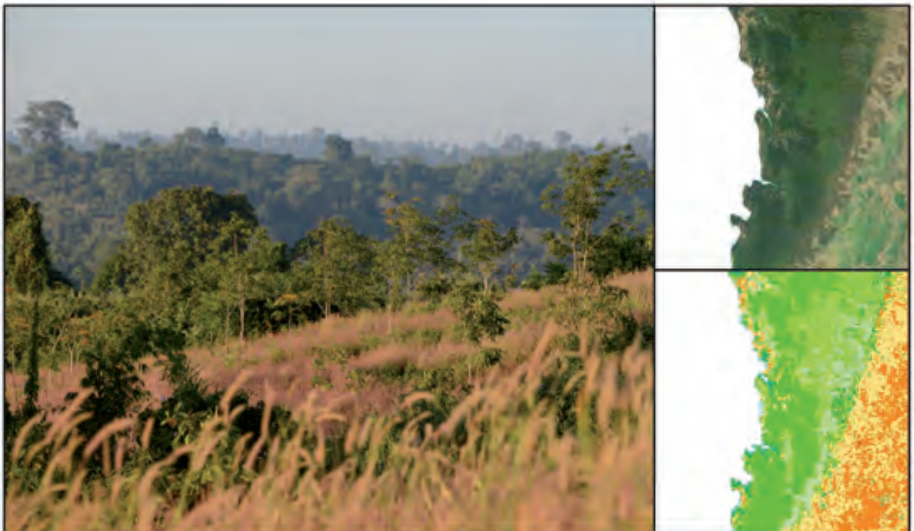

The steep flanks of Rakhine Yoma form a natural barrier between Central Myanmar and the long coastlines of the Rakhine Region. The long and almost undeveloped mountain range can only be traversed by a tew coads; rubber cultivation started recently.
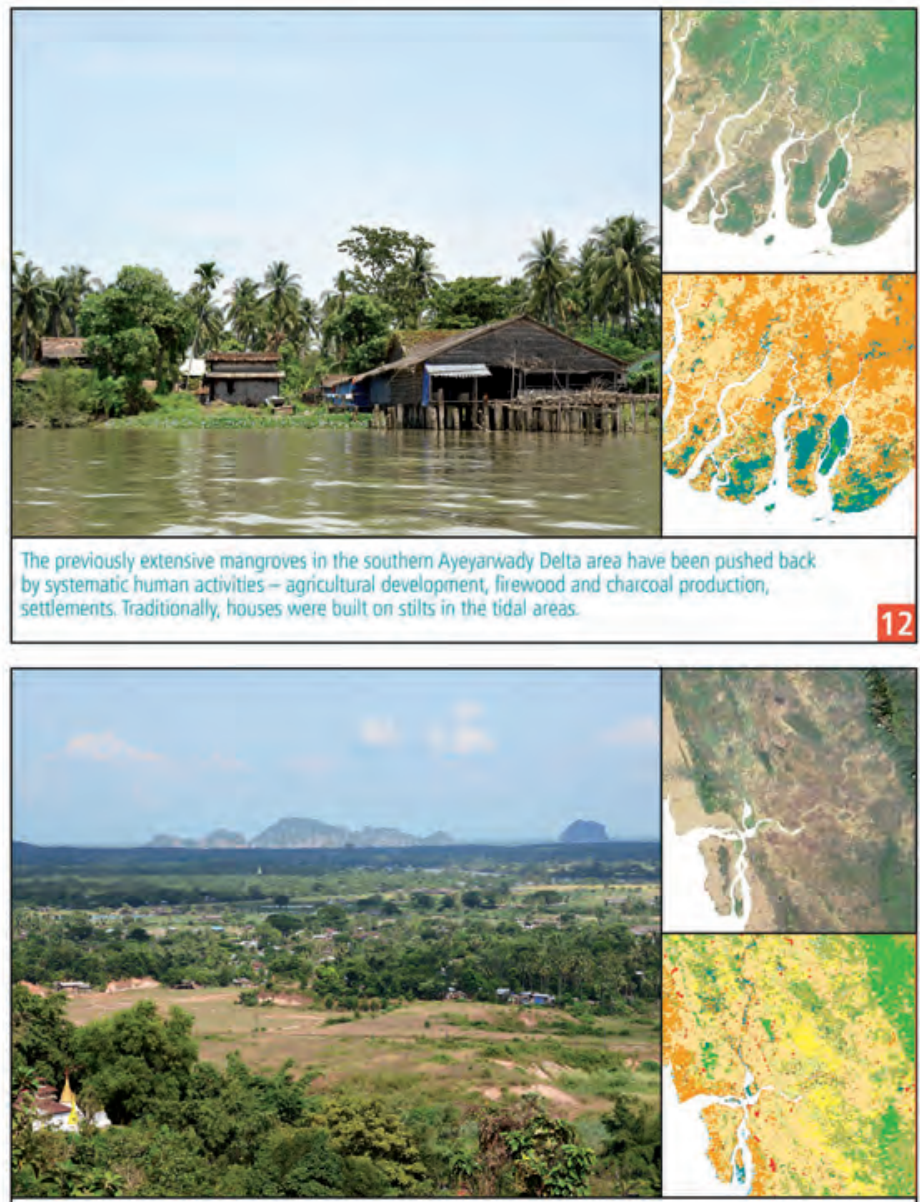

Around Mawlamyine, different formations of karst landscapes are characteristic. Dense population and rich agriculture in the plains and a growing intemational tourism sector constitute strong. potential for future socio-economic development corridors to Thailand.

The 15 photos, satellite images and land cover details show the highly diverse biogeographical characteristics and anthropogenic forms of land use in selected landscapes. This creates great potential for diverse forms of ecological and socio-economic usage.

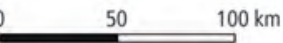

15

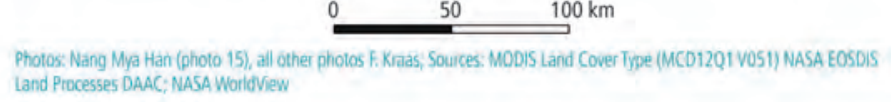




\section{CLIMATE: TEMPERATURE AND PRECIPITATION}

As Myanmar is located in the tropical and subtropical zone, most regions have a monsoon climate. The high mountains surrounding the country to the north, northwest and northeast prevent the entry of cold air masses from Central Asia so that tropical and subtropical air masses from the south determine temperatures and humidity levels. Four (Hla Tun Aung 2003: 99) or five seasons (Tun Lwin 2002, Ohnmar Htway/Matsumoto 2011) can be distinguished for Myanmar: the pre-monsoon season (midApril to mid-May), the monsoon or rainy season (mid-May to mid-October), the post-monsoon season (mid-October to end-November), the dry and cool season (end-November to mid-March) and the hot season (mid-March to mid-April). The date of onset of the summer monsoon in Myanmar 'is defined as the date of the first day of three consecutive rainy days with daily rainfall amount of $2.54 \mathrm{~mm}$ or more' (Ohnmar Htway/Matsumoto 2011: 382). Usually, the summer monsoon reaches the southern parts of the country by the third week of May and the northern parts at the beginning of June (Roy/Kaur 2000: 914).

The Department of Meteorology and Hydrology (DMH) under the administration of the Ministry of Transport and Communications operates 63 meteorological, 39 meteorological and hydrological and 17 agro-meteorological stations in Myanmar, well-distributed over the country. Data and forecasts are provided to the public via television, radio, newspaper and social media channels. Based on these records the regional variations of temperature and precipitation can be analysed.

\section{TEMPERATURES}

Countrywide, the annual mean temperature ranges (with variations according to latitude, altitude and vicinity to maritime influence) between almost 30 and $15^{\circ} \mathrm{C}-$ e.g. Minbu with $27.5^{\circ} \mathrm{C}$, Puta- $\mathrm{O}$ with $20.5^{\circ} \mathrm{C}$ and Kanpetlet with $16.3^{\circ} \mathrm{C}$ (all data, also in the following: $\mathrm{WMO} /$ FAOCLIM, FAO 2005). The monthly mean maximum and minimum daily temperatures also range widely, depending on season and elevation. In the lowlands, especially the dry zone in central Myanmar, monthly mean daily maximum temperatures between 32 and $33.5^{\circ} \mathrm{C}$ are characteristic of the hot and pre-monsoon season while, depending on altitude and local wind systems, the average is between 23 and $29^{\circ} \mathrm{C}$. Only in the mountain areas in the north of Kachin State can monthly mean daily maximum temperatures be as low as $20^{\circ} \mathrm{C}$ or less. The monthly mean daily minimum temperatures range between 21.5 (in the southeast of tropical Tanintharyi Region) and $16^{\circ} \mathrm{C}$ in the lowlands; in the mountain regions, depending on altitude and latitude, the monthly mean daily minimum temperatures range between 18.5 and $6^{\circ} \mathrm{C}$. In the mountains in northern Kachin State, monthly mean daily minimum temperatures can reach around or under freezing point in the cold season.

In the rainy season daily mean temperatures in the lowlands range between 25 and $33.5^{\circ} \mathrm{C}$, while in the post-monsoon season they are between 23 and $28^{\circ} \mathrm{C}$ (according to latitude, altitude and annual monsoonal variation). In the mountains, depending on altitude, they reach around $20^{\circ} \mathrm{C}$ (lower mountains) or $16^{\circ} \mathrm{C}$ (higher mountains). In the cool dry season daily mean temperatures fall to between $14^{\circ} \mathrm{C}$ and $18^{\circ} \mathrm{C}$ in the lowlands, and to just above freezing in the mountains and hills. The hot and pre-monsoon seasons bring the highest temperatures in the lowlands (daily mean temperatures range between 28 and $40^{\circ} \mathrm{C}$, in some locations even higher) together with high humidity, especially along the coast, with less humidity in the dry zone (Hla Tun Aung 2003). In those parts of 
Myanmar which are located in the tropics, i.e. south of $23.5^{\circ} \mathrm{N}$ (roughly the line of latitude of Kalay, Mogok and Lashio), strong temperature fluctuations can be measured during the course of the day - this is known as the 'diurnal climate' (as opposed to the seasonal climate e.g. in Europe).

\section{PRECIPITATION}

While the area weighted average rainfall (period of 1947-1979) ranges from 1,561 $\mathrm{mm}$ (1956) to $2,240 \mathrm{~mm}$ (1961), the average is $1,790 \mathrm{~mm}$ (Roy/Kaur 2000: 915). August and July are the months with most rainfall. Almost $90 \%$ of the rain falls during the summer monsoon period (Ohnmar Htway/Matsumoto 2011). As the rainbearing winds of the southwest summer monsoon cannot rise above the mountain chains along the west coast they bring intensive rainfall to the steep western mountainsides, which have Myanmar's highest annual rainfall values with almost 5,500 $\mathrm{mm}$ (Maung Maung Kha 1945). A second regional maximum is observed in the far north where annual values can be as high as 4,000 mm (Roy/Kaur 2000: 915, FAO 2005: 31). Areas with high precipitation also lie in the southern Ayeyarwady Delta and along the southern Andaman Sea coast. Interestingly and most likely due to the orographic barrier between these areas 'analysis indicates no significant relationship between Myanmar's rainfall and that of Bangladesh or Northeast India' (Roy/Kaur 2000: 921). The same holds true for little correlation between the annual monsoon rainfalls of India and Myanmar (Kripalani/ Kulkarni 1998, Roy/Kaur 2000: 921).

The amounts of mean annual rainfall received are highest at Dawai $(5,637 \mathrm{~mm})$, Thandwe $(5,537 \mathrm{~mm})$, Mawlamyine $(4,958 \mathrm{~mm})$ and Sittwe $(4,209 \mathrm{~mm})$ along the coast and Puta-O in the north $(4,058 \mathrm{~mm})$. The Ayeyarwady Delta receives slightly less rainfall at Pathein $(2,772$ $\mathrm{mm})$, Yangon $(2,392 \mathrm{~mm})$ and Tharrawaddy $(2,261 \mathrm{~mm})$. Mountain and hilly regions such as in Chin and Kachin States and the Shan Highlands also experience high rainfall values due to the orographic effect, e.g. Taunggyi $(1,747$ $\mathrm{mm})$, Falam $(1,642 \mathrm{~mm})$, Lashio $(1,572 \mathrm{~mm})$ and Kengtung $(1,103 \mathrm{~mm})$ (for different data see Khin Khin Han 2016). The higher elevations above 3,500 $\mathrm{m}$ in Kachin State can be subject to snowfall during the cold season from November to February. The dry zone in Myanmar's interior - in the lee of the coastal mountain ranges is protected from the monsoon rainfall; thus the values range between 400 and $1,000 \mathrm{~mm}$ per annum with high evaporation rates, e.g. for Mandalay $(858 \mathrm{~mm})$, Monywa $(831 \mathrm{~mm})$ and Meiktila $(820 \mathrm{~mm})$. The fringe area of the dry zone receives slightly more rain, e.g. in Pyinmana $(1,305 \mathrm{~mm})$ (further and different data see Khin Khin Han 2016). Precipitation rates also seldom exceed 2,000 mm per annum in the Shan Hills.

Rainfall variability, i.e. the temporal and areal variability of precipitation, differs within Myanmar. The lowest variability is observed at Puta-O, the eastern highlands, the coastal areas of the Ayeyarwady Delta and the coastal strip of Tanintharyi Region, with a value of 10 to 15 per cent; rainfall variability is also low towards the southern part of the country (Khin Khin Han 2016). Central Myanmar has more rainfall variation than other parts of the country: the middle part of the Sagaing Region, the western part of Magway Region and the Mandalay Region experience variation from 20 to 25 per cent. Pakokku has the highest variation at 38 per cent.

\section{Frauke Kraas and Khin Khin Han}


Name of weather station (elevation in metres) mean annuai temperature (degree centigrade)
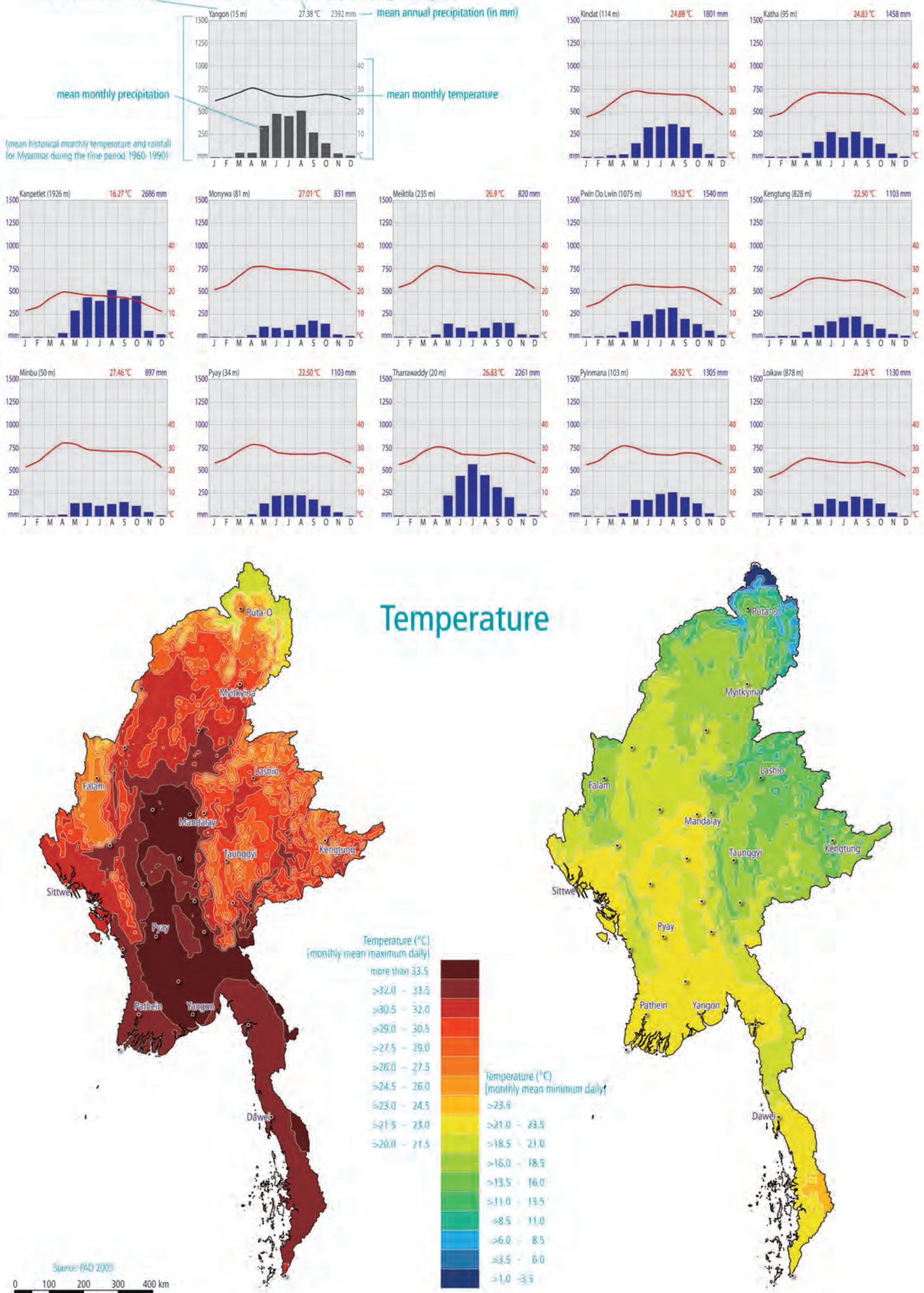

perature
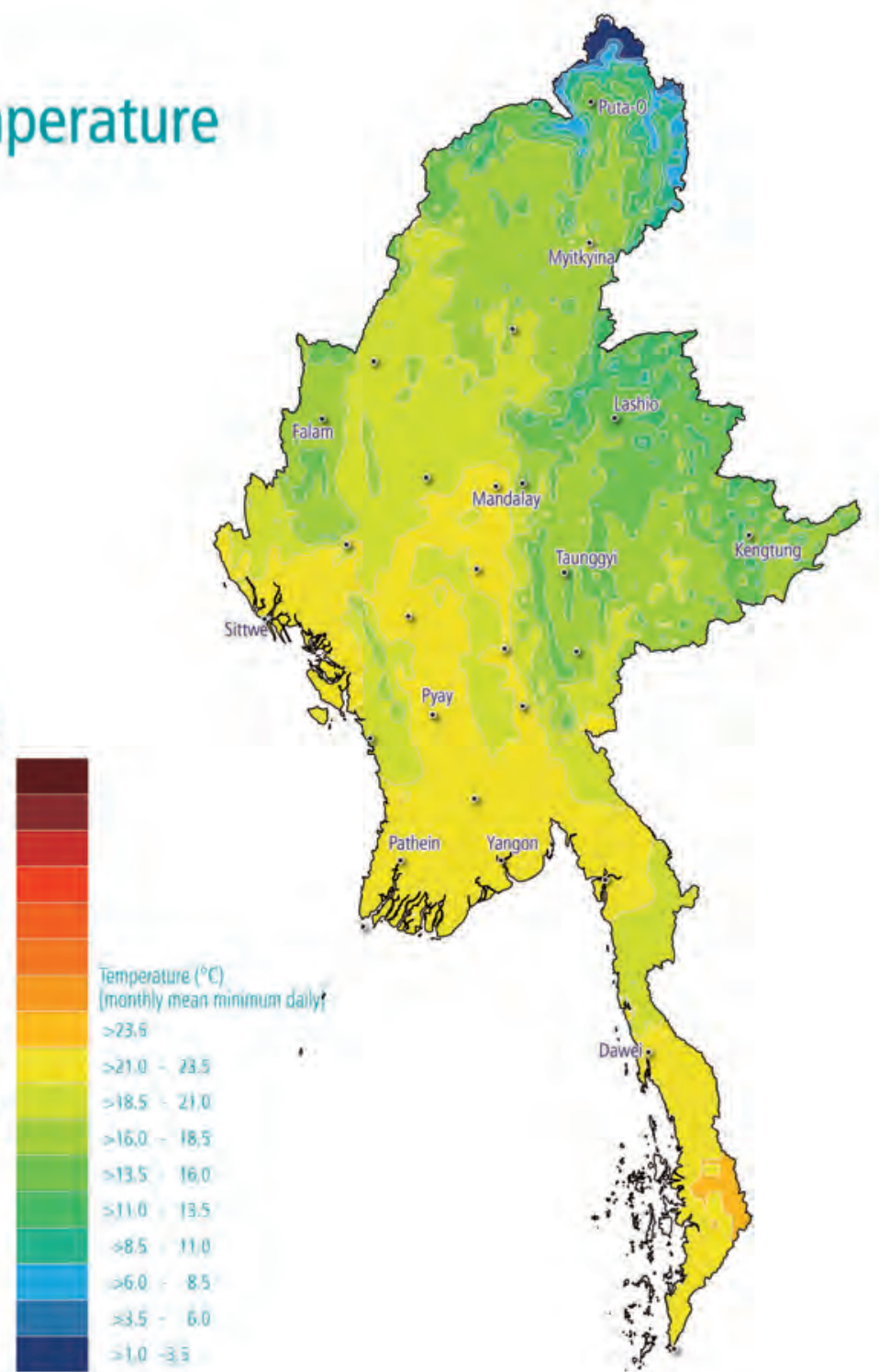

emperature $\left({ }^{6} \mathrm{C}\right)$

monthly mean minimum dally?

$>23.5$

$321.0-23.5$

$>16.0-18,5$

$>13.5 \quad 16.0$

$5110 \quad 13.5$

$38.5 \quad 110$

$26.0-8.5$

$>3.5-6.0$

$310-3=$ 

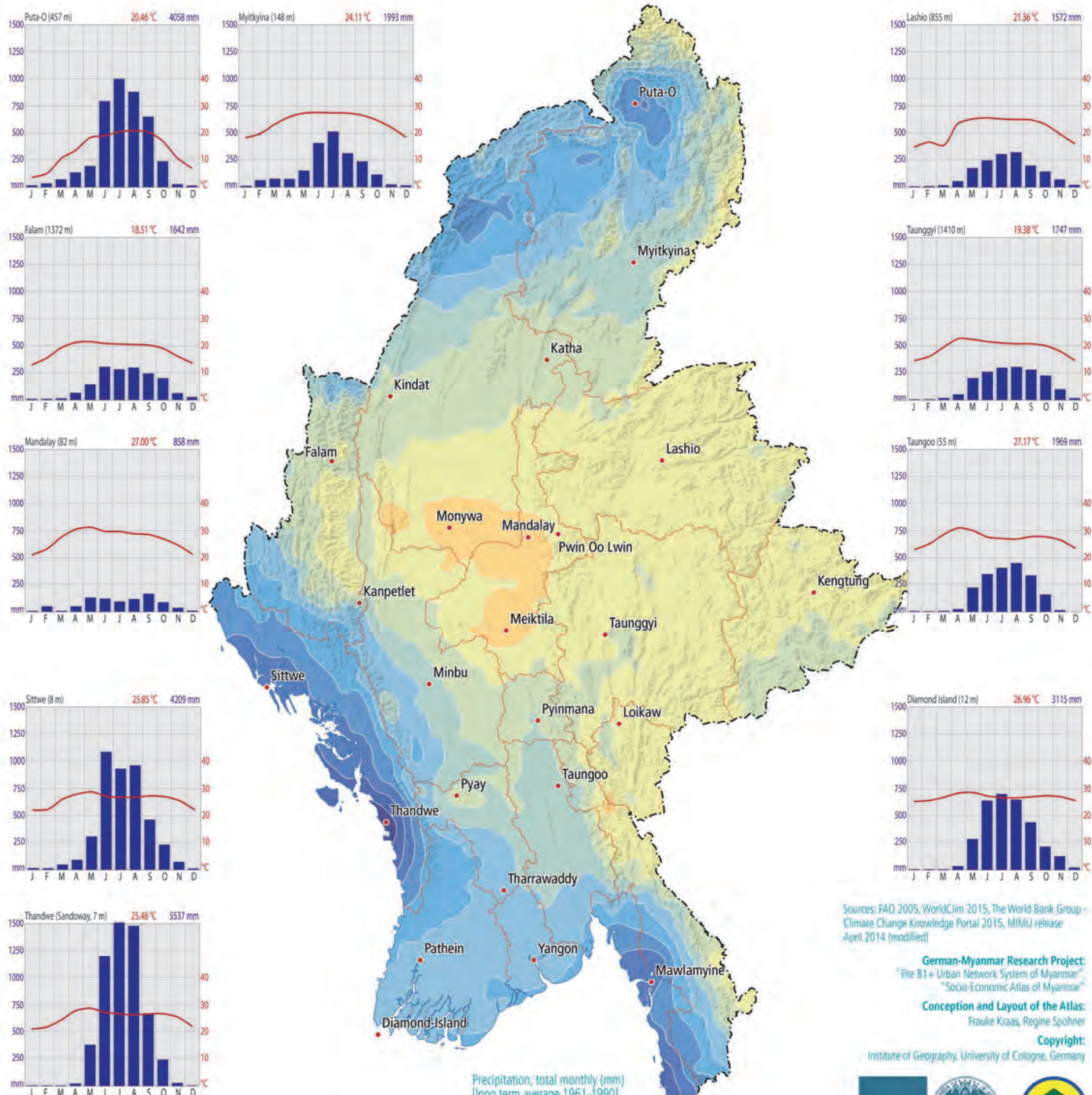


\section{NATURAL HAZARDS AND RISKS}

Myanmar is threatened by numerous kinds of natural hazards; humans are thus at risk in almost all parts of the country. There are frequent earthquakes of various magnitudes which occur in diverse regions across Myanmar, mainly in the seismically active areas along the major fault lines. Along the coast, in the Ayeyarwady Delta and in adjacent regions, tropical cyclones frequently make landfall, bringing heavy rain and causing flash flooding on a wide scale. In mountain regions, especially on steep slopes, landslides pose a threat to infrastructures, settlements and farmland (regional physiography: Hla Tun Aung 2003: 20-59, UNISDR 2009).

Five seismic zones have been identified in Myanmar: Zone V, comprising various sub-zones, is located along the Sagaing Fault - which cuts through the centre of Myanmar in a northsouth direction - and in the northwest of Myanmar. The major cities of Yangon, Mandalay and Nay Pyi Taw and numerous regional centres (including Taunggyi, Sagaing and Bago) lie within this zone. Zone VI is located mainly in the northwest, in other areas of Central Myanmar and in the northeast. The areas least at risk from earthquakes are located in the Ayeyarwady Delta, in Central and Southern Shan State and in the eastern coastal highlands (seismic map of Myanmar: Maung Thein/Tint Lwin Swe 2006).

\section{EARTHQUAKES}

Major earthquakes frequently occur, particularly in the Ayeyarwady catchment and in the large mountain ranges in the west and east of the country (summary list of historical and recent earthquakes in Myanmar: Maung Tein et al. 2009: 50). They result from Myanmar's location in a major area of disturbance, running north to south, in the collision zone between two tectonic plates, criss-crossed by numerous fault lines (including the major Sagaing and Momeik fault lines; Le Dain/Tapponier/Molnar 1984). A broad fault zone runs from north to south through central Myanmar, the Sagaing fault line from Bago in the south to Puta-O in the north (central volcanic line; Vigny et al. 2003). Major earthquakes frequently occur along this line where two major tectonic plates collide; here also the number of potential victims is highest (Wyss 2008). There is considerable volcanic activity (e.g. mud volcanoes and hot springs) around Shwebo, Monywa, Mandalay, Mount Popa, Magway and Tharyarwady.

\section{TSUNAMIS}

Linked to these orogenic processes, the coastal regions are also at risk from tsunamis triggered by seaquakes. These natural events have occurred on various occasions in recent centuries (the first firm evidence relates to the 18th century; Kumar/Achyuthan 2006). However, no systematic studies are currently available (Murty/Rafiq 1991, Cummins 2007).

Myanmar was marginally affected by the tsunami which followed a seaquake (9.1-9.3 on the Richter scale) off the coast of Sumatra on 26 December 2004. This tsunami reached Myanmar, mainly in the southeast, with a time delay of around two to five hours. Myanmar's coasts sustained relatively little damage, however. According to official figures, 71 people in Myanmar lost their lives and up to 1,500 (estimated figure) suffered direct losses and damage (Satake et al. 2006), mostly in the regions around Pyinsalu and Kapyet in the Ayeyarwady Delta and around Dawei, Myeik, Kawthaung and Sittwe. According to eye-witness- 


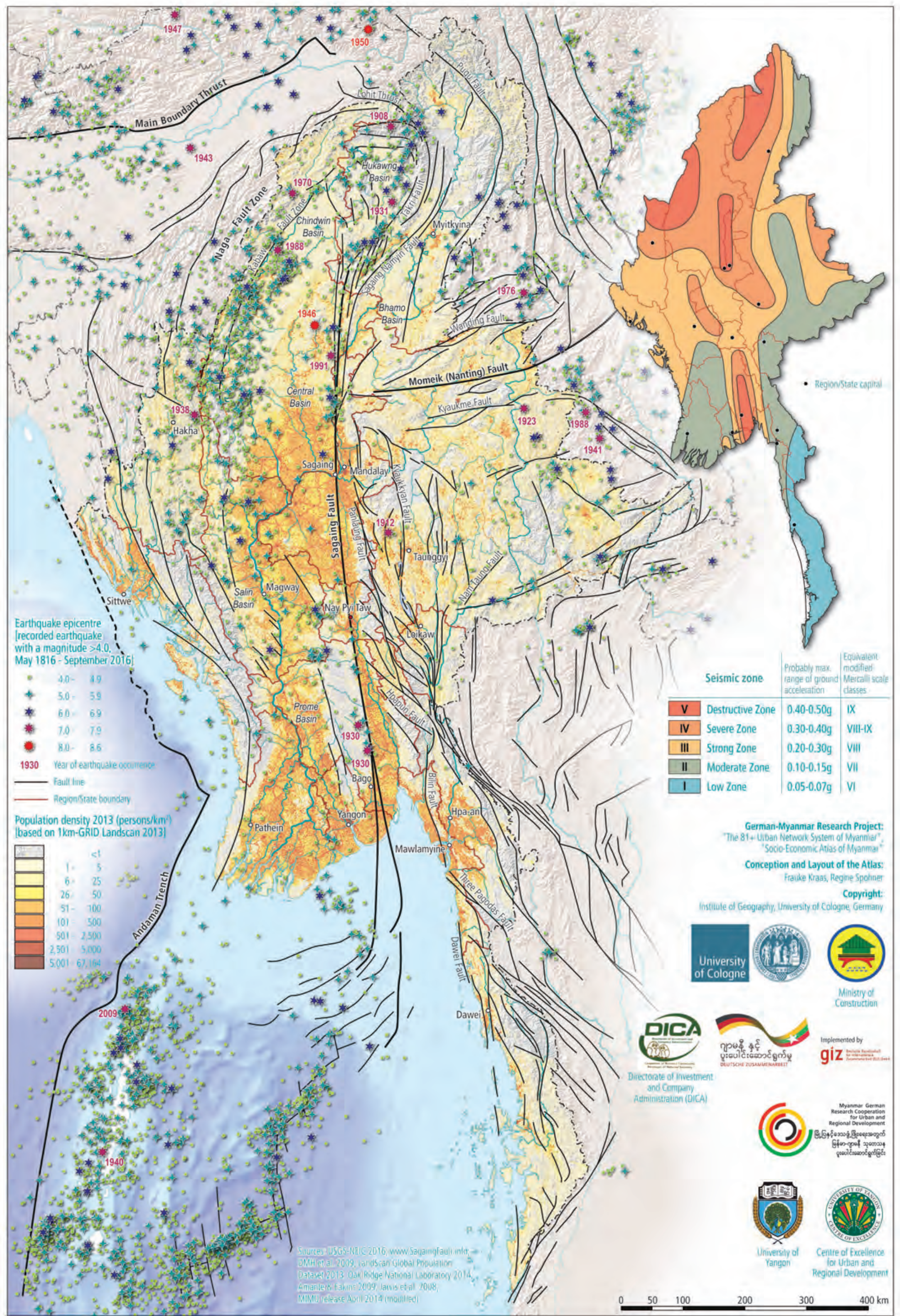


es, the waves reached a height of just 0.4 to 2.9 metres - very much smaller than the waves, up to $20 \mathrm{~m}$ high, which hit southwest Thailand, for example (Satake et al. 2006: 246-251). The relatively small number of victims in Myanmar is also due to the sparser population in coastal regions and to the mangrove forests, still dense in some places, which protect the coastline; more than 800 islands in the Myeik Archipelago also lessened the impact of the waves. Furthermore, there are comparatively few tourist centres along Myanmar's coast, and those which do exist are very much smaller than Thailand's, for example.

\section{FLOODING}

Large-scale flooding and tropical hurricanes in the coastal and delta regions during the pre- and post-monsoon periods are equally serious threats to human communities and their economic base as the seasonal droughts. Large-scale flooding occurs more frequently than these natural events caused by endogenous forces.

During the monsoon period, vast masses of water build up in the Ayeyarwady, which is around $150 \mathrm{~km}$ wide in its delta area, and its $413,674 \mathrm{~km}^{2}$ catchment area. When precipitation rises in the rainy season and there is torrential rain on an almost daily basis, the rivers break their banks and the flat countryside is flooded extensively, as the water masses cannot flow into the sea quickly enough. In the Rakhine Mountains, with precipitation exceeding 3,000 $\mathrm{mm}$, small-scale flash floods in the valleys and following heavy rain are a particular hazard for the inhabitants. Rivers can then rise by several metres within a very short time.

\section{DROUGHTS}

In Myanmar's dry zone, where there is considerable spatial and temporal variation in rainfall, there is a risk of prolonged periods of drought occurring. Falling groundwater levels present additional problems, particularly in urban areas. With rising water demand from agriculture and industry and in urban areas, aridity is worsening. This also has implications for the navigability of rivers.

\section{TROPICAL CYCLONES}

Furthermore, during the pre-monsoon cyclone season between April and June, severe tropical hurricanes occur when the temperature differences between the ocean surfaces and the land, heated up during the dry season, are greatest. When land temperatures rise again in the post-monsoon season (October/November), hurricanes are also a frequent occurrence. Of 477 hurricanes in the period between 1891 and 1970, 131 were severe cyclones; only 36 occurred during the pre-monsoon season (26 of these in May; Hla Tun Aung 2003: 101); the coast of Rakhine is particularly badly affected. The very high wind speeds of the cyclones are less dangerous than the destructive force of the associated tidal waves, in extreme cases 10 to $15 \mathrm{~m}$ high, which penetrate far inland and often cause severe destruction there. Most of the cyclones proceed in a southwest-northeast direction, but may change their course suddenly, making them highly unpredictable and preventing timely warnings to the population.

\section{CYCLONE NARGIS (2008)}

On 2-3 May 2008, Cyclone Nargis made landfall in the Ayeyarwady Delta southwest of Labutta, with wind speeds of more than 210 $\mathrm{km} / \mathrm{h}$ (Category 4 on the Saffir-Simpson Hurricane Wind Scale - SSHS) and local gusts of up to $260 \mathrm{~km} / \mathrm{h}$. No previous recorded tropical cyclone of this magnitude has made a direct landfall on Myanmar's coast at an untypically low latitude near $16^{\circ} \mathrm{N}$ (International Best Track Record for Climate Stewardship Database; Fritz et al. 2009). Recorded high-water marks and flood data show that the storm surge peaked at over $5 \mathrm{~m}$ in the landfall area, with inundation distances reaching $50 \mathrm{~km}$ inland in the delta. More than $1 \mathrm{~m}$ of vertical 
erosion and $100 \mathrm{~m}$ of land loss were measured at various coastal locations from the landfall area, attesting to the cyclone's extraordinary strength (Nature News 2008, Fritz et al. 2009). According to official estimates, the cyclone left around 138,400 people dead or missing; however, as a result of development measures undertaken in the delta area in the preceding years, numerous new villages had sprung up and a large number of temporary workers were employed, so the number of fatalities may well be as high as 200,000 (TCG 2008a: 3, Maung Maung Aye 2010). Estimates of the number of people affected by the loss of family members, destruction of livelihoods and critical infrastructure, loss of food reserves and livestock and at least partial collapse of socio-economic structures vary considerably. Many authors put the figure at around 2.4 million people (International Crisis Group 2008: 3, TCG 2008b: 3, Lateef 2009: 106). Based on high-resolution LandScan 2006-GRID data for a small-scale estimate of the population affected by Cyclone Nargis (Kraas 2009), it is possible to extrapolate a figure of at least 1.4 million people, plus an additional but unknown number of migrants, most of whom arrived after 1988 during the development of the delta. The worst storm damage and flooding occurred in the southeast Ayeyarwady Delta to the east of Labutta, particularly in the regions around Bogale, Pyapon and Kyaiklat and in the southwestern regions around megacity Yangon; in the coastal areas which sustained the highest level of damage, $85 \%$ of villagers were affected. After the disaster, some 800,000 people had to be resettled, mainly in adjacent regions to the north (International Crisis Group 2008: 3).

\section{LANDSLIDES}

Another consequence of heavy precipitation is rainwash on the many steep slopes, particularly in the mountain areas of Chin State and in Shan State, leading to landslides and frequently blocking transport routes and causing damage to farmland and settlements (Kraas 2014a). The damage is especially severe where the vegetation cover has been destroyed, whether through agriculture or cuts made for the construction of transport routes.

\section{Frauke Kraas and Hlaing Maw Oo}

Step-like landslide in Hakha, Chin State in August 2015

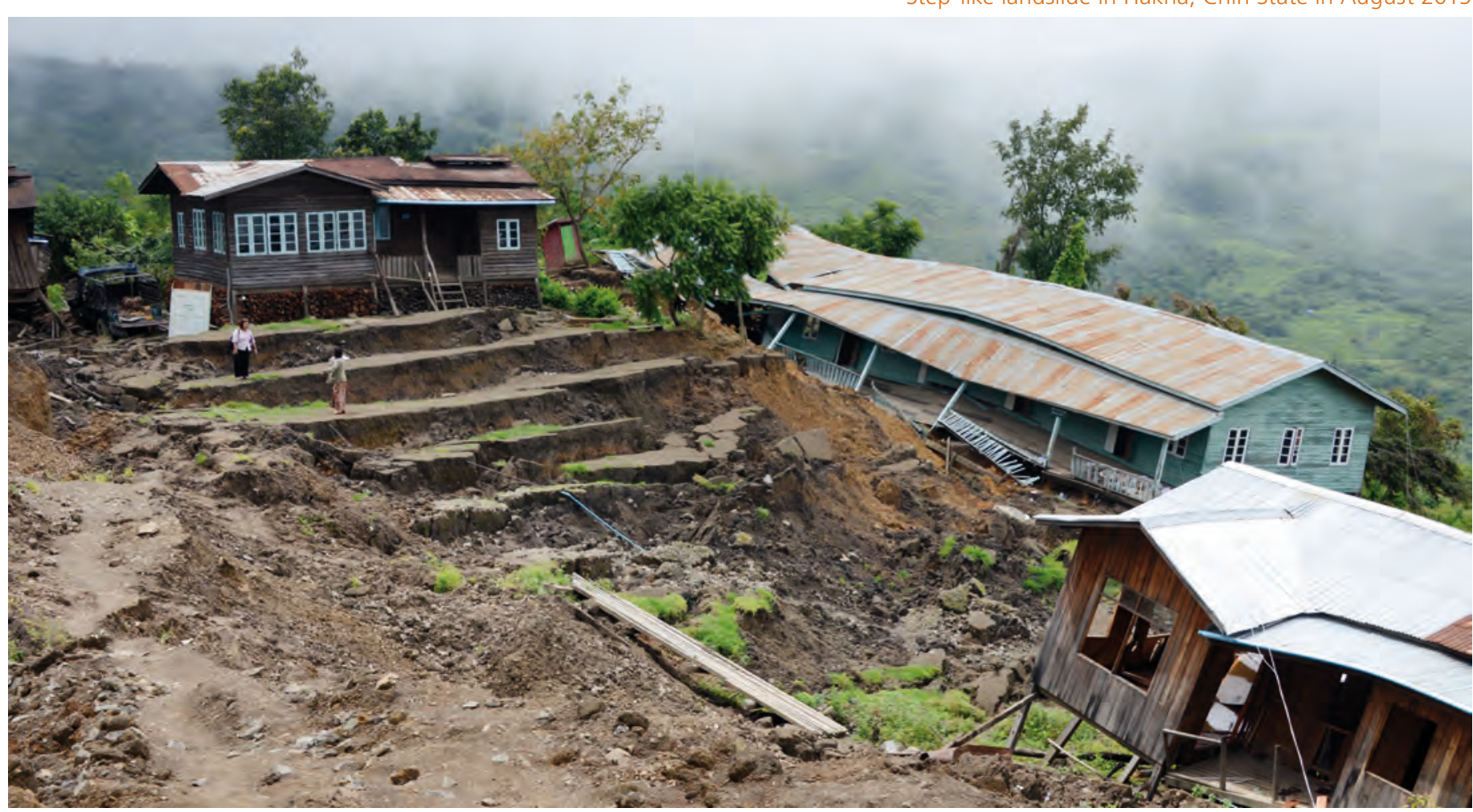




\section{ENVIRONMENTAL PROTECTION}

\section{RICH BIODIVERSITY}

Myanmar is one of the most species-rich regions in the world and is one of 25 global 'hot spots of biodiversity' (Myers et al. 2000). It is 'regarded as the last country in Southeast Asia containing large areas that have not been surveyed for biodiversity, and could harbour 5\% of mammal species (Corbett / Hill, 1992) and $\sim 10 \%$ of bird species of the world' (Hla Naing et al. 2015: 376; also see Avibase 2016). Its spectrum of ecotopes ranges from alpine meadows, dry forests and rainforests to inland lakes, flood plains, river deltas, coasts and estuaries, coral reefs and island archipelagos. The richest biodiversity is found in northern Kachin State (Lasi Bawk Naw 2007), in the forests of Kayin State and across large areas of Tanintharyi Region.

Myanmar is known to have about ' 7,000 plant species, of which 1,071 are endemic. Recorded number of vegetative species in the natural forests of Myanmar has reached 1,347 species of big trees, 741 species of small trees, 96 species of bamboos, 1,696 species of shrubs, 36 species of rattans and 841 species of orchids' (MoF 2005: 18). Kress et al. (2003) compiled a plant checklist, which includes 11,800 plant species. The Ministry of Forestry species list runs to more than 300 mammal, 370 reptile

Country-wide forest cover change in Myanmar between 2002 and 2014 (Baghwat et al. 2017)

\begin{tabular}{|c|c|c|c|c|c|}
\hline \multirow[b]{2}{*}{ Category } & \multicolumn{2}{|r|}{ Cover [ha] } & \multicolumn{2}{|r|}{ Change } & \multirow{2}{*}{$\begin{array}{r}\begin{array}{r}\text { Annual Net } \\
\text { Change }\end{array} \\
\%\end{array}$} \\
\hline & 2002 & 2014 & [ha] & $\%$ & \\
\hline Forest ${ }^{1}$ & $43,962,152$ & $42,365,729$ & $-1,596,454$ & -3.63 & -0.30 \\
\hline Intact $^{2}$ & $18,260,940$ & $16,192,952$ & $-2,067,988$ & -11.32 & -0.94 \\
\hline Degraded 3 & $25,701,243$ & $26,172,777$ & $+471,534$ & +1.83 & +0.15 \\
\hline Non-Forest ${ }^{4}$ & $21,134,373$ & $22,122,214$ & $+987,841$ & +4.67 & +0.39 \\
\hline Plantation ${ }^{5}$ & 917,361 & 1,453,199 & $+535,838$ & +58.41 & +4.87 \\
\hline
\end{tabular}
sum of intact and degraded forests

$>80 \%$ canopy cover in evergreen and mixed deciduous forests; $>60 \%$ canopy cover in dry deciduous forests $10-80 \%$ canopy cover in evergreen and mixed deciduous forests; $10-60 \%$ canopy cover in dry deciduous forests $<10 \%$ canopy cover

Forest plantation (e.g. rubber, cashew) and 1,089 bird species, including around 50 mammal, 30 bird and 25 reptile species found on the CITES Checklist (Convention on International Trade in Endangered Species of Wild Fauna and Flora) or the IUCN Red Data List of Threatened Species (Tun Yin 1993: 275, Kyaw Nyunt Lwin/Khin Ma Ma Thwin 2005, Avibase 2016). Examples are wild elephants (protected since 1879; Leimgruber et al. 2011), tigers, leopards, bears, rare species of primates and deer and a large number of bird, reptile and amphibian species, many of them endemic.

\section{LOSS OF FORESTS}

Due to population growth and development pressure, including the granting of forest and mining concessions to investors from neighbouring countries, land degradation has occurred across much of Myanmar. Contributory factors are (legal and illegal) forest clearance, growth in fuelwood use, expansion of agricultural land and shifting cultivation, over-grazing, large-scale mining activities, expansion of settlement areas and infrastructure, and industrialisation (albeit mostly small and medium-sized enterprises). The impacts are particularly severe across extensive areas of the once forested mountain regions in Rakhine and Bago Yoma and in Chin, Kachin and Shan State and Tanintharyi Region, with this deterioration being observed mainly since the introduction of a market economy from 1988. The once vast mangrove forests in the southern Ayeyarwady Delta, which still covered 385,930 ha in 1990 (MoF 2005: 11), have shrunk by almost $50 \%$ as a result of accelerated development in the Ayeyarwady Delta (Heymann/Löffler 1997; see also: Liu et al. 2015). Key factors include not only the expansion of agricultural land but also mangrove clearance for fuel- 


\begin{tabular}{|lll|}
\hline National Park \\
\hline 1 & Alaungdaw Kathapa & $*$ \\
2 & Khakabo Razi & $*$ \\
3 & Lenya & 0 \\
4 & Lenya (Extension) & 0 \\
5 & Nat Ma Taung & $*$ \\
6 & Pegu Yoma & 0 \\
7 & Tanintharyi National Park & $*$ \\
\hline
\end{tabular}

Marine National Park

8 Lampi Island

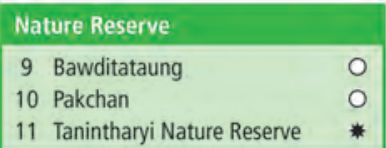

Wildlife Sanctuary

12 Bumhpabum

13 Chatthin

14 Chung Pon Kan

15 Dipayon

16 Hponkan Razi

17 Htamanthi

18 Hukawng Valley

19 Hukawng Valley (Extension)

20 Indawgyi Lake

21 Inle Lake

22 Kadonlay Kyun

23 Kahilu

24 Kelatha

25 Kyaikhtiyo

26 Kyauk-Pan-Taung

27 Lawkananda

28 Letkokkon

29 Maharmyaing

30 Mainmahla Kyun

31 Minsontaung

32 Minwuntaung

33 Moscos Island

34 Mulayit

35 Panlaung-Pyadalin Cave

36 Pidaung

37 Shinpinkyetthauk

38 Shwesettaw

39 Shwe-U-Daung

40 Thamihla Kyun

Bird Sanctuary

41 Moeyongyi Wetland

42 Pyin 00 Lwin

43 Taunggyi

44 Wethtikan

\begin{tabular}{|l|}
\hline Wildlife Park \\
\hline 45 Hlawga \\
\hline Mountain Park \\
\hline 46 Mt. Popa \\
\hline Wildlife Reserve \\
\hline 47 Rat \\
\hline
\end{tabular}

47 Rakhine Yoma Elephant Range * Protected Area

48 Loimwe

49 Par Sar

50 Sein Ye Forest Camp

51 Wunbaik

Elephant Camp

\section{Mying Hay Wun}

53 North Zamari

54 Phokyar

National Botanical Garden

55 Pyin 0o Lwin

Zoological Garden

56 Naypyitaw

57 Naypyitaw Safari Garden

58 Mandalay Yadanabon

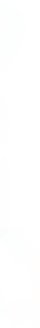

\section{(n)}

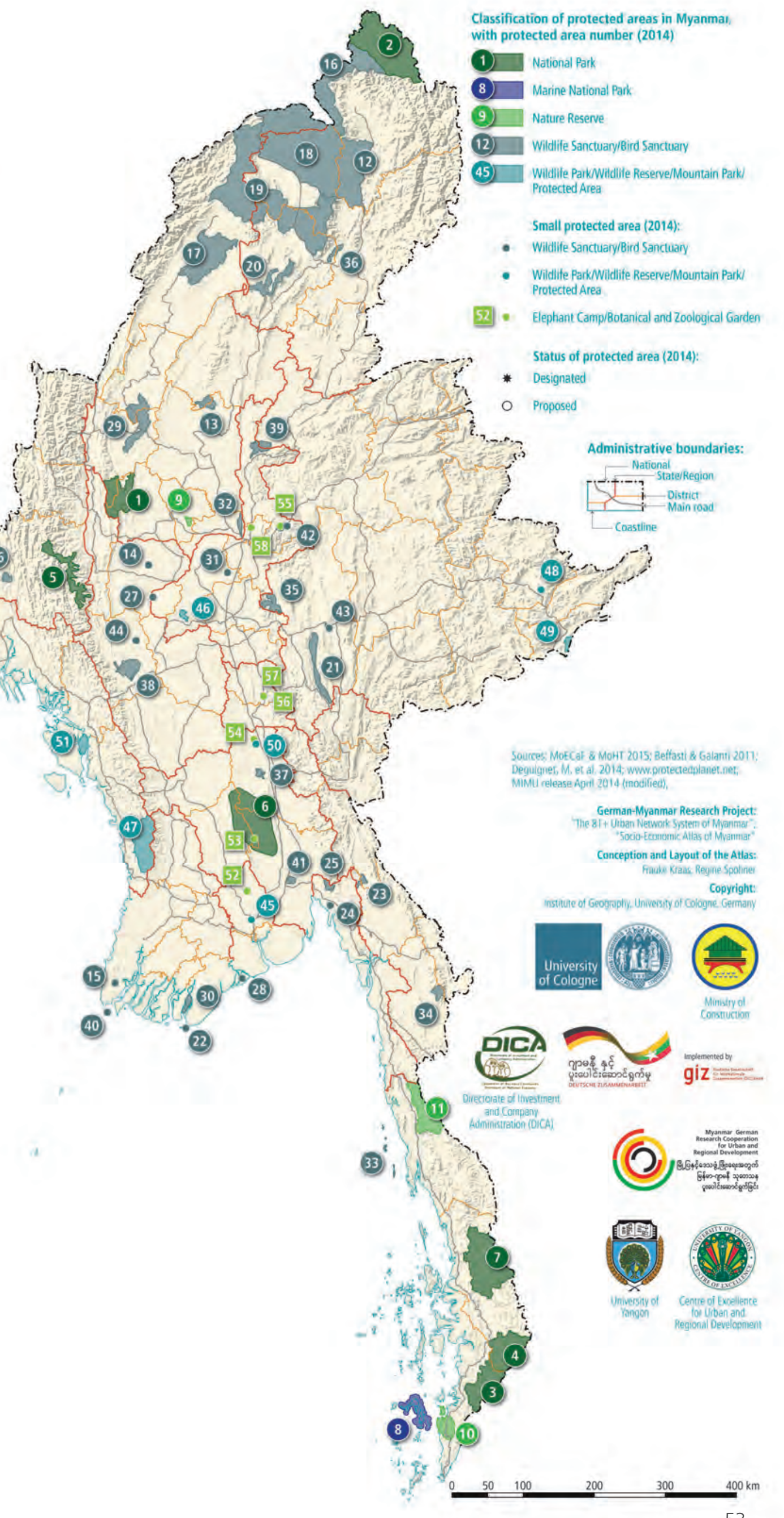

8) Marine National Park

12) Wildlife Sanctuary/Bird Sanctuary

Wildilie ParkNitdlifle Reserve/Mountain ParkJ Small protected area (2014):

Wildlife Sanctuary/Bird Sanctuary

Wildilite Park/Widdife Reserve/Mountain Park/ 


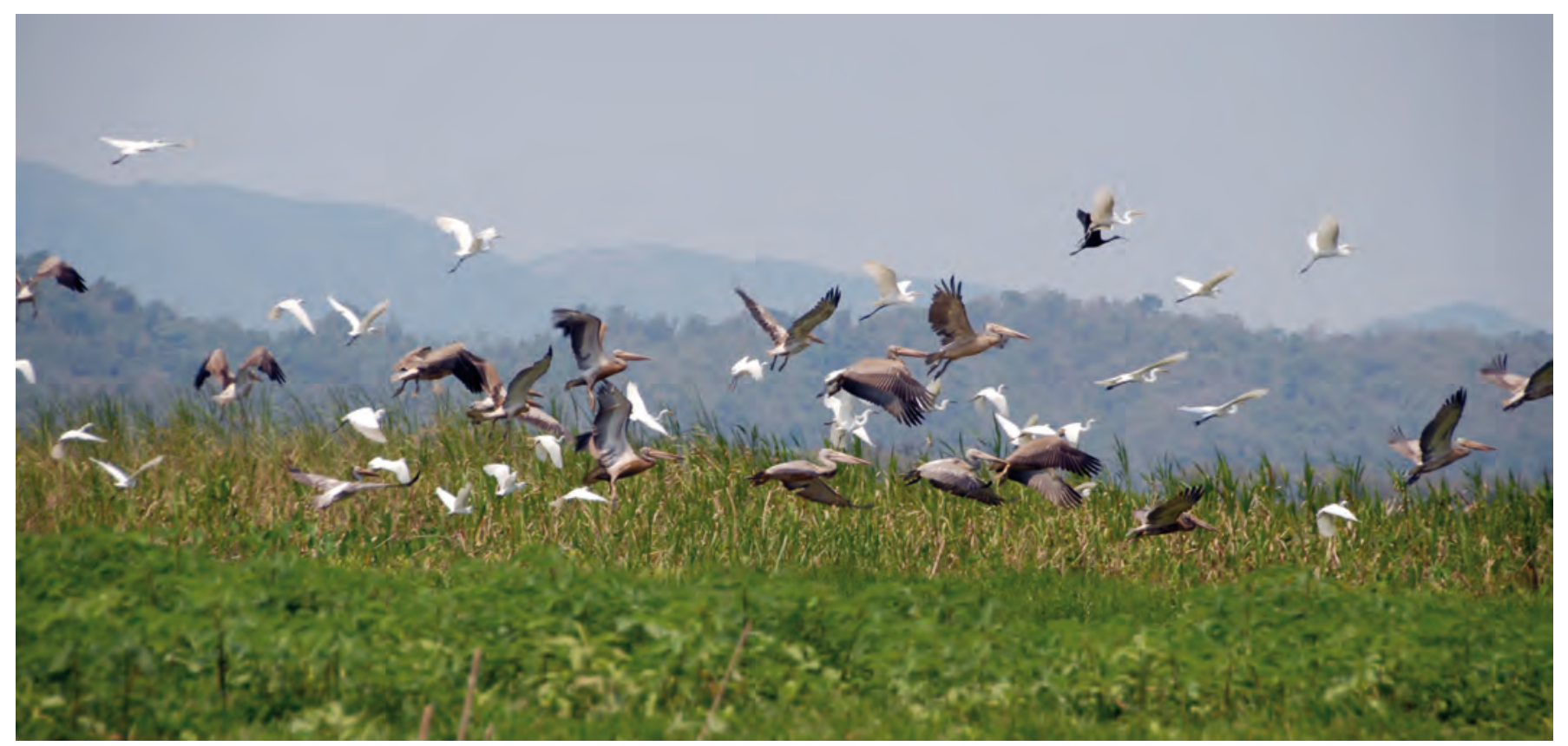

Pelicans and Storks at Indawgyi Lake

wood: as recently as $1990,84 \%$ of the country's energy supply for cooking, lighting and small industries came from firewood und charcoal even in the Yangon metropolitan area (Zin Nwe Myint 2004, MoF 2005: 11).

\section{HISTORY OF PROTECTION AND CONSERVATION}

Forest and wildlife conservation was practised to some extent under Myanmar's kings. In 1752, under King Alaungphaya, all teak trees were declared to be royal property and royalties were demanded for their felling (Mehm Ko Ko Gyi/Saw Win 1997). In 1859, King Mindon ordered that 'threat-free' forest areas be created in 'Yadanapon Nepyidaw' near Mandalay (in Myanmar: bemetaw) (Tun Yin 1993: 275, MoF 2005: 18, Aung Myint 2007). For religious reasons, the grounds of the monasteries have traditionally served as conservation areas: '... in addition to the notified areas as sanctuaries, the monastery compounds and the precincts of the pagodas are likewise declared as sanctuaries which were known as A-ba-ya Hta-na' (Tun Yin 1993: 275).

Systematic scientific forestry and the introduction of forest conservation measures began under Sir Dietrich Brandis (1824-1907), a Ger- man botanist working for the British. As Superintendent of Forests in Pegu from 1856 and head of the British forestry administration in all of Burma from 1858 until 1862, he reformed the system of forestry, reforestation and forest management across what was then British Burma (Hesmer 1975).

Legislation was put in place from the end of the 19th century onwards (an overview of the various laws can be found in Myint Aung 2007: 193). In contrast to the traditional religious principles, wildlife and forest conservation served the purpose of economic utility: the aim was to 'conserve the animals as game' (Tun Yin 1993: 275). The Elephant Preservation Act was adopted in 1897, followed by the Burma Forest Act in 1902 and the Wild Birds and Animal Protection Act in 1912. The Burma Wildlife Protection Act, adopted in 1936, was replaced by the new Protection of Wildlife and Wild Plants and Conservation of Natural Areas Law in 1994 (MoF 2005: 19). To some extent, these laws incorporated traditional rules: the Wildlife Protection Act, for example,prohibited' hunting within 200 yards of the compound of an inhabited Buddhist monastery or of a religious edifice for which trustees have been appointed' (quoted from Myint Aung 2007: 189). 
The first conservation areas, established from 1918, were the Pyin Oo Lwin Bird Sanctuary and the Shwe U Daung and Pidaung Wildlife Sanctuaries (MoF 2005: 18-19; list of dates of establishment: Myint Aung 2007). However, it was only with the FAO-UNDP National Conservation and National Parks Project (19811985) that the foundations were laid for systematic surveys and inventories and the establishment of further national parks and nature reserves, whose purpose, among other things, was to promote more connectivity between 10 biogeographical regions (MoF 2005: 19). In addition, a separate Nature and Wildlife Conservation Division (NWCD) was set up in the Ministry of Forestry. The National Commission for Environmental Affairs (NCEA), an interministerial body responsible for coordinating national environmental policy, was created in 1990 (Myint Aung 2007: 192).

\section{CURRENT PROTECTION}

At present, seven national parks, one marine national park, three nature reserves, 29 wildlife sanctuaries and bird sanctuaries have been designated or proposed across the country (41 protected areas are listed in MoPF 2016: 323$325)$. There are also various wildlife and mountain parks, one wildlife reserve, protected areas and elephant camps. Most conserve terrestrial habitats; very few include inland wetlands, mangrove and marine habitats and caves, with the result that some ecosystems are underrepresented (Myint Aung 2007). In addition to the Botanical Gardens in Pyin Oo Lwin, zoos exist in Yangon, Mandalay and Nay Pyi Taw. The largest conservation area extends across 15,256 square kilometres; however, the majority (14 parks $=42 \%$ of all conservation areas) range in size from 51 to 500 square kilometres; only five are larger than 1,000 square kilometres. Moyingyi, Indawgyi and Inle Lake
Wildlife Sanctuaries are wintering sites for migratory waterfowl (Myint Aung 2007: 195) but most conservation areas are too small to benefit migratory species.

Special protection arrangements are in place for some species. So far, 39 mammal, 50 avian and nine reptile species have been completely protected, and 12 mammal, 43 avian and six reptile species have been protected (Mehm Ko Ko Gyi/Saw Win 2005: 185). Other species enjoy seasonal protection. Nonetheless, a number of species have now died out, including the Giant Panda (Ailuropoda melanoleuca) and the Rhinoceros (Rhinoceros sondaicus, Rhinoceros unicornis, Dicerorhinus sumatrensis) (Tun Yin 1993: 102, 283).

Most conservation areas are increasingly under threat from the expansion of agriculture, mining and infrastructure. Specific problems include the lack of law enforcement ('paper parks') and management plans, understaffing and inadequate training, (partly illegal) logging and mining, (partly clandestine) hunting of game, poaching, natural and anthropogenic forest fires during the dry season, effects of grazing and removal of forest products, poor border demarcation, underfunding, low level of public awareness to sustainability (Webb et al. 2012 and 2014), low prioritisation of conservation in the context of economic modernisation, the wildlife trade (flora and fauna), mainly across the borders with China, India and Thailand, and, lastly, conflicts in peripheral regions (Hemley/Mills 1999, Myint Aung et al. 2004, Myint Aung 2007: 195-202, Tordoff et al. 2012). New threats include the planned expansion of hydroelectric power generation and several dam projects, posing a risk to riverine landscapes (Taft/Evers 2016), and the challenges associated with climate change (Schmidt 2012, Rao et al. 2013).

\section{Frauke Kraas and Win Maung}




\section{MINERAL RESOURCES}

Myanmar's rich mineral resources originate in the specific geological history of Southeast Asia, induced by overall processes of plate tectonic. Three different orogenetic phases determine the main geological units; they took place in different regions. Thus, the mineral resources are distributed unevenly within the country. Usually, three main geological units are distinguished: (A) the Indoburman Ranges in the West (subdivided, from north to south, into the Patkoi Ranges, the Naga Ranges, the Chin Ranges and the Rakhine Yoma), (B) the Innerburman Tertiary Basin and (C) the East Myanmar Units; metamorphic rocks are flanking the Innerburman Tertiary Basin (Bannert/ Lyen/Htay 2011: 11). Chhibber (1933) additionally mentions the coastal strip of Rakhine.

Furthermore, four major geotectonic units of Myanmar can be distinguished, (a) the Rakhine Coastal Zone, (b) the Rakhine Chin Ranges, (c) the Inner Myanmar Tertiary Basin (Central Zone) and (d) the Eastern Highlands (Bender 1983). They are usually subdivided into six major tectonic domains, stretching from north to south (Chhibber 1933 and 1934a, Bender 1983). These are, according to ESCAP (1996: 6-20): (1) the subduction zone of the Rakhine Coastal Area which is predominantly made up of Miocene folded, disturbed and structurally deformed sandstones and siltstones. (2) The Rakhine Chin Ranges are mainly built by Tertiary flysch-like sediments and allochtonic Cretaceous and Triassic rocks and are separated by a major fault system from the (3) Western Inner Myanmar Tertiary Basin (as fore arc), which consists of several long and wide sub-basins, containing up to $10,000 \mathrm{~m}$ Eocene/Oligocene to Recent folded sediments. (4) The Central Volcanic Belt of intermediate to acid igneous rocks (Late Mesozoic and Tertiary) stretches over $1,200 \mathrm{~km}$. The 'young post-Paleocene to Recent volcanics ... lie large- ly along parallel N-S linear trends' (ESCAP 1996: 14); two of them are well-defined, the inner volcanic arc (from Mt. Loi-Mye via Wuntho, Monywa, Mt. Popa, Pyay) and the eastern volcanic line (close to the Shan-Sittaung Boundary Fault, via Katha, Mandalay, Pyinmana, Thaton), both with earthquakes and numerous volcanic occurrences, e.g. a large number of hot springs or mud volcanoes (Chhibber 1934a, Bender 1983). Outside of the Central Lowlands, Tertiary or Recent volcanism can be found at Nat Ma Taung (Mt. Victoria) or near Lashio. (5) In the east, the Eastern Inner Myanmar Tertiary Basin (as back arc) follows; it is separated by the Shan Boundary Fault Zone from the (6) Sino Myanmar Ranges (or KachinShan-Tanintharyi Highlands or Eastern Highlands Belt) with mostly folded, partly metamorphosed Palaeozoic sediments. It is part of the land mass of the Indo-Chinese peninsula. They are subdivided in the West Kachin Unit in the north, the East Kachin/Shan Unit (forming the largest unit) and the Kayin/Tanintharyi Unit in the South. They are divided by the Lashio Fault system with its ENE and EW trending faults; the Mogok deposits are located inbetween.

\section{PRODUCTION}

Development and production agreements for mineral oil and natural gas fields, gold mines, precious stones and copper and nickel deposits are driven mainly by foreign capital and ventures. Furthermore, key industrialisation processes are based on Myanmar's own mineral resources. According to Fong-Sam (2016), the most important mineral fuels mined in 2013 were lignite coal (380,272 metric tons), natural gas (12,894 million cubic metres), crude oil (5,875 thousand 42-gallon barrels) and petroleum refinery products $(4,000$ thousand 
$\triangle \Delta$ coaloccurrence Shwebo Basin Coal basin

$\diamond \diamond \quad$ Gas field / surface or subsurface gas show

$\bullet \quad$ Oll field / surface or subsurface oil show

Yadana Name of main gas or oil field

— Intemational pipeline for export

Kyaukphyu-Kunming gas and oil pipeline

Domestic pipeline

Oil and gas blocks (2015)

Offshore company operating block

Offshore open block

Onshore company operating block

Onshore open block
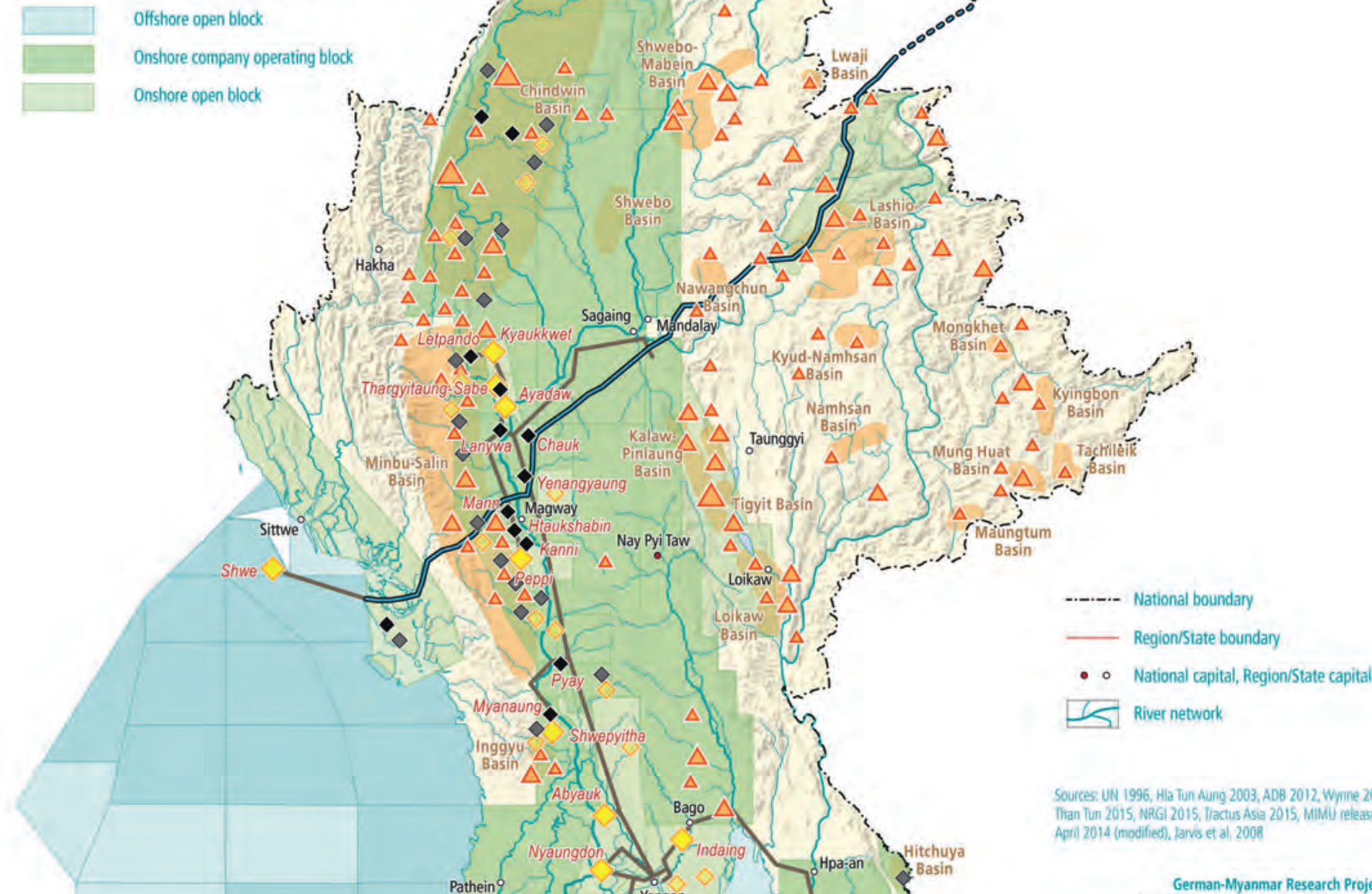

Souces UN 1995, Hla Tin Aung 2003, ADB 2012. Wyme 2015 hian Tun 2015. NRG1 2015, Tlactus Asia 2015, MiMU retease pril 2014 (niodified), larvis et al 2008

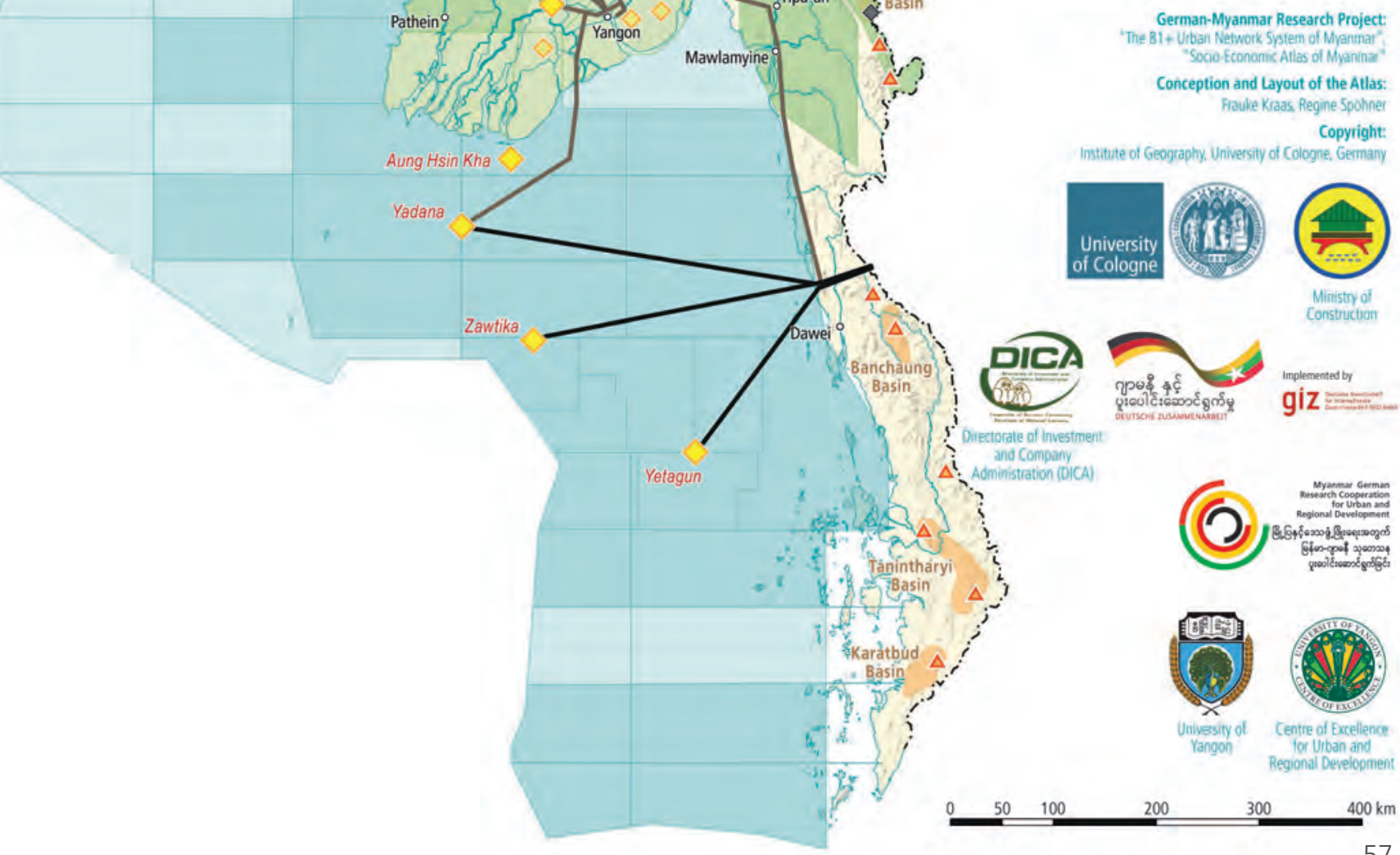


42-gallon barrels). Precious and semiprecious stones were extracted in the following amounts: jade (12.76 million kilograms), rubies (397,711 kilograms), sapphires $(1,059,559$ kilograms) and spinel (417,441 kilograms). Metals were mined at constant levels since 2006, among them manganese $(160,000$ metric tons), lead (11,700 metric tons), copper (25,000 metric tons) and zinc (5,000 metric tons) (Fong-Sam 2016, Chhibber 1934b). Among Myanmar's total trade in 2013 , which was at $\$ 18.05$ billion (exports totalled $\$ 8.98$ billion), natural gas exports accounted for $\$ 3,67$ billion (equalling $40.8 \%$ of total exports), while the exports of base metals and ores were estimated at $\$ 92.0$ million (Fong-Sam 2016). Main export partners were Thailand, China, India and Japan.

\section{FUEL MINERALS}

Fuel minerals, mainly oil and natural gas fields, can be found in the sedimentary basins which cover approximately three quarters of the territory (for the following: ESCAP 1996: 58-73). The Myanmar Tertiary geosyncline with an area of about 140,000 square $(\mathrm{km} 2)$ is the main oil and natural gas potential region where offshore and onshore drilling has been extended since decades. Since pre-colonial times, oil seepages have been known in the Ra- khine Coastal Basin (e.g. Ramree and Cheduba islands). The largest offshore fields - Shwe, Yadana, Zawtika and Yetagun - are internationally connected for export. Oil from the Yadana field contributes to the increasing amount of gas for local consumption in Yangon, moreover it is connected to two power plants in Bangkok; the main operators are the France-based Total E\&P Myanmar (31.24\%), the US-based Chevron Corp. (28.3\%), the Thailand-based PTTEP (25.5\%) and MOGE (15\%) (Fong-Sam 2012). In 2013, the $794 \mathrm{~km}$ long Kyaukphyu Kunming gas and oil pipeline was completed to transport natural gas to Yunnan Province/China; a parallel pipeline measuring $771 \mathrm{~km}$ in length is under construction to transport crude oil from the Middle East (Fong-Sam 2016). The domestic pipeline links the largest onshore oil and natural gas fields of Ayadaw, Chauk, Htaukshabin and Yenangyaung. Numerous major and minor coal deposits ranging from Mesozoic to Tertiary age have been surveyed, the Kalewa and southwestern Shan mountain basins currently being the largest exploitation areas. Tertiary coals are usually of the lignite type with low calorific power due to high percentages of moisture and volatile constituents.

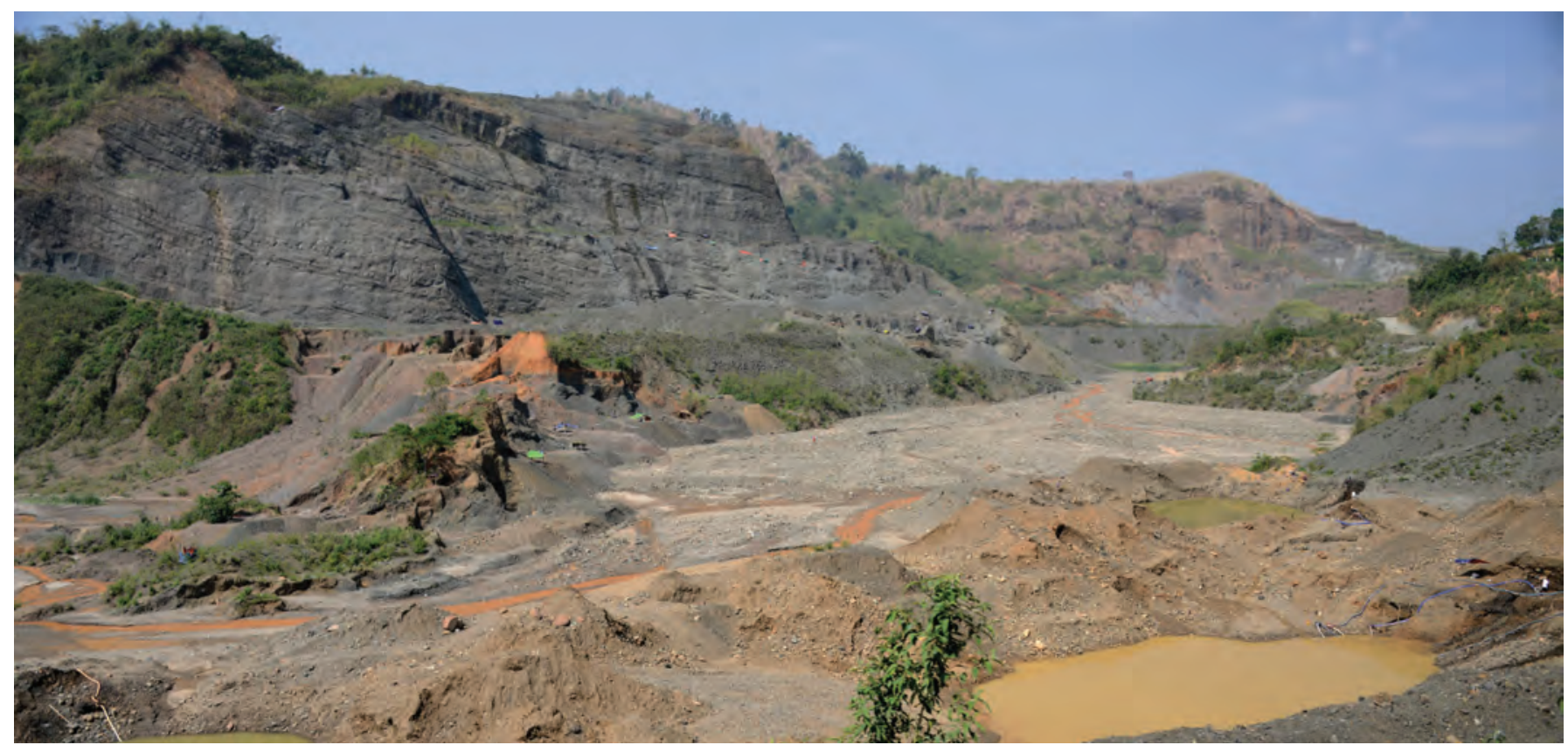


Iron and ferro-alloy metals

$\theta \otimes \operatorname{chromium}(C r)$

$\gg>\operatorname{Iron}(\mathrm{Fe})$

$\otimes \otimes$ Manganese (Mn)

$\triangleq \otimes$ Molybdenum (Mo)

$\Leftrightarrow \otimes \operatorname{Nickel}(\mathrm{Ni})$

\\. Tungsten (W)

Base metals

$\square$ Copper (Cu)

[) ע] Mercury $(\mathrm{Hg})$

미 Lead (Pb)

미 Antimony (Sb)

므 믜 $\operatorname{Tin}(5 n)$

[D] $\operatorname{Zinc}(\mathrm{Zn})$

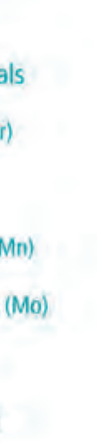

.
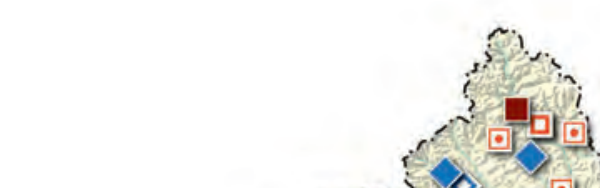


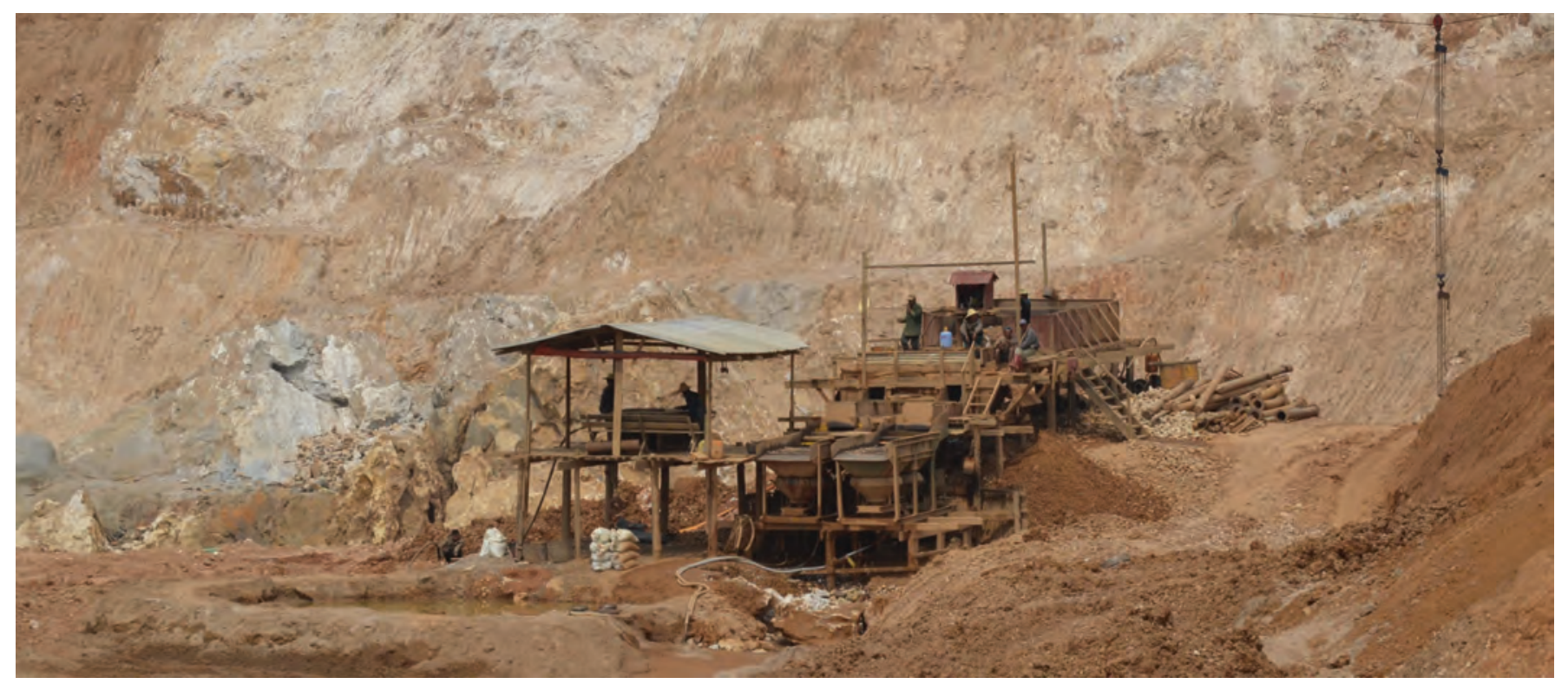

Ruby mine in Mogok

\section{METALLIC MINERALS}

The country's rich metallic minerals are mostly concentrated in the Eastern Highland Ranges. Iron ore deposits have been found near Hpakant, Myitkyina, in Northern Shan State, the area around Taunggyi and numerous, yet hardly explored areas in Shan State. Chromium and nickel are mainly found in Rakhine Yoma and western Kachin State, manganese in western Shan State and tungsten predominantly in western Shan State and the Tanintharyi Region. Copper mines are located in central Myanmar, among them large mines such as the Letpadaung mine in Sagaing Region, and many in the Eastern Highland Ranges. Tin and tungsten are mainly mined in the southern highlands as part of the tin/tungsten belt which runs from the tin islands of Banka and Bilitung (Indonesia) via the Malayan peninsula to the area around Loikaw and south of Nay Pyi Taw, then further as far as China. Tin placers are found in eluvial, colluvial, fluviatile and lacutrine sediments and also as near-shore marine tin placers offshore of the Tanintharyi coasts (ESCAP 1996: 98).

\section{PRECIOUS METALS AND GEMSTONES}

Precious metals, most of all gold, can be found in many locations, mostly in the inner-Myan- mar tertiary basin near Monywa and in the Sino-Myanmar Ranges (e.g. Kyaunkpahto and Kyaukpazat gold projects). Among the most well-known are the Mogok and Hpakant areas. Jade is predominantly mined in and around Hpakant, amber is found mostly in Hukawng valley. Numerous mining sites are located in the surroundings of Mogok, among them Ywa Thar Yar, Chaung Gyi, Kyauk Pya That and Pyaung Gaung (Keller 1983, Kane/Kammerling 1992, Lucas/Pardieu 2014, Kraas 2016c). The most valuable gemstones here are members of the corundum group (the red variety is referred to as ruby; other colours are referred to as sapphires; Harlow/Bender 2013, HponePhyo Kan-Nyunt et al. 2013). In Mogok, numerous other precious and semi-precious stones and metals can be found, such as apatite, amethyst, red- and orange-coloured spinel, green peridot, lapis lazuli, garnet, moon stone, garnet, topaz, tourmaline, zircon, peridot, chrysoberyl or gem beryl, and gold. There are also several extremely rare minerals, such as the predominantly brown-dark violet painite, the black-brown hibonite, the pink poudretteite, the predominately violet taaffeite (Thanong et al. 2014), the yellowish monazite, the black columbite, the black tantalite or the titanite.

Frauke Kraas and Nay Win Oo 
Precious metals

9 Gold (Au)

O) Silver (Ag)

C) Platinum Group (Pt)

Precious stones
Q) Diamonds
Q) Jade
Q) Ruby
- Saphire
C) Semi-precious stones (eg: Amber)

Rare earths and radioactive metals
$\Delta$ Niobium, Tantalum (Nb)
$\triangle$ Rare earths (RE)
ㅁ. Uranium (U) 
I.

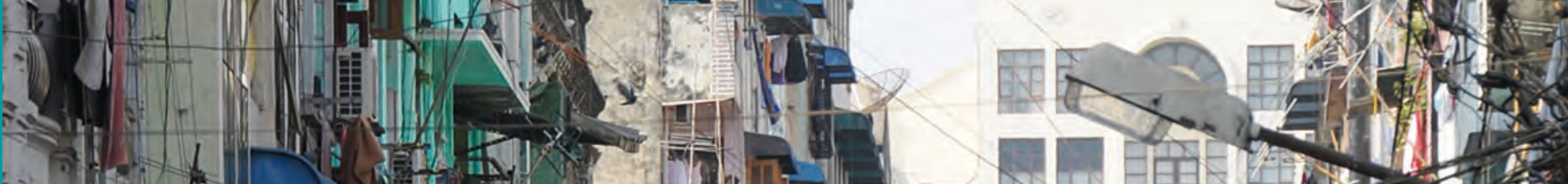

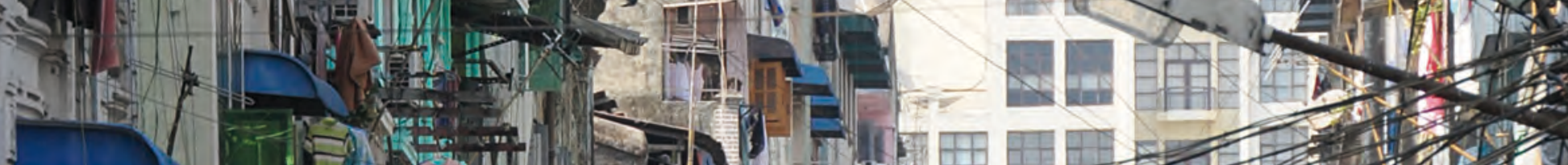

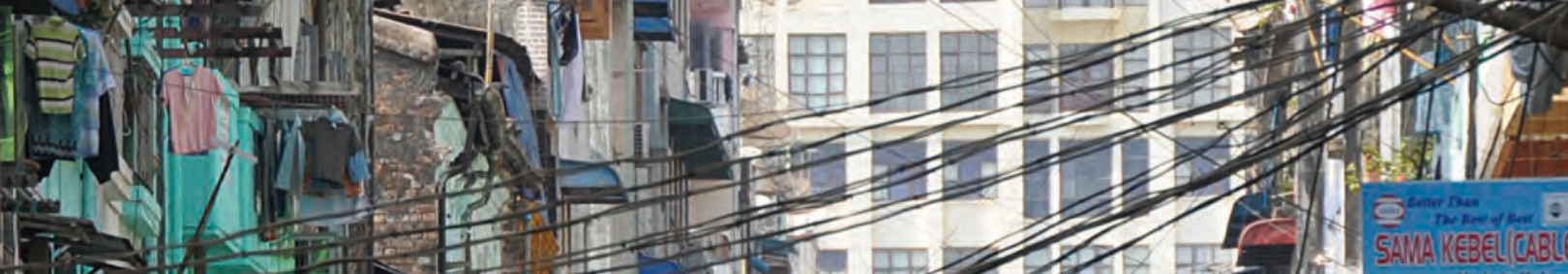

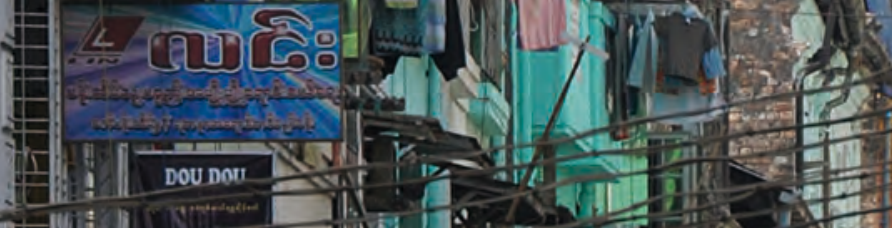
$\sqrt{10}$ (1)

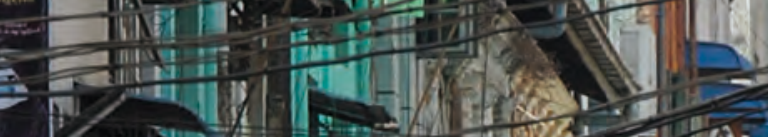

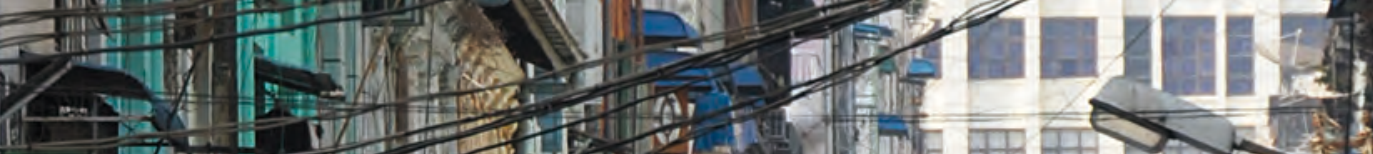
*1 and 1 I $=$ (a)

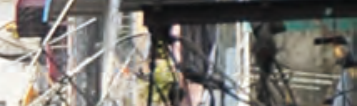
$\frac{1}{(4)}$

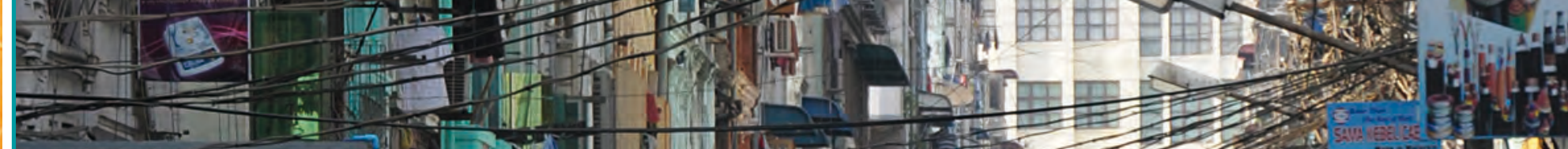

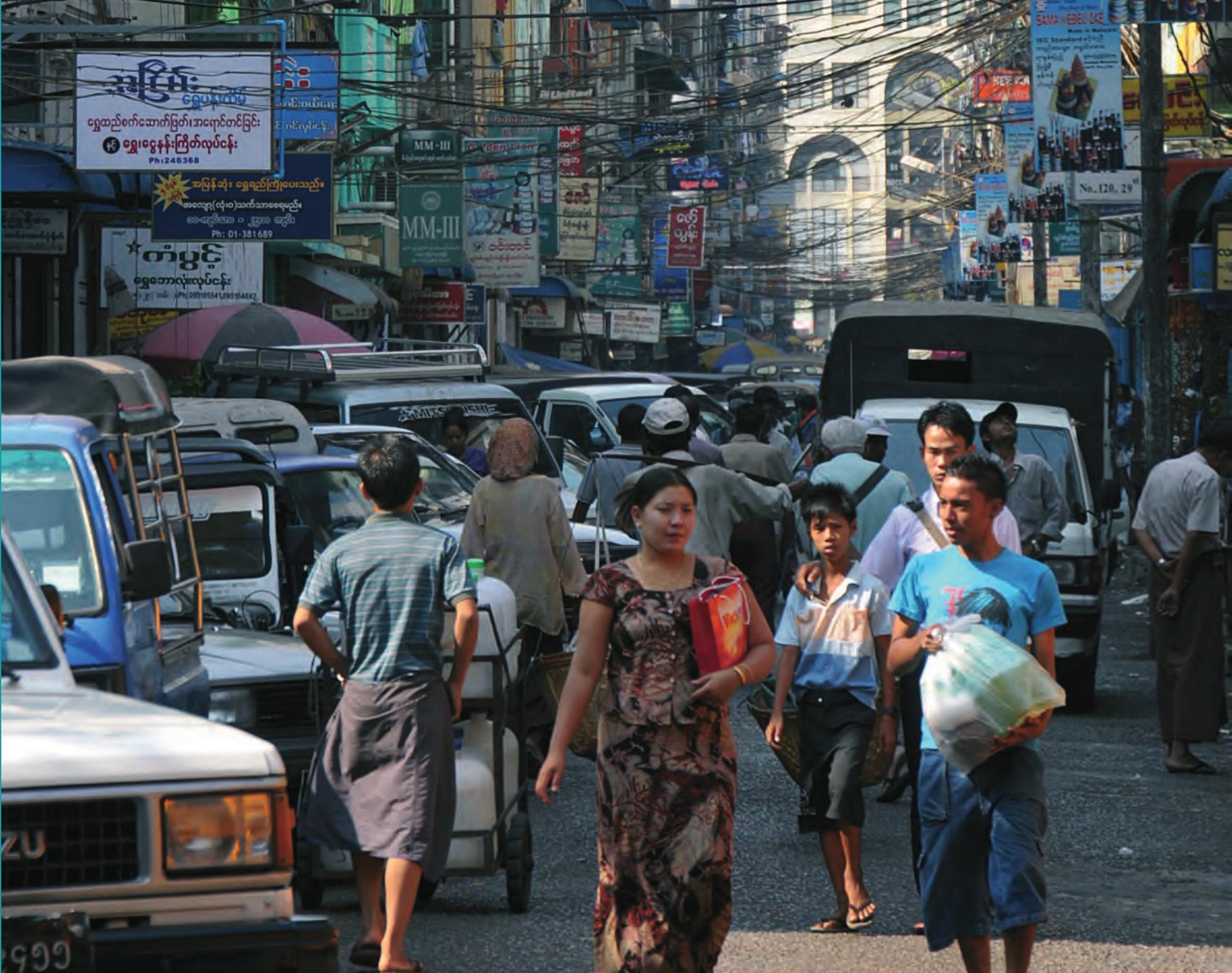




\section{POPULATION, SETTLEMENTS AND URBANISATION}

64 POPULATION

65 TOTAL POPULATION AND SEX RATIO

68 POPULATION DENSITY BY TOWNSHIP

69 POPULATION DENSITY - POPULATION DISTRIBUTION MODEL

70 URBAN AND RURAL POPULATION

72 URBANISATION PROCESSES AND THE URBAN SYSTEM

80 RANKING AND LOCATION OF CITIES/TOWNS 


\section{POPULATION}

The 2014 nationwide census in Myanmar the first since 1983 - enabled the key socioeconomic data required for planning and development purposes to be updated. Regional population figures are the essential basis for all socio-economic analyses, while the figures for Myanmar's 330 townships are a very good starting point for spatially differentiated comparisons (Kraas/Spohner 2015). The total population figure of 51,486,253 includes estimated figures of 1.09 million in Rakhine State, 69,753 in Kayin State and 46,600 in Kachin State (census findings 2014; MoIP 2015b). The slight gender imbalance $(24,821,176$ males $(48.2 \%)$ compared with $26,598,244$ females (51.8\%)) reflects the fact that more men than women are labour migrants living in neighbouring countries.

The most populous areas are Yangon Region (7,360,703 inhabitants; $14.3 \%$ of the population), Ayeyarwady Region $(6,184,829$ inhabitants; $12.0 \%)$, Mandalay Region $(6,165,723$ inhabitants; $12.0 \%)$, Shan State $(5,815,384$ inhabitants), Sagaing Region (5,320,299 inhabitants) and Bago Region (4,863,455 inhabitants), followed by Magway Region (3,912,711 inhabitants), Rakhine State (3,188,963 inhabitants), Mon State (2,050,282 inhabitants), Kachin State $(1,689,654$ inhabitants), Kayin State (1,572,657 inhabitants), Tanintharyi Region $(1,406,434$ inhabitants) and Nay Pyi Taw Capital Region (1,158,367 inhabitants; $2.3 \%$ of the population). Chin State $(478,690$ inhabitants; $0.9 \%)$ and Kayah State $(286,627$ inhabitants; $0.6 \%$ ) have the lowest population figures (all figures: MoIP 2015a: 3). Three areas of population concentration stand out on the map of the total population distribution: the area around Yangon, until 2005 capital of Myanmar in the south, close to the sea, Mandalay, the last capital of the Myanmar kings before the arrival of the British colonial powers, and Nay Pyi Taw, the country's new capital. While Yangon officially has 5,211,431 inhabitants - which makes Yangon, according to international urban standards (Kraas 2007), an emerging megacity - Mandalay follows with 1,489,271 and Nay Pyi Taw with 1,160,242 inhabitants (MoIP 2015b).

\section{POPULATION DISTRIBUTION AS A HISTORICAL LEGACY}

This bipolarity mirrors the country's history: during the era of the Burmese kingdoms, the centre of political power, population and the economy lay inland in the dry zone, the region to the north of present-day Pyay that extends across Bagan and Mandalay to Shwebo. Accordingly, most of the historical capitals were located in Central Myanmar. The Mon empire in the south in the area around present-day Mawlamyine, Thaton and Bago was, by comparison, a sparsely populated region until the early 19th century. According to different historic sources, Burma's population in pre-British time was estimated roughly at 3-3.6 million to 17 million (as carefully analysed by Richell 2006: 8-15). Three of the sources (Burney 1795 (to be corrected: Burney 1842), Yule 1826 and Alves 1855, quoted after Richell 2006: 9) have produced similar estimates - ranging from 3 million to 4.2 million inhabitants in 'Burma Proper', i.e. with the exception of the Mergui Peninsula, Arakan and the Upper Chindwin - which were 'all largely drawn from the sittan records assembled by the Burmese kings in 1783 and 1826' (Richell 2006: 9).

This concentration of the population in the centre of the country radically changed when the British colonial powers gradually seized control of what was then Burma in the three Anglo-Burmese Wars (1824-1826, 1852-1853 


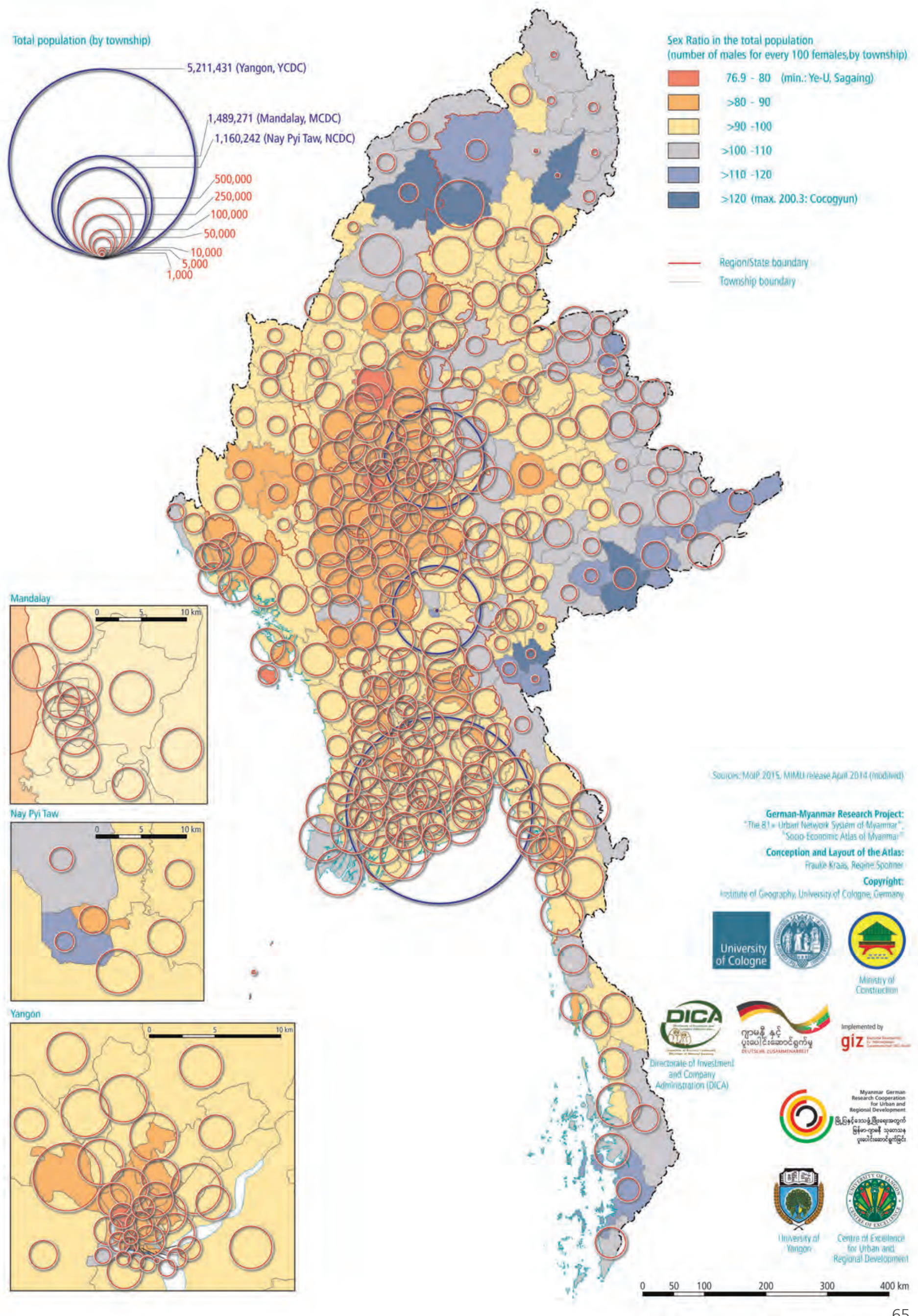


and 1885). Burma thus came under the rule of the British Raj as a province of India. Much of the population shifted towards the coast or migrated to the new and up-and-coming economic region being developed under British rule along the coast. A second new population centre also emerged: after the British moved their capital from Moulmein (now Mawlamyine; capital city from 1826-1852), the port of Rangoon was massively expanded. Within a few decades, the British had developed the Ayeyarwady delta and transformed it into the 'rice bowl' of Asia. By the 1930s, 40,500 km² of land had been cleared and integrated into the colonial economy with a new transport network, irrigation systems, settlements and trade centres (Kraas 2016b). The railway line between Henzada and Bassein was completed by 1915; from here, rice from the western delta was shipped to Rangoon (Nishizawa 1991: 21). Employment, investment and consumption opportunities sprang up in abundance (Furnivall 1957, Nishizawa 1991: 11-13), and as rice exports from the delta boomed, Burma became the world's largest rice exporter.

Territorial development and the processing industries were extremely costly and labourintensive and required a very large workforce. This led to a massive population shift from central Burma to the delta region: by 1901, around $10 \%$ of Burma's four million people had migrated to the Ayeyarwady Delta (Adas 1974). The British also brought in hundreds of thousands of workers from India and Malaya. By 1901, 297,000 Indians had arrived, with around $70 \%$ initially concentrated in Rangoon, which became the British Burmese capital in 1852 (Kraas/Yin May/Zin Nwe Myint 2010). Indians thus made up more than 51\% of the urban population. Between 1852 and 1937, around 2.6 million Indians migrated to Burma, partly on a seasonal basis during the winter months at first. However, from the 1880 s, growing numbers moved into the new settlements and cities in the Ayeyarwady Delta, where they became farmers and land owners and steadily established themselves in urban trade (Cheng 1968: 124-130, Aung-Thwin/ Aung-Thwin 2012: 207).
THE CENTRE-PERIPHERY DIVIDE AND BIPOLAR POPULATION DISTRIBUTION IN THE CENTRAL LOWLANDS

With an overall average population density of 76 inhabitants $/ \mathrm{km}^{2}$, the population of Myanmar today is concentrated in the historic 'heartland' of central Myanmar and the Mandalay agglomeration as well as in the Yangon agglomeration and the Ayeyarwady Delta (MoIP 2015a: 3). At the level of the states and regions, Yangon Region (716 persons/ $\mathrm{km}^{2}$ ), Mandalay Region (206 persons $/ \mathrm{km}^{2}$ ), Ayeyarwady Region (176 persons $/ \mathrm{km}^{2}$ ) and Mon State $\left(167\right.$ persons $\left./ \mathrm{km}^{2}\right)$, Nay Pyi Taw Capital Region (164 persons $/ \mathrm{km}^{2}$ ) and Bago Region (123 persons $/ \mathrm{km}^{2}$ ) have the highest population densities, followed by Magway Region (87 persons $/ \mathrm{km}^{2}$ ), Rakhine State (87 persons $/ \mathrm{km}^{2}$ ), Sagaing Region (56 persons $/ \mathrm{km}^{2}$ ), Kayin State (52 persons $/ \mathrm{km}^{2}$ ), Shan State (38 persons $/ \mathrm{km}^{2}$ ) and Tanintharyi Region (32 persons $/ \mathrm{km}^{2}$ ). Kayah State $\left(24\right.$ persons $\left./ \mathrm{km}^{2}\right)$, Kachin State (19 persons $\left./ \mathrm{km}^{2}\right)$ and Chin State (13 persons $/ \mathrm{km}^{2}$; MoIP 2015b) have the lowest population densities.

Looking at the population densities based on the land area of the 330 townships, the divide is striking. In the extensive central lowlands of the Ayeyarwady River and Sittaung River, the Ayeyarwady Delta and intermittently along the coast, densities generally range from 100 to 500 persons $/ \mathrm{km}^{2}$. The figures are substantially lower in townships in the mountain regions of Chin State, the north-western Sagaing Region, Kachin State, southern and eastern Shan State, Kayah State, northern Kayin State and in Tanintharyi Region, with fewer than 10 persons/ $\mathrm{km}^{2}$. In contrast to other countries in Asia, the inhabitants in the more densely populated central Myanmar are - apart from the two largest urban agglomerations of Yangon and Mandalay -distributed fairly evenly, mainly due to the fact that most people are farmers and thus living mostly in rural villages.

The highest densities are reached in the townships in urban areas, particularly Yangon and Mandalay, with values ranging from more than 5,000 to a maximum of 49,377 persons/ 
$\mathrm{km}^{2}$. The areas around Mawlamyine and Sittwe along the coast and around Nay Pyi Taw, Bago, Monywa, Pyay, Hinthada, Taunggyi, Kalay and Mogok inland also stand out.

In a comparison of density values for the (extensive) administrative units with those obtained from the LandScan calculation, which is based on analysis of data from high-resolution satellite imagery (LandScan 2013TM, Landsat 8 Data Archive), the population centres stand out to an even greater extent. The map based on satellite imagery clearly shows Myanmar's bipolar settlement structure, with two main population centres - one in Central Myanmar in the quadrant to the west and south of Mandalay, and the other extending from the Yangon agglomeration with the adjacent Ayeyarwady Delta to the northwest, west and southwest. Two settlement ribbons running along a north-south axis and linking these two population centres are also clearly discernible. The western ribbon is broad and extends along both banks of the Ayeyarwady River, while the narrower but more densely populated eastern ribbon mainly runs to the west of the Sittaung River. The map also clearly shows the extent to which the north-south Bago Yoma forms a barrier between the two ribbons, which do not converge until they reach Bago in the south and Nay Pyi Taw in the north. It is easy to spot the settlement areas around Sittwe and Mawlamyine, which extend from the coast far inland, and the narrow settlement belts which mainly run north to south along the upper Ayeyarwady River, across the basin at Puta-O and Machanbaw, around Kalay, from Hopin to Myitkyina, from Pyin Oo Lwin to Muse, from Kyatpyin to Mogok, from Loikaw to Kalaw and Taunggyi, south of Mawlamyine to Thanbyuzayat and Ye and around Dawei. The small settlement areas or isolated towns occasionally found on the peripheries, such as Hakha, Kengtung and Ann, also stand out. And finally, the map clearly shows the vast scale of the uninhabited areas where there are no significant human settlements or development.

Frauke Kraas, Aye Aye Myint and Than Than Thwe

\begin{tabular}{|c|c|c|c|c|c|c|c|c|c|c|}
\hline & \multicolumn{3}{|c|}{ POPULATION } & \multicolumn{3}{|c|}{ URBAN POPULATION } & \multicolumn{3}{|c|}{ RURAL POPULATION } & \multirow{2}{*}{\begin{tabular}{|r} 
URBAN \\
POPULATION (\%) \\
$(\%)$
\end{tabular}} \\
\hline & Male & Female & Sex ratio & Male & Female & Sex ratio & Male & Female & Sex ratio & \\
\hline UNION OF MYANMAR & $24,228,714$ & $26,051,186$ & 93.0 & $7,114,224$ & $7,763,719$ & 91.6 & $17,114,490$ & $18,287,467$ & 93.6 & 29.6 \\
\hline KACHIN STATE & 855,353 & 787,488 & 108.6 & 297,643 & 294,725 & 101.0 & 557,710 & 492,763 & 113.2 & 36.1 \\
\hline KAYAH STATE & 143,213 & 143,414 & 99.9 & 35,679 & 36,739 & 97.1 & 107,534 & 106,675 & 100.8 & 25.3 \\
\hline KAYIN STATE & 739,127 & 765,199 & 96.6 & 163,280 & 165,886 & 98.4 & 575,847 & 599,313 & 96.1 & 21.9 \\
\hline CHIN STATE & 229,604 & 249,197 & 92.1 & 47,198 & 52,611 & 89.7 & 182,406 & 196,586 & 92.8 & 20.8 \\
\hline SAGAING REGION & $2,516,949$ & $2,808,398$ & 89.6 & 430,408 & 480,927 & 89.5 & $2,086,541$ & $2,327,471$ & 89.6 & 17.1 \\
\hline TANINTHARYI REGION & 700,619 & 707,782 & 99.0 & 164,982 & 173,437 & 95.1 & 535,637 & 534,345 & 100.2 & 24.0 \\
\hline BAGO REGION & $2,322,338$ & $2,545,035$ & 91.2 & 501,157 & 571,179 & 87.7 & $1,821,181$ & $1,973,856$ & 92.3 & 22.0 \\
\hline MAGWAY REGION & $1,813,974$ & $2,103,081$ & 86.3 & 270,624 & 317,407 & 85.3 & $1,543,350$ & $1,785,674$ & 86.4 & 15.0 \\
\hline MANDALAY REGION & $2,928,367$ & $3,237,356$ & 90.5 & $1,033,433$ & $1,110,003$ & 93.1 & $1,894,934$ & $2,127,353$ & 89.1 & 34.8 \\
\hline MON STATE & 987,392 & $1,067,001$ & 92.5 & 273,561 & 298,628 & 91.6 & 713,831 & 768,373 & 92.9 & 27.9 \\
\hline RAKHINE STATE & 989,702 & $1,109,105$ & 89.2 & 166,857 & 187,431 & 89.0 & 822,845 & 921,674 & 89.3 & 16.9 \\
\hline YANGON REGION & $3,516,403$ & $3,844,300$ & 91.5 & $2,441,229$ & $2,719,283$ & 89.8 & $1,075,174$ & $1,125,017$ & 95.6 & 70.1 \\
\hline SHAN STATE & $2,910,710$ & $2,913,722$ & 99.9 & 692,453 & 703,394 & 98.4 & $2,218,257$ & $2,210,328$ & 100.4 & 24.0 \\
\hline AYEYARWADY REGION & $3,009,808$ & $3,175,021$ & 94.8 & 412,693 & 459,907 & 89.7 & $2,597,115$ & $2,715,114$ & 95.7 & 14.1 \\
\hline NAY PYI TAW & 565,155 & 595,087 & 95.0 & 183,027 & 192,162 & 95.2 & 382,128 & 402,925 & 94.8 & 32.3 \\
\hline
\end{tabular}




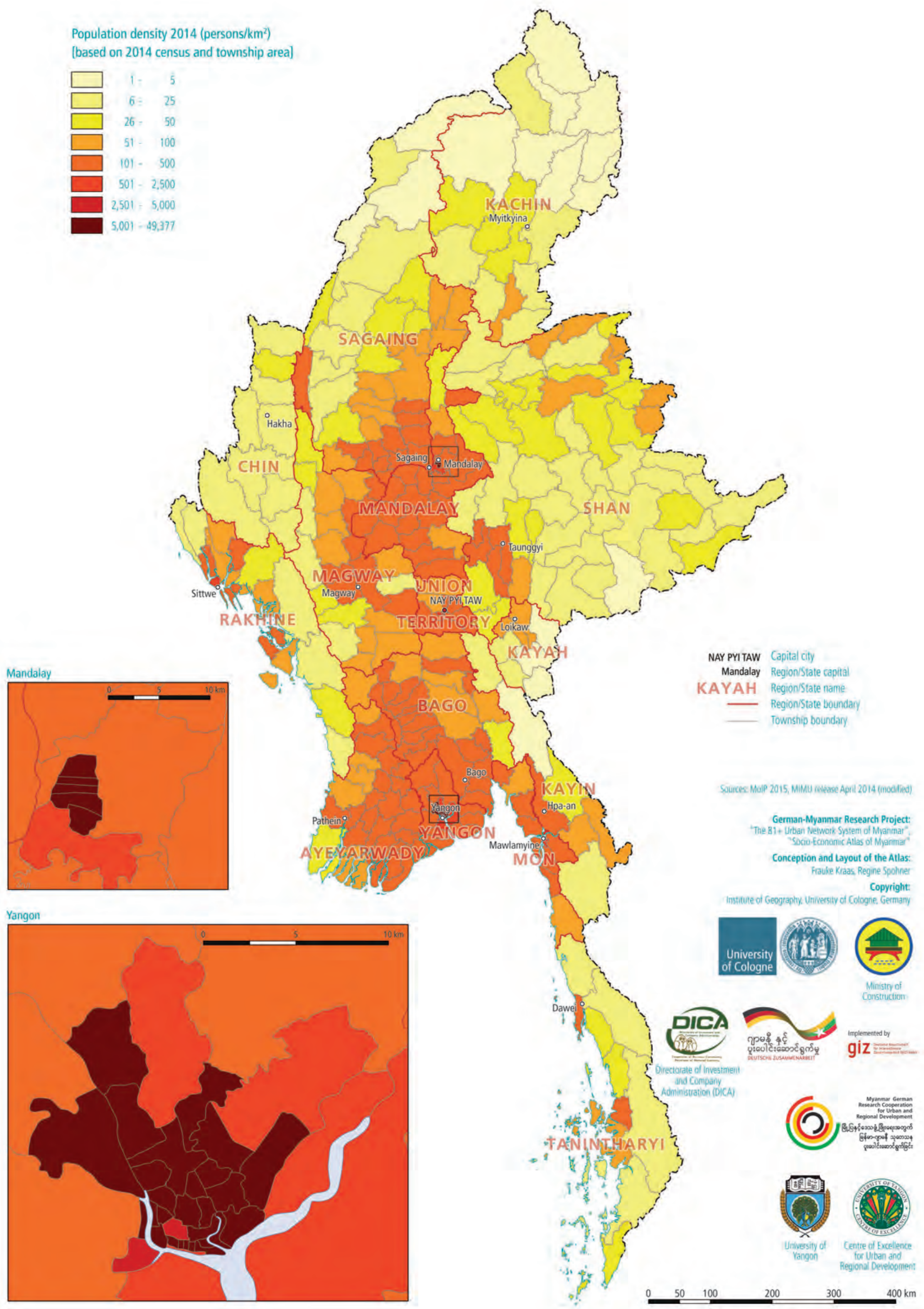


Population density 2013 (persons $/ \mathrm{km}^{2}$ ) [based on 1 km-GRID Landscan 2013]

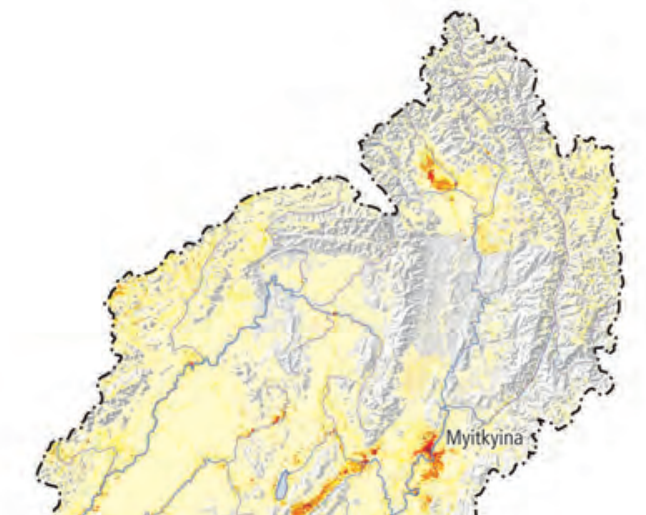




\section{URBAN AND RURAL POPULATION}

The 2014 census in Myanmar provided statistical data for townships across the country, enabling more detailed conclusions to be drawn about the current distribution of the rural and urban population. The 2014 census figures are thus a good starting point for more in-depth population analyses based on the 330 townships.

The 15 regions and states have highly diverse urbanisation rates. Nationally, the urban population averages $29.6 \%$ of the total population. As is to be expected, however, the percentage is very much higher in Yangon (70.1\%) and Mandalay (34.8\%) Regions, and in Nay Pyi Taw Union Territory (32.3\%). In Kachin State, too, there is a high population concentration in urban centres, due to the security situation. The rural population figures, as a percentage of the total population, are highest in Ayeyarwady Region (85.9\%), Magway Region (85\%) and Sagaing Region (82.9\%).

The rural-urban gender ratio is broadly similar across the country. There is a slight gender imbalance, with females predominating in both urban and rural areas, reflecting the fact that more men are labour migrants (in some cases seasonal or temporary) in neighbouring countries (Grundy-Warr/Yin 2002, Myat Mon 2010, Pearson/Kusakabe 2012). By contrast, Kachin State stands out for its noticeable surplus of males, amounting to more than $13 \%$, mainly in rural areas, and $1 \%$ in urban areas. This is caused by selective labour in-migration by men in the mining sector (e.g. in Hpakant or the areas west of Indawgyi Lake; Nyi Nyi 2013). In terms of age structure, there is little difference between the rural and urban populations nationally: $30.6 \%$ of the rural population is below 15 years of age, while the figure for urban areas is $28.6 \%$, and $6 \%$ of the urban population is over 65 years of age, compared with $5.7 \%$ of the rural population (MNPED 2015: 16).

A far more nuanced picture emerges from analysis of the townships: alongside a small number of areas of urban population concentration of more than $75 \%$ in several townships in Yangon and Mandalay and one township in Myitkyina, there are some townships - all of them, without exception, located in regional and in some cases border cities around the country - with an urban population concentration above $50 \%$. Nationwide, however, townships with a rural population concentration above $75 \%$ predominate. Most of them are located in the main settlement area in the lowlands, from Central Myanmar to the Ayeyarwady Delta, and along the coasts, and have much higher absolute population numbers than the mountain areas, the majority of which also have a predominantly rural population. Unlike many other developing countries, then, Myanmar still has a very even population distribution with low urban polarisation at present.

Frauke Kraas, Nilar Aung and Zin Nwe Myint 


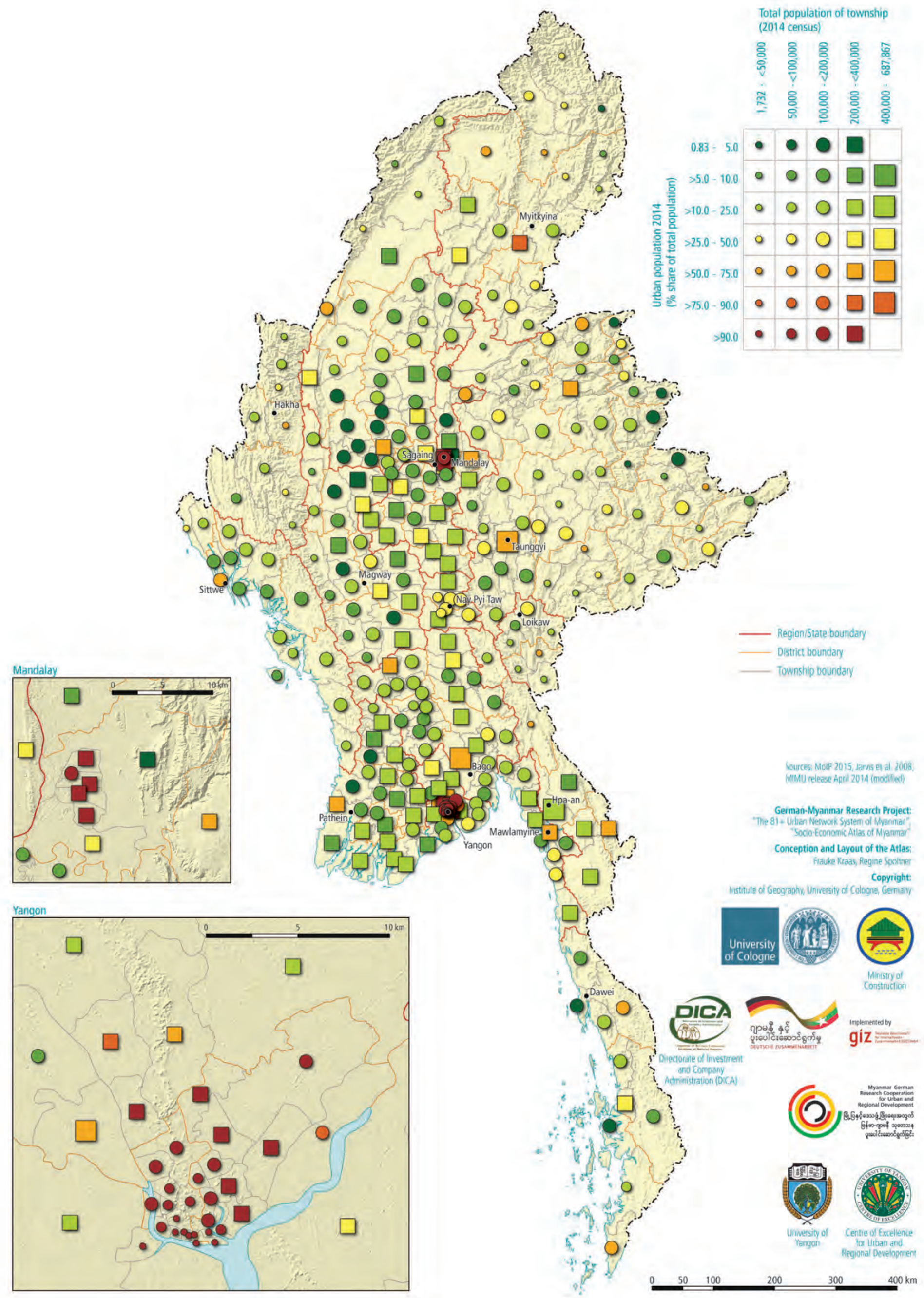




\section{URBANISATION PROCESSES AND THE URBAN SYSTEM}

\section{EARLY URBANISATION}

Cities and urban development have a long history in Myanmar - if, that is, the comparatively large settlements in question may be classed as cities, particularly in a European sense, in that they were characterised by, for instance, some degree of centrality, functional differentiation and social diversity and had a reasonably efficient transport system. There is a body of physical evidence to suggest that they may indeed be classed as such, specifically the extensive areas of palaces, pagodas and urban settlements dating back to pre-colonial times, which were the embodiment in stone of the cosmogonic principles underpinning the Hindu-Buddhist high cultures of continental Southeast Asia under their godkings. Notable examples are the cultural systems, empires and cities of the Pyu, in and around Pyay, Mandalay and Bagan, the Mon empire in the area around present-day Mawlamyine, the landlocked cities along the state and territorial borders, most of which have remained remarkably stable for centuries, and the ports and trading centres along the coast of Rakhine, the Ayeyarwady Delta, Mon and Tanintharyi (for Sri Ksetra: Hudson/ Lustig 2008, Su Su/Win Kyaing 2016, for Bagan: Kan Hla 1977, Hudson/Nyein Lwin/ Win Maung 2001). Various studies on these early (pre-colonial) settlements explore the consolidation of their influence based on their religious and cultural (Dumarcay/ Smithies 1995, Frasch 1996) or political and economic significance (Frasch 2002, Moore/ San Win 2007) and provide evidence that in their heyday, they were centres of both sacred and secular power (Taylor 2009). Many walled sites and particularly the water management in the towns have been investigated (Moore 2004, Moore/Swe Than 2006, Moore/San Win 2007, Moore/San Win/Pyiet Phyo Kyaw 2016).
Under British colonial rule, which commenced in the coastal regions in 1826 and, after the three Anglo-Burmese Wars, was then consolidated across the entire territory of present-day Myanmar from 1886, an urban-based administrative and trading network was established. However, outside Yangon, the capital in those days and a major port (Pearn 1939), an extensive economic and social reshaping of existing settlements - in other words, urbanisation in a European sense - did not occur, for until 1937, the colony of British Burma was, to a large extent, ruled by the British Raj as an eastern province of India. Burma was regarded simply as an annex - an additional space of primary interest as a source of natural resources, until it was finally granted at least administrative autonomy, lasting only a few years. Nonetheless, two development trends could be observed during the British colonial era: firstly, the cities gained in significance with the expansion of resource extraction (mining, timber extraction), accompanied by a modest flowering of industry (Storz 1967: 237-277) and an increase in population numbers (in this context, individual urbanisation processes during the colonial era would be a worthy subject of study), and secondly, the existing system if it can be described as such - of settlements and cities was reorganised, with a shift of economic focus southwards towards the metropolitan area of Yangon. There are numerous individual depictions of cities, dating back to the British colonial era and the early years of independence, in documents of a statistical and descriptive nature, most of them in encyclopaedic format (see, in particular, O'Connor 1907, Anderson 1876, for example). 


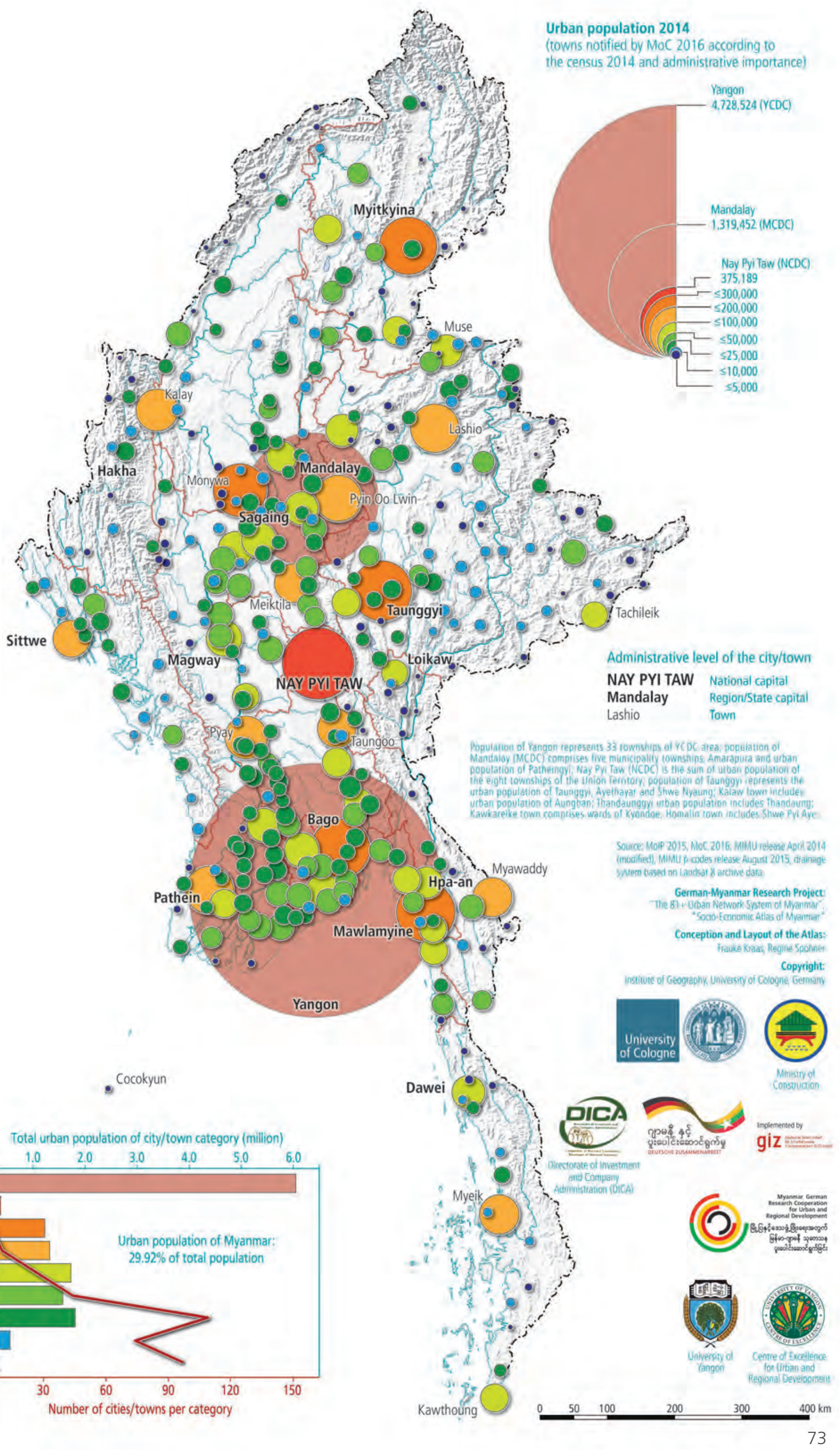


With independence in 1948, the beginnings of industrialisation and, particularly in the 1950s, the influx of rural refugees due to political instability, insurrection and rebel attacks in the countryside, the country's few cities - viewed as safe havens - briefly experienced a massive population increase (for Yangon, see Kraas/Yin May/Zin Nwe Myint 2010, Thomson 1995). In subsequent years, this influx generated further momentum towards urbanisation, primarily in Yangon and Mandalay, but to some extent also in Pathein, Mawlamyine and Myitkyina. After 1962 and the proclamation of a 'Burmese Way to Socialism', an ideology which was to a large extent distinctly anti-urban (or at least pro-rural) determined the direction of the country's regional development for decades. Only in the capital Yangon were there several phases in which 'new towns' were constructed. Despite the name, however, they cannot be compared with British new towns from this period; in terms of their phenotype, they were more akin to rural settlements, albeit located on the outskirts of Yangon. Nonetheless, this led to some limited urban expansion (Aung Win 2006, Zin Nwe Myint 1998, Kraas/Yin May/ Zin Nwe Myint 2010, Yin May 1962, 1999 and 2006).
With the start of Myanmar's transition and the introduction of a market economy in 1988/90, urbanisation picked up pace, initially and most visibly in the then capital Yangon (Leonard 1985, Mya Than/Rajah 1996, Naing Oo 1989, Seekins 2005, Than Than Nwe 1998, Zin Nwe Myint 2006a) and in Mandalay, the largest city in central Myanmar. From the mid to late 1990s, visible signs of urban transformation could be observed in other larger cities (Mawlamyine, Bago, Monywa, Pathein, Meiktila and Sittwe) as well as in some settlements close to the border (Lashio, Myitkyina, Dawai and Kengtung), where transregional trade strengthened markets and transport hubs. The extent to which these trends - no longer isolated cases by then - can be described as a system or network of cities/settlements merits further discussion.

After the end of British colonial rule (and the first systematic nationwide censuses were conducted), the urban population as a percentage of the total population fluctuated considerably, falling from $12.3 \%$ (947,000 persons, 1891) to 9.3\% (991,000, 1901), 9.3\% (1.13 million, 1911) and $9.8 \%$ (1.3 million, 1921) and then rising to $10.4 \%$ (1.52 million, 1931). It should be noted that improvements in the agricultural economy had a dampening effect on migration and

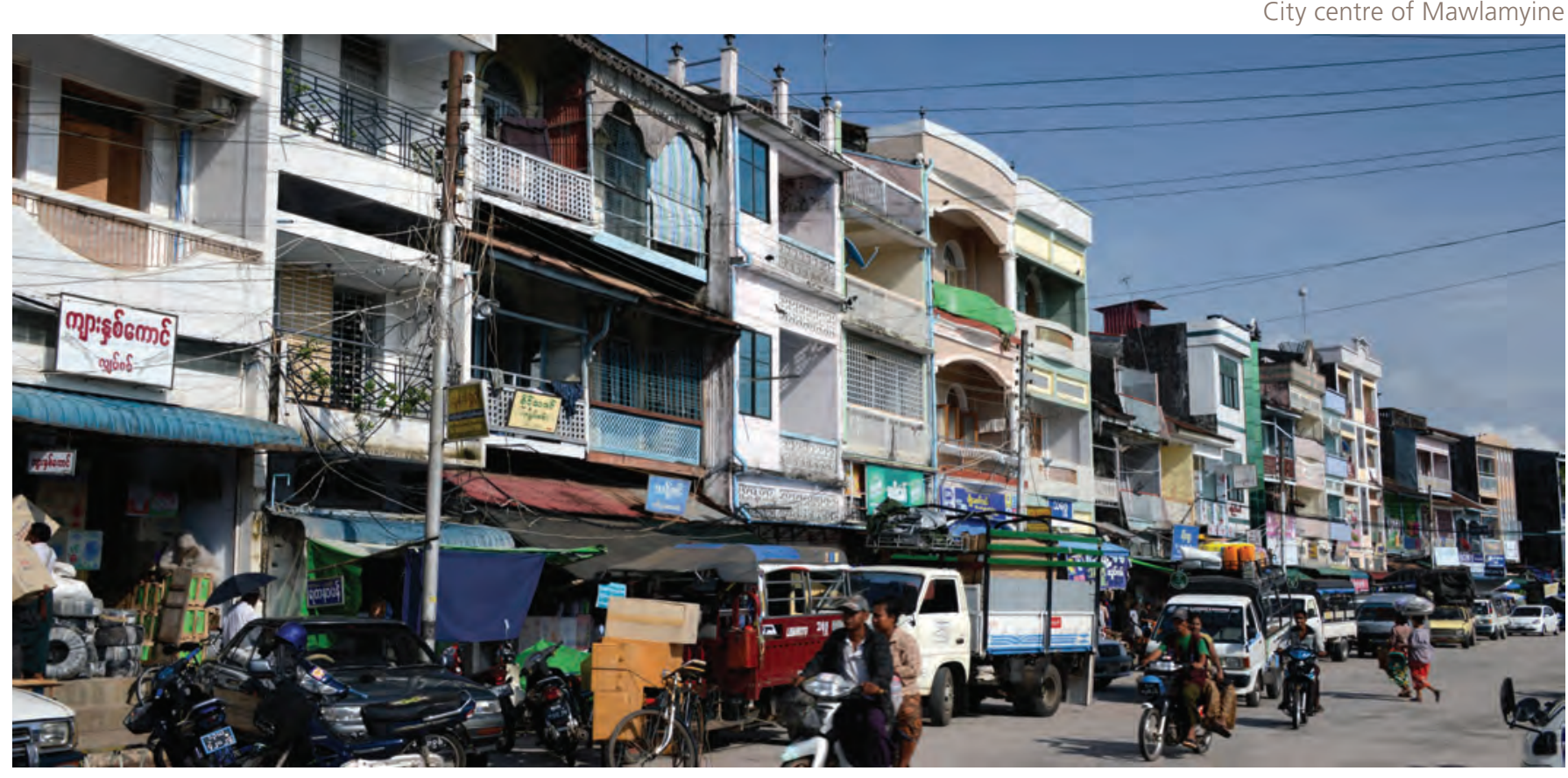


that more efficient census data gathering in rural areas is also likely to be reflected in the statistics (Hla Tun Aung 2003: 204-205). Since independence, the urban population has risen from $13.5 \%$ (2.58 million, 1953), $23.6 \%$ (6.8 million, 1973) and $24 \%$ (8.5 million, 1983) to 28.8\% (13.1 million, 1996) (Hla Tun Aung 2003: 205).

\section{DEVELOPMENT OF MYANMAR'S URBAN SYSTEM}

A small number of studies conducted to date explore the development of individual cities, at least indirectly, with a focus on particular historical periods (Frasch 2002, Kraas/Gaese/Mi Mi Kyi 2006, Rivet 2000, Singer 1995). Currently, however, no publication deals specifically with the urban system in Myanmar (or Burma, as it was known until 1989).

In the era of the pre-colonial empires, specifically those of the Pyu and Mon, and within and among the territories in the Shan Hills, around Mrauk-U/Sittwe (Zin Nwe Myint 2016, Zin Nwe Myint et al. 2016) and Myeik, trade relations undoubtedly existed over longer distances, later extending across major regions, e.g. via the Burma Road and the Assam-Bhamo-Yunnan Route (Thant Myint U 2011). However, a more elaborate network which consisted of more than linear connections was slow to emerge and generally existed only in sub-regions under certain territorial rulers (Hla Tun Aung 2003: 203-205).

One example is the region around Bagan, an ancient city which, chronicles show, was fortified in or around $850 \mathrm{AD}$ by King Pyinbya (Frasch 1996: 43-44). From the 11th century, Bagan was, for around 250 years, the capital of the Kingdom of Pagan, the first kingdom to unify the regions that would later constitute modern Myanmar. During this period, Bagan became one of the most influential cities in continental Southeast Asia, with a population thought to have exceeded 200,000. Its ascendency as the world's largest Buddhist metropolis of its time began in 1057, when King Anawrahta (1044-77) conquered the Mon capital of Thaton and - as was the custom in Southeast
Asia after successful military campaigns brought back captives, among them craftsmen, masons, plasterers, smiths, doctors and scribes. A construction boom began, triggering a wave of settlement and territorial expansion. In its heyday, the Bagan/Pagan Kingdom encompassed large areas of the Ayeyarwady plain, with the exception of Bago and some districts in the Delta; other territories were obliged to pay tribute. Two centuries later, in 1287, a Mongol army led by Kublai Khan invaded, pillaging and burning. In 1299, hostile Shan princes sealed its fate. It is clear that these invasions came after an era of progressive social decline, with a weakening of secular rule and an increase in the power of the monasteries (Frasch 1996: 342). At its height, thousands of buildings were constructed in Bagan; estimates vary between 2,230 and around 5,000 monuments and more than 12,000 individual buildings in all (Dumarcay/Smithies 1995: 9-27, Kraas 2002). Rich stucco ornamentation created from a mixture of sand and limestone, precious murals and elaborate friezes with depictions of demons, mythical creatures, birds, fig leaves and pearls adorned its structures, attesting to a sophisticated culture and advanced artistic skills. Like Angkor, the Bagan Kingdom was built on the wealth generated from rice production, but unlike Angkor, the government and administration were obviously neither 'hierarchically structured nor rationalised through the allocation of specific tasks to individual officials' (Frasch 1996: 36). It may thus be assumed (although this requires separate investigation) that in the surrounding area, too, no obviously hierarchical or strategic system of trade - and therefore no single system of settlement/urban development - was in evidence. Beyond its 'internal' administration transregional economic and geostrategic factors appear to have been a key factor in the city's founding on this site, above all its ideal location at the confluence of the Chindwin and the Ayeyarwady, within reach of the fertile rice growing areas around Kyaukse and Minbu and at the intersection of major trade routes linking China with northern Myanmar, Assam and Bengal. 


\section{URBANISATION SINCE 1988}

Given the still moderate pace of development during Myanmar's early transition compared with other Southeast Asian countries and the relatively firm control of the process by the administrations, few of the 'classic' urbanisation problems affecting other Southeast Asian cities, notably in the context of urban densification and sprawl, can be observed at present. However, developments are now starting to pick up speed.

Since the introduction of a market economy in 1988, the pace of urbanisation has accelerated significantly. For example, the urbanisation rate - in other words, the urban population as a percentage of the total population - in Myanmar has increased from less than 20\% (1980) to $31.9 \%$ (2007) and 29.6\% (2014) (Kraas/Spohner 2015). The urbanisation rates in the states and regions vary considerably: Yangon Region has the highest urban proportion (70.1\%), followed by Kachin State (36.1\%, Mandalay Region (34.8\%), Nay Pyi Taw Capital Region (32.3\%), Mon State (27.9\%) and Kayah State (25.3\%). Less than a quarter of the population is urban in Shan State (24.0\%), Tanintharyi Region (24.0\%), Bago Region (22.0\%), Kayin State (21.9\%), Chin State (20.8\%), Sagaing Region (17.1\%), Rakhine State (16.9\%), Magway Region (15.0\%) and Ayeyarwady Region (14.1\%; MoIP 2015a: 5). Along emerging development corridors (e.g. the Taunggyi west-east axis, the corridor east of Mawlamyine towards Thailand or the link from Mandalay to China, first to the northeast and then switching north), the onset of increasing urbanisation is evident. The same is true of several border towns, e.g. the growing trade centres of Muse, Tachileik or Myawaddy (Kraas 2014c).

With its 367 cities and towns (official figure) and degree of equilibrium in its urban system, Myanmar - still - has the potential to expand its regional and small towns (Kraas/Zin Nwe Myint/Khin Khin Soe 2016) into drivers of relatively well-balanced national development through a policy of decentralised concentration. However, since political liberalisation commenced in 2010, development processes have begun to be concentrated to an ever greater extent on Yangon and Mandalay (Kraas/Yin May/Zin Nwe Myint 2010).

With the construction of the new capital Nay Pyi Taw - Myanmar's official seat of government since 6 November 2005, located around $350 \mathrm{~km}$ north of Yangon (Gärtner 2011a) - key administrative functions and a substantial number of officials employed by the ministries and public authorities have relocated or are commuting regularly to Nay Pyi Taw, with a considerable two-way movement between

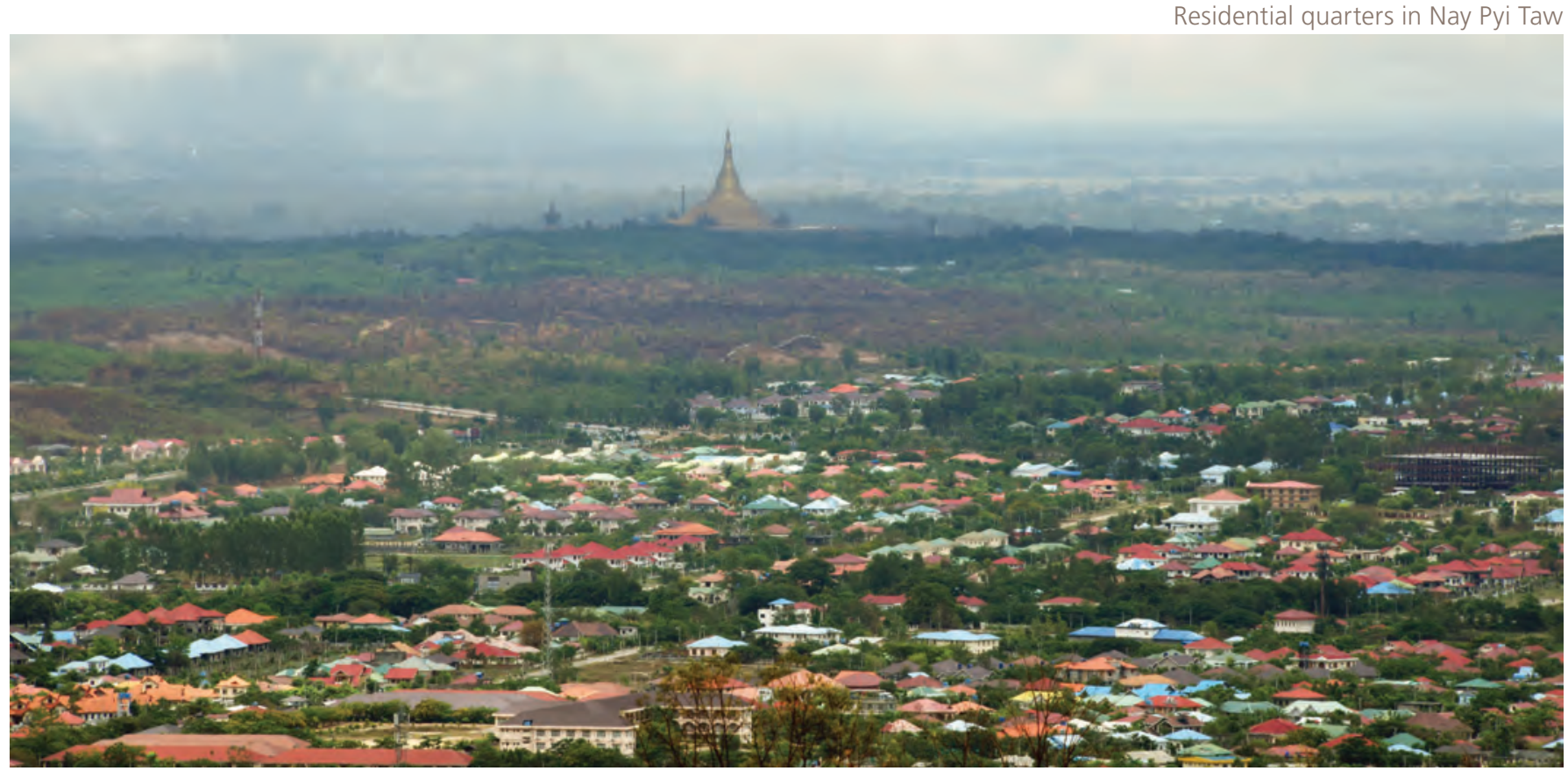


home and workplace. This shift north has moved the capital back to the traditional precolonial heartland of Upper Myanmar (Kraas 2014b).

The numerous regional towns - each with a population of less than 200,000 and in most cases between 10,000 and 25,000 - are strung out like pearls along the country's main infrastructure corridors. Yangon and Mandalay are linked by three transport routes, with the western route passing through Pyay and the two eastern corridors - one the old highway, the other the new expressway - running to some extent in parallel through Bago, Nay Pyi Taw and Meiktila. The transport link from Bago via Mawlamyine to the south of Myanmar also passes through numerous settlements.

This has been accompanied by a gain in significance for the urban economy in the national context and by broad differentiation between the formal and the informal sectors, especially in the cities. In view of the still moderate development dynamics and relatively strong municipal administrations in Myanmar, signs of strain on the urban infrastructure - typical of other Southeast Asian countries (Kraas 2017) - are since a few years being observed and include traffic congestion, infrastructural bottle- necks, energy and electricity constraints (leading to high woodfuel consumption; Zin Nwe Myint 2006a), pollution and displacement of social groups. However, urban expansion - the encroachment of the cities into surrounding green and agricultural space - is clearly taking place, along with the emergence of gated communities (self-standing newly constructed settlements for the middle class and elites, with their own security personnel) and structural change in inner cities, with a functional shift away from housing and towards offices at the most sought-after - and now very expensive locations, especially in downtown Yangon and Mandalay.

\section{STRUCTURAL CHANGE IN INNER CITIES}

Since the introduction of the market economy, visible processes of urbanisation have been discernible in almost all of Myanmar's cities as a consequence of the surge in private sector start-ups, especially in commerce, finance and tourism services. The pace of transformation varies, however, according to local economic conditions and is most dynamic in the seven largest cities - Yangon, Mandalay, Mawlamyine, Bago, Monywa, Meiktila and Pathein.

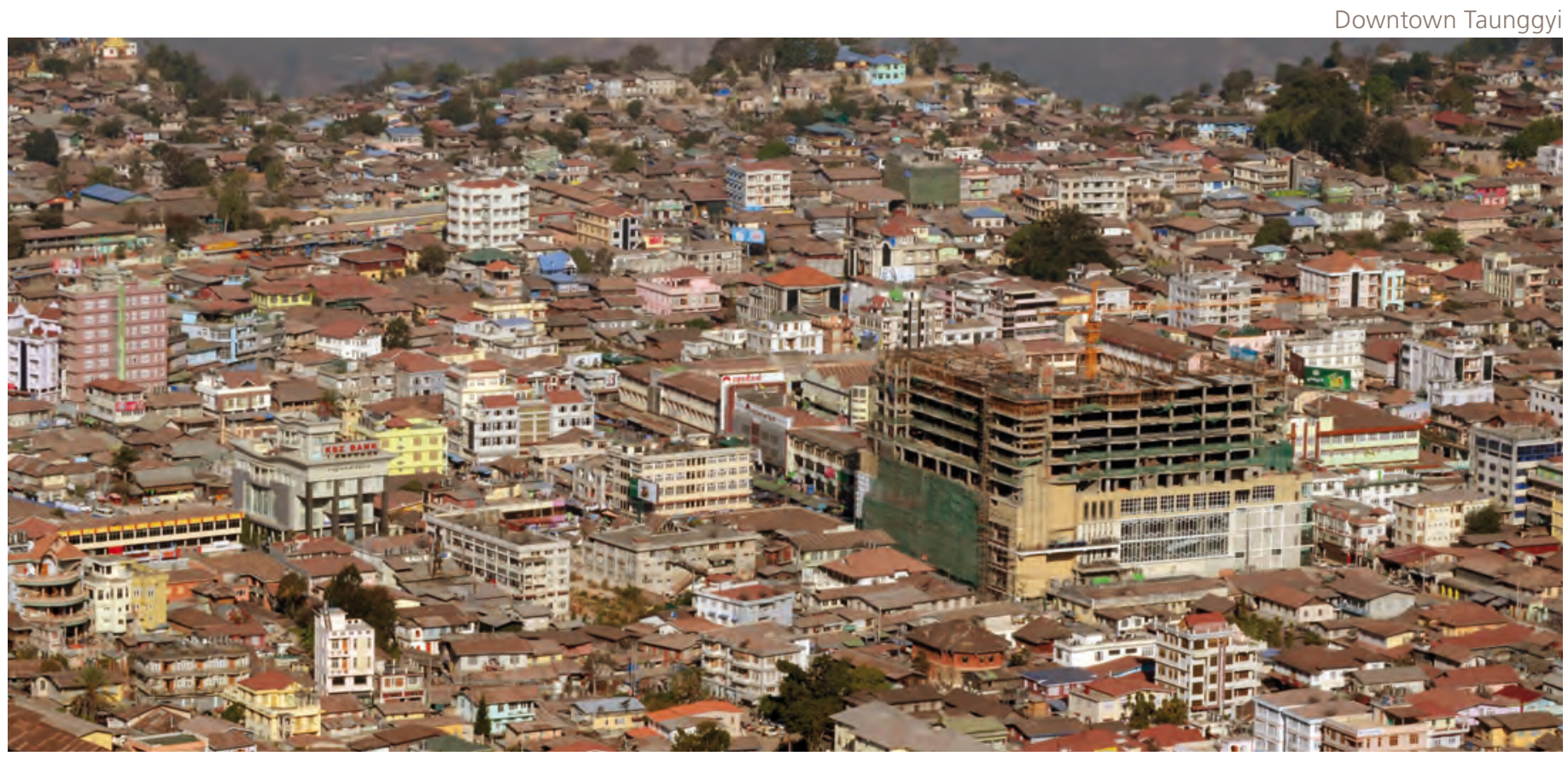


The most obvious processes are catch-up tertiarisation and city-building and the emergence of real estate markets (land and property). The inner-city market and distribution systems are also evolving dynamically, with supermarkets and shopping malls springing up alongside traditional local markets. The boom in construction by private developers, especially the transition 'winners', and the construction of new tower blocks or the addition of storeys to existing buildings are resulting in social polarisation and partly resettlement. As a result of a surge in car ownership and the expansion and upgrading of much of the road network, suburbanisation is occurring in outlying areas. Although still at an early stage, some urban districts are beginning to form separate enclaves in the general cityscape; examples are international shopping malls and complexes with serviced apartments and gated communities. These new features of the urban landscape are planned, constructed, marketed and operated mainly by private developers and management companies and therefore evade strong regulation - evidence of the increasing importance of private capital-driven urban development based on international paradigms. Furthermore, the urban fringe - hitherto used for agricultural purposes - is increasingly being absorbed by new districts (such as Than- lyin to the southeast of Yangon) with conceptually integrated and coherent functionality and futuristic architecture. This shows the extent to which the demands of the emerging middle class are encroaching on space and having a visible impact on the urban landscape.

The most obvious change is currently taking place in the old quarters whose design and architecture date back to colonial times - in Yangon, this is the old city between Merchant and Anawrahta Road near the Sule Pagoda (Hlaing Maw Oo 2006, Kraas et al. 2014 and 2015). Here, large swathes of the old city - urban heritage of importance to the city's identity and citizens' identification with it (Hlaing Maw Oo 2006, Roberts 2016) - are being demolished to make way for new development (shopping malls, office blocks and apartment buildings, partly financed with foreign capital). With selective upgrading and gentrification, it may still be possible to save the substantial urban heritage in Yangon and other cities (AMA 2012, Kraas/Hlaing Maw Oo/Spohner 2014 and 2015). However, the fact that these downtown neighbourhoods are characterised by colonial-era architecture and stylistic elements can pose problems, as some decision-makers regard their upgrading as undesirable for historical reasons.

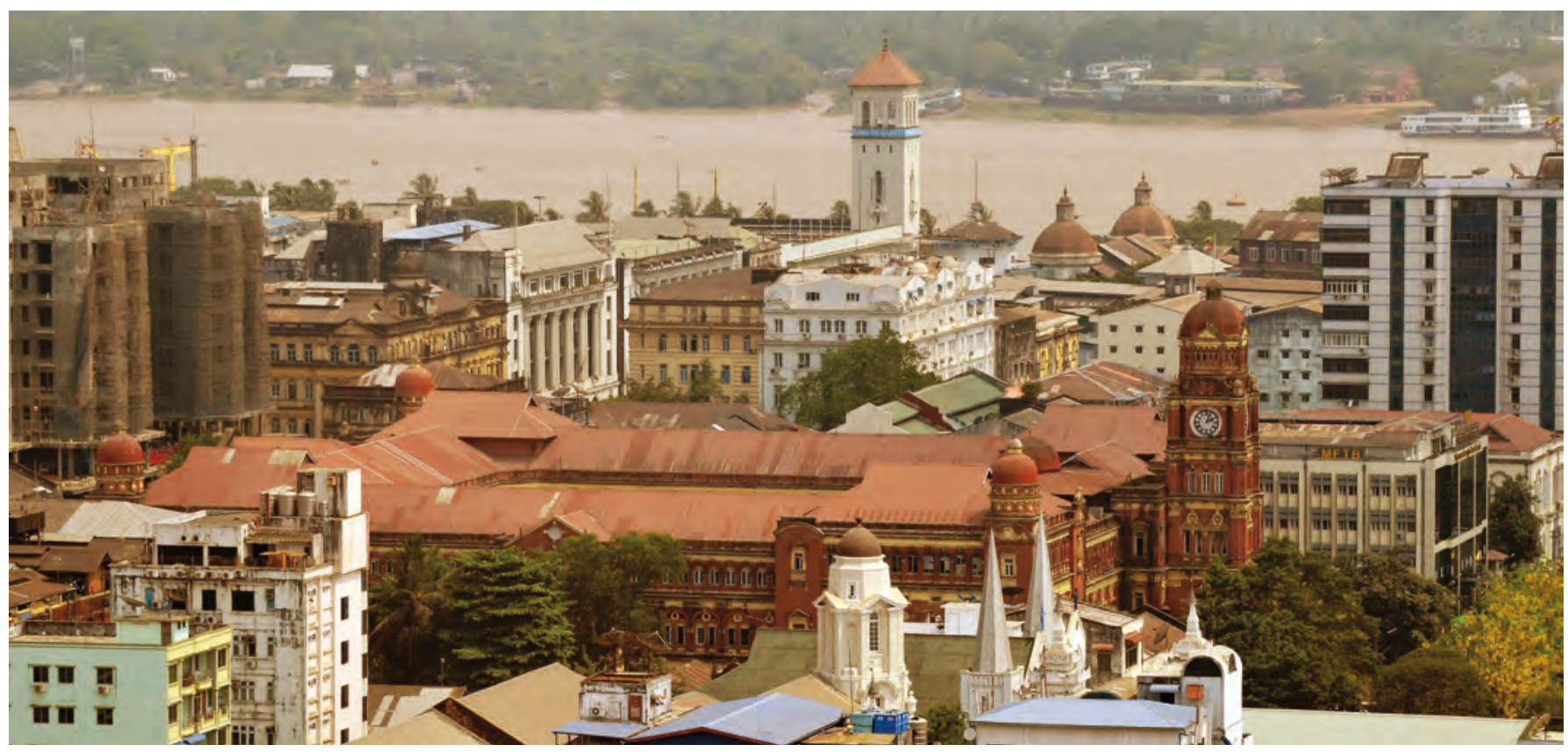


In addition, there is a risk that some modernisation projects lack sensitivity, with displacement of lower-income groups and much of the informal sector, with the threat that the vibrant and organic life of these downtown communities will give way to sterile heritage-type development, benefiting tourism at best.

\section{NAY PYI TAW: THE NEW CAPITAL}

With the construction of the new capital Nay Pyi Taw - the official seat of government since 6 November 2005 - around $350 \mathrm{~km}$ north of Yangon, key administrative functions and a substantial number of ministerial employees have relocated to Myanmar's interior (Gärtner 2011a). The spacious new capital is divided into distinct functional zones - government district, business centres, residential areas, embassies, hotel zones and recreation areas linked by major transport routes. Notwithstanding all the criticisms of the scale and artificiality of the new city, whose convergence with the old districts of Pyinmana, Leway and Tatkone has scarcely begun, there is no disputing that with its relocation northwards, the capital has moved closer to the country's population centre and the historic heartland of Upper Myanmar. Moreover, unlike other, mostly congested and burdened Southeast Asian capitals, Nay Pyi Taw is functioning well in terms of urban efficiency without over-congestion and has an excellent quality of life.

\section{YANGON: FORMER CAPITAL, NOW AN ECONOMIC CENTRE}

There has been a small settlement, Dagon, on the territory of present-day Yangon since at least the 12th century. Its focal point was the famous Shwedagon Pagoda (Golden Pagoda), thought to date back to the 6th century. In its day, the pre-colonial city was located on the periphery of the empires and only gained significance after Myanmar came under British rule, when secure harbour access was required. Having suffered extensive fire damage in 1841 and after being almost entirely destroyed in the war against the British in 1852, Rangoon as it was then known - was elevated to the status of capital of the British colony in 1885 (Pearn 1939). Planned on the basis of a grid pattern of main roads running from east to west and minor roads running from north to south, the city was designed by the British in accordance with contemporary notions of functionality and style in modern colonial cities. Initially planned for a population of 36,000 , the city grew rapidly with the systematic expansion of agriculture in the Ayeyarwady Delta, an ever more extensive urban infrastructure (port, trams, suburbs) and the growth of industry. There was a massive influx of people from the northern regions of the country, with targeted incentives being provided for Indian and (to some extent) Chinese, resulting in an almost threefold increase in the urban population - to 98,100 - by 1872 . In 1921, the population reached almost 342,000 . In 1951, the arrival of refugees from the post-independence insurgency had pushed the population of the then capital up to 650,000 (Yin May 1962, 1999 and 2006, Kraas/Yin May/Zin Nwe Myint 2010). Today, Yangon officially has a population of almost five million $(4,728,520$; MoIP 2015b), not taking into account seasonal inmigration. If smaller towns in outlying areas with close functional links to Yangon are included, the total population of this conurbation is around seven million.

Frauke Kraas, Aye Aye Myint, Hlaing Maw Oo, Myint Naing and Zin Nwe Myint 


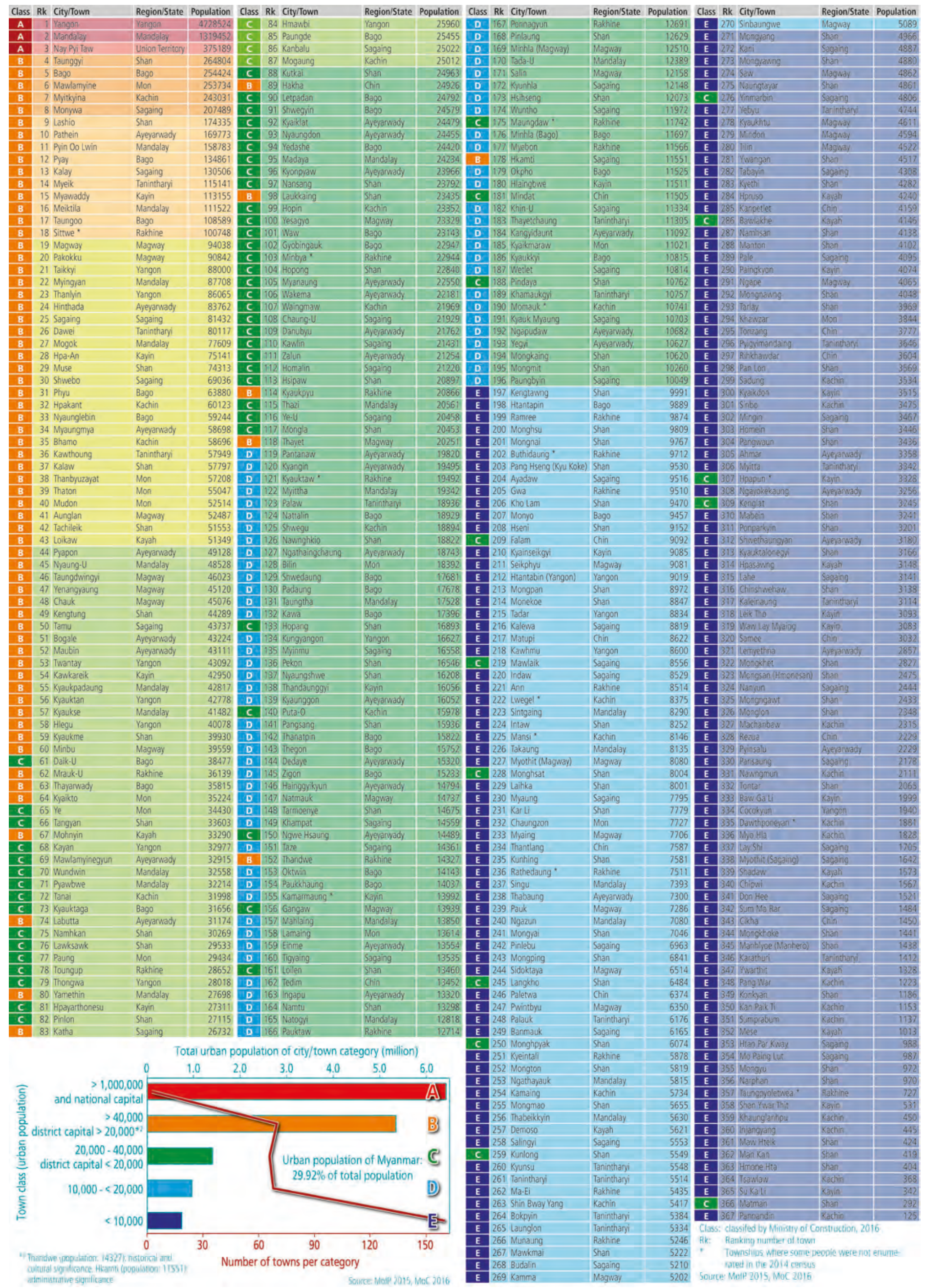




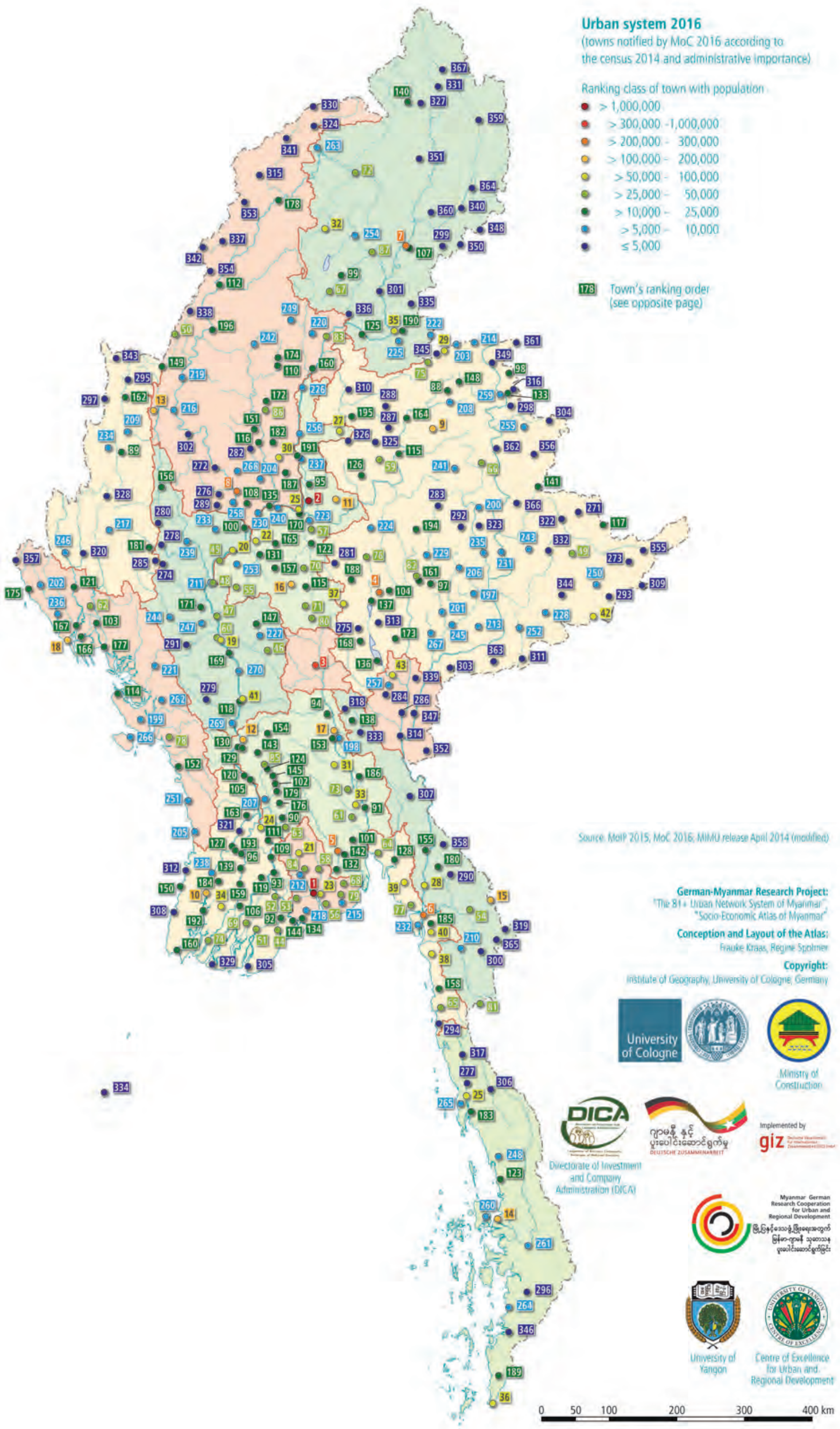



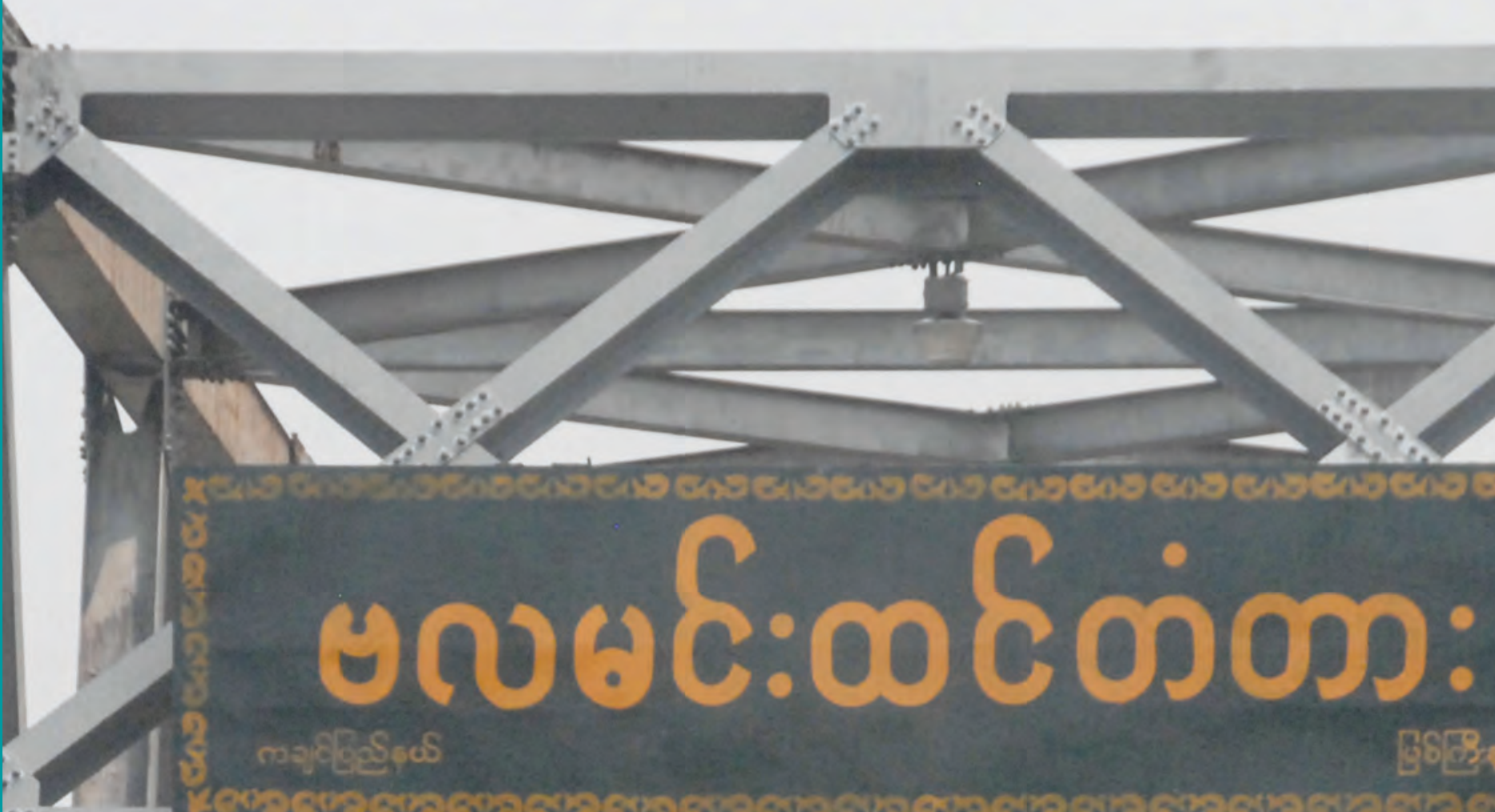

3 .

$\because$

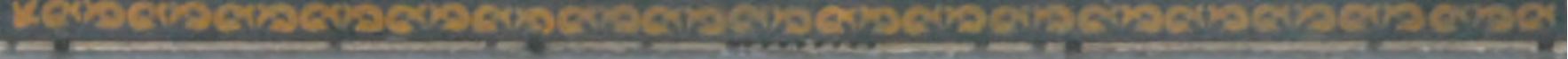

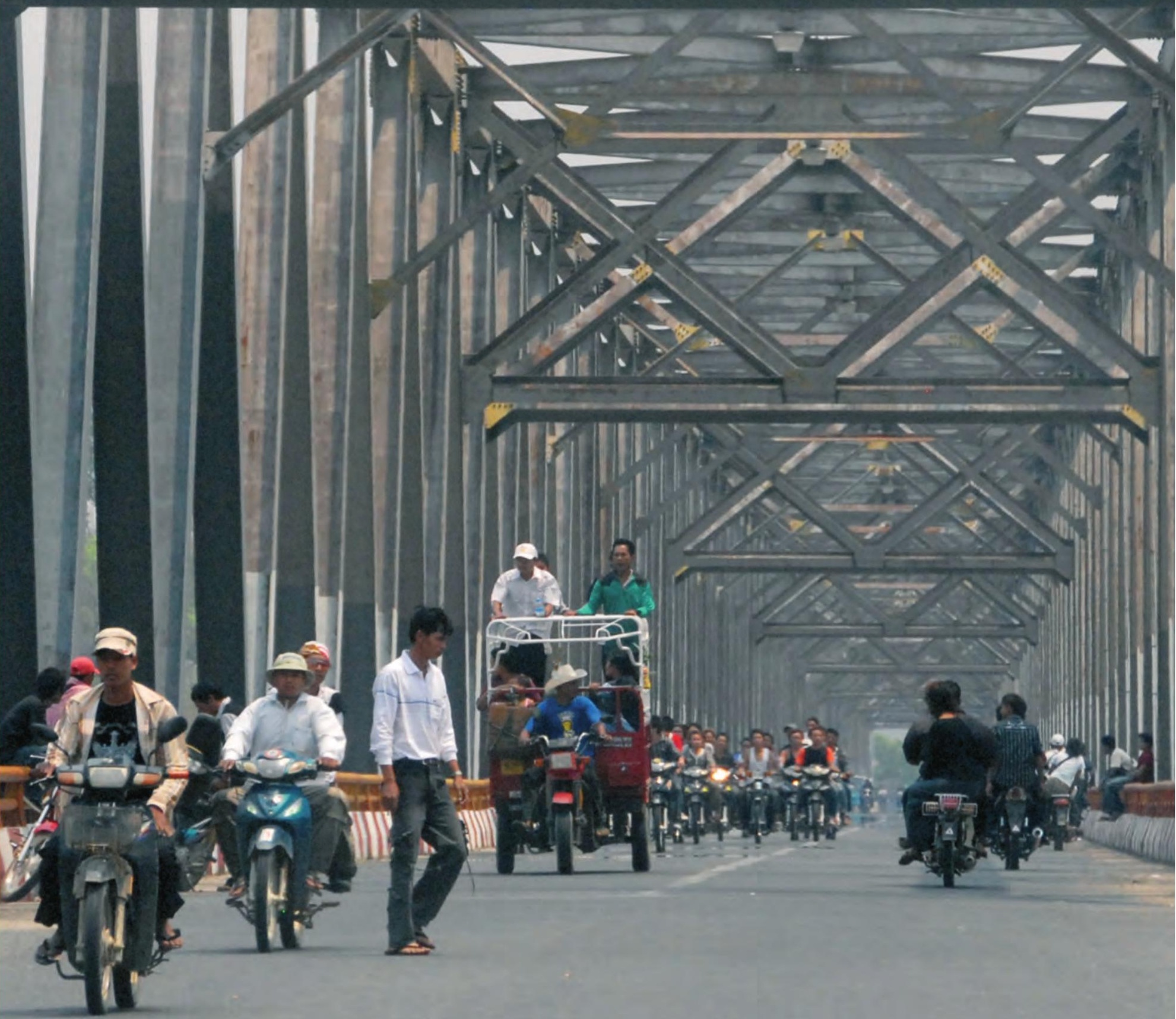




\section{INFRASTRUCTURE}

84 ROADS, RAILROADS, AIRPORTS, PORTS

92 ENERGY SUPPLY

93 HYDROPOWER AND THERMAL POWER PLANT PROJECTS

94 TELECOMMUNICATIONS

95 INFORMATION AND COMMUNICATION TECHNOLOGY I MPT TOWERS

97 INFORMATION AND COMMUNICATION TECHNOLOGY I OOREDOO AND TELENOR TOWERS 


\section{ROADS, RAILROADS, AIRPORTS, PORTS}

Due to the scale and physiography of its major geographical regions, all of Myanmar's large roads and waterways run to this day on a north-south axis. Until well into the 20th century, the Ayeyarwady River - the 'Road to Mandalay', as the poem calls it - and its tributaries formed the only unbroken corridor linking north and south. By comparison, the west-east axes are less developed: due to the topography of Myanmar's mountain ranges, most of which run north to south, the westeast route poses much greater problems for construction and, for that reason, was hardly developed until comparatively late.

In the pre-colonial era, the road system consisted of local tracks for oxcarts and horsedrawn vehicles, but there was already a network of long-distance overland routes - well-developed for its time - for the transportation of goods across present-day Myanmar and into neighbouring regions. They included the roads connecting China and India with the amber and ruby mines in Mogaung and Mogok, the jade deposits in Kachin and the tin-tungsten mines in Kayah (KTAM Report 1953: 361, Hla Tun Aung 2003: 513-514). A well-developed, good-quality cart track between Mandalay and Taungoo existed in the late 19th century.

\section{EXPANSION IN COLONIAL TIMES}

After the country's progressive annexation by the British, modern roads and railway lines were constructed, mainly to support the extraction and transportation of natural resources. In 1881, the country had around 1,421 $\mathrm{km}$ of roads, just $499 \mathrm{~km}$ of them metalled, but road-building progressed rapidly thereafter: by 1891 , there were more than $4,614 \mathrm{~km}$ in Lower and 4,672 km in Upper Burma, of which
$1,540 \mathrm{~km}$ and $320 \mathrm{~km}$, respectively, were metalled (Hla Tun Aung 2003: 515). However, it was not the roads but the railways which were crucial for the transportation of goods and people in the British colonial period: 'Prior to the war, Burma Railways carried from 80 to $90 \%$ of the freight and practically all passengers' (KTAM Report 1953: 256). The $260 \mathrm{~km}$ railroad from Rangoon to Prome opened in 1877, followed by a $620 \mathrm{~km}$ rail link from Rangoon to Mandalay in 1889. By 1903, the rail network had been extended to $2,113 \mathrm{~km}$, with connections to Myingyan, Myitkyina, Alon, Lashio and Bassein-Letpadan, and by the Second World War, it had increased to $3,312 \mathrm{~km}$. The Ava Bridge near Sagaing, built in 1934, was the first to span the Irrawaddy (KTAM Report 1953: 256, Storz 1967: 149). The British also drove the large-scale development of the Irrawaddy Delta as the 'rice bowl' for British India. Although this relied in part on the construction of roads and a railway line from Rangoon to Henzada and onward to Bassein, the country's dense network of small ports and docks played a key role, increasing the volume of shipping along the rivers, channels and canals.

By the beginning of the Second World War, the British had built 10,961 km of paved roads suitable for year-round use and a further 9,030 $\mathrm{km}$ of earth and gravel roads which were passable only in the dry season (Hla Tun Aung 2003: 515). As the Second World War wore on, the US Army constructed the strategically important Ledo (later Stilwell) Road from Myitkyina via Mogaung to the Pangsau Pass. The route to India was also upgraded and extended with the construction of the KalewaTamu Road. The Burma Road from Mandalay via Hsipaw and Lashio to Muse improved the transport link to China, and the highway from Kengtung to Tachileik was extended as far as 
Mae Sai in Thailand (KTAM Report 1953: 362, Storz 1967: 144-146, Yhome 2015a).

\section{RECONSTRUCTION AND A NEW START DURING THE EARLY YEARS OF INDEPENDENCE}

The legacy of war, along with unrest and insurgency during the post-war years, brought rail transport to a virtual standstill and inflicted serious damage on the road network. This began when numerous road and rail bridges and much of the rolling stock were destroyed by the British Army as it retreated from the advancing Japanese; in subsequent years, all the warring parties engaged in defensive and aggressive action and thus had a hand at various times in systematically destroying the country's transport systems, which were seen as targets for ground operations and aerial bombardments (Storz 1967: 139, 149; Allen 1984, McCormack/Nelson 1993, Nesbit 2009). In 1940, the country had 3,314 km of rail track; by 1945 , only $1,190 \mathrm{~km}$ were still functioning (Storz 1967: 149). Moreover, much of the pre-colonial network of inland waterways that had proved its worth over so many centuries - extending for around $6,500 \mathrm{~km}$, with 3,200 $\mathrm{km}$ navigable in the Ayeyarwady Delta alone (Storz 1967: 154) - was unusable as almost all the ports, harbours and ships had been destroyed. Some of the vessels which had been deliberately scuttled in order to block the shipping routes were not raised until well into the 1960s. Making matters worse, there was also a lack of skilled workers for the reconstruction effort (KTAM Report 1953: 283, 336; Storz 1967: 155-157).

It was the first Eight-Year Plan (1952) which finally enabled the country to begin investing in rebuilding its infrastructure, the aim being to re-establish domestic and international trade links, cut transport costs, consolidate national cohesion by facilitating the transport of people and goods and create a more integrated transport system (Storz 1967: 139). By 1962, as part of the plans for an Asian Highway System, the development of two major west-east axes was already under discussion, the first being the route from Tehran via Delhi and Calcutta to Kalewa, via Mandalay, Taunggyi, Kengtung and Tachileik to Lampang and Bangkok and then to Battambang and Phnom Penh and on to Saigon, and the second running from Chittagong via Prome to Rangoon, Thaton and Hpa-an and onward to Bangkok, Kuala Lumpur and Singapore (Storz 1969: 143-144).

As the first step, several key bridges (notably those spanning the Pazundaung, Bago and Sittaung Rivers) and major overland routes were rebuilt, foremost among them the highway from Rangoon to Mandalay and onward to Myitkyina, and the Tavoy-Mergui axis. Several west-east routes were also developed or proposed for expansion, e.g. from Prome to Taungoo, from Meiktila to Taunggyi, and from Prome to Taungup (KTAM Report 1953: 378-379, Storz 1967: 146-148). It also took comparatively little time - from 1956 to 1960 - to restore the rail network to a length of $3,100 \mathrm{~km}$. In 1950, repairs were carried out to the Gokteik viaduct, constructed in 1900; the Inwa Bridge near Sagaing was renovated in 1953 (Hla Tu Aung 2003: 534). The expansion of aviation also played an important role. By the late 1960s, the country had 33 airfields, including seven which were accessible even during the monsoon season (Storz 1967: 163 165). During the period of nationalisation after 1962 until the transition to a marketoriented policy of openness in 1988, the transport networks were further upgraded, not least through the expansion of the road system from 17,194 km (1961) to 23,462 km (1988) (Hla Tun Aung 2003: 519).

\section{DEVELOPMENTS AFTER THE TRANSI- TION TO A MARKET-ORIENTED ECONOMY}

During the transition to a market-oriented economy, national development was given a boost by a large number of new infrastructural projects which extended into hitherto largely inaccessible peripheral regions. In the process, the road network was extended from $27,840 \mathrm{~km}$ (1995) to $40,575 \mathrm{~km}$ (2015); more 
importantly, however, major improvements were achieved in the quality of road-building (almost 23,000 km were tarred, compared with only 10,000 km in 1995). Road network expansion focused mainly on the Ayeyarwady, Magway, Mandalay and Sagaing Regions and on Chin, Kachin, Rakhine and Shan States. The number of registered vehicles also increased more than tenfold during this period, from 302,833 to 5,077,699, rising from 174,379 to 679,485 in Yangon alone. The rail network was extended from $3,977 \mathrm{~km}$ (1995) to 6,107 $\mathrm{km}$ (2015), and the number of railway stations rose from 612 to 960 . Although the provision of state aviation services decreased between 1995 and 2015 - measured in terms of the number of flights (down from 5,090 to 4,474), distance flown (down from 4,501,000 to 3,885,000 km) and number of aircraft in service (down from 13 to just 10) - the volume of private civil aviation increased substantially, with a sharp rise from 2011 onwards: the number of flights per year increased almost tenfold from 2,360 (1995) to 21,361 (2015), and from just two aircraft in 1995, there were 64 in service in 2015 (all the comparative data for 1995 and 2015 are taken from MNPED 2015: 407-439).

\section{THE TRANSPORT INFRASTRUCTURE: CURRENT STATUS}

A glance at the current scale of the transport infrastructure shows the dominance of the north-south axis across all modes of transport, albeit with a small number of roads running in a west-to-east direction, e.g. from Pathein to Yangon, from Chauk via Meiktila to Taunggyi, and from Mandalay via Lashio to Muse, with various less significant routes leading into the mountains and towards the international borders. The backbone of Myanmar's transport system is the $587 \mathrm{~km}$ Yangon-Mandalay Expressway, constructed from 2005 onwards and opened in late 2010, which connects its three major political and economic centres, i.e. Nay Pyi Taw, Yangon and Mandalay. The idea for the project goes back to the Pyidawtha Plan, conceived in 1952 during the period of post-war renewal (Government of Burma
1952, Lockwood 1958) but not implemented at first. The Expressway is open to cross-country buses and private vehicles but not to heavy goods vehicles and trucks. The rail network follows broadly similar routes but also fills the gaps in the road system, e.g. between Pakkoku and Kalay, between Monywa and Myitkyina, and in central Myanmar. Numerous airports and airfields have improved access to the peripheral regions (e.g. Kalay, Homalin, Puta-O, Kengtung, Tachileik, Myeik and Kawthaung). Alongside the major ports of Yangon, Sittwe, Thandwe, Pathein, Myeik and Kawthaung and the new major terminal at Thilawa, Myanmar has a number of smaller harbours. Deep-sea ports are currently planned in Kyaukpyu, Mawlamyine and Dawai.

\section{LOOKING TO THE FUTURE: LARGE- SCALE PROJECTS}

With an eye to the future, Myanmar is planning a number of large-scale projects whose purpose is to improve infrastructural connectivity within Asia. Several of these major projects aim to strengthen Myanmar's links to neighbouring countries by establishing new transport corridors. As a member of the Association of Southeast Asian Nations (ASEAN), the Greater Mekong Subregion (GMS) and the Bay of Bengal Initiative for Multi-Sectoral Technical and Economic Cooperation (BIMSTEC), Myanmar is involved in numerous long-term infrastructure projects. As the volume of trade with neighbouring countries increases (Kyaw Min Htun et al. 2011, Florento/ Corpuz 2014), Myanmar is likely to become a key regional centre due to its outstanding geostrategic location, with the potential to become a major transportation hub und gateway within Asia.

The Asian Land Transport Infrastructure Development (ALTID) project (established by UN-ESCAP in 1992) aims to expand the existing pan-Asian infrastructure initiatives. Its major components are the Asian Highway Network, the Trans-Asian Railway (TAR) and the upgrading of the intermodal transport terminals, including port infrastructures 


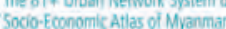

Conception and Layout of the Atlas:

Frauke Kras, Regine Spother

Copyright:

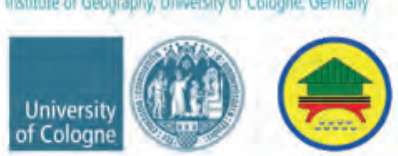

Constinuction

미소

(ivid
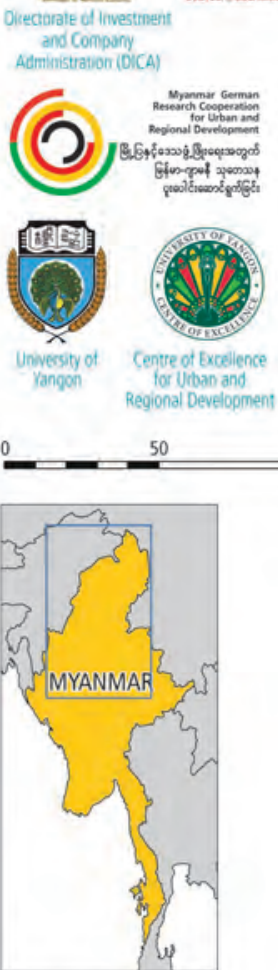

$100 \quad 150 \mathrm{~km}$

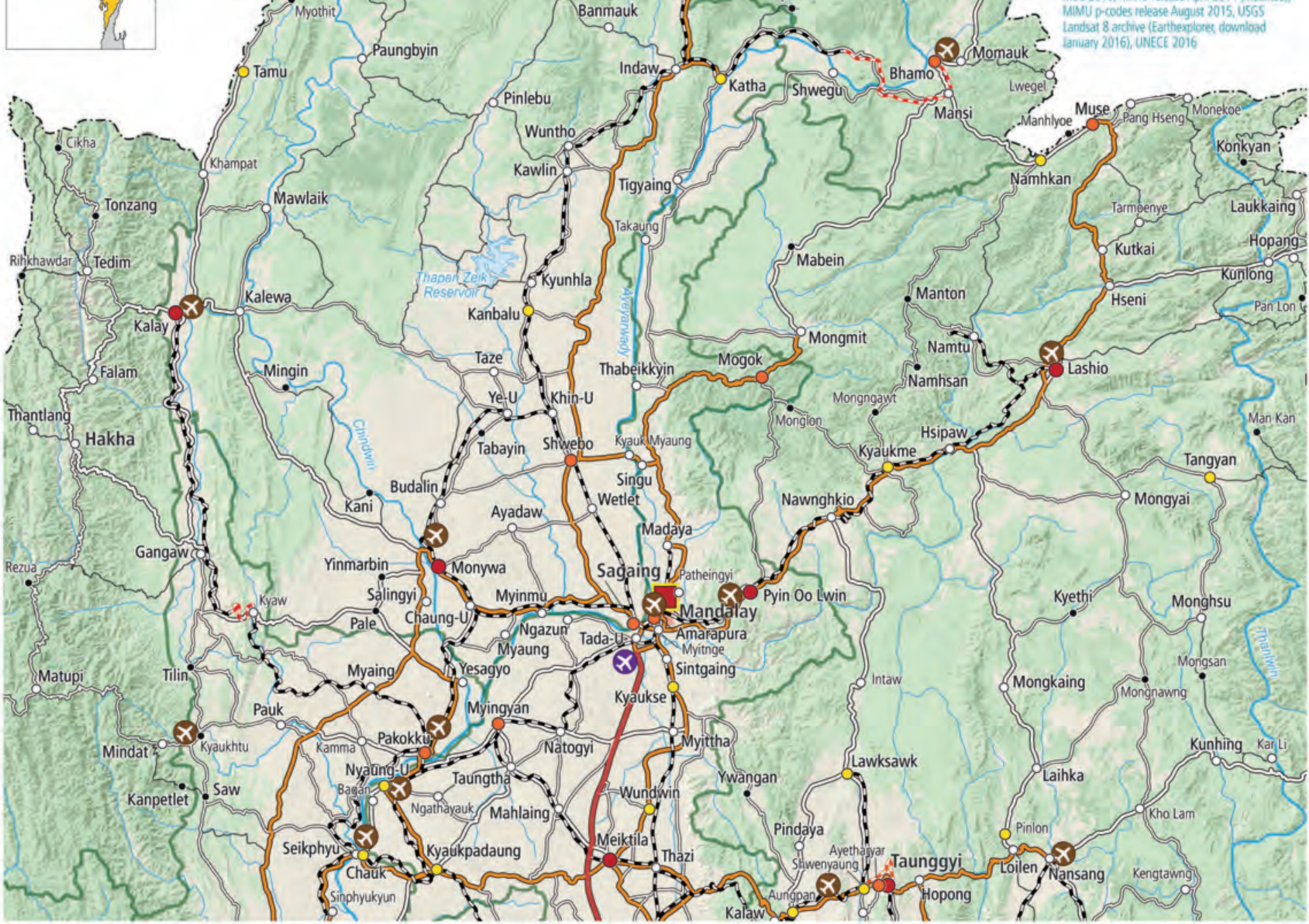

(towns defined by GAD, MIMU p-codes release August 2015)

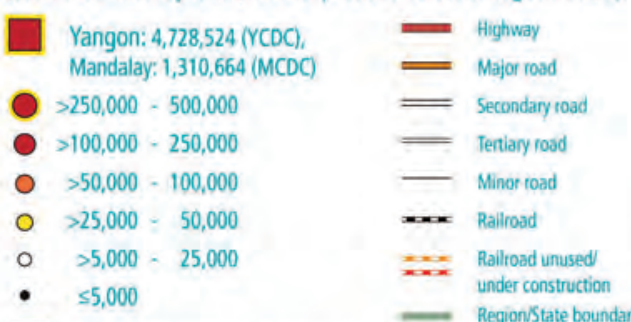

(x)

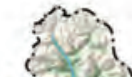

$x=2019$

Yxuman

l.

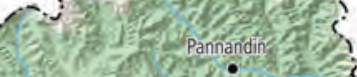

$\square$ Closed to open forest (\$40\% coverage)

- Regionstate boundat

Nawngmun 3 iो

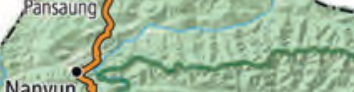

Sumprabum

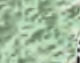

of 2 in

Isawlaw wis

$\left\{\right.$ Injangyang $a^{\text {Chipwi }}$
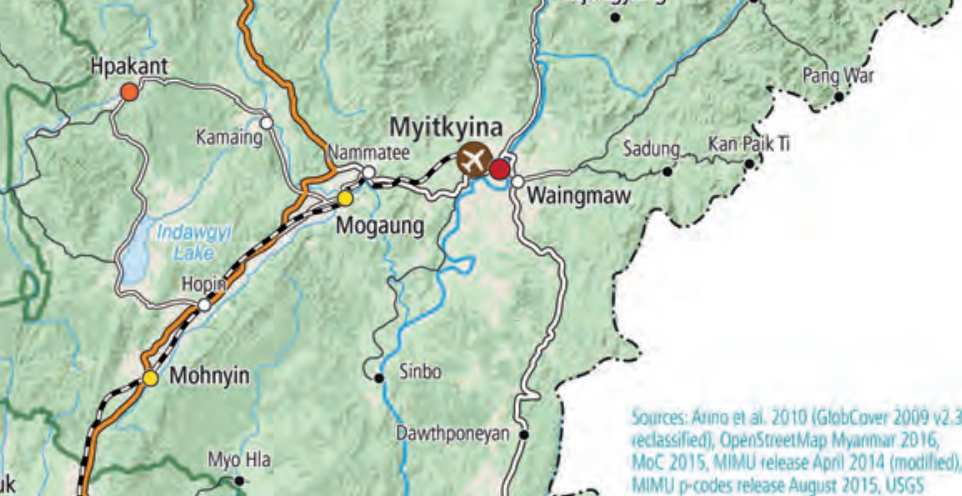

MiMU p-codes relezse August 2015. USG 
Urban population 2014
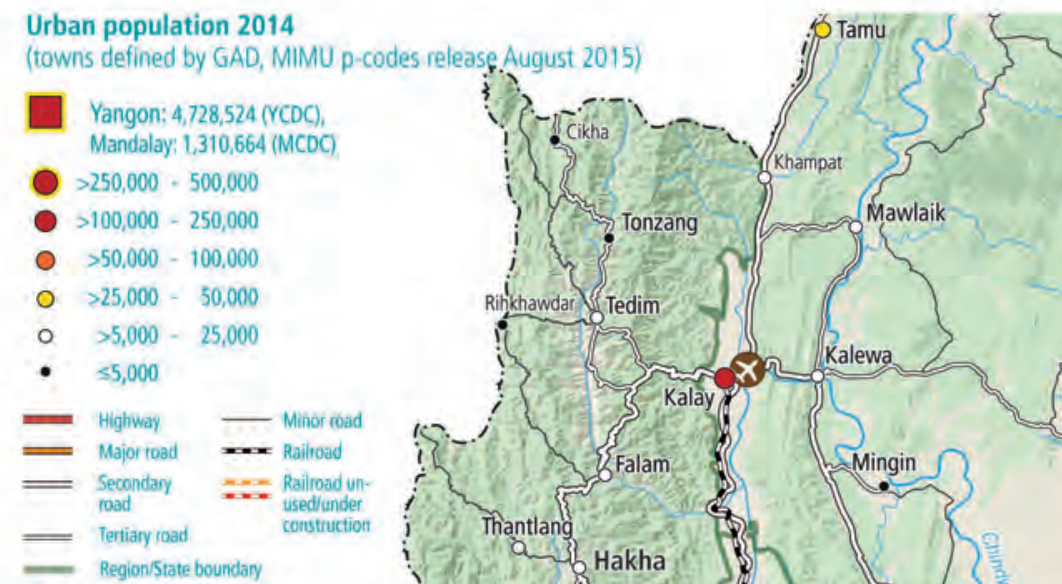

8 international airportunder construt

\section{O}
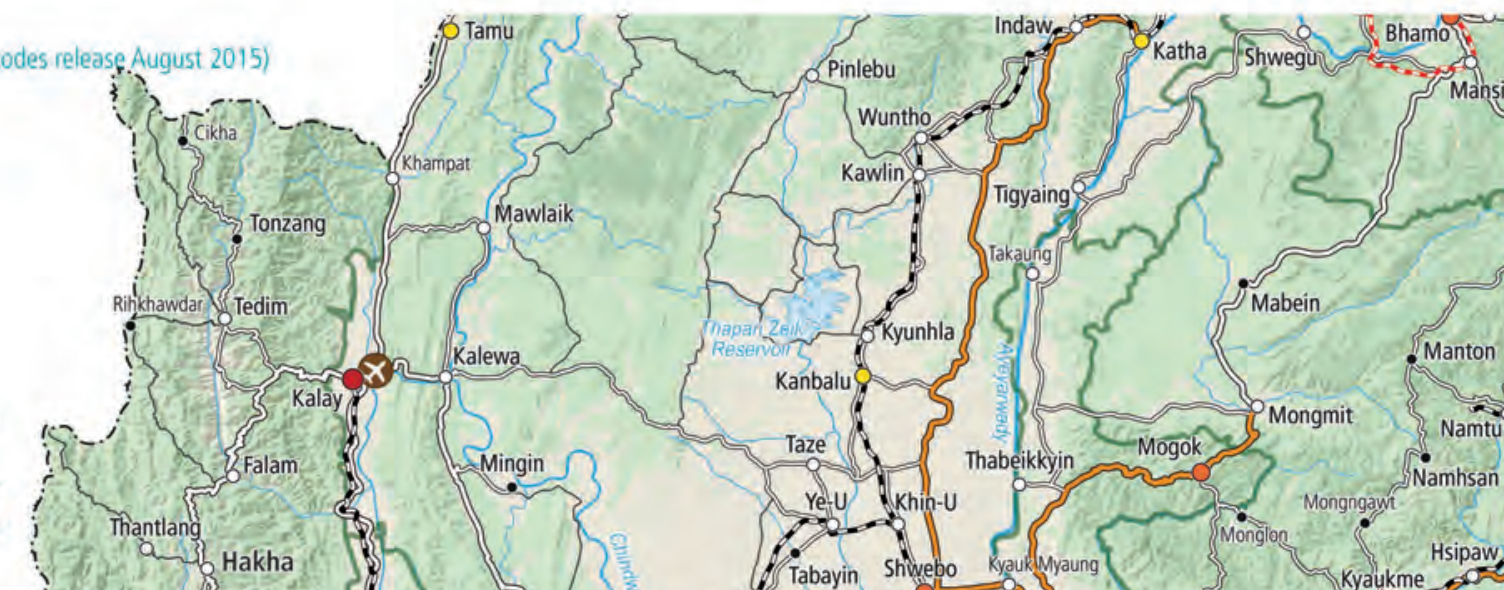

Kanbalu

Mogok 3 Mongmit $\}$ Namtu
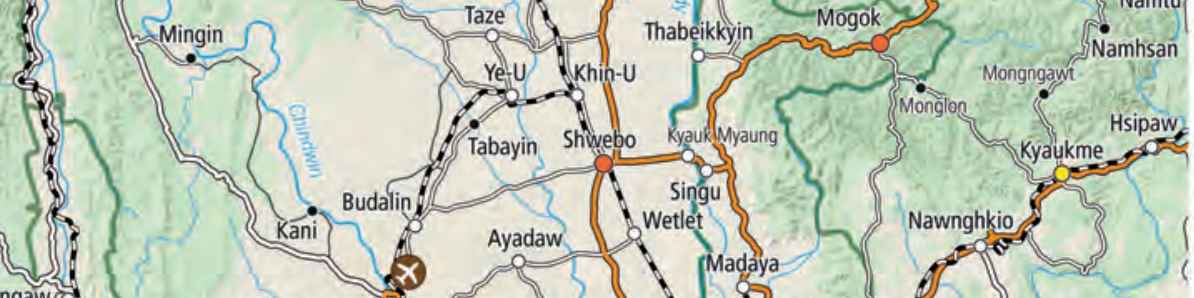

Deep 5es Port dornestic coastal traflici
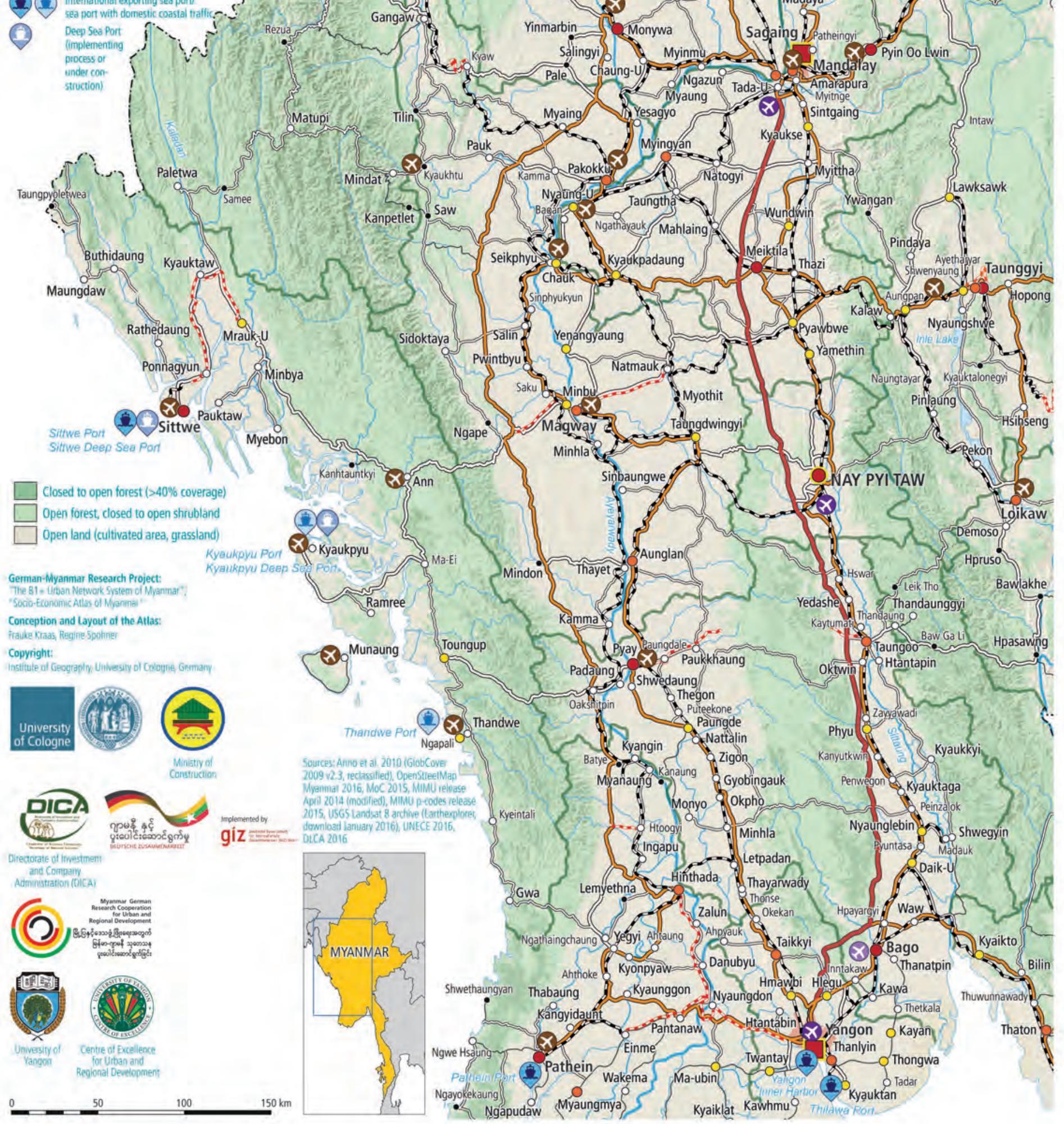


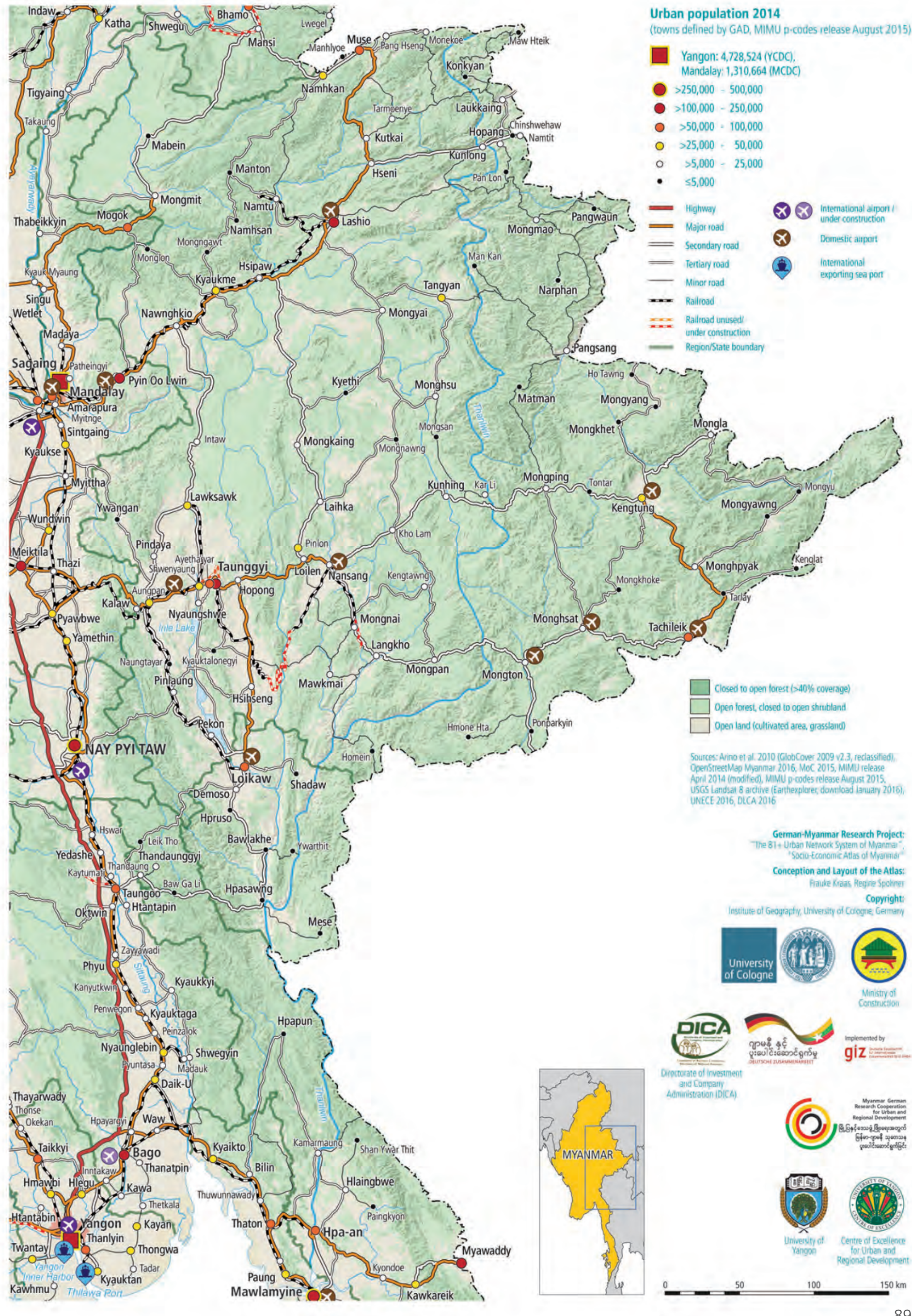


(Florento/Corpuz 2014: 9-11). Expansion of the infrastructure and development corridor from Mandalay to Muse has been under way for some years (Fan 2011, Zhao/Yang 2012). The first priority for the new schemes is to develop the border sections of Asian Highway 1 (from Kalay via Kalewa to Monywa in the west and from Myawaddy via Kawkaraik in the east) and Asian Highway 2 (specifically, from Kengtung to Taunggyi) as part of the India-Myanmar-Thailand trilateral highway project, which will ultimately result in a twolane rapid transit route from Manipur (India) to central Thailand (Kyaw Min Htun et al. 2011). And for northern Myanmar, longterm development plans are in place for roads which faded into oblivion after independence, including the Zawkhawdar-Rhi and Nampong-Pangsu routes (the former Ledo/ Stilwell Road; Kyaw Min Htun et al. 2011: 186, Florento/Corpuz 2014: 10-12, Yhome 2015a). Other bilateral and large-scale projects are being implemented as part of the Asian Highway schemes, including the Asian Development Bank's GMS corridor (Duvall 2008, ADB 2012b). Plans are also in place to establish a Myanmar-Lao PDR-Viet Nam Trilateral East-West Corridor.

Currently, road transportation, as compared to other modes such as rail and inland waterways, is the most important public service for logistics; this applies to both passenger and cargo transport. The Ministry of Construction (MoC) has responsibility and has proposed a long-term strategy for road transportation involving a network of seven plus five expressways. Strategy formulation is supported by Korean experts from KOICA. This envisages five expressways for the South-North axis and seven for the East-West axis. MoC further recommends 6 packages of road network development which are prioritised for mid-term planning in accordance with national development policy. They are Mandalay-Myitkyina, Pathein-Monywa-Shwebo, Minbu-AnnKyaukphyu Deep Seaport, Yangon-Mandalay, Thilawa SEZ-Thanatpin-Kyeikhto, and Yangon-Pathein-Ngayokkaung.
The development of the border crossing points is also important and is an area where good progress has been made in recent years, notably in Muse, Tachileik and Myawaddy. Along the 1,643 km border between Myanmar and India, there are currently four Land Customs Stations (LCSs), of which the Moreh-Tamu LCS (open since 1995) is the busiest, whereas Champai-Rih (since 2004) and Nampong-Pan Saung handle relatively low volumes of trade. Avakhung-Pansat/Somrai is still at the planning stage (Das 2014). The lack of modern infrastructure and inadequate security continue to pose problems, with informal trade, smuggling, bribery and human and narco-trafficking adversely affecting cross-border relations (Florento/Corpuz 2014: 3-9). Also planned for the long term, with the Kaladan Multi-Modal Transit Transport Project, is the expansion of the route between Sittwe in Myanmar and Mizoram in India; this is being driven primarily by India as a solution to North-East India's landlocked situation (Yhome 2015a, 2015b).

The Port of Yangon currently handles more than two-thirds of Myanmar's ship-bound exports and imports $(76.3 \%$ of net tonnage in 2017/15; MNPED 2015: 420). A new terminal is being constructed in Thilawa, linked to an industrial zone with a special economic zone (SEZ). In addition, deep-sea ports are being constructed in Kyaukphyu (Rakhine State), Kalegauk (Mon State), Dawei and Bokpyin (Tanintharyi Region) (Kyaw Min Htun et al. 2011: 190-195, Florenzo/Corpuz 2014: 14-17).

The Trans-Asian Railway (TAR) project is based on plans devised in the 1960s to establish a $14,000 \mathrm{~km}$ rail link between Singapore and Istanbul. Currently, the entire TAR network consists of $117,000 \mathrm{~km}$ of railroad. A new line from Jiribam via Imphal to Moreh will connect Myanmar's section of the route from Tamu via Kalay and Segyi and between Thanbyuzayat, Namtok and Kanchanaburi to the Singapore-Kunming Railway Link (SKRL) (Florento/Corpuz 2014: 13-15).

Frauke Kraas, Aye Aye Myint, Hlaing Maw Oo and Myint Naing 


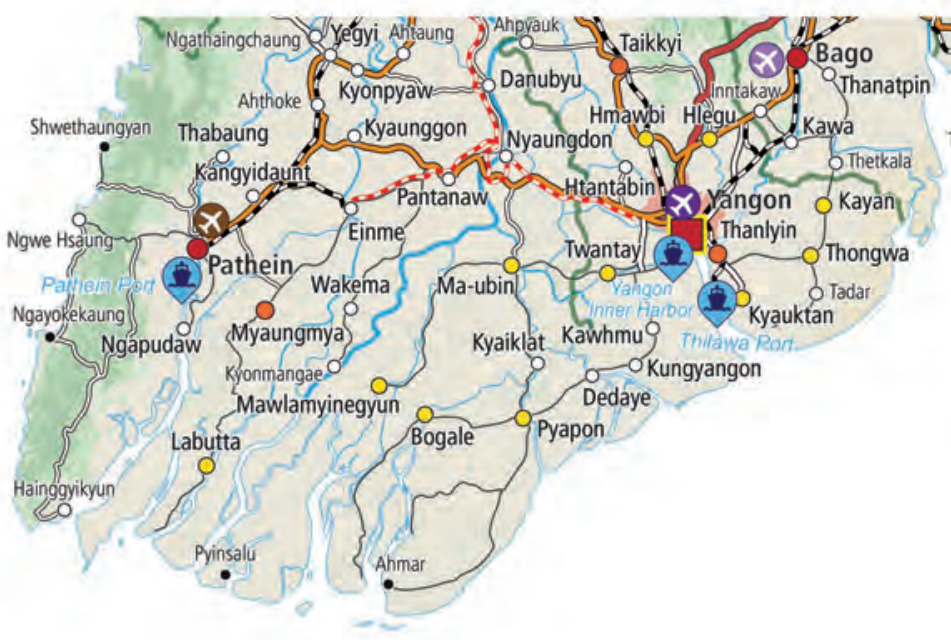

Urban population 2014

(towns defined by GAD, MIMU p-codes release August 2015)

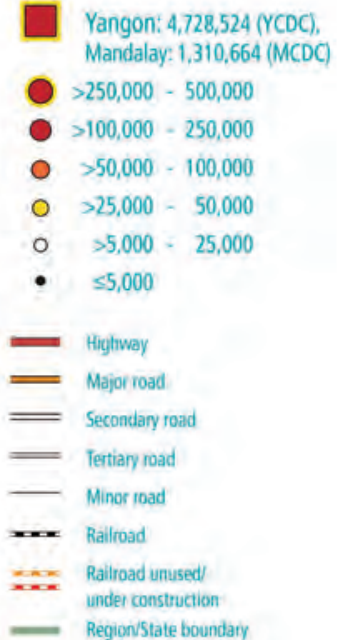

- Region'state boundary

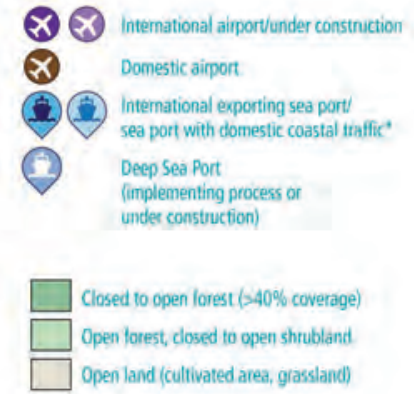

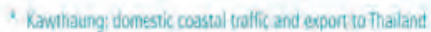
Sources: Aino ef a), 2010 (GlobCover 2009 v2 3), rediassilledt). OpenStreetMap Mvininar 2016, Moc 2015, MiMUL release Agil 2014 (modilied), MiMu p-odes release August 2015 , UNECE 2016 DLCA 2016

German-Myanmar Research Project: The 81+ Uitanil Network Systent af Myantma Socio-Economic Atlas of Myanmar"

Conception and Layout of the Atlas: frauke Krak Regine Spotine

Copyright:

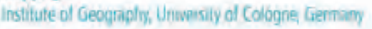
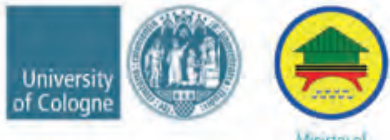

Ministiy of

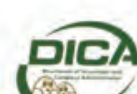

需 Directorate of linvestinat

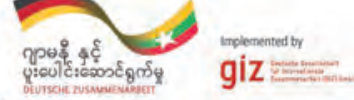
Actrinistation iDicas

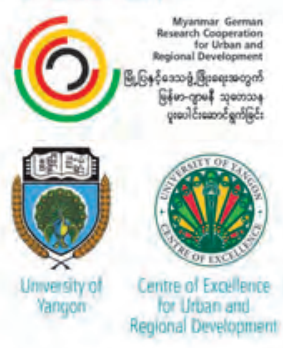

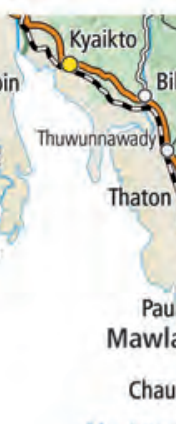

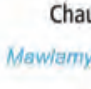$$
\text { Kya }
$$

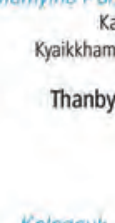

Kalagauk
Deep Sea Port

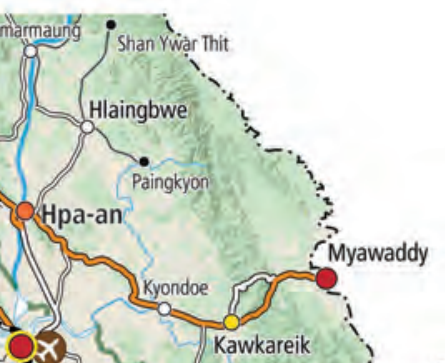
Myawaddy Lamaing?

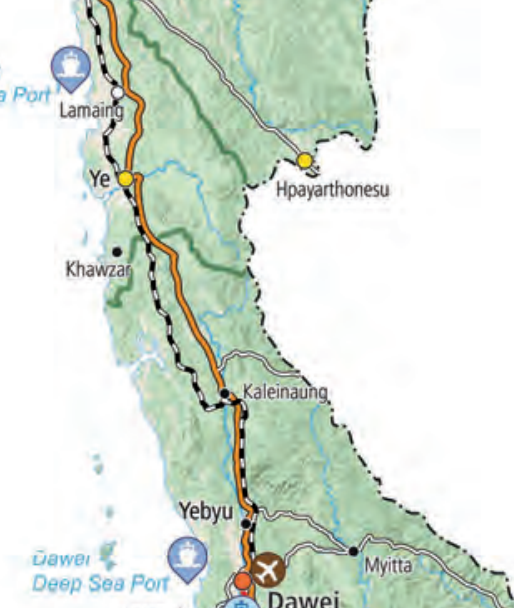
Dेawer \&ै
Deep Ses
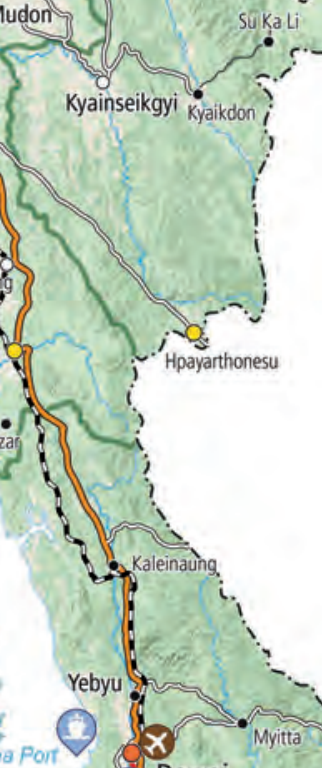

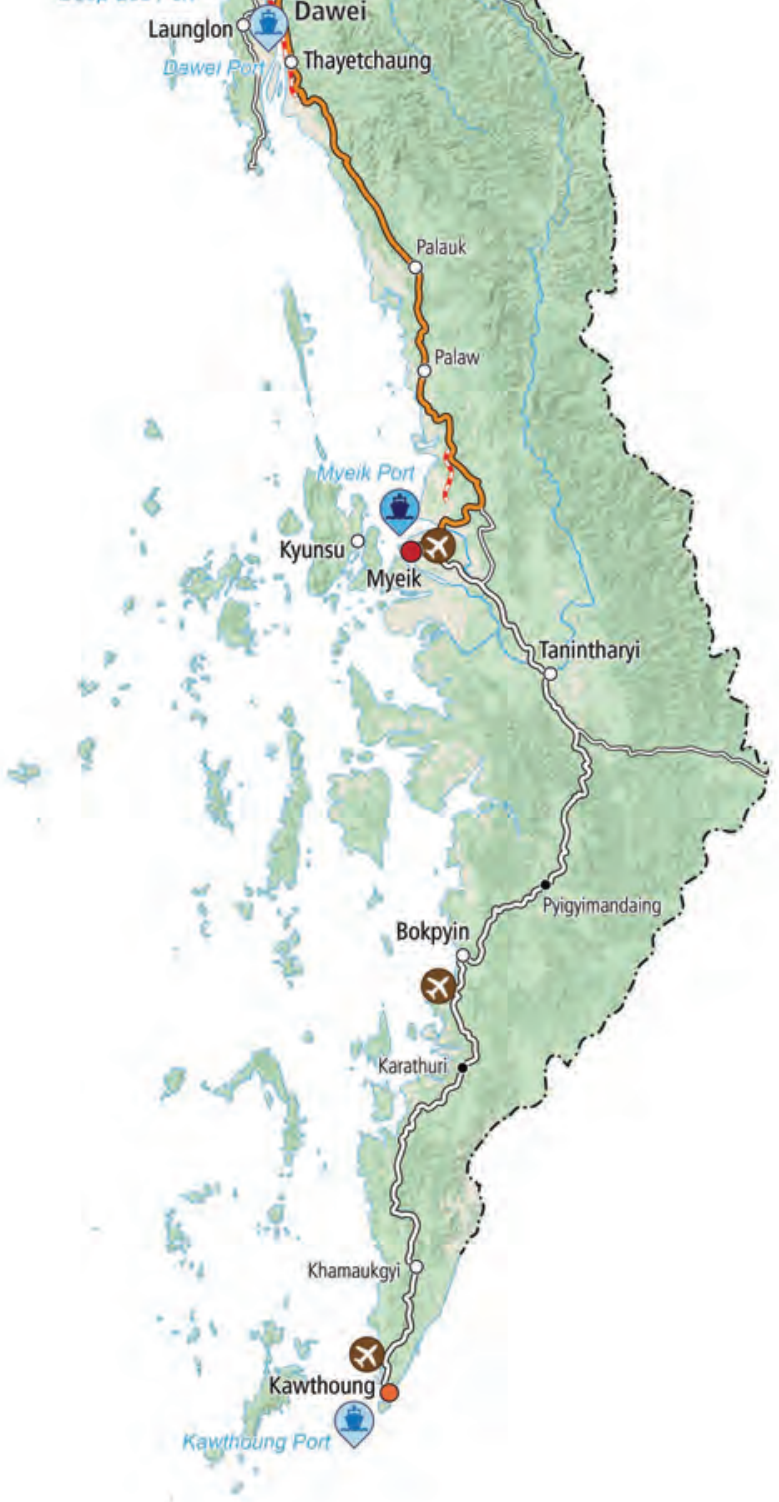




\section{ENERGY SUPPLY}

Myanmar's energy sector continues to develop. The installed energy capacities available have increased from $980 \mathrm{MW}$ (2000) to 3,735 MW (2013); of these $2,780 \mathrm{MW}(66.9 \%)$ are produced using hydropower, 996 MW (29.5\%) from natural gas and $120 \mathrm{MW}$ (3.2\%) from coal (Hennig 2016: 1234-1235). However, despite expanding production in the natural gas sector, mostly based on foreign investment, only a very small proportion is used for domestic energy supplies due to existing export obligations. From 2000 to 2013 electricity consumption in Myanmar increased threefold to 10,112 GWh, but the country remains nonetheless among those with the lowest per-capita energy consumption in the world: $165 \mathrm{kWh}$ (Hennig 2016: 1235).

The areas with the best energy supplies are Nay Pyi Taw, Yangon and Mandalay, followed by a few regional centres. The supply to several regions on the border to China (in the north and east of Shan State and Kachin State) is also relatively good, as cross-border trade and concessions for the extraction of raw materials provide higher incomes and better infrastructure in the locality. However, in the majority of the country less than half and often only a quarter of households have access to electricity. The peripheral mountain areas of Rakhine State, Tanintharyi Region and parts of Kachin State are characterised by poor energy supplies with less than $5 \%$ of all households having access to electricity, for instance for lighting. Energy supplies in Chin State are not quite as poor, a situation that can be attributed to external support provided by charitable organisations, civil society initiatives and available remittances. Also, energy is at some locations delivered across the border from India.
Thirty hydropower plants are currently in existence, 29 of them with a capacity of less than $10 \mathrm{MW} ; 17$ are multipurpose dams that store water for irrigation as well as for electricity production and also help control flooding (ADB 2013). Three of the 15 largest hydropower plants were erected before 2000. These include the Baluchaung-2-Project, built in 1960 and financed by post-war Japanese reparations, which supplies electricity primarily to Yangon and Mandalay. Other large-scale projects, including the Kinda Multipurpose Dam and Yeywa, supply Mandalay and Nay Pyi Taw (Hennig 2016: 1237).

Estimates suggest that it would be possible to develop 302 potential hydropower locations with a total capacity of up to $46.3 \mathrm{GW}$ in Myanmar (Hennig 2016: 1236). The controversial large-scale project of the Myitsone Dam at the confluence of N'Mai Hka and Mali Hka with the Ayeyarwady River was suspended by the Thein Sein government in 2011 due to strong public reservations (Sun 2012, Simpson 2013, Kirchherr/Charles/Walton 2016, Kirchherr et al. 2017). A number of other projects, proposed mostly by China but also by India and Thailand - for instance Nawchanka and Shweli or Tamanthi, Shwesyay and Mawlight on the Chindwin - largely or wholly for the export of energy to China and India, were in 2013 also suspended (Hennig 2016: 1237-1238, Kirchherr/ Charles/Walton 2016, Mizuno 2016, each with lists of possible future projects). There has to date been no comprehensive, independent reevaluation of planned projects that assesses ecological, economic, social and political factors.

Frauke Kraas, Aye Aye Myint and Myint Naing 
Medium and large hydro and thermal power plant projects 2015 (>10 MW)

\begin{tabular}{|c|c|c|c|c|}
\hline $\begin{array}{l}\text { Type of } \\
\text { power plant }\end{array}$ & operational & $\begin{array}{c}\text { under } \\
\text { construction }\end{array}$ & $\begin{array}{l}\text { planning } \\
\text { process }\end{array}$ & $\begin{array}{l}\text { no status } \\
\text { information } \\
\text { suspended }\end{array}$ \\
\hline water & & & & \\
\hline coal & & & & \\
\hline gas & & & & \\
\hline steam & & & & \\
\hline steam/coal & & & & \\
\hline
\end{tabular}

Installed/proposed capacity (MW)

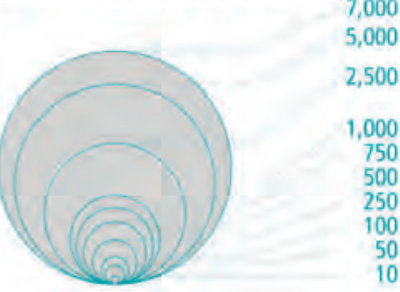

Major hydrobasins

13 Ayeyarwady

Thanlwin

[1]III] Sittaung

I. Mekong

VII] Bay of Bengal

Peninsula Malaysia

Ganges/Brahmaputra

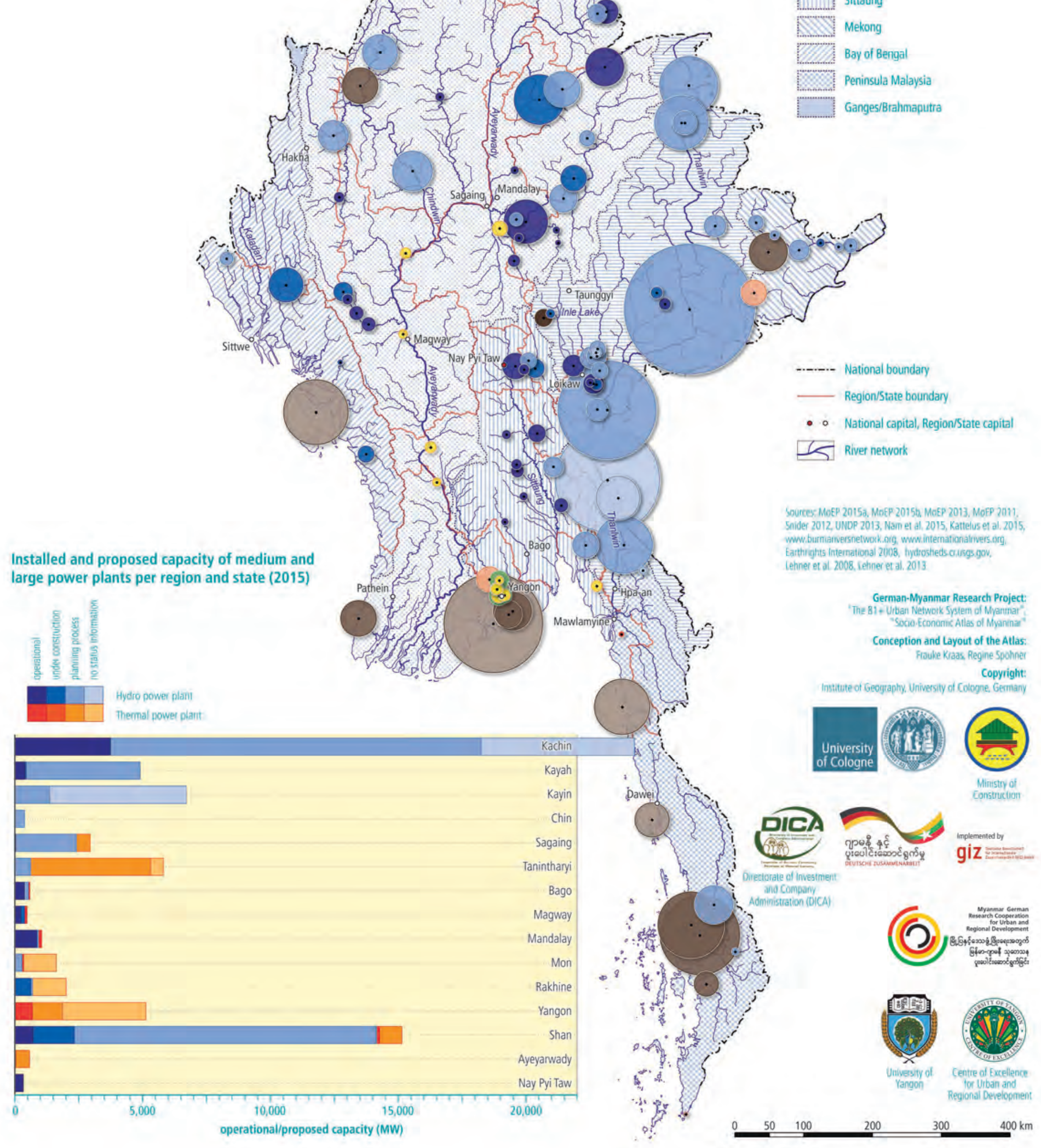




\section{TELECOMMUNICATIONS}

Starting with the first post office in 1854, the first military telegraph office in 1861 and the establishment of a public telegraph service from 1895 (KTAM Report 1953: 495, Hla Tun Aung 2003: 552), the telegraph system had expanded to almost $50,000 \mathrm{~km}$ of wire by the Second World War, with 656 stations, 331 of them owned by the railway administration (Storz 1967: 166). The first telephones were installed in 1888; from 1904, wireless radio broadcasters were producing news bulletins for shipping and aviation. The first Burma broadcasting station was set up in 1937, telex was introduced in 1971 and telefax followed in 1987 (KTAM Report 1953: 495, Hla Tun Aung 2003: 556).

Reconstruction of the postal and telegraph network, which was badly damaged during the war, commenced in the 1950s, initially with an emphasis on the more secure airmail system and wireless telephony, which offered greater reliability during the campaign against insurgents. Wireless lines and landline facilities were then progressively improved during the 1960s. The international telephone and telegraph service, which before the war relied on a connection via Madras, became more international in focus after 1960 with connections via other Asian cities.

From the 1990s, the mobile services began to evolve: 'MPT launched a variety of cellular systems in the major urban areas, such as Advanced Mobile Phone Service (AMPS), Digital Advanced Mobile Phone Service (D-AMPS), International Direct Dialling Service, Wireless in the Local Loop (WLL) automatic radio telephone systems (TDMA), Digital European Cordless Telecommunications (DECT) radio telephone system and CDMA ... MPT launched GSM in Yangon and Mandalay in 2002, and W-CDMA in 2008' (Thaw Tar Min/Fife/Bohlin 2014: 5/6).

\section{MODERNISATION}

As part of the liberalisation from 2010, the telecommunications sector was restructured. Nonetheless, until 2014, Myanmar Post and Telecommunication (MPT) was the only nationwide provider of mobile services, mainly serving Yangon, Mandalay and Nay Pyi Taw. With the subsequent award of nationwide licences, first to two local providers (MPT and Yatanarpon Teleport YPT) and then to two foreign operators (Telenor und Ooredoo), the number of mobile phone and internet users has rapidly increased.

Due to restrictive controls and the impossibility of expanding the telecommunications sector for many years, Myanmar has been dubbed a 'telecommunications greenfield' or the 'last frontier' in the global context (Goeres/White/ Tun 2013, Fife 2014). The few studies which exist describe the major expansion potential in detail (Ericsson 2012, Chhor et al. 2013, Goeres/White/Tun 2013, Fife 2014, Thaw Tar Min/Fife/Bohlin 2014).

In 2014, Myanmar was reported to have 0.98 telephone lines per 100 population and 54.04 cellular subscriptions per 100 population. The number of internet users was reported as 2.1 per 100 population (all figures: ADB 2016; also see Johnsson 2014). The official statistics for 2014/15 (MNPED 2015: 441) refer to 18,405,814 telephones nationwide, including 5,844,375 in Yangon. The number of MPT mobile phones rose from $13,480(2000 / 01)$ to $1,637,629$ $(2011 / 12)$ and then $17,839,244$ (including $5,590,071$ in Yangon), with Telenor accounting for a further 6,400,000 and Ooredoo 3,329,000 (figures for 2014/15; MNEPD 2015: 441).

The greatly improved provision is concentrated on the urban areas, with rural regions still underserved. The highest number and density 

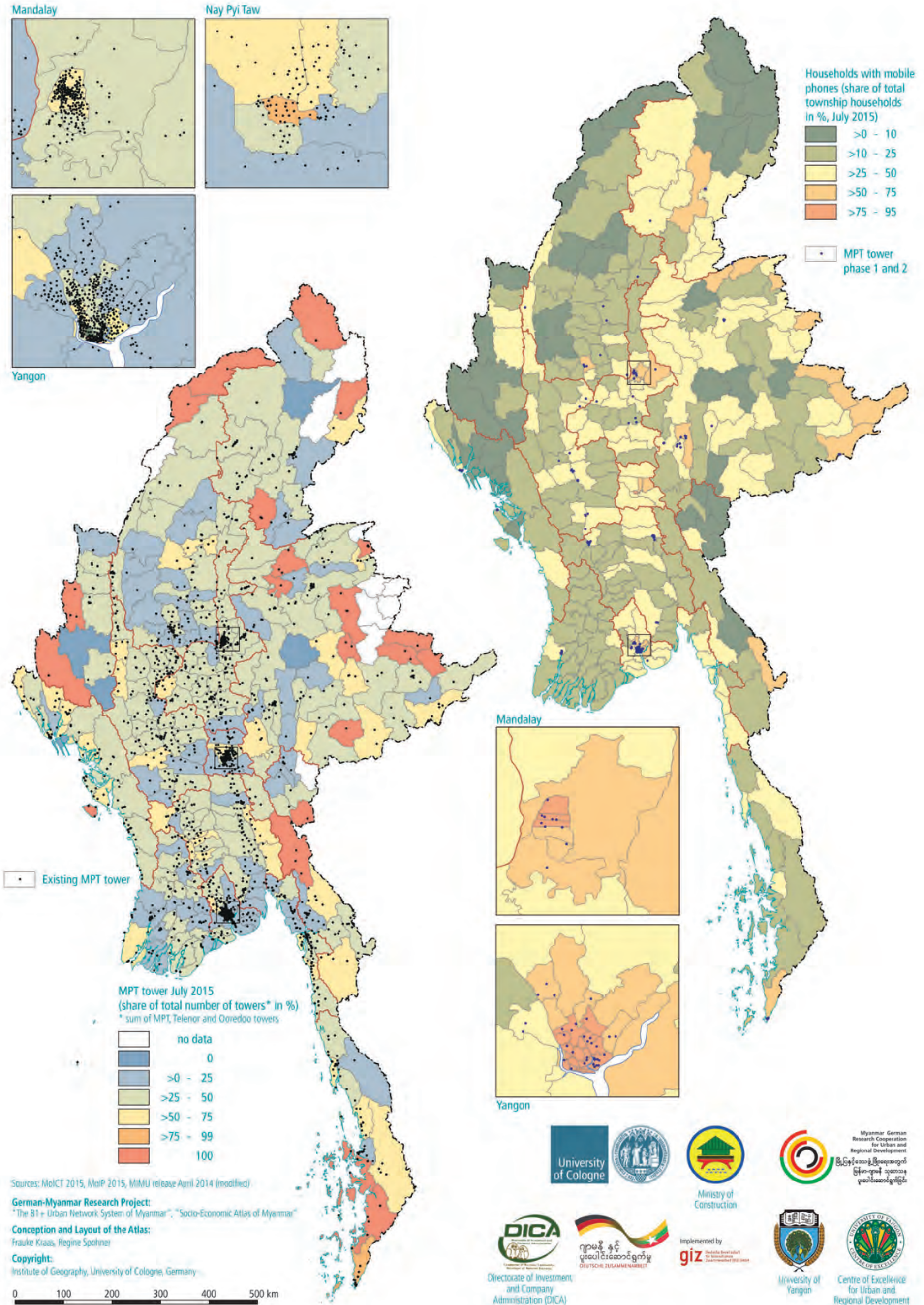

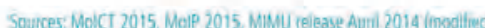

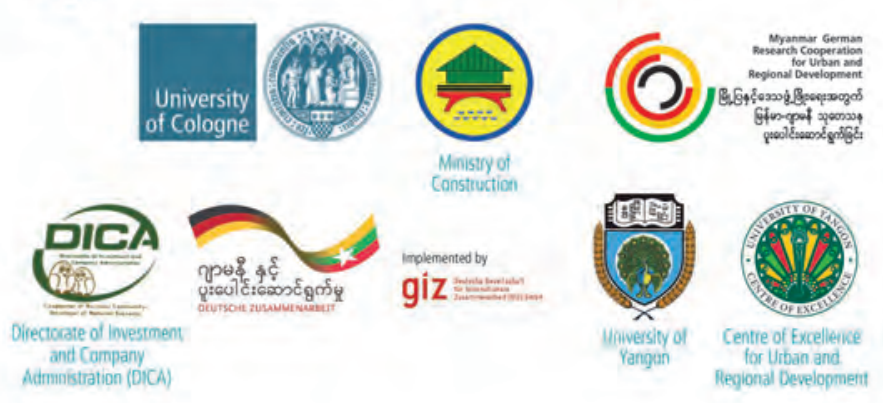


of the MPT towers are found in urban areas and along the country's main transport routes; provision is much poorer in the rural, mountain and peripheral regions. This is reflected in the low level of household mobile phone ownership, but it is also noticeable that the number of households with mobile phones in border regions (especially to China and Thailand) is very high along stretches with higher population densities. As regards the distribution of the towers owned by private providers (Telenor and Ooredoo), it is noticeable that preference was given first to urban and densely populated areas.

\section{MOBILE COMMUNICATION}

The use of mobile communications shows Myanmar-specific traits:

- The main user group is the young and educated population, particularly the 18-34 age group and university graduates (Thaw Tar Min/Fife/Bohlin 2014: 15).

- Many users share a mobile phone with family members and friends, largely on account of the high purchase costs of handsets and expensive phone tariffs.

- The main motive for having a mobile phone is for use in emergencies (96\%), convenience (95\%), communication (94\%), time-saving (92\%) and direct access to information (90\%) (Thaw Tar Min/Fife/Bohlin 2014: 11).

- The predominant forms of use are voice calling (83\%), texting (52\%) and social network- ing (43\%) (Thaw Tar Min/Fife/Bohlin 2014: 13) - a user preference which reflects and compensates for the difficult and expensive general transport situation in Myanmar.

- When asked about the most important functions and services that should be further expanded, community information is the first preference (40\%); almost one third of respondents would like to see the expansion of healthcare services via mobile phone, a further 23\% mention job opportunities and $6 \%$ want to see a rollout of mobile money transfer services (Thaw Tar Min/Fife/Bohlin 2014: 13).

As regards the further expansion of mobile communications services in particular, the providers are pursuing different strategies: due to the inadequate UMTS infrastructure, 3G is available only to a very limited extent and LTE $(1800 \mathrm{MHz})$ is still in its infancy. In cooperation with France Telecom/Orange, MPT launched international roaming services for GSM and WCDMA in 2014 (Thaw Tar Min/ Fife/Bohlin 2014: 5/6). 'Telenor has intended to implement $2 \mathrm{G}$ network in rural areas and both $2 \mathrm{G}$ and $3 \mathrm{G}$ networks in urban centers. ... Ooredoo has decided to jump directly to $3 \mathrm{G}$ networks, providing both $3 \mathrm{G}$ and $4 \mathrm{G}$ networks in urban areas and 3G in rural areas' (Thaw Tar Min/Fife/Bohlin 2014: 6).

Frauke Kraas, Aye Aye Myint and Myint Naing

\begin{tabular}{|r|r|r|r|r|r|r|} 
& $2010-2011$ & $2011-2012$ & $2012-2013$ & $2013-2014$ & $2014-2015$ & $\mathbf{2 0 1 5 - 2 0 1 6}$ \\
\hline $\begin{array}{r}\text { NUMBER OF } \\
\text { INTERNET USERS }\end{array}$ & $\mathbf{5 9 1 , 3 2 0}$ & $\mathbf{6 9 2 , 4 4 3}$ & $\mathbf{1 , 0 9 2 , 1 2 1}$ & $\mathbf{2 , 7 7 7 , 2 1 8}$ & $\mathbf{1 7 , 9 8 8 , 5 7 0}$ & $\mathbf{3 9 , 4 3 8 , 7 5 8}$ \\
\hline GOVERNMENT & 68,784 & 183,427 & 256,898 & 28,354 & 36,050 & 42,506 \\
\hline PUBLIC & 522,536 & 509,016 & 835,223 & $2,748,864$ & 223,374 & 273,599 \\
\hline MPT SATELLITE & & & & & 8,720 & 8,850 \\
\hline MOBILE & & & & & $17,720,426$ & $39,113,803$ \\
\hline
\end{tabular}




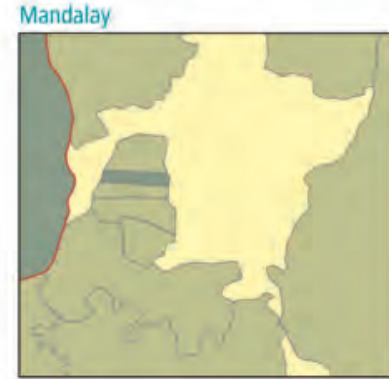

Total towers July 2015

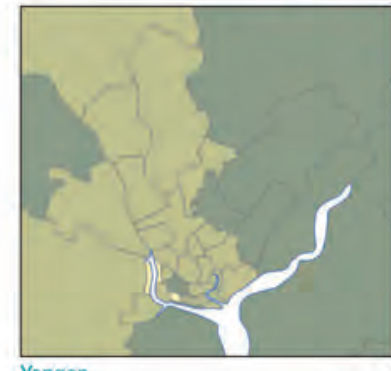

(MPT, Ooredoo, Telenor)

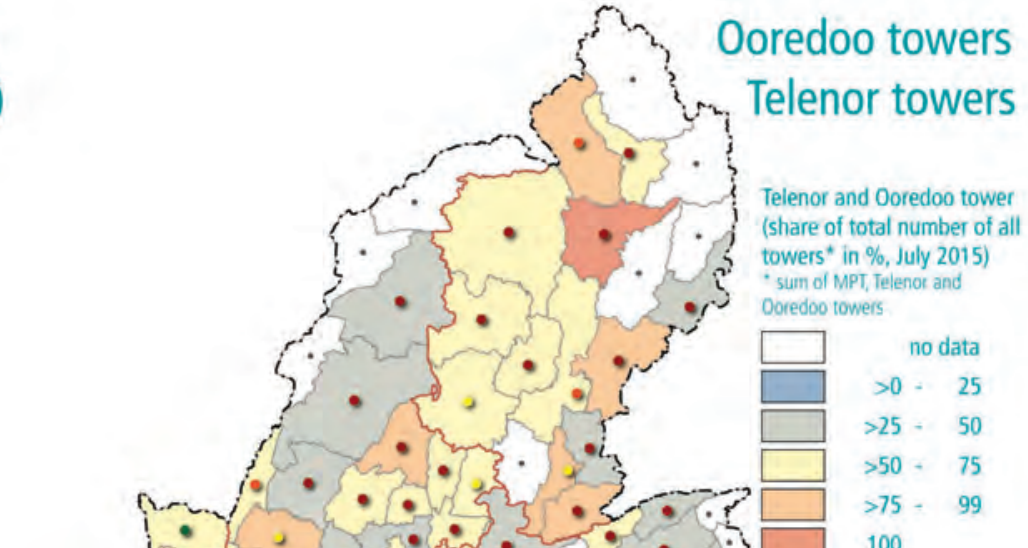

Yangon
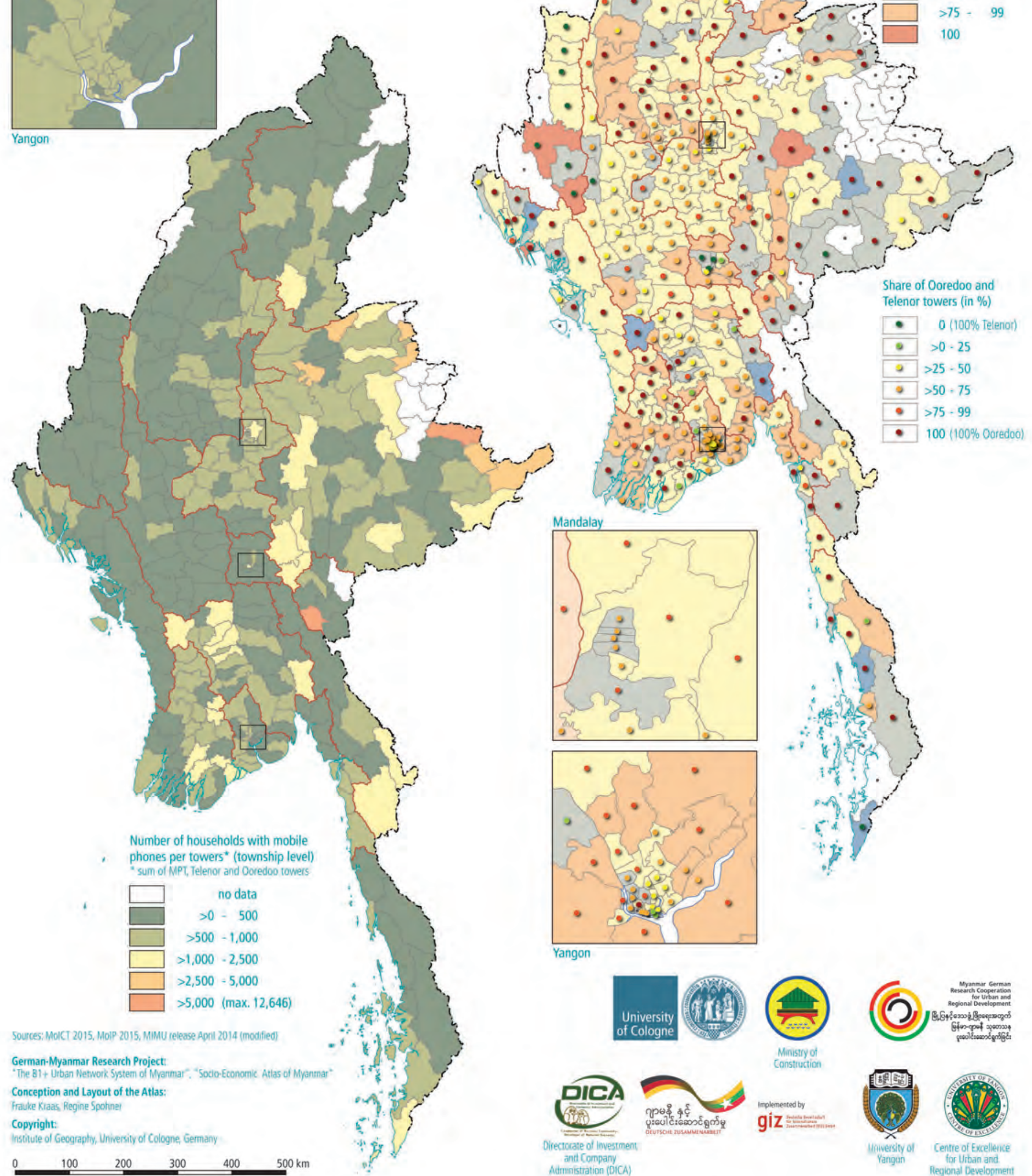

German-Myanmar Research Project

Conception and Layout of the Atlas:

frauke Kiaas, Regine Spohne

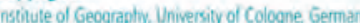
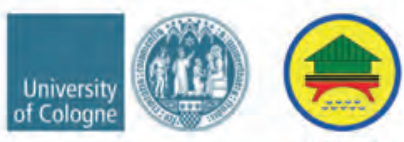

Monistry of
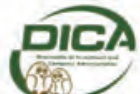

Directorate of inversment

and Company
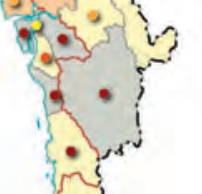

in
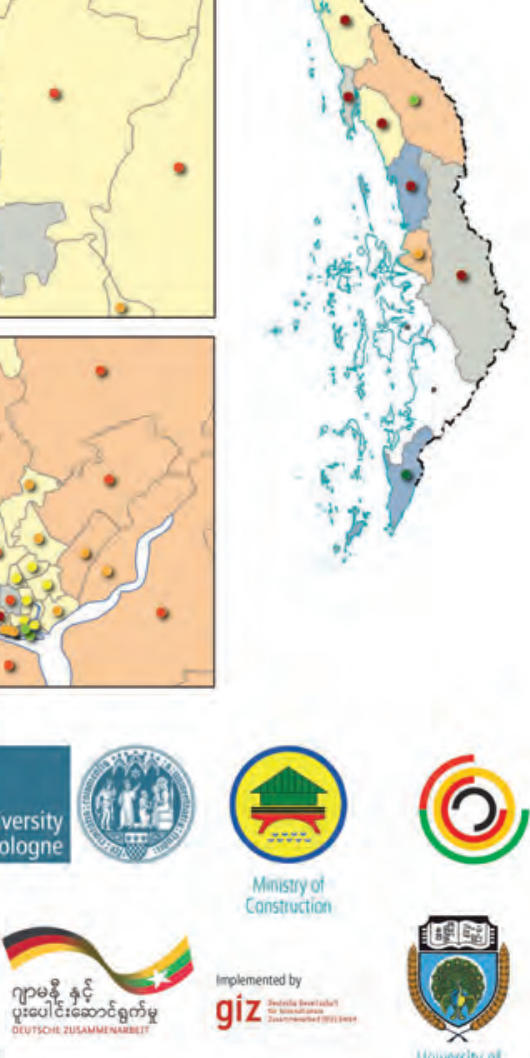
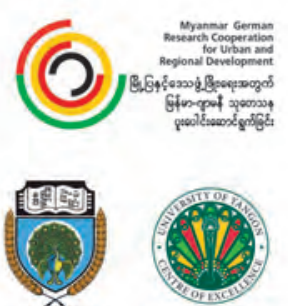

liniversity of 


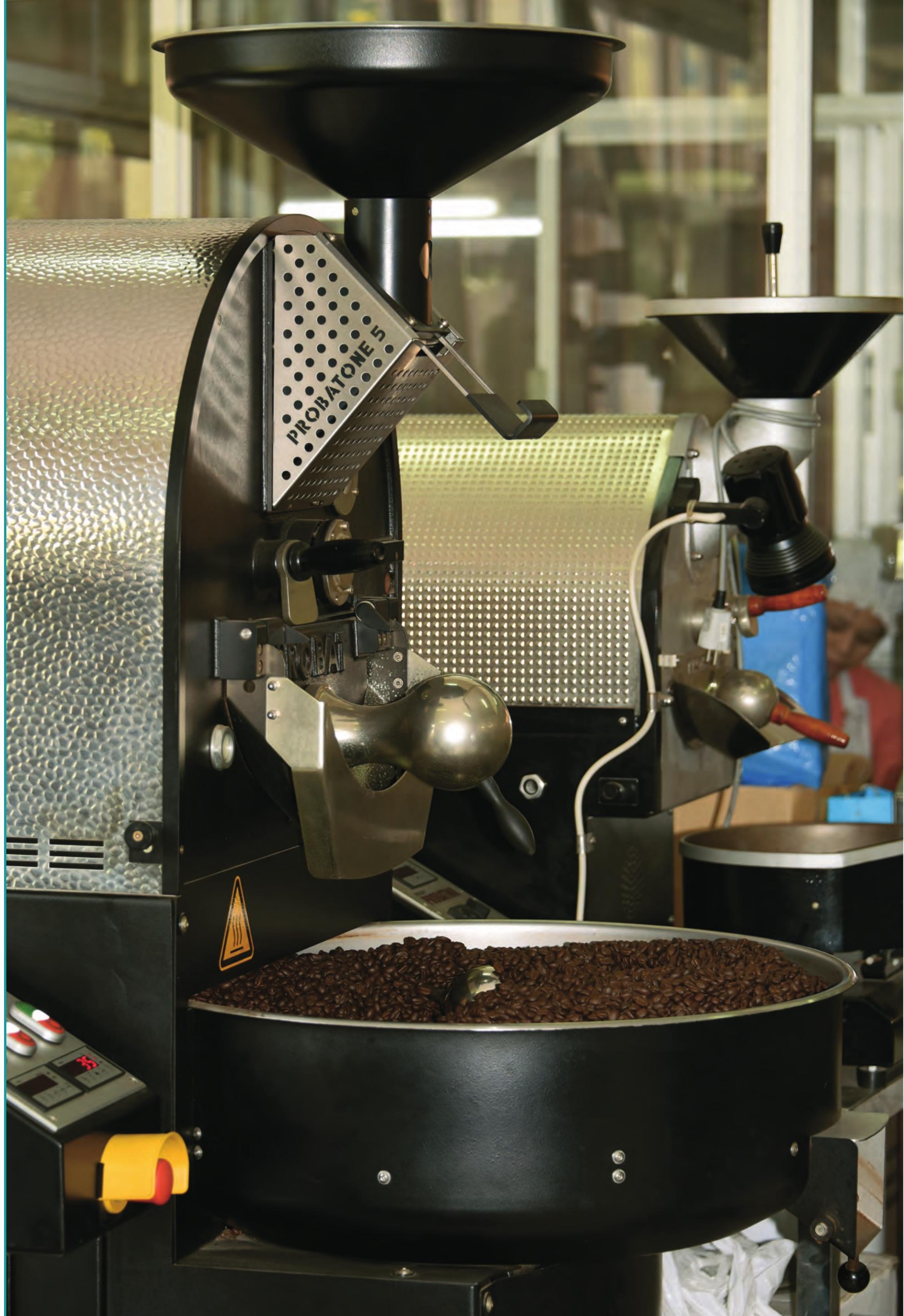




\section{ECONOMIC DEVELOPMENT}

100 GROSS DOMESTIC PRODUCT

102 DOMINATING ECONOMIC SECTORS' SHARES

104 AGRICULTURAL DEVELOPMENT

105 RAIN PADDY PRODUCTION

107 SUMMER PADDY PRODUCTION

109 CHANGE OF PADDY YIELD

110 AGRICULTURAL REGIONS

116 GROSS DOMESTIC PRODUCT: SHARE OF PRIMARY SECTOR

117 SHARE OF PRIMARY SECTOR IN TOTAL GDP

118 AQUACULTURE

122 DEVELOPMENT AND INDUSTRIALISATION

123 SHARE OF SECONDARY SECTOR IN TOTAL GDP

126 CRAFTS

128 GARMENT INDUSTRY IN YANGON

130 THE TERTIARY SECTOR: ADMINISTRATION, TRADE, TRANSPORTATION AND TOURISM

131 GROSS DOMESTIC PRODUCT: SHARE OF TERTIARY SECTOR

133 TOURISM CENTRES AND REGIONS 


\section{GROSS DOMESTIC PRODUCT}

The regional breakdown of Gross Domestic Product, based on Myanmar's 330 townships (MNPED 2015), provides more detailed information about each region's contribution to the country's economy. Apart from Yangon's dominant position as Myanmar's main economic centre, what is striking about these figures is the familiar division of the country, with a strong economy in the central lowlands and comparatively weak economic performance in the mountain regions. Within these two major regions, however, there is considerable homogeneity in the economic performance of their respective townships. Overall, the figures for the lowland townships are generally 10 to 20 times higher than for the mountain regions.

The figures for the contributions to Gross Domestic Product by township mirror the high absolute values for the cities and towns with an industrial base and service sector. Leading the field is Yangon with 11.85 million Kyats, Mandalay with 2.56 million Kyats and Nay Pyi Taw with 1.42 million Kyats (2014-2015; MNPED 2015). Yangon's contribution is almost five times higher than Mandalay's. Within Yangon, the contributions of the townships which host the major industrial zones stand out, particularly Hlaingtharyar, Dagon Myothit and Insein. Some regional cities are also notable on account of their high absolute values for GDP, primarily Bago and Pathein (whose administration covers the tourist areas of Chaungtha and Ngwe Hsaung). Also striking are the substantial contributions made by the specialised regions, including the productive agricultural areas such as the Ayeyarwady Delta and the central lowlands and the prosperous mining regions, e.g. Thabeikkyin with its gold mines and Kalaymyo with coal, nickel, copper and cobalt production. By contrast, most of the mountain regions are lagging far behind. The contribution made by some trade-oriented border crossings and corridors also stands out; examples are the corridors from Muse to Lashio and from Tachileik to Kengtung.

The data offer important insights into trends in the generation of GDP in Myanmar. However, their informative value should not be exaggerated, as some factors are fully or partially excluded from the calculation of GDP, such as the substantial contribution made by subsistence farming, by unremunerated domestic work or work in family businesses, and by the informal sector, shadow economy and unregistered production, all of which are typical features of a developing country. Another obvious problem with the data is underreporting: it is surprising, for example, that the figures for major tourist regions such as Bagan and Inle Lake are not particularly high. Ultimately, Gross Domestic Product is merely an expression of traded production output (to the extent that it is officially reported), not of a region's prosperity.

Per capita GDP allows economic regions of various sizes to be compared with each other. It is also a measure of a region's material prosperity as it shows the total output of a country broken down by the number of inhabitants. However, the mean values provide no information about the actual range of the per capita values. The regional breakdown reveals high values for some cities (mainly in Yangon, Mandalay, Nay Pyi Taw and Pathein) and relatively high values for central Myanmar (e.g. around Monywa and Magway) and areas around development projects (e.g. Kyaukphyu), but it is clear that the figures for some townships need to be reviewed or analysed in more detail before they can be accurately interpreted.

Frauke Kraas and Zin Nwe Myint 


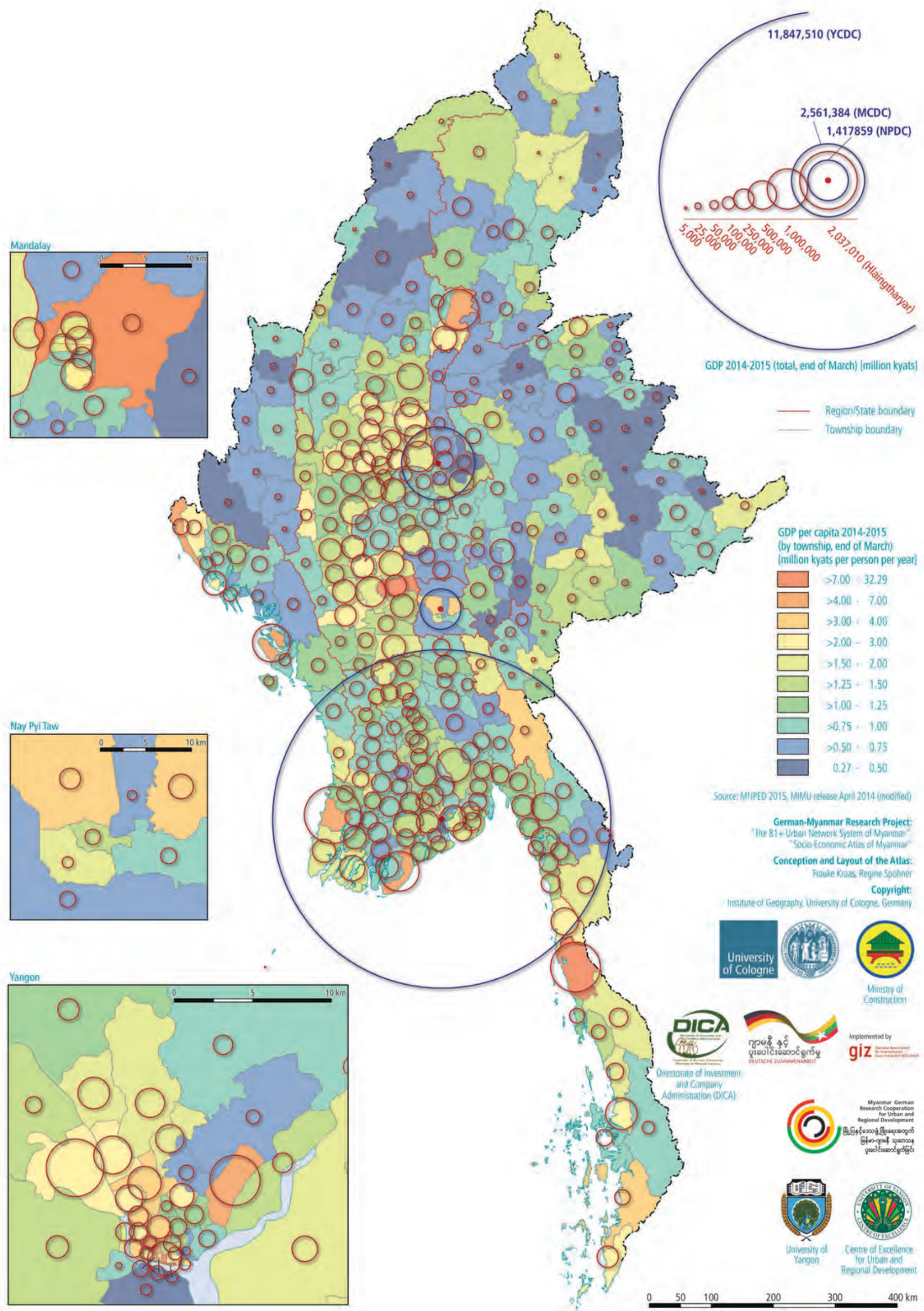




\section{DOMINATING ECONOMIC SECTORS' SHARES}

In Myanmar, the individual economic sectors make different contributions to total gross domestic product (GDP). According to statistics from the Department of Planning, the primary sector (agriculture, livestock and fisheries, forestry) generates $27.9 \%$ of GDP, the secondary sector (energy, mining, processing and manufacturing, electric power, construction) accounts for $34.4 \%$ and services (transportation, communications, financial institutions, social and administrative services, rental and other services, trade) contribute 37.7\% (MNPED 2015: 203).

If the townships are 'localised' within the sector triangle - in other words, if the percentage of GDP generated in each township is shown in terms of its dominant economic sector (primary, secondary or tertiary) - it is striking that in 86 of the 330 townships, the primary sector generates more than $50 \%$ (up to 75\%) of GDP. Most of these townships are located in the central lowlands in the dry zone and the Ayeyarwady Delta, although a small number lie in predominantly agricultural moun- tain regions. In a further 166 townships, the primary sector contributes more than 25\% (but less than $50 \%$ ) to GDP. There are only 20 townships in which the secondary sector accounts for more than 50\% (but less than 75\%) of GDP. Just three townships - Kyaukpyu, Pathein and Yebyu - are dependent on the secondary sector for more than $75 \%$ of their contribution to GDP. In 128 townships, between $25 \%$ and $50 \%$ of GDP is generated by the secondary sector. The majority of these townships are located in cities and towns across the country, indicating a broad regional spread of the secondary sector. In 40 townships, the tertiary sector accounts for $50 \%$ to $75 \%$ of GDP; in Pabedan/Yangon and Zayarthiri/Nay Pyi Taw, the figure is above $90 \%$. As expected, GDP production is dominated by the tertiary sector in urban townships and, in some isolated cases, in border regions with dynamic trade. Surprisingly, none of the main tourist regions stand out.

Frauke Kraas and Zin Nwe Myint

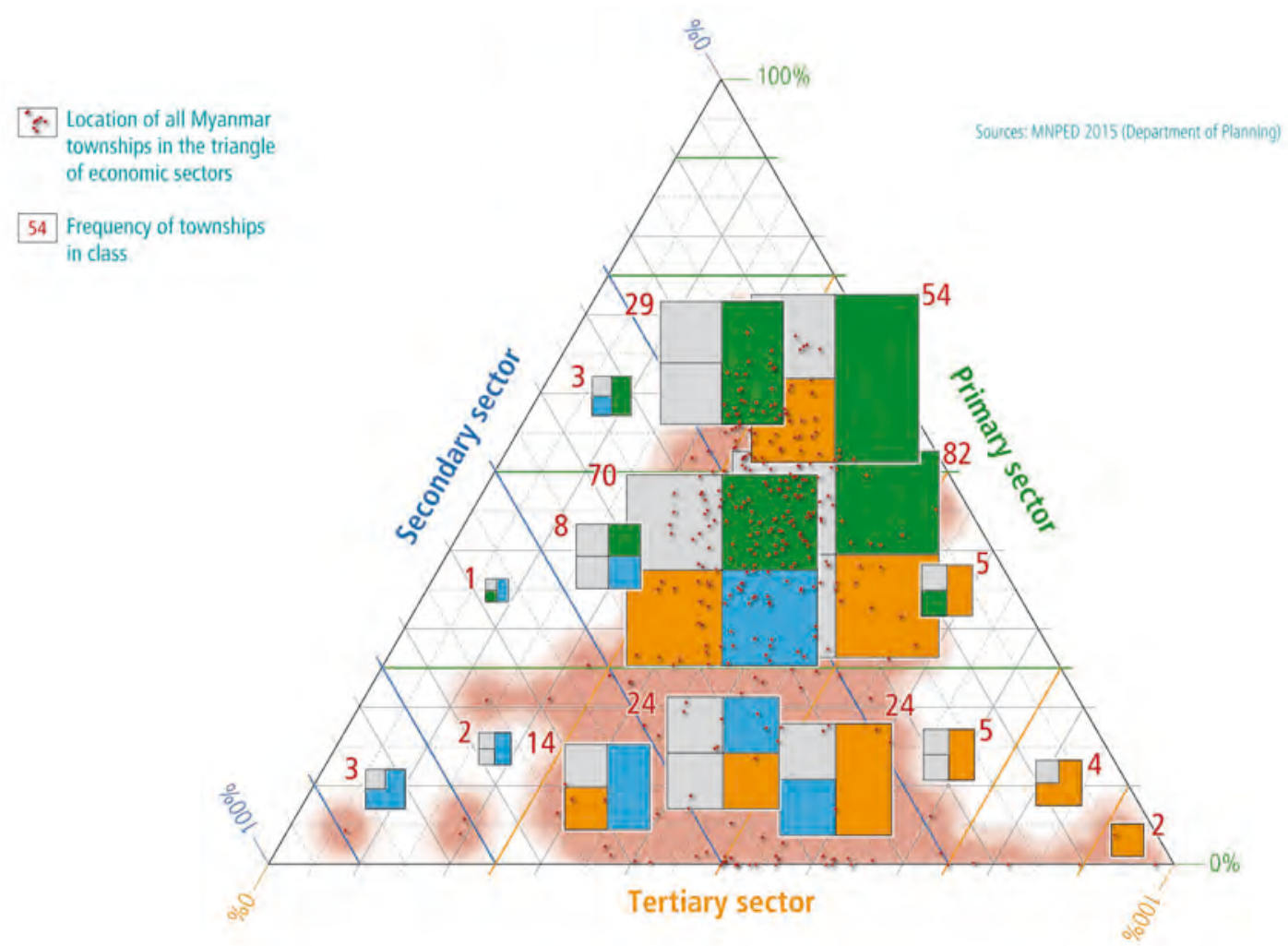




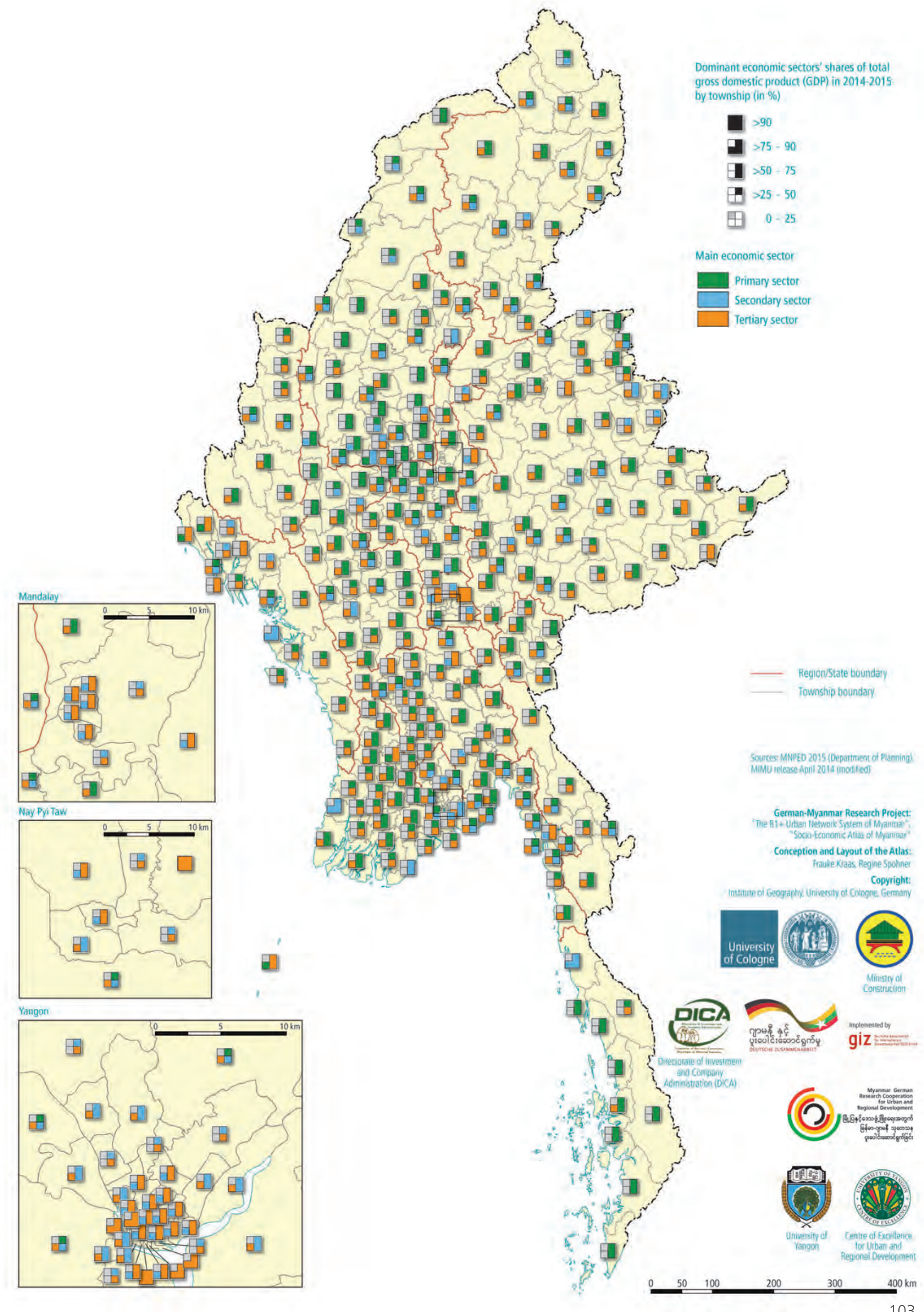




\section{AGRICULTURAL DEVELOPMENT}

Subsistence-oriented agriculture in the lowlands, on nutrient-rich soils in valley bottoms and on frequently nutrient-poor substrata on the slopes of the mountain regions, is the most important economic pillar of the country and the main basis of employment. As during the British colonial period (more than $68 \%$ employed in agriculture; Storz 1967: 157; Saito/ Lee 1999: 26) and upon the introduction of a market-oriented economy after 1988 (1990/91: 65.5\%; Saito/Lee 1999: 30), about 61.2\% (MoAI 2013) of all workers are employed in agriculture today (Khin Khin Soe/Yin Yin Lwin 2015). The sector contributes a good third of gross domestic product, i.e. $36.4 \%$ of national GDP (2012-13) and $17.5 \%$ of total export earnings (Aung Kyaw et al. 2013). About 26\% of the country's entire area is used for agriculture and permanent crops (MoAI 2013). In 2010-2011, the area under paddy accounted for $70 \%$ of the total arable area and it contributed about $30 \%$ of Myanmar's gross agricultural and $95 \%$ of total cereal output. Less than $20 \%$ of agricultural land is artificially irrigated; this is primarily located in the Ayeyarwady Delta, near the Bago Yoma dams, in the drier central area (dry zone) and parts of the north of the country.

The most important product for domestic consumption is rice. Rice is also Myanmar's main agricultural product and the second most important exportable agricultural commodity after beans and pulses, and is thus a very important income source for farmers. Total paddy production was 18,580 (000'MT) in 1995-96 and increased to 27,704 (000'MT) in 2012-13; cropping intensity increased from $140.5 \%$ in $1995-96$ to $158.3 \%$ in $2012-13$ (Settlement and Land Records Department 2013). Rice production is concentrated in the Ayeyarwady Delta and occupies about $40 \%$ of the 15.85 million ha of cultivated land (FAO
2005: 5, Aung Kyi 2006). The agricultural crops with the highest yields are, according to their production (2012-13): sugar cane, blackgram, maize, ground nuts, greengram, onions, vegetables, potatoes, cotton, natural rubber, fruits and tea (Settlement and Land Records Department 2013). Moreover, oilseeds, pulses, cotton and soya beans are important crops (FAO 2005: 5). Animal husbandry is practised nationwide, with a focus on poultry in the Ayeyarwady Delta and pigs in the mountain regions and in the north of the country. Pasture land is developed in the Sagaing, Bago, Magway, Mandalay and Yangon Regions and Mon State (Than Than Htay 2012: 155). Dairy farming in the mountain regions of Shan, Kayah and Kachin States has been declining for some years; there are not enough pastures due to deforestation and the expansion of tillage.

Of the 4.8 million farming families that live solely or predominantly from agriculture, $63 \%$ have access to less than 2 ha of agricultural land (small farmers and landless farmers are included in the statistics), 25\% have 2-4 ha and $13 \%$ have more than 4 ha (Ardeth Maung Thawhghmung 2003, Aung Kyi 2006). While small farmers mostly practise subsistence farming, larger farms, including plantations, are either under state control (state-owned enterprises), government-favoured enterprises or in the hands of foreign investors (indirectly, as these can only act through intermediaries).

Basic food security for the country's population has not been a problem in the past, with the exception of wartime: rice was always available in sufficient quantities, even if not all regions produced constant surpluses. However, the quality of the supply is not secure countrywide, especially among small farmers and agricultural labourers, the majority of whom are landless. Food expenditure amounts to 


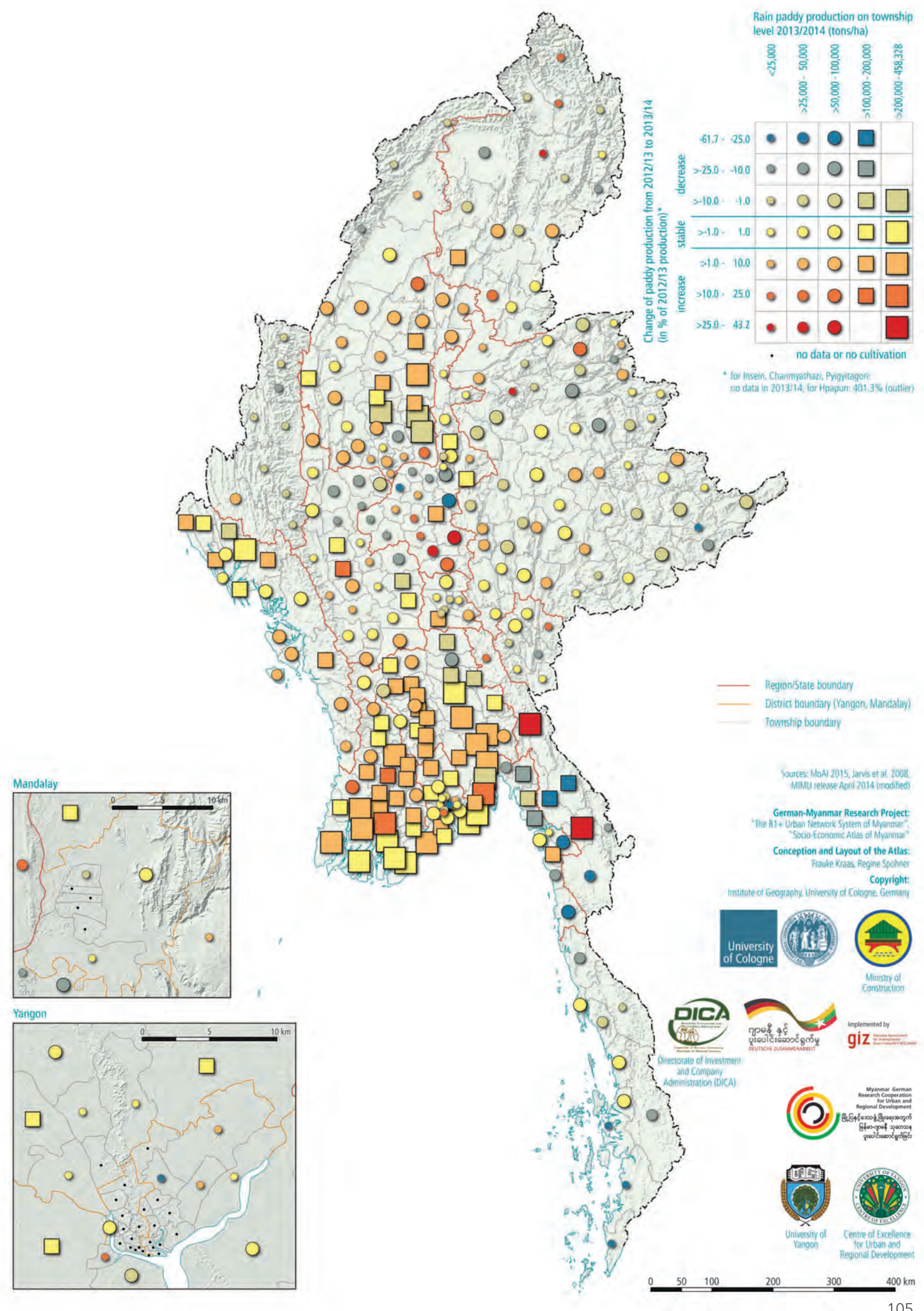


$72 \%$ of the total consumption expenditure of an average family in Myanmar. Of this total food expenditure, about one fifth is needed to buy rice. In the countryside and villages, the share of food (especially rice) in total consumption is higher. This is particularly so in the rural areas of Chin State where food accounts for $76 \%$ of total household consumption expenditure, with the share of rice in total food expenditure coming to roughly a quarter.

\section{REGIONAL DIFFERENCES}

The wide range of very disparate natural conditions and socio-culturally determined, mostly 'traditional' agricultural forms creates a highly differentiated regional picture. Diverse historical influences must also be taken into account. The structural patterns of agriculture that evolved in the pre-colonial period were first radically altered during the British colonial period (1824-1948), when agriculture was expanded across the country and thitherto untouched natural landscapes were systematically developed, in particular in the Ayeyarwady Delta and the mountain regions (Cheng 1968, Kan Zaw et al. 2011, Keck 2015, Kraas 2016b). Furthermore, soon after what was then Burma gained independence, there followed almost three decades of the 'Burmese
Way to Socialism', the fundamental character of which continues to show through in planning and policy even after the introduction of a market-oriented economy in 1988.

For the Myanmar governments since then, the improvement of agriculture has been one of the most important economic goals: area expansion, the expansion of irrigation, mechanisation, technical modernisation and improvement of crop yields are to provide food security for the population, expand Myanmar's export capacity and further the development of agroindustry (Mi Mi Kyi 2005: 79; FAO 2005: 5). Special measures to encourage 'model villages' are intended to promote integrated rural development (Mi Mi Kyi 2005: 94) while improving rural infrastructure, education and health care, thereby also creating a better general foundation for agriculture.

\section{MODERNISATION AND DEVELOPMENT POTENTIAL IN AGRICULTURE}

With the introduction of market-oriented production after 1988 and more so since 2010/11 the government gradually initiated other modernisation processes in agriculture (Tin Soe 2004). While achieving production targets has hitherto been a priority in agricul-

Rice planting in teh Ayeyarwady Delta near Pathein

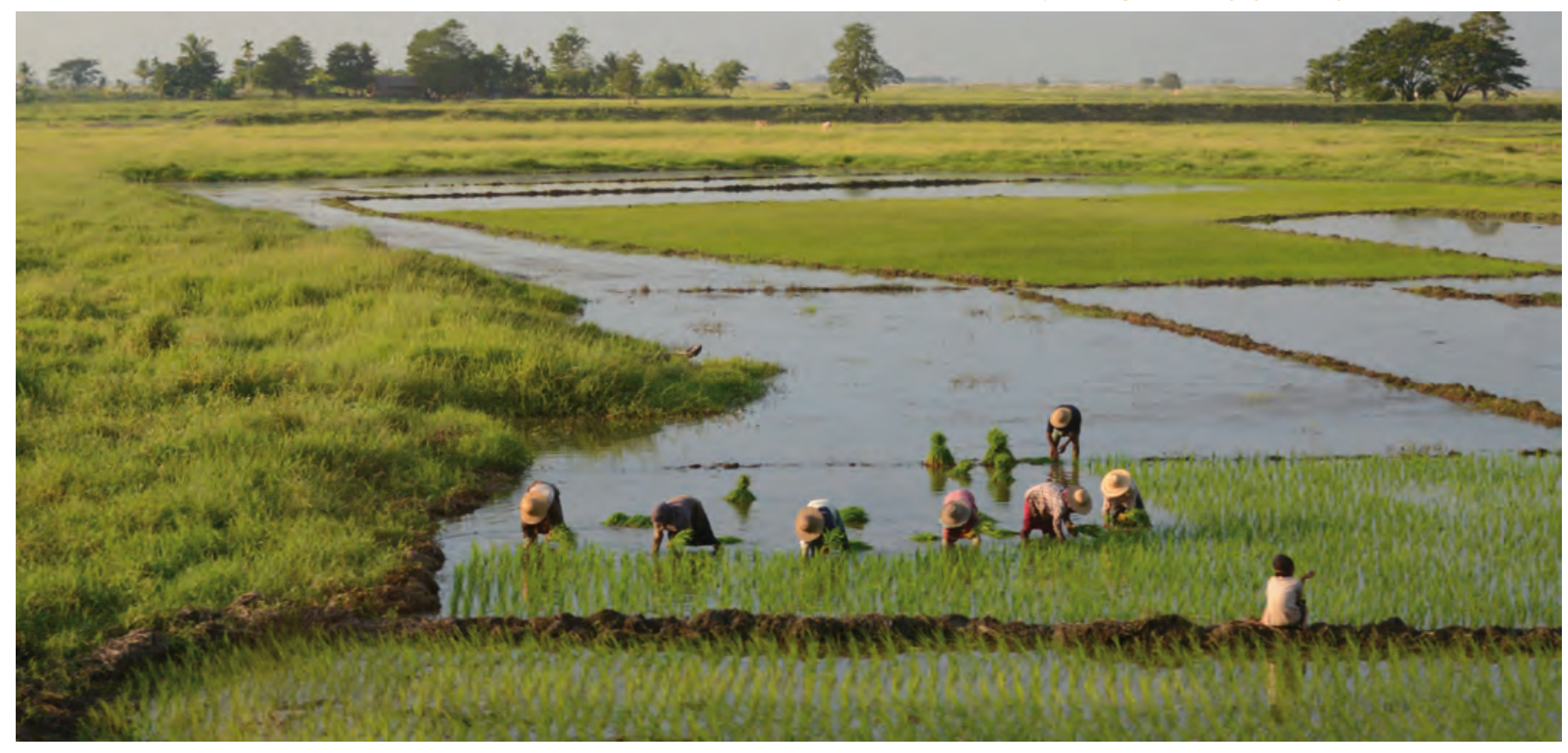




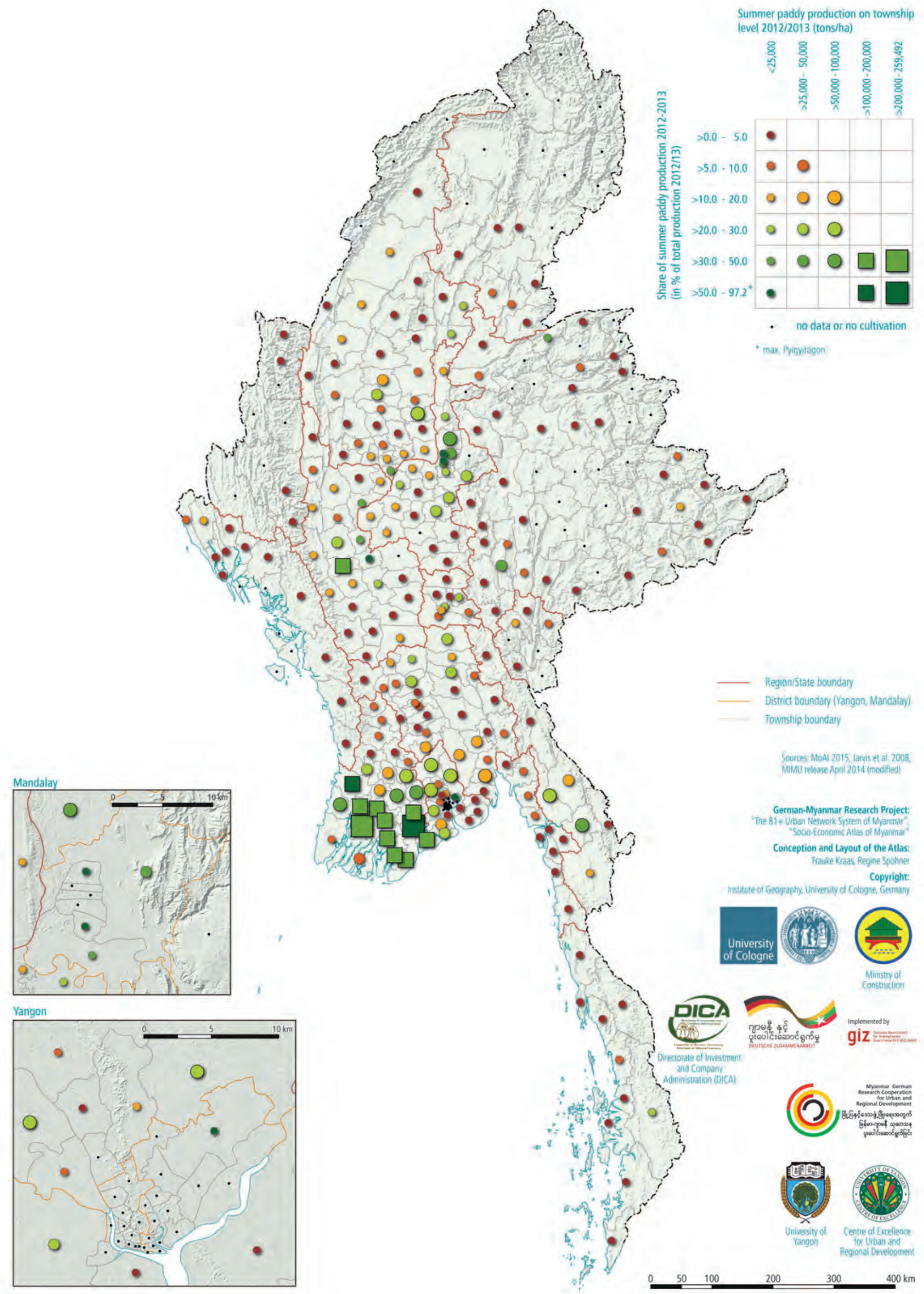


ture, the focus has not yet been explicitly on self-sufficiency, the diversification of agricultural products and crop sequences or income security for farmers.

More recent reform strategies have recommended a (holistic) broadening of focus to embrace the situation in agriculture as a whole, and follow a development path from a household-oriented subsistence economy to a regionally and internationally competitive market economy (Aung Kyi 2006).

The priorities of such strategies are as follows. Firstly, ecological aims are to be pursued, e.g. the establishment of soil protection and erosion prevention policies, measures against soil salination, and the creation of systematic wind barriers. Secondly, from an economic point of view the diversification of the crops cultivated, the consolidation of secondary crops, the reduction of post-harvest losses as well as improved access to loans, the stabilisation of the finance sector and a broadening of farmers and agricultural labourers income basis in agriculture, in association with agriculture and outside of agriculture, are necessary. From a structural point of view, improved land policies and resource development, the provision of transparent market information, a systematic development of human resources and the encouragement of agro-technology are called for. Finally, regionally differentiated improvements are perceived as necessary, rather than (too) general strategies. The main long- and medium-term goal is to achieve significantly improved integration and networking of the eight agricultural zones as well as further development of the endogenous socio-economic potential of the individual regions.

\section{SUMMER AND RAIN PADDY: PRODUCTION AND YIELDS}

Yields of rain and summer paddy vary considerably depending on natural conditions in and around the individual townships and in particular on soil quality and monthly rainfall.

Nationally, average yields of rain paddy are between 3.5 and 4.5 tons/ha; they are lower in coastal areas and in middle Shan State and significantly lower in the mountainous regions of Chin State, northern Kachin State and Kayah State. Higher yields of up to 8.7 tons/ha are achieved in the Sagaing and Magway Regions and in northern Shan State. Overall, yields are average by comparison with other ASEAN nations (USDA 2015) and stable over the country as a whole.

Yields vary in different parts of the country: yields of rain paddy in the delta areas of the Ayeyarwady and Sittaung rivers and in Rakhine State are high by comparison with the rest of the country and have been rising in recent years (2012-2014) in the core area, while on the coasts they are stable and in some townships of the central dry zone they are falling. Yields have fallen sharply in recent years in Kayin State and Mon State, largely on account of the shortage of labour as a result of the migration of workers to Thailand, lack of access to loans for modernisation and increasing cultivation of other agricultural commodities that command higher prices (all data: MoAI 2015).

Although the volume of summer paddy that is produced is significantly lower than that of rain paddy, the second rice harvest that summer paddy provides is nevertheless important for the national rice supply. Geographically the production of summer paddy is concentrated mainly in the southern Ayeyarwady Delta. Substantial harvests are also achieved in parts of the Magway and Mandalay Regions; productivity is high at between 5.0 and 7.0 tons/ha. Little summer paddy is harvested in other parts of the country, chiefly because of insufficient rainfall and limited capacities for artificial irrigation (all data: MoAI 2015).

Frauke Kraas and Khin Khin Soe 

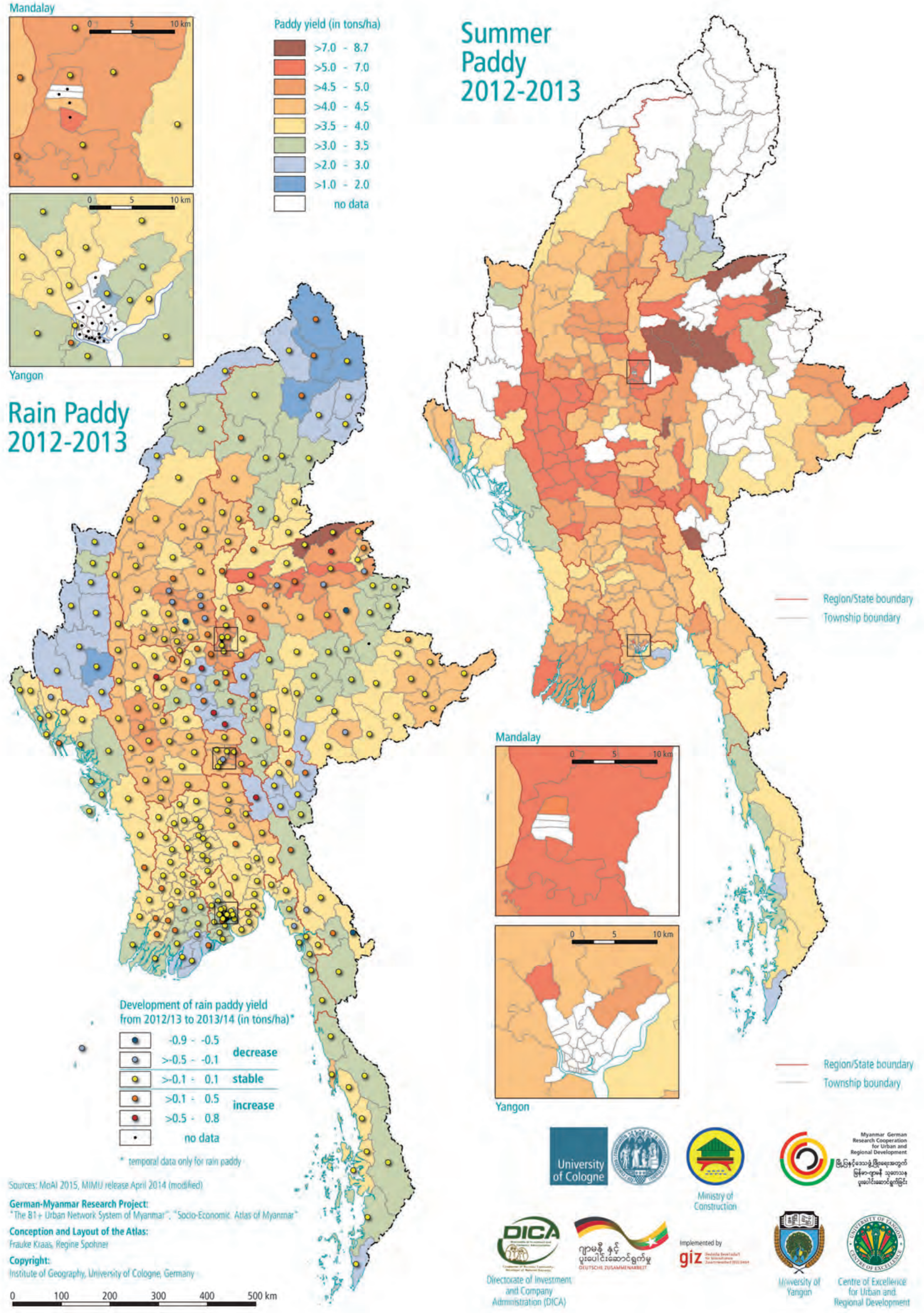

Rain Paddy
2012-2013
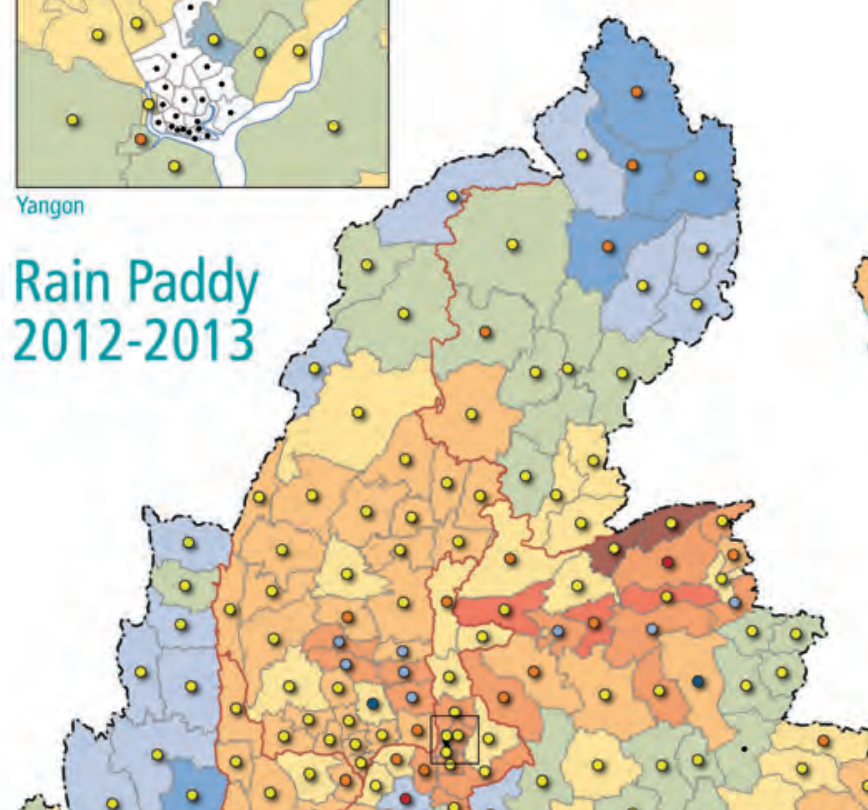

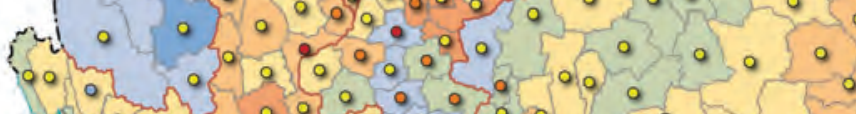

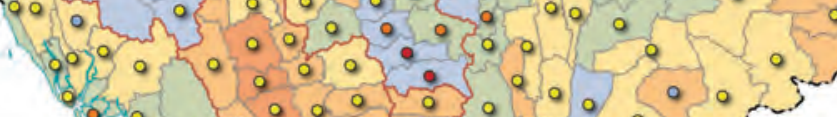

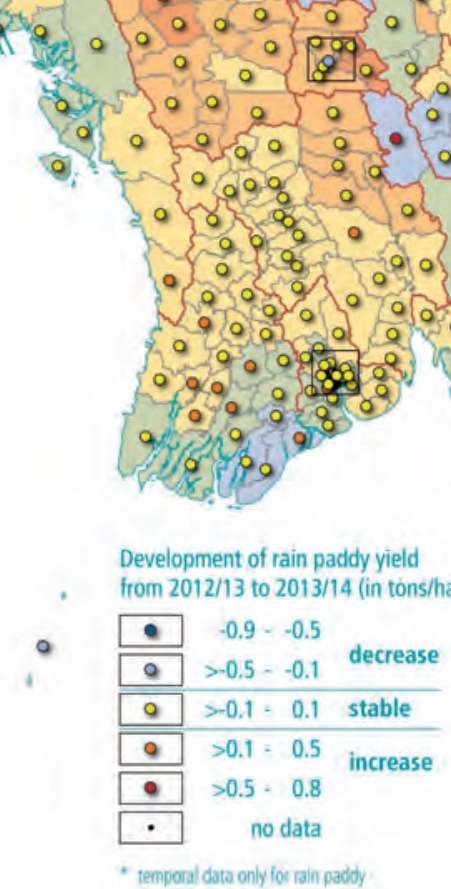

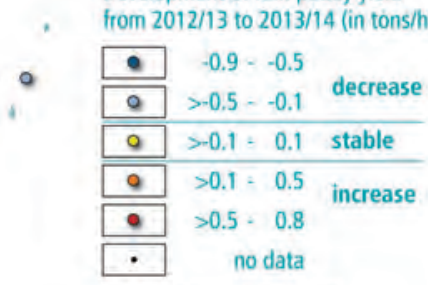

Souces: MoAi 2015, MiMu release April 2014 (modified)

German-Myanmar Research Project:

The a $1+$ Urban Network System of Mrarna

Conception and Layout of the Atlas:

rauke Kiaas Regine Spohne:

Copyright:

Institute of Geography, University of Cologne, Germany
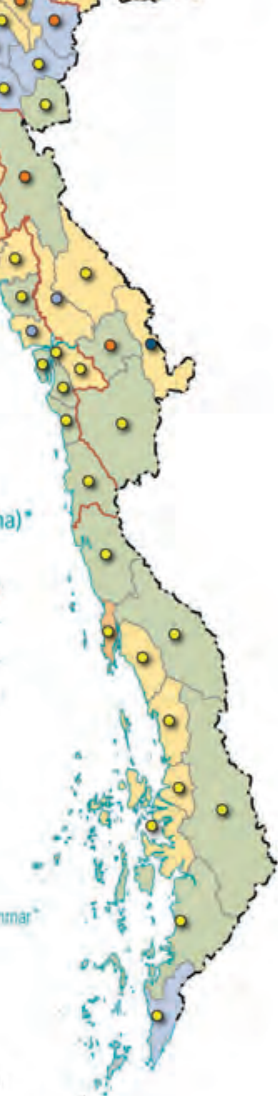


\section{AGRICULTURAL REGIONS}

Myanmar can be divided into different agricultural regions according to their natural and socio-economic conditions and characteristics. It would be too simplistic to distinguish agricultural regions primarily on the basis of natural conditions. The wide range of very disparate socio-culturally determined, mostly 'traditional' agricultural forms creates a highly differentiated picture. Thus, for example in Chin, Kachin and Shan States different cultivation methods and traditions, different agricultural products, crop sequences and specialisations are to be found, simply because of the different ethnic groups in these regions. Also to be taken into account are diverse historical influences. The structural patterns of agriculture that evolved in the pre-colonial period were altered during the British colonial period, when agriculture was expanded across the country and hitherto untouched natural landscapes were systematically developed.
The differentiation of eight agricultural regions was derived from a synthesis of several criteria, based on primary and secondary data as well as qualitative characteristics (Kraas 2015): a) topography/relief (based on topographic maps and satellite images), b) total annual precipitation (data from the Department of Meteorology and Hydrology Myanmar), c) current land-use and vegetation (based on global land cover data; Chen et al. 2014), d) official agricultural statistics from the Ministry of Agriculture and Irrigation, e) numerous interviews with public authorities, entrepreneurs and famers in the states and regions of Myanmar, f) field observation. Based on these criteria, eight different agricultural regions can be distinguished which shall briefly be characterised.

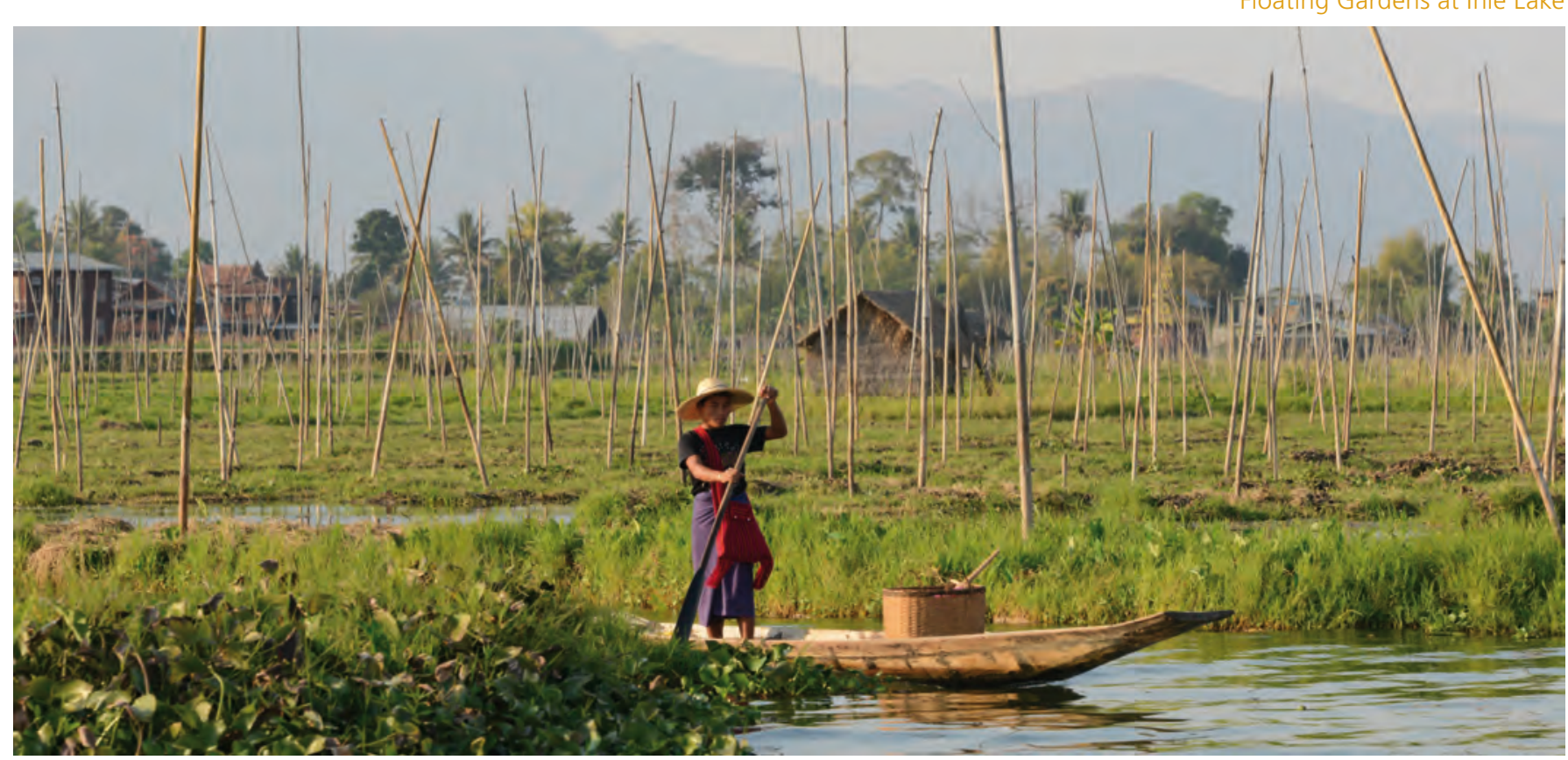




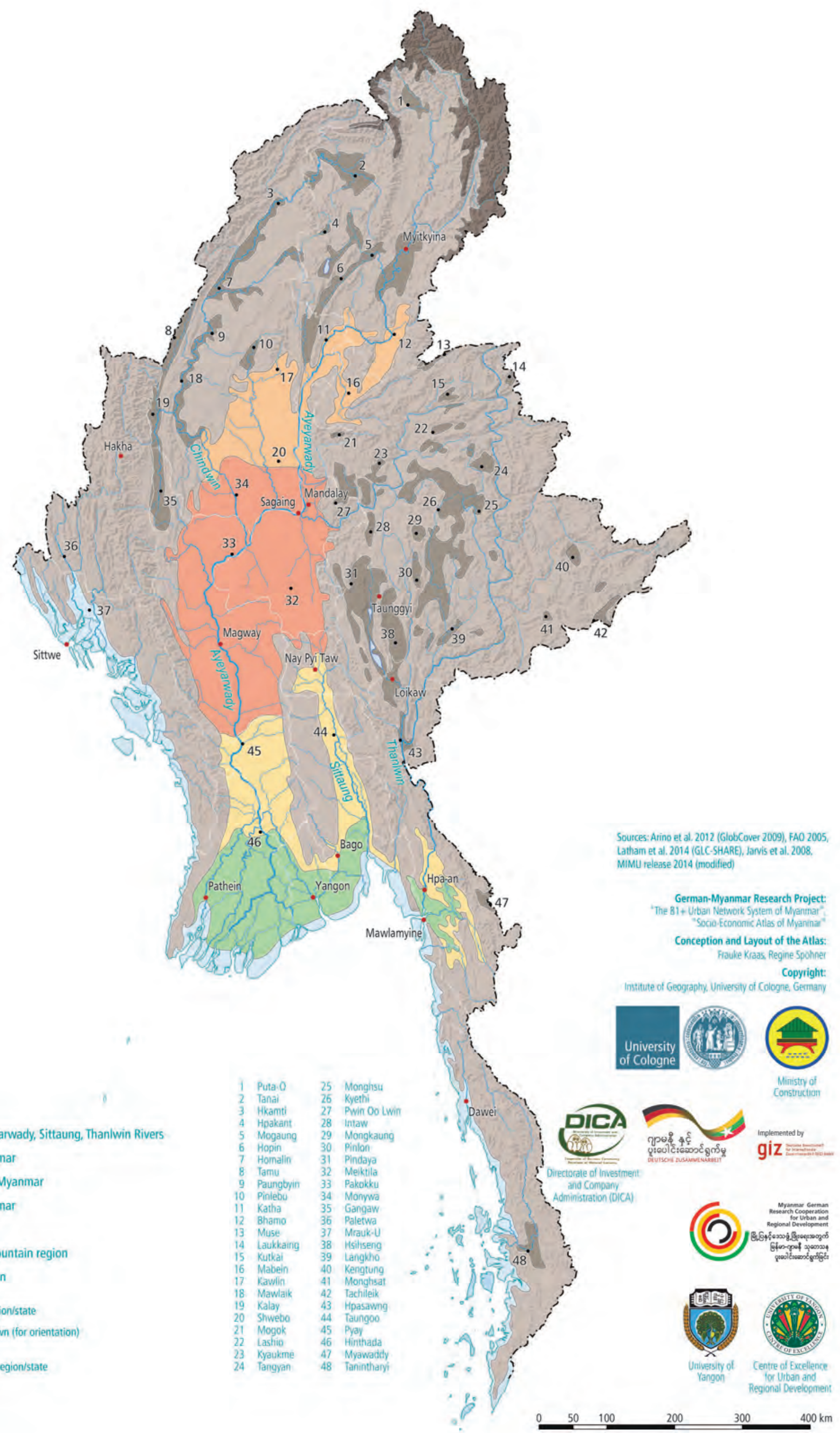

Agricultural region

$\square$ Coastal region
Delta region of Ayeyarwady, Sittaung, Thanlwin Rivers
South Central Myanmar
Dry zone of Central Myanmar
North Central Myannar
Mountain region
Basin or valley of mountain region
High mountain region

Sources: Arino et al. 2012 (GlobCover 2009), FA0 2005, SHARE), Javis et al. 2008 .

Myanmar Research Project: and Layout of the Atlas: Copyright: Institute of Geography, Universily of Cologne, Geman 


\section{COASTAL REGIONS}

Along the coast, the dominant activities are fishing and gathering (marine animals, seafood and firewood; Heymann/Löffler 1997) in the adjoining brackish areas with frequently relatively untouched mangrove, nipa and bamboo forests. The agricultural potential along the coast is low, especially as the workforce is already seasonally occupied in fishing and tourism in a few places with early tourism development. Wet rice cultivation is mostly practiced for subsistence in the elongated coastal marshes beyond the beach walls, often together with vegetable cultivation for local markets.

\section{DELTA AREAS OF THE AYEYARWADY, SITTAUNG AND THANLWIN RIVERS}

The intensively cultivated southern Ayeyarwady Delta is the core of Myanmar's agricultural production today (Adas 1974, Nishizawa 1991, Brown 2005, Hedley/Bird/Robinson 2010). This is the 'rice bowl' of the country, with extensive cultivated areas only a few metres above sea level, covering an area of over $20,000 \mathrm{~km}^{2}$. Also rain-irrigated wet rice cultivation, pulses and vegetables are grown. Often, elongated houses on stilts for hens and ducks are erected in the basins, providing important extra income. Where storage reservoirs, dams and canal system enable irrigated farming outside of the rainy season, up to three harvests are possible. The potential of artificial irrigation is considered to be underutilized (Kraas 2016b).

The specialized cultivation of fruit - pomelos, watermelons, mangoes, durian or jackfruit diversifies agricultural income. While most agricultural products in the deltas are produced for the national market, the export share of fruit and especially fish and prawns (dried or increasingly fresh-chilled) to Southeast Asia, China and Japan is rising continuously.

In areas easily accessible from Yangon and Mawlamyine and along the now well-developed trunk roads, e.g. to Maubin and Pathein, traditional tillage is increasingly being displaced by capital-intensive aquaculture, often owned by foreign investors (from Japan, Vietnam, Thailand) or joint ventures.

Following the devastation caused by Cyclone Nargis in 2008 (Kraas 2009), numerous reconstruction and development aid projects have led to the modernisation and mechanisation of agriculture in the Ayeyarwady Delta.

\section{SOUTH CENTRAL MYANMAR}

As precipitation and population densities decline northwards, rice accounts for a falling proportion of the harvest, and its yield levels drop. Oilseeds (sunflowers, peanuts, sesame) and cotton are increasingly cultivated. The share of sorghum and pulses - various peas, lentils, beans - rises, whereby the high diversity of the endogenous crops cultivated, many of them still very widespread, indicates how strongly Myanmar's agriculture has been oriented towards the domestic market and its demands for many decades. Systematic and improved processing, marketing and quality improvement would enable a rise in farmers' incomes and at the same time help to develop agroindustry.

\section{THE DRY ZONE OF CENTRAL MYANMAR}

In the dry zone of central Myanmar, which lies in the rain shadow of the major mountain ranges and receives between 400 and 1,000 $\mathrm{mm}$ annual precipitation with up to seven arid months, generally only dry farming is possible. As well as various species of acacia, the natural vegetation includes dwarf shrubs and succulents; some animals are kept where these grow. The main dry zone crops are peas, maize, cotton, sesame, onions and chillies (FAO 2005). Palm sugar production (toddy palm) attracts seasonal labourers from all around the country.

Apart from the irrigation zones near the Ayeyarwady River and its tributaries, where up to three harvests are possible, the potential for artificial irrigation has so far not been exploit- 


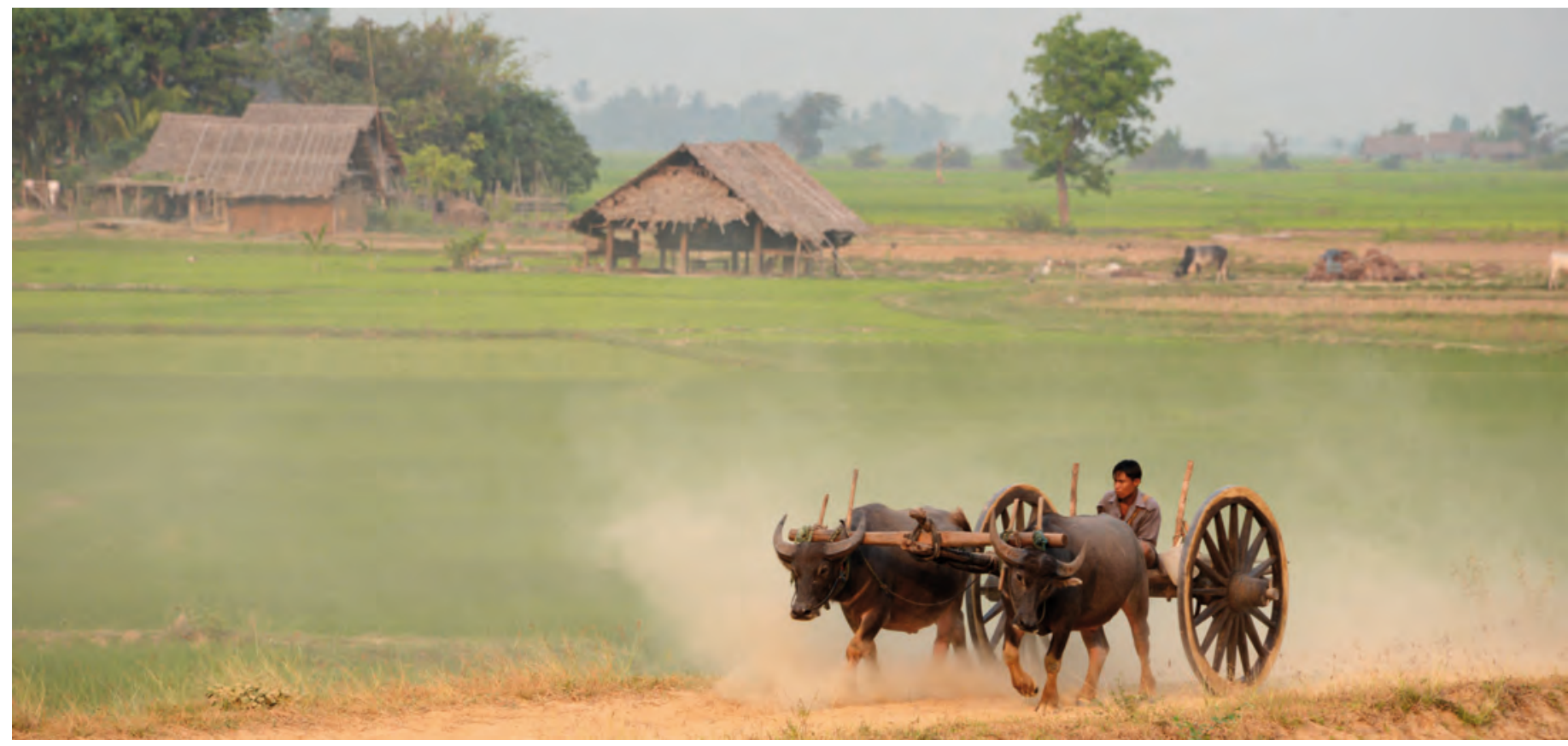

Agriculture in the Dry Zone of Central Myanmar

ed systematically. However, it should also be borne in mind that agriculture competes with urban employment opportunities in the Mandalay agglomeration, and the expansion of irrigation would have ecological consequences for the lower reaches of the Ayeyarwady River.

\section{VALLEYS OF NORTH CENTRAL MYANMAR AND KACHIN STATE}

In the broad fertile valleys of the Chindwin and Ayeyarwady Rivers with annual precipitation levels between 1,000 and $3,500 \mathrm{~mm}$, sugar cane, rubber, oil palm, potatoes and mustard plant are cultivated as well as the dominant rice. Linked to the relatively low population densities, cultivation is less intensive than in the south of the country. The formerly widespread subsistence agriculture has changed since the late 1980s with the ongoing improvement of transport routes, although the north of the country remains poorly connected to the central lowlands. During the dry period, subsistence rice and vegetable cultivation is practised on the sandy islands and sloping banks of the large rivers. For some years harvested crops have increasingly been sold to Yunnan/China, as well as to India via the border crossing at Tamu or Rihkhawdar. The choice of plants cultivated (e.g. maize, yams, citrus fruits) has also changed in response to the growing demand from neighbouring countries for food and animal feed.

In principle, there is considerable potential for intensification. However, in view of the numerous nature reserves and conservation potential, the opening up of new areas to agriculture is questionable. As the region is thinly settled and many workers are already employed in extensive mining activities, there is currently little pressure to expand agricultural land-use.

\section{MOUNTAINOUS REGIONS (BAGO YOMA, RAKHINE YOMA, CHIN STATE, NORTHERN SAGAING REGION, KACHIN AND SHAN STATES)}

The highly differentiated mountainous regions of Myanmar, reaching heights between 2,000 and 4,000 $\mathrm{m}$, with a high relief energy in Chin State and a somewhat lower relief energy in the Shan Hills, form numerous parallel mountain chains running north-south, composed mostly of limestone and granite.

Flatter slopes are usually cultivated as clearances. Slash-and-burn cultivation often occurs on the slopes in the typical Myanmar Taungya cultivation, where the fires are controlled and selected tall trees, so-called legacy trees, are 
left standing in the course of clearance in order to support reforestation after two to three years of agricultural use. Shortly before the onset of the monsoon, mostly rice, sorghum, soya and maize are sown directly into the ashes. As yet there are few areas with permanent crops such as fruit trees, tea or coffee, as so far there is a lack of agricultural techniques and knowledge, capital and a functioning marketing system to encourage permanent crops.

Also grown are wheat, potatoes, vegetables, maize, onions and garlic. The intensively farmed permanent crops on the flatter slopes include fruit (apples, grapefruit, grapes, pineapples and strawberries), macadamia trees and above $1,500 \mathrm{~m}$ coffee and tea, usually in the form of plantations, which were initiated during the British colonial period. Furthermore, at higher elevations the cultivation of medicinal plants (castor oil plant, ginger or cinnamon), tobacco and traditional spices is expanding. Currently, these are mainly sold on the domestic market for traditional medicine or local specialities and are rarely subject to specific quality controls. On sunny slopes near Taunggyi, viticulture is now successfully practised in a pioneering venture.

In particular in the mountains around Inle Lake and along the long-distance roads from Thazi via Kalaw to Taunggyi and from Pyin Oo Lwin via Hsipaw to Lashio and Muse, the cultivation of mid-latitude crops has expanded considerably in recent years, since the growing demand in urban and (seasonal) tourism centres can be met thanks to improved transport links (Nilar Aung 2007). Near mining cities (e.g. Mogok, Kyatpyin or Hpakant), agriculture is in competition with mining so that with the availability of more capital, more intensive forms of cultivation have developed, e.g. slope cultivation with furrow irrigation or localized irrigation, greenhouses, partly with seasonal labourers.

Many coastal mountain ranges (large parts of the southern Rakhine Yoma and the mountains parallel to the coasts of Mon State and Tanintharyi Region) are subject to increasing land-use pressure, whereby rubber planta- tions, and in the south oil palm plantations, dominate.

In many mountain regions there are large national parks with a high biodiversity of flora and fauna, including wild elephants (protected since 1879), tigers, rare species of deer and a large number of bird, reptile and amphibian species, some of them endemic. There are also numerous nature reserves where subsistence agriculture is permitted. These protected areas are a tremendous resource for the country insofar as their natural flora and fauna have hitherto been little influenced by human land-use. An expansion of agriculture in these regions is possible and conceivable, but is not very feasible in respect to the significance of their ecological potential.

\section{BASINS AND VALLEYS OF THE MOUNTAIN REGIONS}

Within the mountain regions, numerous basins and valleys facilitate more intensive farming than on the hill slopes. Because of the altitude-related lower annual average temperatures (under $18^{\circ} \mathrm{C}$ ), with lowest temperature values just above freezing point at high altitudes, mid-latitude vegetables and fruit are cultivated. Some of these were introduced during the British colonial period, while many were brought to the country by missionaries in the context of aid activities to improve basic nutrition: potatoes, cabbage, tomatoes, cucumber, carrots, radishes, celery etc. Since 1988, the influence of China and Thailand has been apparent, especially in the Shan Hills: Traders import seeds which produce higher yields and better-looking crops, although these often prove less resistant to plant diseases and pests than local varieties. For this reason, local seed providers have become established in recent years. Through the connection to Thailand, and increasingly also to China and India, increasing amounts of pesticides and artificial fertilizers are being applied in agriculture, so that the special potential of relatively unspoiled soils which could be used for organic farming, is gradually dwindling. 


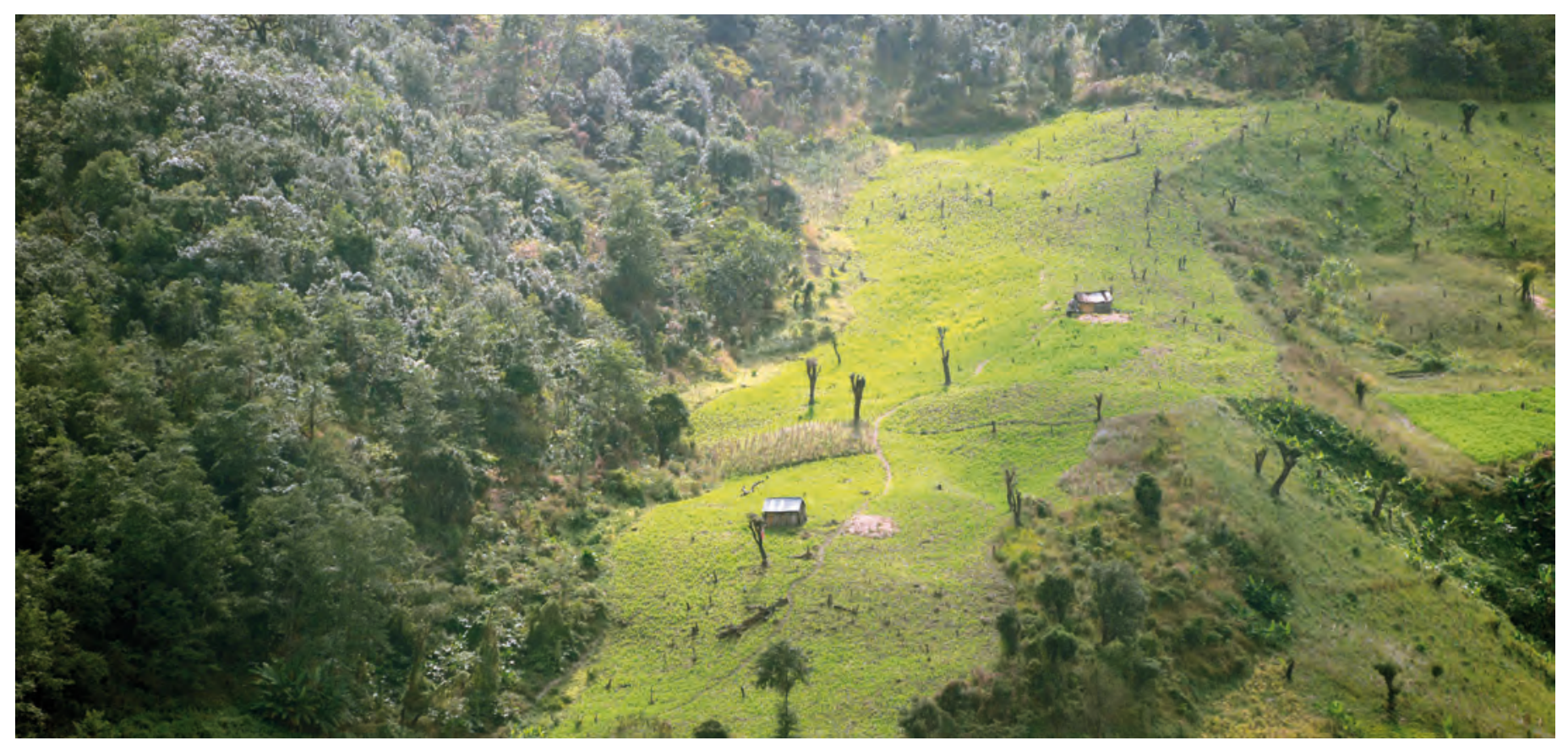

Taungya slash-and-burn cultivation in the Chin Mountains

High-yielding agriculture is primarily practised at an altitude of about $900 \mathrm{~m}$ in the Shan Hills and around Inle Lake, Myanmar's second largest inland lake. Traditionally, socalled 'floating gardens' (Wilhelmy 1986) are created on the lake: On artificial islands and earth-covered mats anchored in the lake floor with woven roots and climbing plants as well as wooden posts, lake sediments and plant detritus are repeatedly deposited to expand and deepen the soil layer. The main crops on these islands are tomatoes, beans, onions, leeks, aubergines and flowers. The constant supply of water from the lake makes several harvests per year possible. The cultivation and harvesting of the elongated 'fields' is effected from boats that access the plants along narrow canals and transport the harvested crops. On the lake banks the crop is sorted, packed and then transported, mostly by truck, to the agglomerations of Yangon and Mandalay (Nilar Aung 2007).

\section{HIGH MOUNTAINS}

The mountain regions above $2000 \mathrm{~m}$ in the north of Kachin State have hitherto been quite inaccessible because of a lack of transport links and are only used for agriculture in scat- tered locations. The mountain massifs of the eastern foothills of the Himalayas surrounding the country's highest mountain Hkakabo Razi are largely inaccessible. The dense mountain rainforests at lower altitudes with oaks, chestnuts, tree ferns and bamboo, pines and rhododendrons give way to open bush- and grasslands at higher altitudes. Subsistence agriculture is carried out mainly in the valleys, sometimes on terraces, with rice and vegetable cultivation dominating; Taungya slash-andburn cultivation is practised sporadically, making dry rice cultivation possible. Hunting and gathering are also common in the forests, though limited in many places by local restrictions on their use.

Frauke Kraas, Aung Kyaw and Nay Win Oo 


\section{GROSS DOMESTIC PRODUCT: SHARE OF PRIMARY SECTOR}

Detailed analysis of the data for Myanmar's 330 townships reveals a regional differentiation that is highly characteristic.

The share of the primary sector in total GDP by township (2014/2015; indicated by the colour of the frame of the squares) shows that the sector accounts for shares of more than $50 \%$ in predominantly rural regions without major urban centres (for instance in the west of the Ayeyarwady lowlands and delta, and in peripheral townships of the Shan Highlands and in the Sagaing and Tanintharyi Region). In larger towns and cities and their surroundings, the share of the primary sector in total GDP drops to less than $25 \%$, as would be expected. In some locations it is less than $5 \%$, which is due to urban and periurban industry and the high share of trade and services. Correspondingly, the lowest shares of the primary sector in GDP are found in Yangon, Mandalay, Nay Pyi Taw, larger regional urban centres (such as Mawlamyine, Sittwe or Myitkyina) and some border towns (such as Muse and Tachileik).
A look at the shares of the 'agriculture' and 'livestock and fisheries' subsectors in the primary sector shows the huge importance of agriculture in the central lowlands of Ayeyarwady and in the peripheral highlands of Shan, Kayin and Kayah State and the Sagaing Region. Fisheries dominate along the coasts, notably aquaculture in the southern delta of the Ayeyarwady. In the peripheral mountain regions with infertile soils, high relief energy and low levels of market integration, such as in Chin State, the major importance of livestock is evident. The contribution of forestry and agroforestry to GDP is below the 25\% threshold in all townships. This contribution can only be derived indirectly from the available data insofar as forestry and agroforestry play a supplementary role in GDP generation in all the locations where agriculture, livestock and fisheries do not make up more than $90 \%$.

\section{Frauke Kraas and Khin Khin Soe}

Rice harvest in Ayeyarwady Delta

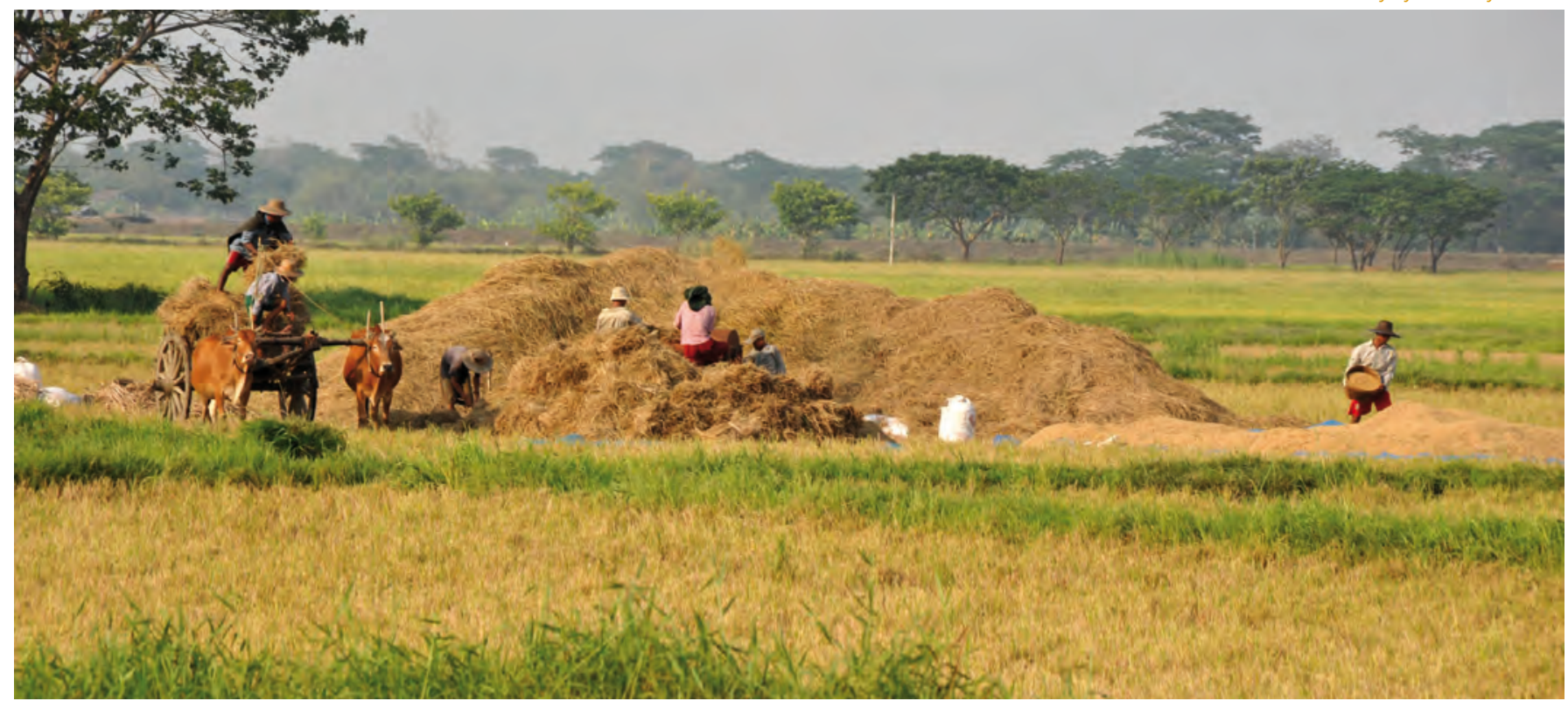


Primary sector share of total GDP in 2014-2015 by township (in \%)
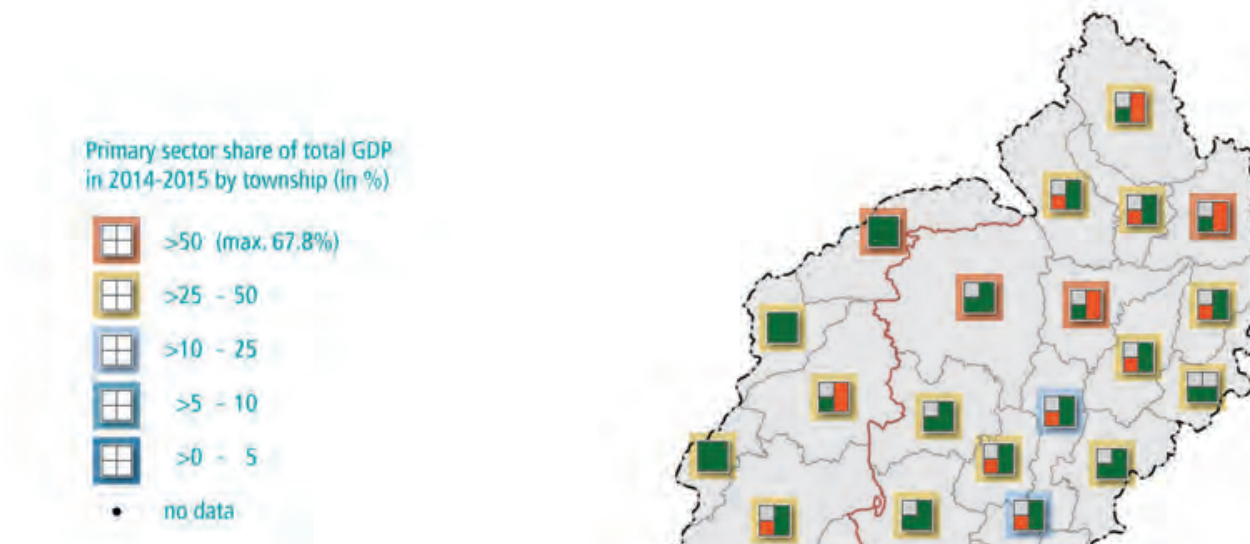

Dominant subsectors' share of primary sector GDP in 2014-2015 (by township, in \%)

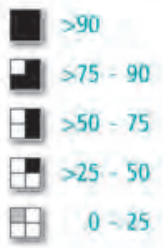

Subsectors of the primary sector ${ }^{*}$

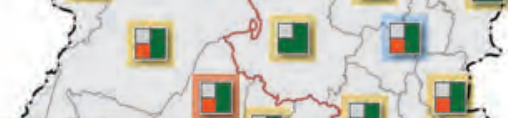
Arable farming

Animal husbandry and fishing
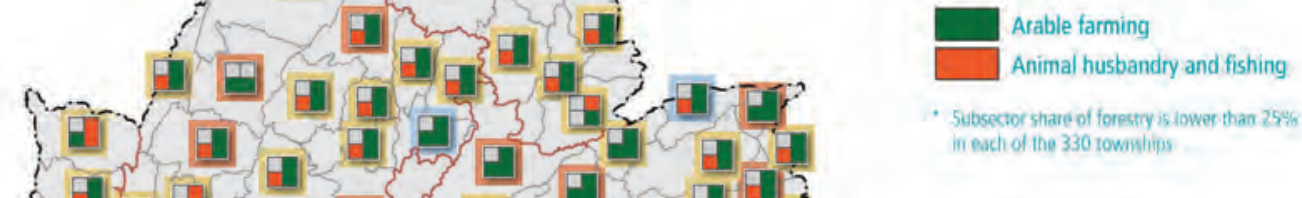

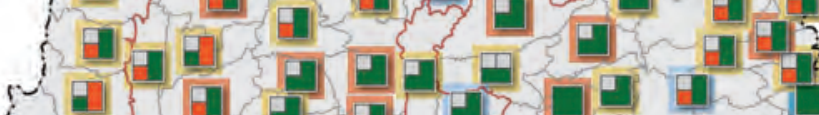
in each of the 330 townships

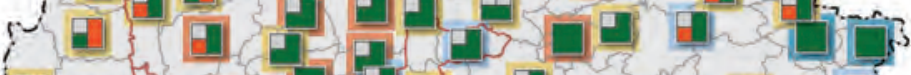

(1) D. (D)

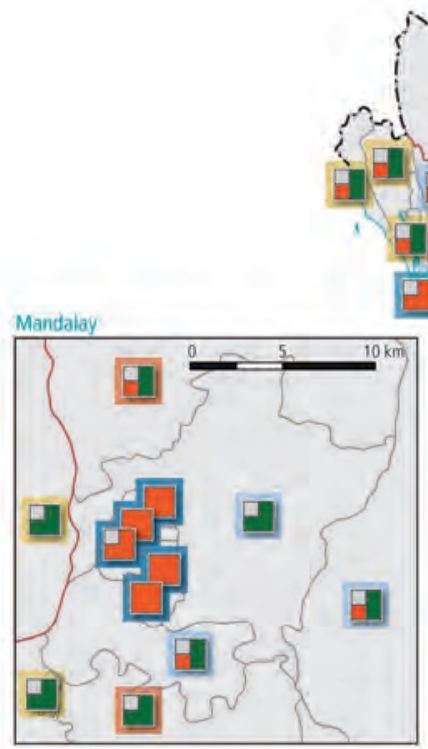

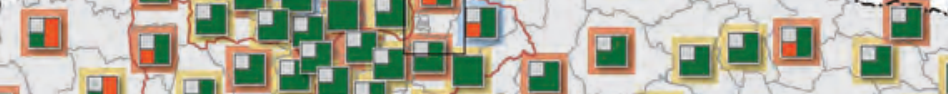

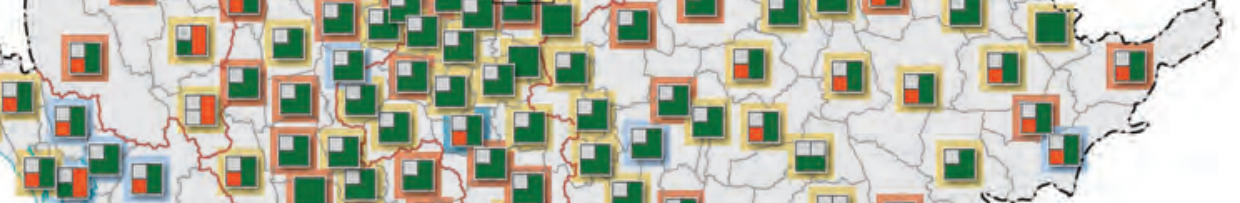

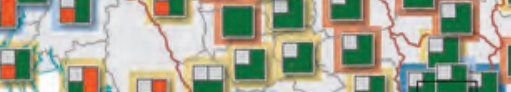
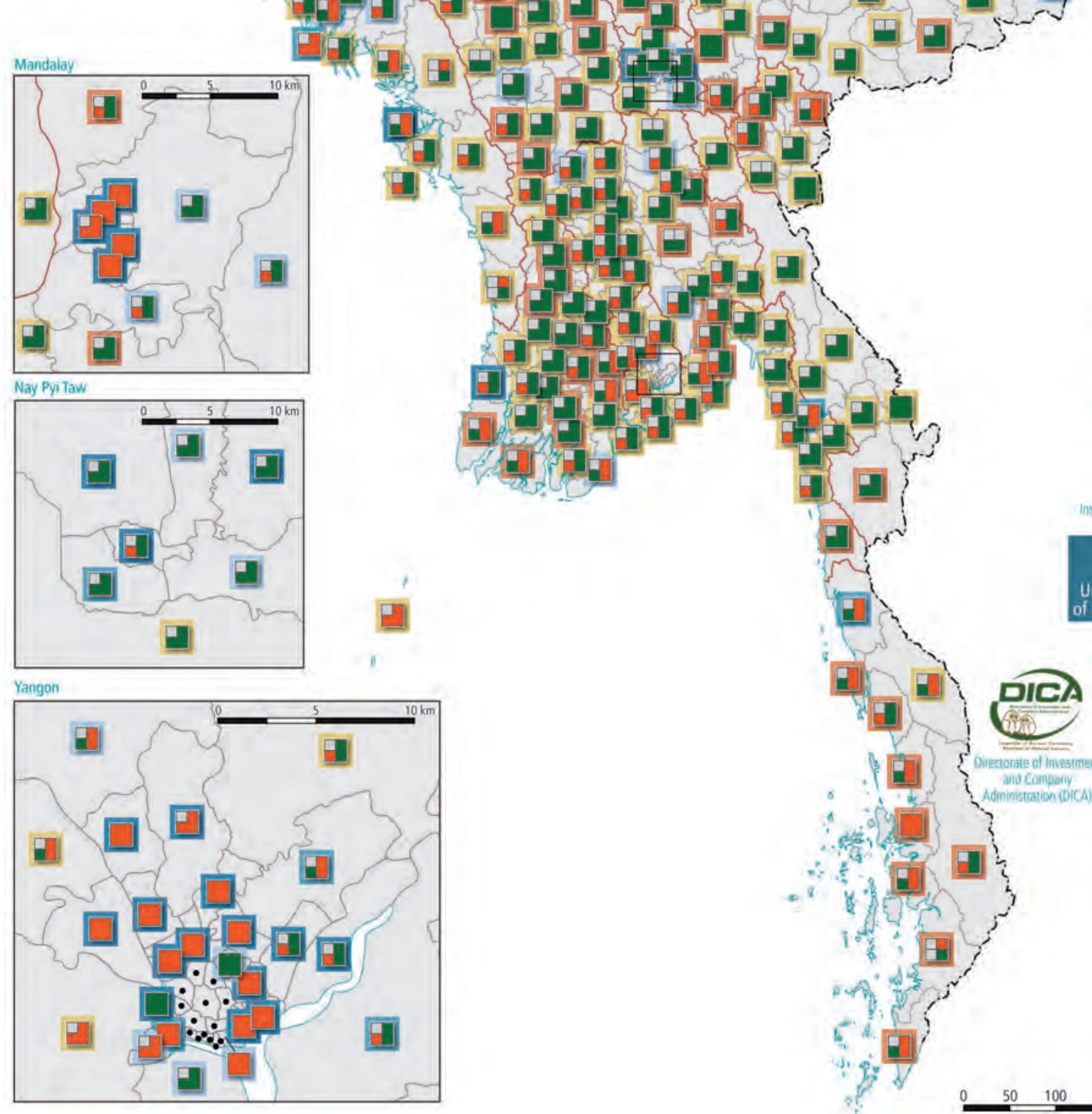

- Region/State boundary
- Township boundary

Source Mwived 2015 (DEfartment of Plarminty) MiMU release Apoil 2014 (modilied)

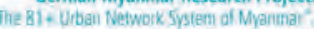

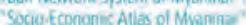

Conception and Layout of the Altas Frouke Kraas Regine Spohner Copyright: Instatue of Geography, Universily of Cologne. Germany
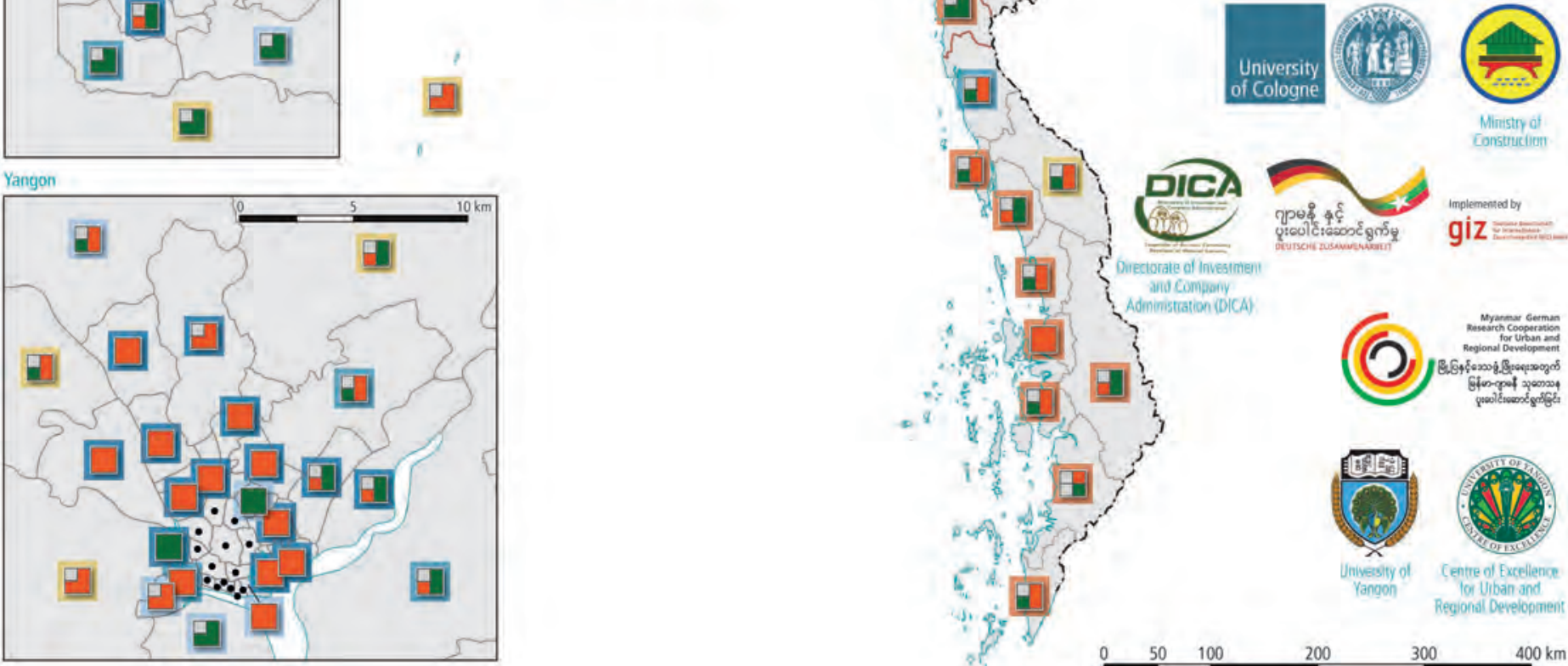

Regiondil Developmein 


\section{AQUACULTURE}

In addition to rice, fish and fish products are the most important source of domestic food security in Myanmar ('rice fish culture'); with almost $55 \mathrm{~kg} / \mathrm{capita} /$ year Myanmar heads up per capita consumption worldwide (Belton et al. 2015: 8, 21). Almost as much of the household budget is spent on fish (14\%) as on rice (19\%; Belton et al. 2015: 23).

Fish production in Myanmar is derived from marine capture fish, freshwater capture fish or from aquacultures. Fishing in natural waters dominates throughout the country; there are also numerous mostly small or medium-sized artificial fishponds. Inland fishing has been particularly promoted since the PyidawthaPlan (Government of Burma 1952, Hla Tun Aung 2003: 355-356). Freshwater fishing is favoured over saltwater; in addition to cast-nets and drag-nets, weirs, fish-cages and angling tackles are used. Deep-sea fishery dates back to the time of Japanese occupation but remains less developed (Storz 1967: 221, Hla Tun Aung
2003: 355-357); it is restricted by a lack of technical equipment, knowhow and the difficulties of ensuring timely cold chain transport. Following the decline of salt production on the coast of Rakhine (Ba Shwe 2012: 77-90), traditional salting practices have lost significance.

Aquacultures are found in almost all the country but are concentrated in the coastal and delta regions, in the Ayeyarwady Delta and in the vicinity of Yangon, especially in Maubin, Twante, Nyaungdon, Kyauktan and Khayan (Mi Mi Kyi 2005, Kyauktan TPDC 2006). Here are about $90 \%$ of the nation's fish farms. Aquaculture was first introduced in the mid-1960s ('proto-aquaculture'; Beveridge/Little 2002), and gained greatly in significance after 1988 with the introduction of the market-oriented economy and the end of the armed conflicts in the eastern Ayeyarwady Region. In 1980, giant shrimps (Macrobrachium sp.) was introduced in Myanmar (Tint Tint Moe 1997) and is since then produced on commercial scale. Shrimps

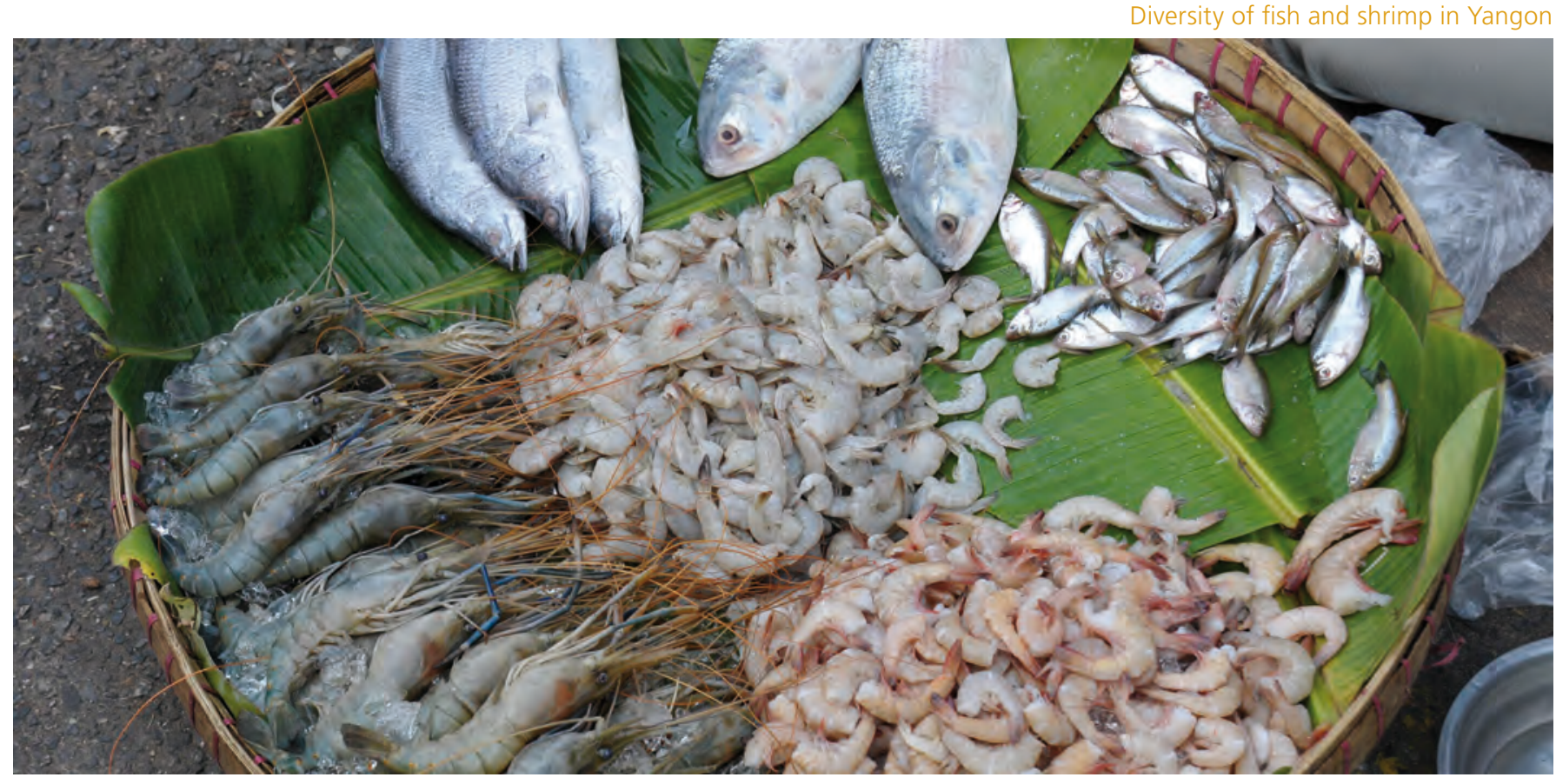




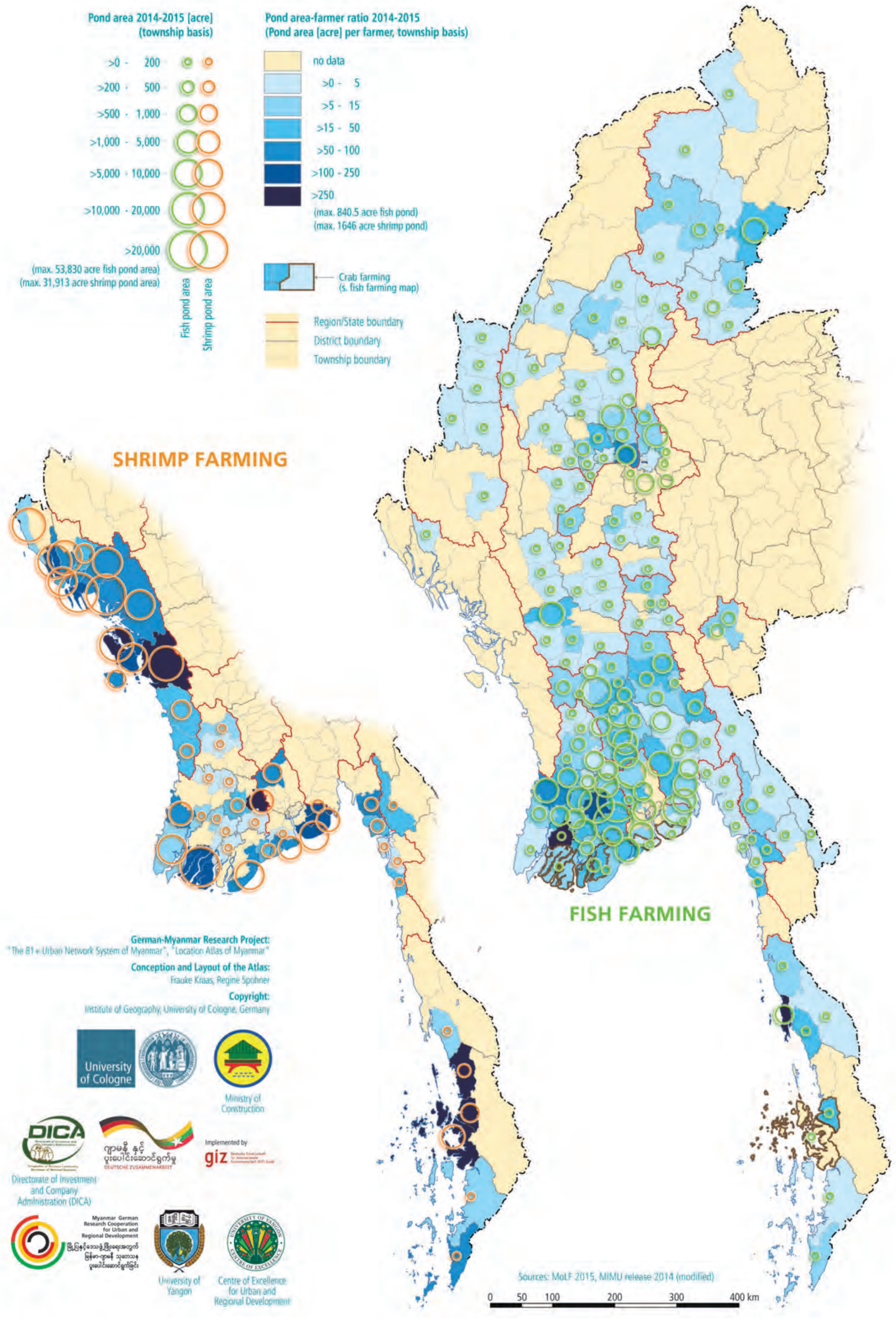




\begin{tabular}{|r|r|r|r|r|} 
& $\mathbf{2 0 0 0 - 2 0 0 1}$ & $\mathbf{2 0 0 5 - 2 0 0 6}$ & $\mathbf{2 0 1 0 - 2 0 1 1}$ & $\mathbf{2 0 1 5 - 2 0 1 6}$ \\
\hline UNION OF MYANMAR & $\mathbf{7 8 5 , 4 9 5}$ & $\mathbf{1 , 5 8 0 , 0 5 1}$ & $\mathbf{2 , 5 4 8 , 0 3 7}$ & $\mathbf{3 , 4 2 4 , 4 1 3}$ \\
\hline KACHIN STATE & 4,371 & 11,742 & 17,906 & 20,771 \\
\hline KAYAH STATE & 5 & 410 & $\mathbf{7 1 6}$ & 942 \\
\hline KAYIN STATE & 1,999 & 5,763 & 9,087 & 13,866 \\
\hline CHIN STATE & 50 & 457 & 732 & 1,265 \\
\hline SAGAING REGION & 15,809 & 34,878 & 57,264 & 84,625 \\
\hline TANINTHARYI REGION & 30,925 & 471,552 & 703,135 & $1,066,626$ \\
\hline BAGO REGION & 37,378 & 131,013 & 210,346 & 286,910 \\
\hline MAGWAY REGION & 3,034 & 5,470 & 10,080 & 11,351 \\
\hline MANDALAY REGION & 15,450 & 27,814 & 45,851 & 46,049 \\
\hline MON STATE & 26,124 & 90,173 & 165,404 & 170,127 \\
\hline RAKHINE STATE & 59,856 & 96,687 & 152,507 & 171,718 \\
\hline YANGON REGION & 40,163 & 149,619 & 226,238 & 330,951 \\
\hline SHAN STATE & 1,745 & 3,449 & 6,265 & 12,048 \\
\hline AYEYARWADY REGION & 270,306 & 551,024 & 942,506 & $1,204,473$ \\
\hline NAY PYI TAW & 0 & 0 & & 2,691 \\
\hline
\end{tabular}

Production of Fish and Prawns by Region and State [absolute values in thousand viss] (MoPF 2016: 293)

\begin{tabular}{|r|r|r|r|r|} 
& $\mathbf{2 0 0 0 - 2 0 0 1}$ & $\mathbf{2 0 0 5 - 2 0 1 0}$ & $\mathbf{2 0 1 0 - 2 0 1 1}$ & $\mathbf{2 0 1 5 - 2 0 1 6}$ \\
\hline TOTAL & $\mathbf{7 8 5 , 4 9 5}$ & $\mathbf{1 , 5 8 0 , 0 5 1}$ & $\mathbf{2 , 5 4 8 , 0 3 7}$ & $\mathbf{3 , 4 2 4 , 4 1 3}$ \\
\hline FRESH WATER FISHERIES & $\mathbf{2 1 5 , 0 5 4}$ & $\mathbf{7 3 8 , 1 4 1}$ & $\mathbf{1 , 2 2 0 , 1 0 7}$ & $\mathbf{1 , 5 8 9 , 2 2 2}$ \\
\hline FISH CULTURE & 70,911 & 351,894 & 508,254 & 621,228 \\
\hline LEASABLE FISHERIES & 55,660 & 93,447 & 153,025 & 207,411 \\
\hline OPEN FISHERIES & 88,483 & 292,800 & 558,828 & 760,583 \\
\hline MARINE FISHERIES & $\mathbf{5 7 0 , 4 4 1}$ & $\mathbf{8 4 1 , 9 1 0}$ & $\mathbf{1 , 3 2 7 , 9 3 0}$ & $\mathbf{1 , 8 3 5 , 1 9 1}$ \\
\hline IN-SHORE FISHING & 211,063 & 311,507 & 491,334 & 679,021 \\
\hline OFF-SHORE FISHING & 359,378 & 530,403 & 836,596 & $1,156,170$ \\
\hline
\end{tabular}

Producation of fish and prawns by nature of catch by Region and State [absolute values in thousand viss] (MoPf 2016: 292) and prawns are cultivated along the coast, especially in Rakhine State and the Tanintharyi Region (even though they only account for 5.6\% of aquacultures; Belton et al. 2015: 15, FAO 2016). After the construction of the Yangon-Thanlyin Bridge, aquaculture expanded substantially in Kyauktan township (from 125.49 acres in 1995 to $4,872.00$ acres in 2000; Khin Khin Soe 2008). Similarly, fish cultures expanded along the Bago-Khayan-Thongwa road with its upgrading process.

Although care is required when considering the statistics - the surface area of ponds is markedly under-reported while yields are markedly over-reported (Belton et al. 2015: 37, 39, 90-92) - two trends can be identified. Yields have more than doubled in the last decade and a half due to a combination of increases in the area under aquaculture and, especially, intensification (Belton et al. 2015: 16). The operating structure is polarised: more than half of the enterprises are very large farms that received concessions for the small amount of land in the Ayeyarwady Delta that was previously uncultivated; otherwise there are numerous small and medium-sized farms and over 200,000 small 'backyard ponds' or 'homestead ponds' in the neighbourhood of farmhouses, particularly

Traditional marine fishery in Ngwe Hsaung

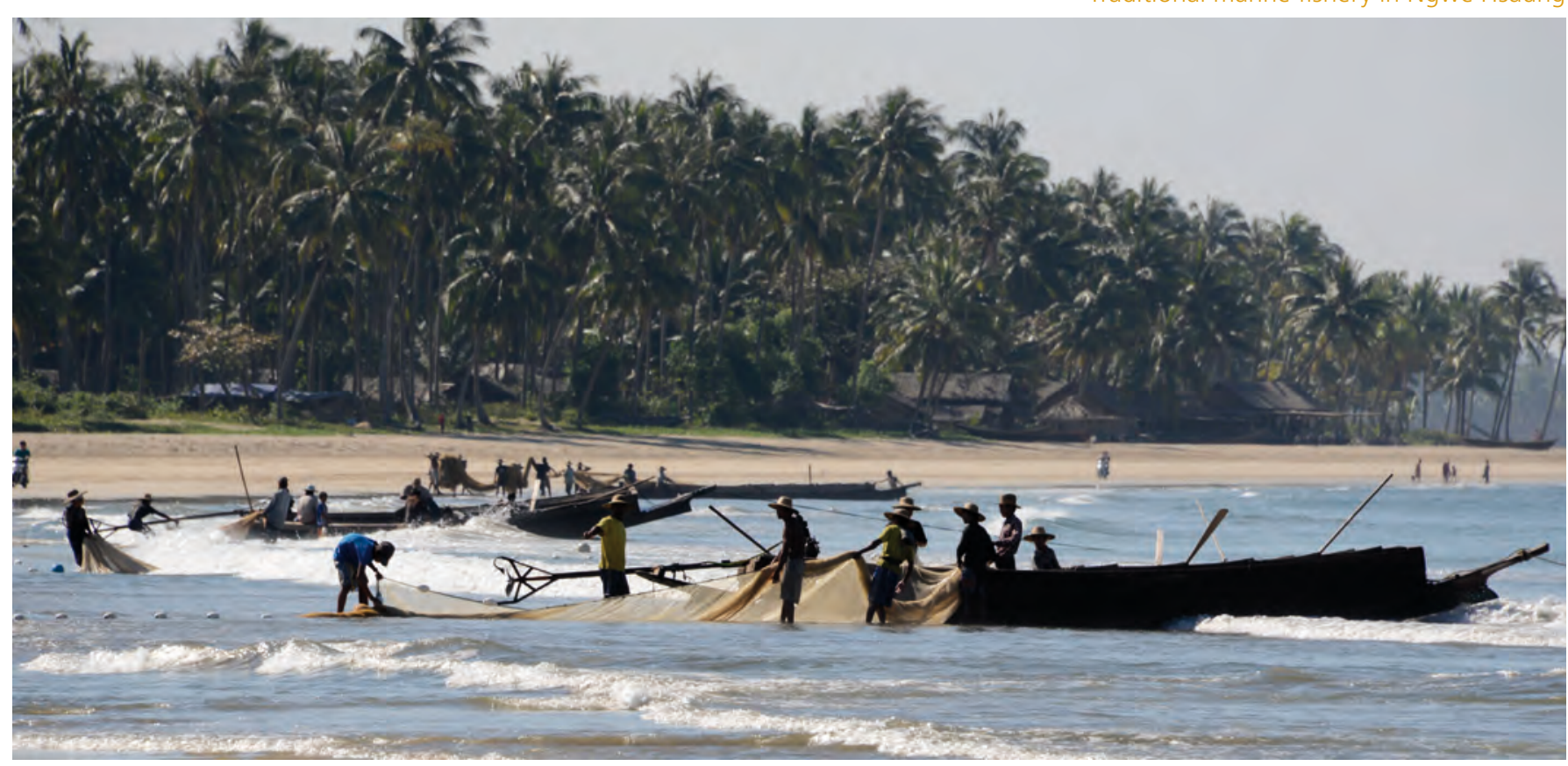


in the southern Ayeyarwady Delta and near Thongwa (Belton 2015: 37, 61).

To date fish farms account for about $20 \%$ of inland fish production; about $38 \%$ of the total volume of farmed fish sold domestically is bought in cities, 62\% in rural areas (Belton et al. 2015: 4). Contrary to the common perception that the majority of aquaculture products are used for export, apparently only about $20 \%$ of products are actually exported, particularly to Kuwait, Saudi Arabia, Bangladesh, UAE and Singapore (Khin Kin Soe 2008, Belton et al. 2015: 18-20).

To date, indigenous carp (rohu, nga myit chin, Labeo rohita) dominate the fish farms, accounting for about $70 \%$ of catches (Belton et al. 2015: 15/16, FAO 2016). Integrated poultry-fish production is increasingly practised; the poultry - usually ducks, chicken or geese - are kept in elongated houses over the fishponds (especially in Hlegu or Kayan; Belton et al. 2015: 33, 35).

More than double the amount of labour is invested in fish-farming than in rice farming. A significant proportion is recruited on a temporary basis and used for the labour-intensive fish harvest or pond construction and repair.
The produce is usually transported by bus and private cars, sometimes by boat to Yangon to Hlaing Thayar or one of the two leading fish markets, San Pya wholesale market in the south-west of Yangon or Shwe Padauk, where the goods are mostly traded and sold through brokers. Dried fish is mostly sent through Bayint Naung Market to Mandalay and Myingyan; salted fish and Nga Si Baung (swim bladder) is sent through Bayint Naung Market to China (Khin Khin Soe 2008).

The sector could be significantly strengthened by the promotion of sustainable forms of production, combined with improved environmental awareness, better advisory services, capacity enhancement, specialised higher education and the development of microcredit-systems for small and medium-sized enterprises (Steins et al. 2015, Nang Mya Han 2016).

Frauke Kraas, Nilar Aung and Khin Khin Soe

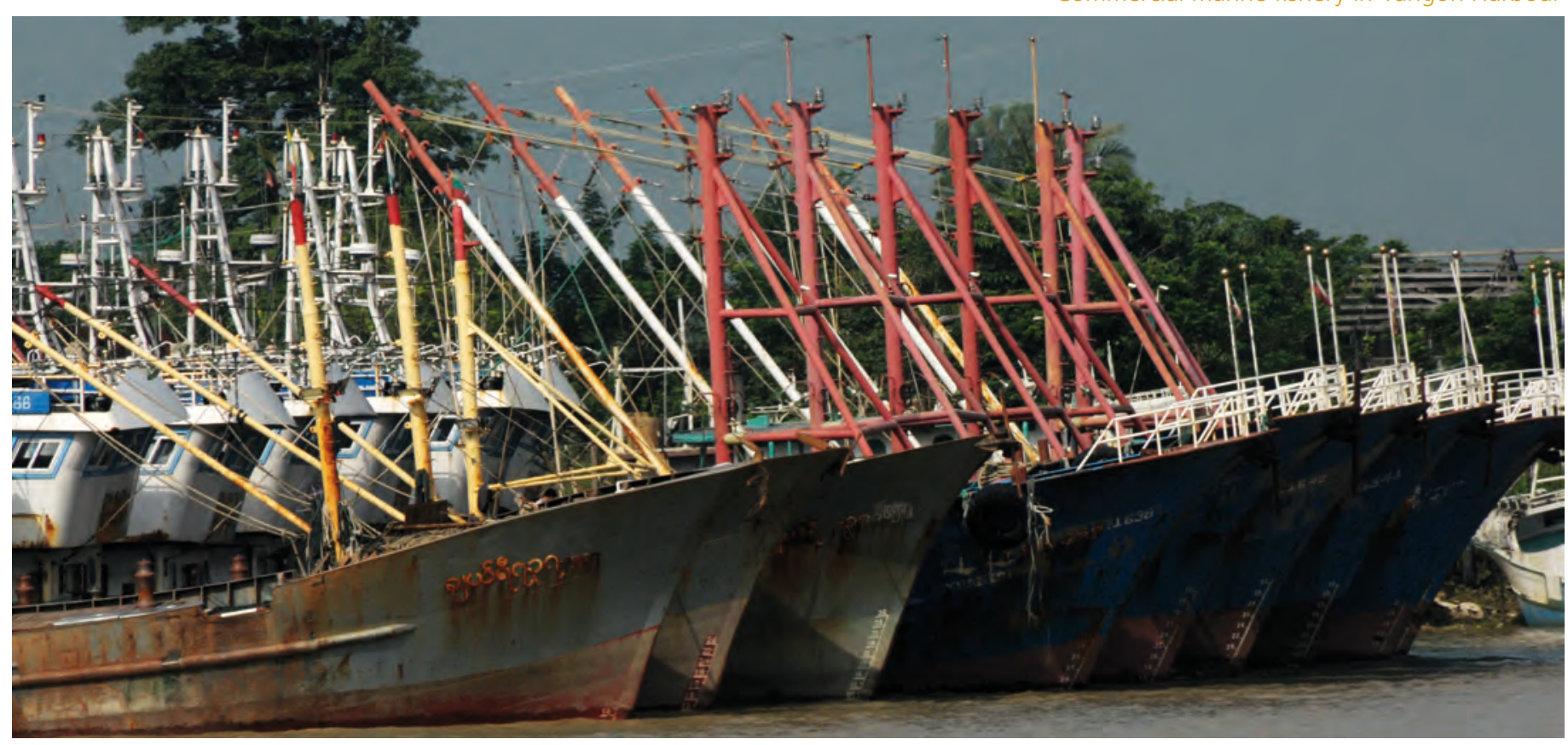




\section{SECONDARY SECTOR DEVELOPMENT AND INDUSTRIALISATION}

Although the secondary sector has been growing in recent years, prior to the post-2011 reforms its role in the country's economic development was relatively minor by comparison with the primary and tertiary sectors: its contribution to GDP was $9.7 \%$ in $2000 / 01$ and $17.5 \%$ in $2005 / 06$. Since $2010 / 11$ its share has risen steadily from $26.5 \%$ to $34.4 \%$ (2014/15), with processing and manufacturing accounting for nearly 20\% of this (MNPED 2015: 203).

\section{HISTORIC DEVELOPMENTS}

Some moves towards industrialisation were made in pre-colonial times under King Mindon, who sought to expand traditional crafts such as sawmills, pottery, shipbuilding and lacquerware production (Aung Tun Thet 1989: 43). During the colonial era the British established large sugar mills (in the 1840s) and rice mills (in the 1860s) as well as textile, rubber and beverage factories, thereby laying the foundations for a food and consumer goods in- dustry (Spate 1941, Andrus 1947). From the 1870s onwards, a colonial export economy based on profits from the 'rice rush' that followed the opening up of the Ayeyarwady Delta (Adas 1974, Aung Tun Thet 1989: 126) developed alongside the traditional subsistence economy that then predominated. In 1940 there were 1,027 factories in operation, including 673 rice mills and 116 sawmills; two-thirds of them were in foreign hands (Walinsky 1962: 46; Aung Tun Thet 1989: 3, Chit So 1999: 127). The opening of the Suez Canal in 1869 boosted the colonial policy of industrialisation of agriculture (Furnivall 1948: 85-90). This was “"agriculturisation" rather than industrialisation' (Kudo 1999: 215) and at the same time 'growth without development' (Aung Tun Thet 1989: 33), because there was no structural reform and domestic entrepreneurship and human resources remained underdeveloped. The industrial sector, which was based almost entirely on resource extraction, led to the statement that 'Burma is a land of isolated outposts of industry' (Grant 1942: 47).

Industrial zones Shwe Lin Ban and Shwepyithar 1 in Yangon

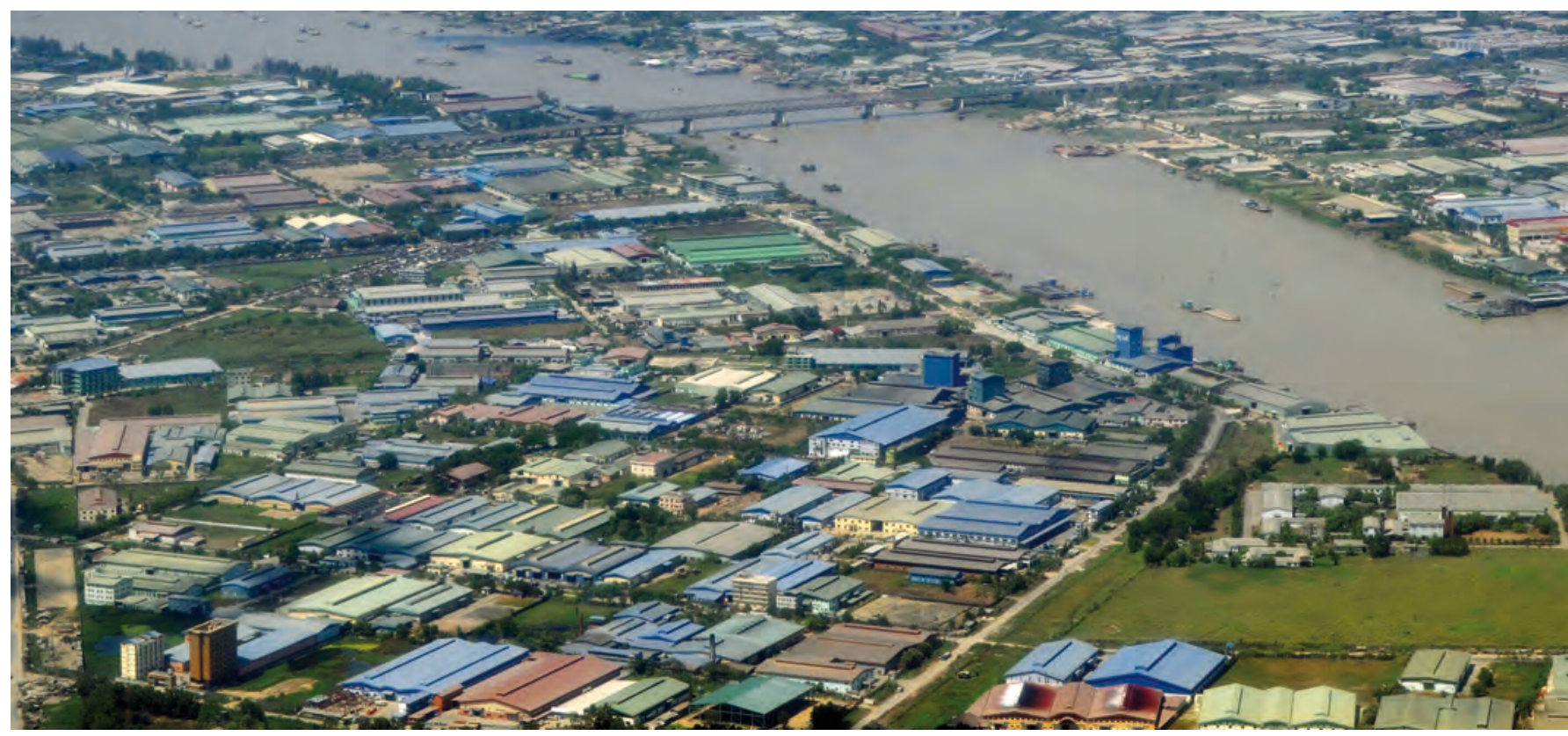


Secondary sector share of total GDP in 2014-2015 by township (in \%)

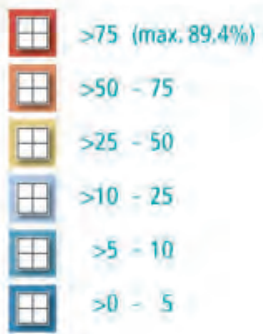

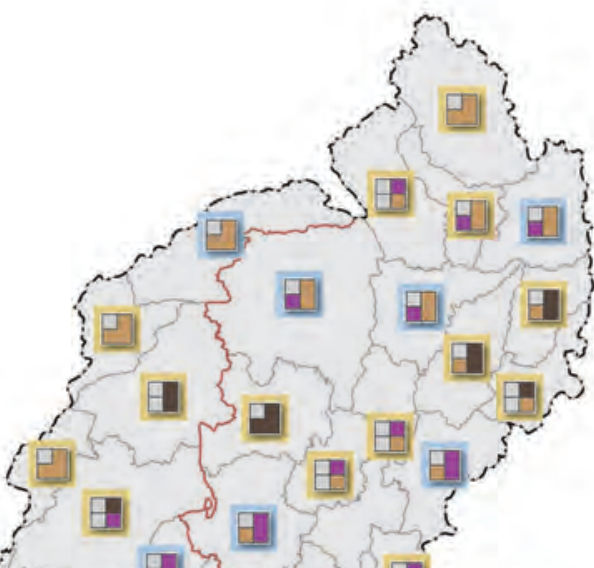

i

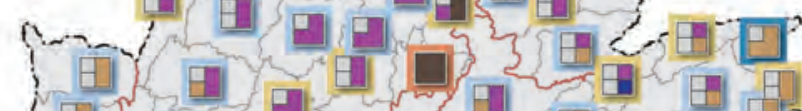

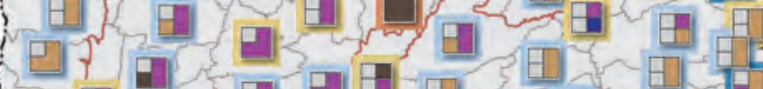

0 D

(a) 田

i n

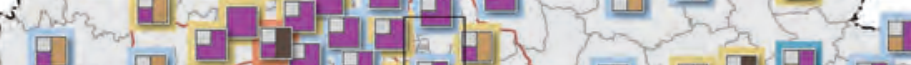

\{.

Un

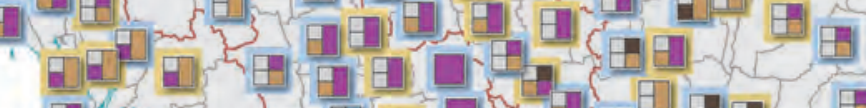

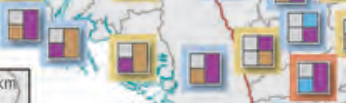

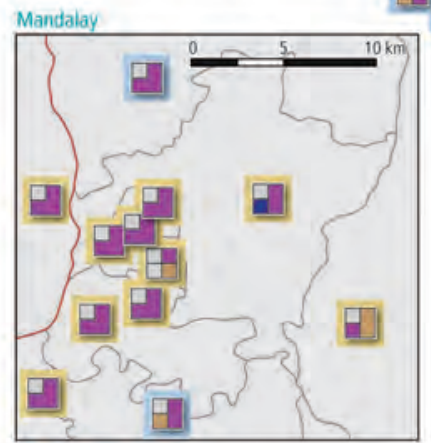

口ir

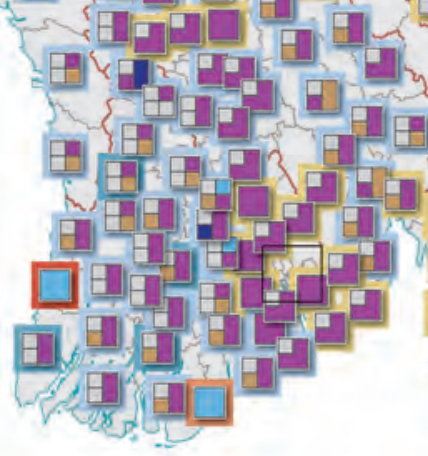

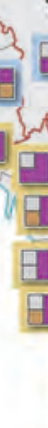

Dominant subsectors' share of secondary sector GDP in 2014-2015 (by township, in \%)

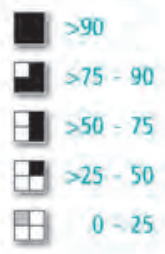

Subsectors of the secondary sector"

$\square$ Energy

Production and Manufacturing Electric power

Construction
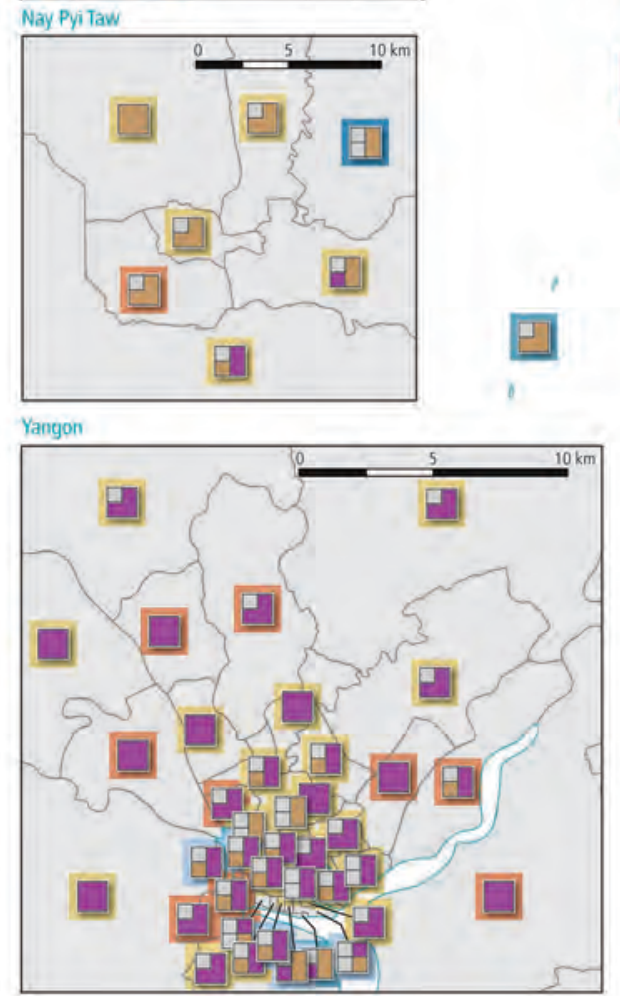

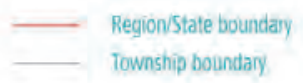

Source Mwied 2015 (Defratment of Plarminty). MMMU celiease Apoll 2014 imodified)

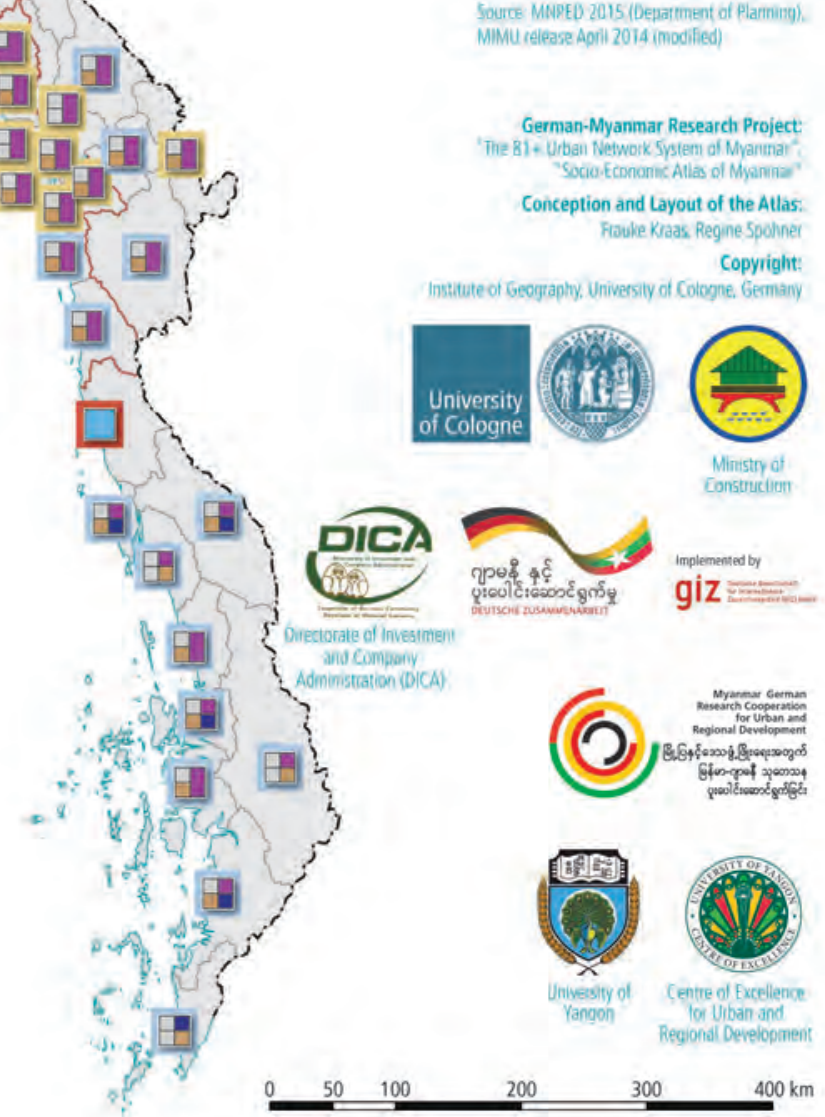




\begin{tabular}{|c|c|c|}
\hline MAIN ECONOMIC ACTIVITY OF BUSINESS & NUMBER & $\%$ \\
\hline $\begin{array}{r}\text { RETAIL TRADE } \\
\text { (EXCEPT MOTOR VEHICLES AND MOTORCYCLES) }\end{array}$ & 27,492 & 21.7 \\
\hline $\begin{array}{r}\text { MANUFACTURE OF FOOD PRODUCTS, BEVERAGES AND } \\
\text { TOBACCO PRODUCTS }\end{array}$ & 27,127 & 21.4 \\
\hline FOOD AND BEVERAGE SERVICE ACTIVITIES & 18,890 & 14.9 \\
\hline $\begin{array}{r}\text { WHOLESALE TRADE } \\
\text { (EXCEPT MOTOR VEHICLES AND MOTORCYCLES) }\end{array}$ & 8,480 & 6.7 \\
\hline $\begin{array}{l}\text { MANUFACTURE OF RUBBER AND PLASTIC PRODUCTS, } \\
\text { AND OTHER NON-METALLIC MINERAL PRODUCTS }\end{array}$ & 7,137 & 5.6 \\
\hline $\begin{array}{r}\text { TRADE AND REPAIR OF MOTOR VEHICLES AND } \\
\text { MOTORCYCLES }\end{array}$ & 5,397 & 4.3 \\
\hline OTHER SERVICE ACTIVITIES & 4,624 & 3.6 \\
\hline TRANSPORTATION AND STORAGE & 4,150 & 3.3 \\
\hline $\begin{array}{r}\text { OTHER MANUFACTURING; REPAIR AND INSTALLATION } \\
\text { OF MACHINERY AND EQUIPMENT }\end{array}$ & 4,109 & 3.2 \\
\hline $\begin{array}{r}\text { MANUFACTURE OF TEXTILES, WEARING APPAREL, } \\
\text { LEATHER AND RELATED PRODUCTS }\end{array}$ & 3,930 & 3.0 \\
\hline $\begin{array}{l}\text { MANUFACTURE OF BASIC METALS AND FABRICATED } \\
\text { METAL PRODUCTS, EXCEPT MACHINERY AND EQUIPMENT }\end{array}$ & 3,077 & 2.4 \\
\hline ACCOMMODATION & 2,348 & 1.8 \\
\hline ADMINISTRATIVE AND SUPPORT SERVICE ACTIVITIES & 1,904 & 1.5 \\
\hline $\begin{array}{r}\text { MANUFACTURE OF PAPER PRODUCTS; PRINTING AND } \\
\text { REPRODUCTION OF RECORDED MEDIA }\end{array}$ & 1,455 & 1.0 \\
\hline MANUFACTURE OF FURNITURE & 1,229 & 1.0 \\
\hline MANUFACTURE OF WOOD PRODUCTS & 1,114 & 0.9 \\
\hline HUMAN HEALTH ACTIVITIES & 610 & 0.5 \\
\hline $\begin{array}{r}\text { PUBLISHING, AUDIOVISUAL AND } \\
\text { BROADCASTING ACTIVITIES }\end{array}$ & 560 & 0.4 \\
\hline MINING AND QUARRYING & 504 & 0.4 \\
\hline MANUFACTURE OF TRANSPORT EQUIPMENT & 486 & 0.4 \\
\hline IT AND OTHER INFORMATION SERVICES & 332 & 0.3 \\
\hline EDUCATION & 331 & 0.3 \\
\hline ARTS, ENTERTAINMENT AND RECREATION & 320 & 0.3 \\
\hline PROFESSIONAL, SCIENTIFIC AND TECHNICAL ACTIVITIES & 318 & 0.3 \\
\hline $\begin{array}{r}\text { MANUFACTURE OF CHEMICALS AND } \\
\text { CHEMICAL PRODUCTS }\end{array}$ & 299 & 0.2 \\
\hline $\begin{array}{l}\text { MANUFACTURE OF BASIC PHARMACEUTICAL } \\
\text { PRODUCTS AND PHARMACEUTICAL PREPARATIONS }\end{array}$ & 228 & 0.2 \\
\hline MANUFACTURE OF MACHINERY AND EQUIPMENT N.E.C. & 187 & 0.1 \\
\hline CONSTRUCTION & 161 & 0.1 \\
\hline $\begin{array}{r}\text { ELECTRICITY, GAS, STEAM AND } \\
\text { AIR CONDITIONING SUPPLY } \\
\end{array}$ & 104 & 0.1 \\
\hline MANUFACTURE OF ELECTRICAL EQUIPMENT & 51 & 0.0 \\
\hline $\begin{array}{r}\text { WATER SUPPLY; SEWERAGE, WASTE MANAGEMENT AND } \\
\text { REMEDIATION }\end{array}$ & 44 & 0.0 \\
\hline REAL ESTATE ACTIVITIES & 29 & 0.0 \\
\hline TOTAL & 126,928 & 100.0 \\
\hline
\end{tabular}

Distribution of Businesses Across Economic Sectors (MoPF 2016: 359)
After independence there were four periods of economic liberalisation during which deliberate attempts were made to promote industrialisation (Myat Thein 2004, Kudo/Odaka 2016: 156-160): (1) The aims of the brief liberalisation that followed the Eight-Year Economic Plan (the Pyidawtha Plan of 1952) included the transfer of foreign-owned companies to Myanmar nationals and a state-driven boosting of industrial production (Government of Burma 1952, KTAM 1953, Myat Thein 2004: 16-21). This period ended with the coup d'état of 1962 . The nationalisation that took place as part of the 'Burmese Way to Socialism' saw private companies converted into state-owned ones. (2) After 1974 the country became eligible to receive official development assistance (ODA). These payments did little to revive the industrial sector, instead leading only to an accumulation of foreign debt and, as the country began to slide into recession and political opposition mounted, resulting (3) from 1988 onwards in the introduction of a market-oriented economy (von Hauff 2007). Despite a restructuring of foreign direct investment and abolition of the nationalisation policy, twelve key sectors remained under government control after 1989. They included forestry, oil and gas, gemstones, energy, post and telecommunications, transport, the media and arms production (Kudo/Odaka 2016: 158). Moreover, in the wake of the Asian financial crisis of 1997 and the imposition of sanctions by western nations, industrialisation struggled to get under way. (4) It was only as part of the latest post2011 transformation processes, which gathered pace after the 2015 elections, that significant economic liberalisation, internationalisation and growing industrialisation occurred.

\section{CURRENT SITUATION}

Nationalised businesses currently suffer from inadequate modernisation, low labour efficiency, undercapitalisation, renovation backlogs, poor horizontal networking and weak sales markets, while private-sector companies are hampered by bureaucratic obstacles, poor basic infrastructure, inadequate access to electricity and financial loans and insufficient pre- 
paredness for international competition. Privatisation is also hindered by the institutional environment, a poorly trained workforce, limited market-economy thinking and a shortage of managers. Furthermore, there is a lack of standards for waste disposal, hygiene, environmental protection and sustainability awareness (Tin Maung Maung Than 2007, Kudo/Odaka 2016: 170-183).

Geographically, enterprises in the secondary sector that contribute to the gross domestic product (GDP) are concentrated on the one hand in some centres of mining and energy generation and on the other in industrial manufacturing sites, the majority of which are located in the central lowlands and the regional cities. In the peripheral parts of the country, GDP is generated mainly by the construction sector. Privately owned factories are concentrated in two separate areas: the Mandalay Region (2009: $17.7 \%$ of all companies in Myanmar) and the Yangon Region (14.0\%). With the addition of the Bago, Sagaing and Ayeyarwady Regions, almost $70 \%$ of all private-sector industrial companies are located in these five areas (Kudo/Odaka 2016: 173). The food and beverage industry is distributed evenly between the regions. Textile manufacture, metal processing and machinery production are concentrated in the area in and around Mandalay, while Yangon is the centre of chemical, paper, plastic, rubber and non-metallic production (Kudo/Odaka 2016: 173). The creation of special industrial zones is intended to foster industrialisation throughout the country. However, many of these zones - especially those located in or near the big cities, notably Yangon and Mandalay - are not altogether successful. Development is hindered by bureaucratic obstacles, the time-consuming process of obtaining licences, blocked development as a result of land speculation, inadequate access to electricity and in some cases water, poor waste and sewage disposal facilities, limited technological modernisation, lack of access to loans, and environmental problems (Zin Nwe Myint 2006b, Moe Kyaw 2009, San Thein 2012, von Hauff 2016).

In the medium term it is likely that if industrialisation continues it will result in an economic dualism in which a small technologically modernised industrial sector with an increasingly international outlook contrasts with a large number of small and medium enterprises that continue to employ traditional production methods and are not internationally competitive (Kudo/Odaka 2016: 171). In addition, regional and social disparities within the country may well increase.

Frauke Kraas and Zin Nwe Myint

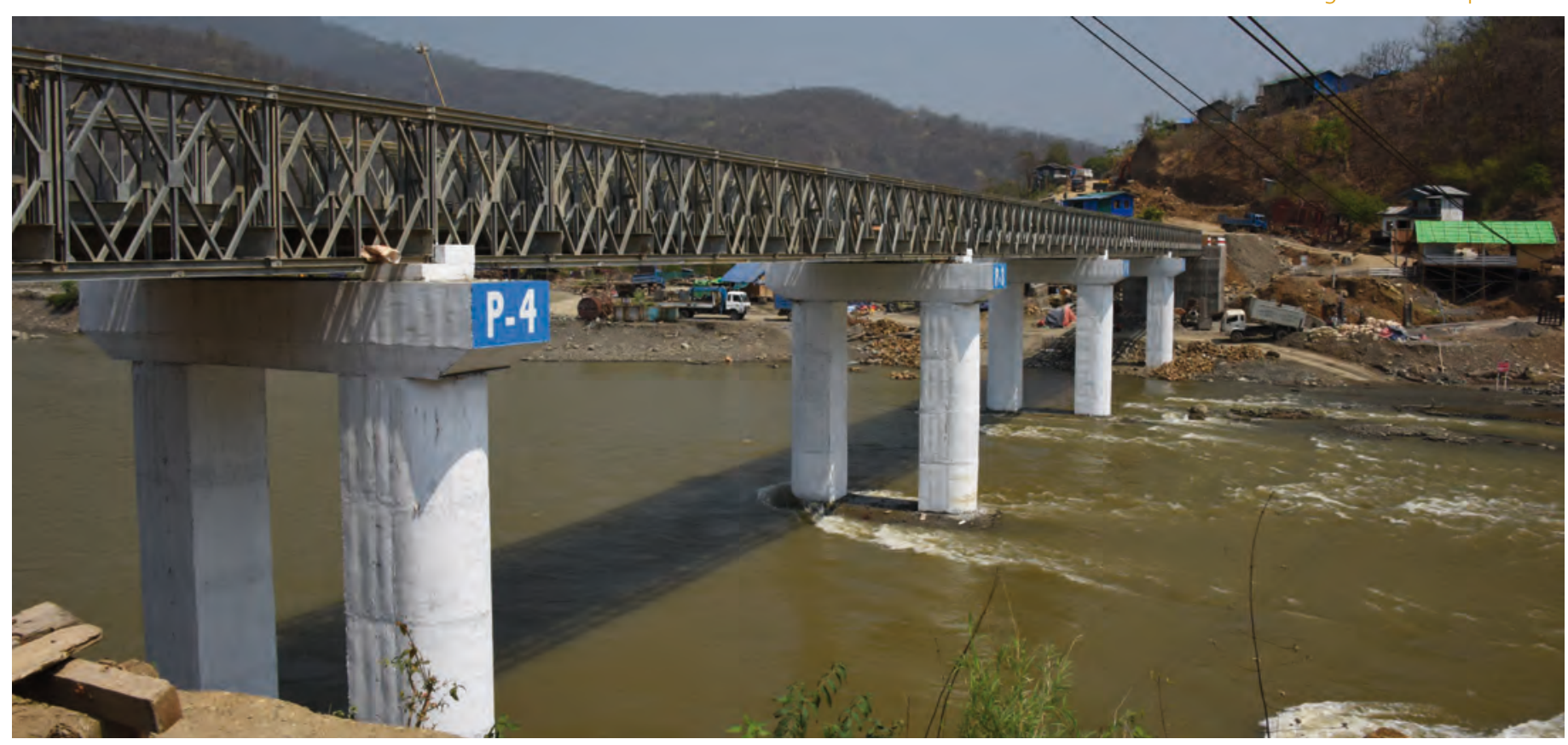




\section{CRAFTS}

Crafts are one of the most valuable assets of Myanmar and represent an enormous potential. Incomprehensively, they have not yet received much attention in the economic development of the country. Various craft traditions have developed over the centuries - some at the courts of the kings and rulers, some as quotidian art through everyday objects - and there are numerous regional specialisations.

Fraser-Lu stated that there was no 'distinction between the 'fine arts' and the decorative or 'applied arts'. The arts of the metalworker and those of the wood-carver and lacquer worker are not regarded as secondary to architecture, painting, and sculpture. All art in Burma traditionally had the same purpose, that of furnishing the religion and court with objects of consummate beauty and of providing the common people with attractive, well-crafted objects for everyday use' (1994: 7).

The craft culture encompasses a rich spectrum of different products (Fraser-Lu 1994, Golloch 2014):
- The weaving of traditional fabrics and longyis is widely distributed through all parts of the country. The products display typical patterns, colours and fabrications for different ethnic groups. In the villages many households still practise traditional weaving (often jacko weaving) but larger looms, weaving for wages and mechanical weaving mills are increasingly widespread.

- Elaborate wood carving with figural and floral motifs decorates numerous wooden monasteries and pagodas, for instance in Mandalay (Moilanen/Ozhegov 1999). But buildings, agricultural machinery and everyday objects are also impressively decorated.

- Traditional lacquerware production is concentrated in the area of Bagan, but workshops are also found in Inwa, Maungdaung, Kyaukka, Mandalay, at Inle Lake, in Laihka and Kengtung (Weigelt 2005: 10). The base material is normal wood, soft wood, bamboo split into thin strips or basic forms

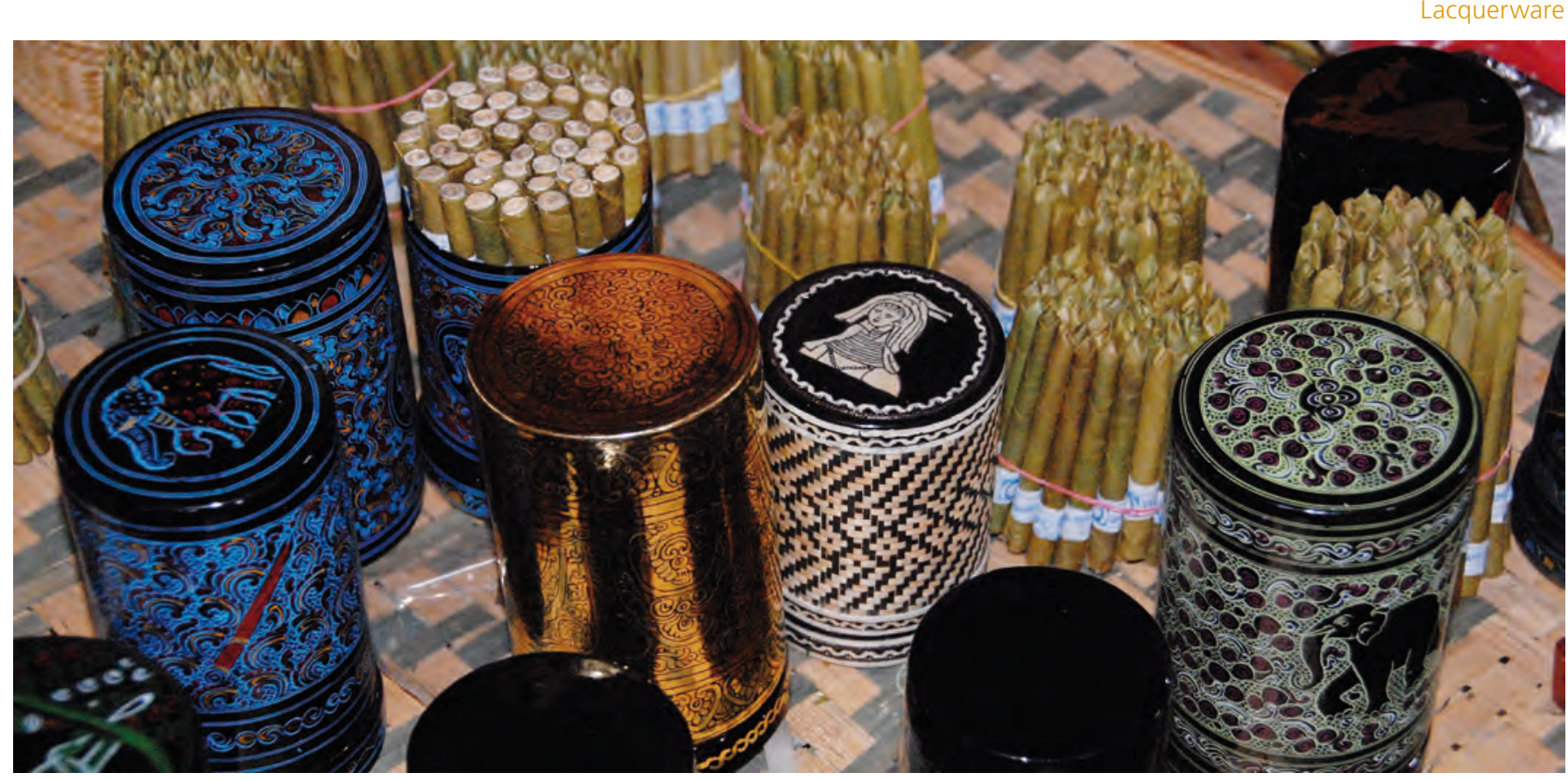


made of braided horsehair. The lacquer is applied to this material layer by layer, dried and smoothed, then decorated with coloured patterns and ornaments, and in some cases with gold leaf, and polished. Very different techniques, decorations and designs characterise the different workshops (Fraser-Lu 2000).

- The workshops of artistic stonemasons are concentrated in the larger area of Mandalay and Sagaing. Marble from the Sagyin marble quarry north of Mandalay is used here, primarily to create sculptures of Buddha. Specialised bronze and brass foundries are also located in the area and use traditional techniques to manufacture sculptures, bells and small articles - increasingly for international customers.

- Precious and semi-precious stones are worked into jewellery, sculptures and pearls or are artistically scattered or laid out to create gemstone pictures, particularly in Mogok and Kyatpyin, but also in Mandalay, Sagaing and Yangon.

Many other regional craft centres exist in almost all parts of the country: pottery is manufactured especially in Pakkoku, Sagaing (Khin Khin Soe/Kraas/Yee Yee Than 2016) and Twante, umbrella production is concentrated in Pathein and at Inle Lake. At Inle Lake and in Taunggyi production furthermore centres around traditional Shan bags, valuable fabrics made from lotus plants, handmade paper created from petals, and cheroots and tobaccos. Other special craft traditions include silversmithing and goldsmithing, the textile art of the kalagas, beadwork, and the manufacture of marionettes, musical instruments, chin-lon balls, mats, panels, trays, all sorts of baskets, slate panels, wooden pipes, Pumtek beads and papier-mâché masks and toys.

Little comprehensive work has been undertaken on the spatial focuses or economic and social significance of local crafts, and there are no relevant statistics. Reports on economic performance often fail to even mention crafts. In contrast to many other Asian states that have been transformed by globalised economic development, Myanmar still possesses an enormous store of living and intact traditional knowledge on craft - along with the rich reserves of raw materials this represents the largest endogenous potential of the country in the current transformation process.

Frauke Kraas and Khin Khin Soe

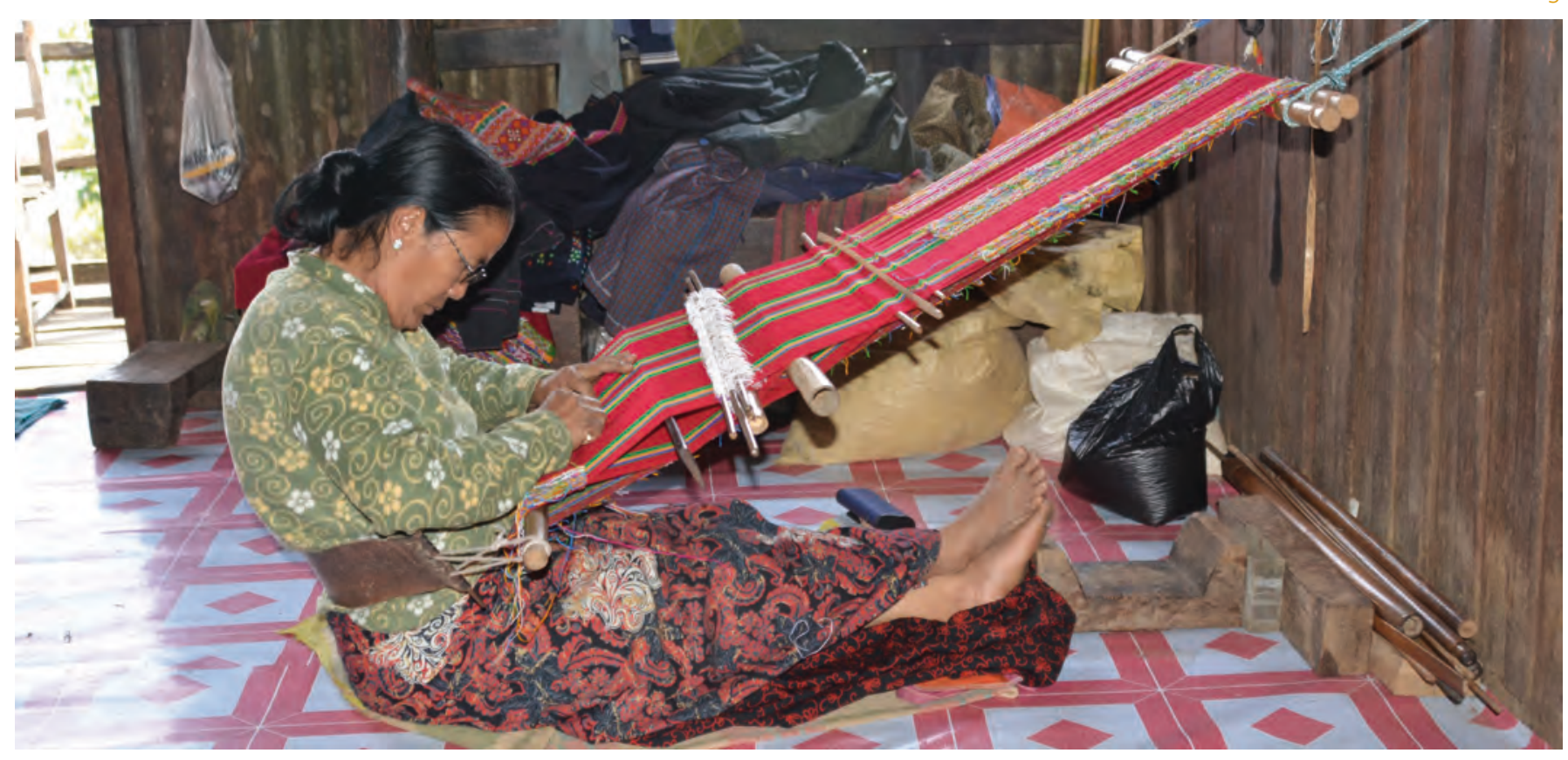




\section{GARMENT INDUSTRY IN YANGON}

The development of an export-oriented textile and clothing industry in Myanmar after the shift to a market-oriented economy is a young process. Its origins lie in the fact that in the early 1990s state-owned, military-related textile and clothing factories pursuing a policy of import substitution started to produce for the foreign market, after companies from, in particular, Korea and Hong Kong had begun to gain a foothold in Myanmar through joint ventures. Companies that were entirely foreignowned followed, and they were joined from the mid-1990s by the first domestic private enterprises. This led to a production and export boom at the end of the 1990s; the boom peaked in 2001, when clothing worth 868 million US dollars accounted for $40 \%$ of all Myanmar's exports (Kudo 2009b: 79). The export-led development strategy was temporarily halted by the imposition of sanctions by the USA and western countries in 2003.

The sector's growth was fuelled by the growing market demand from the European Union (which took approx. 50\% of production) and the USA (approx. 45\%). The majority of businesses operated on the basis of the cutting, making and packaging (CMP) principle. Production involved conventional technology and low levels of investment. The business environment was favourable, because under the MultiFibre Agreement (MFA) there were virtually no import restrictions, and Myanmar had a pool of sufficiently cheap labour. There were also advantages inherent in the CMP system, since it allowed the raw material to be imported at low cost (Kudo 2009b: 81). 'Myanmar industrialists did not need to concern themselves with the controls surrounding imports and exports, or by tedious procedures, as in other sectors. ... they could have access to imported raw materials without "export earnings" under the CMP arrangement' (Kudo 2009b: 82). Furthermore, the private companies were not competing with the state-owned economic enterprises (SEEs), which meant that the boom under the prevailing conditions of the marketoriented economy could be achieved through self-sustained growth primarily on the basis of market incentives: 'The government did nothing to promote it, but also did nothing to impede it' (Kudo 2009b: 85).

Geographically the garment industry is concentrated in and around Yangon, where production takes place in the large industrial zones and industrial parks, especially in Hlaing Tharyar Industrial Zone, Yangon Industrial Park, Shwe Lin Ban Industrial Zone and Shwe Pyi Thar Industrial Zones I and II, with up to 35,000 jobs in each. Other smaller clusters are located in other industrial zones in the former capital city. Outside Yangon only Bago, Thanlyin, Hmawbi and Pathein are involved in the garment industry. On account of the almost complete concentration on the labourintensive and export-oriented cutting-makingpackaging principle, virtually nothing is produced for the local market. To a very small extent (geographically mostly in inner-city locations), some design and training takes place. The majority of the companies involved are joint ventures or funded by foreign investment; some companies from Myanmar operate in the industrial zones of Hlaing Tharyar, Shwe Pyi Thar, Pyin Mabin, Shwe Pauk Kann Mayangone and South Dagon (all data: statistical details for 2015, MGMA 2015).

Frauke Kraas and Zin Nwe Myint 


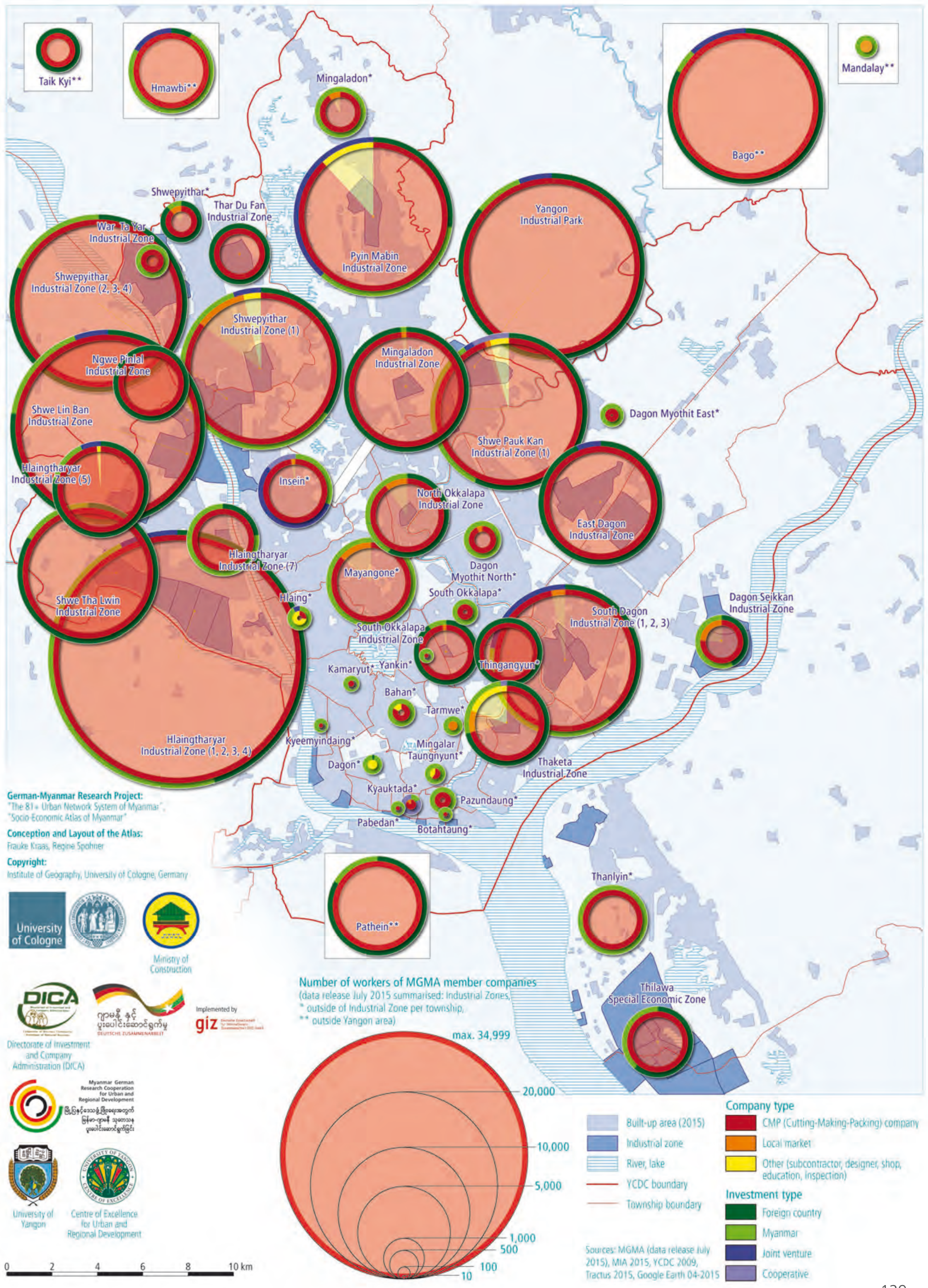




\section{THE TERTIARY SECTOR: ADMINISTRATION, TRADE, TRANSPORTATION AND TOURISM}

After the primary sector it is the tertiary sector that plays the next most important economic role in Myanmar, and within this sector trade and transport predominate. The tertiary sector's contribution to GDP rose from $33.0 \%$ in $2000 / 01$ to $36.7 \%$ in $2010 / 11$ and $37.7 \%$ in $2014 / 15$. The proportion accounted for by trade fell from $24.0 \%$ in $2000 / 01$ to $20.1 \%$ in $2010 / 11$ and $18.7 \%$ in 2014/15, while the figures for the transport sector in these three periods rose from 5.7\% to $11.5 \%$ and then remained at $11.5 \%$. Slight increases were also reported in the shares accounted for by communications $(0.3 \%$ to $0.8 \%$ and $1.9 \%)$ and social and administrative services $(1.5 \%$ to $2.3 \%$ and $3.1 \%$ ) (all data: MNPED 2015: 203).

Regional differences in the tertiary sector's contribution to GDP - both overall and specifically through trade and transport - are also informative. As expected, the geographi- cal focal points are the cities of Yangon and Mandalay. A large proportion of trade is concentrated in the central lowlands in general, the Greater Yangon area and the southern Sagaing Region. The lowlands also account for a large proportion of transport, as do Rakhine and Mon States, where the tertiary sector is almost the sole generator of GDP. Trade dominates in large parts of the mountainous areas of the Sagaing and Tanintharyi Regions and Shan State. As is to be expected, tertiarisation is particularly strong in the capital city: more than $75 \%$ of the GDP generated there comes from employment in public administration. Administrative and social services also make a noticeable contribution to GDP generation in the structurally weak mountainous areas - that is, in Chin State and the peripheral townships of Kachin State.

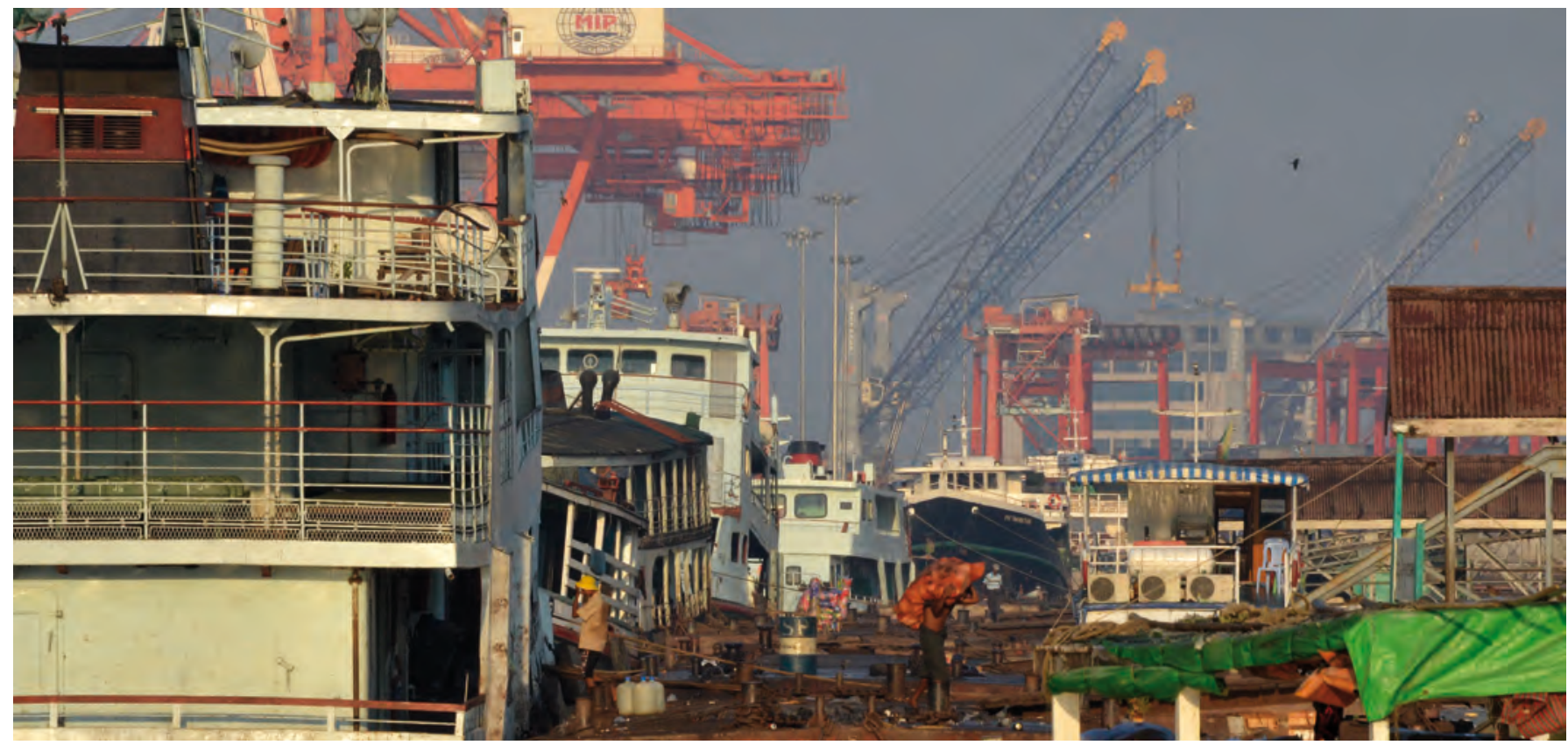


Tertiary sector share of total GDP in 2014-2015 by township (in \%)
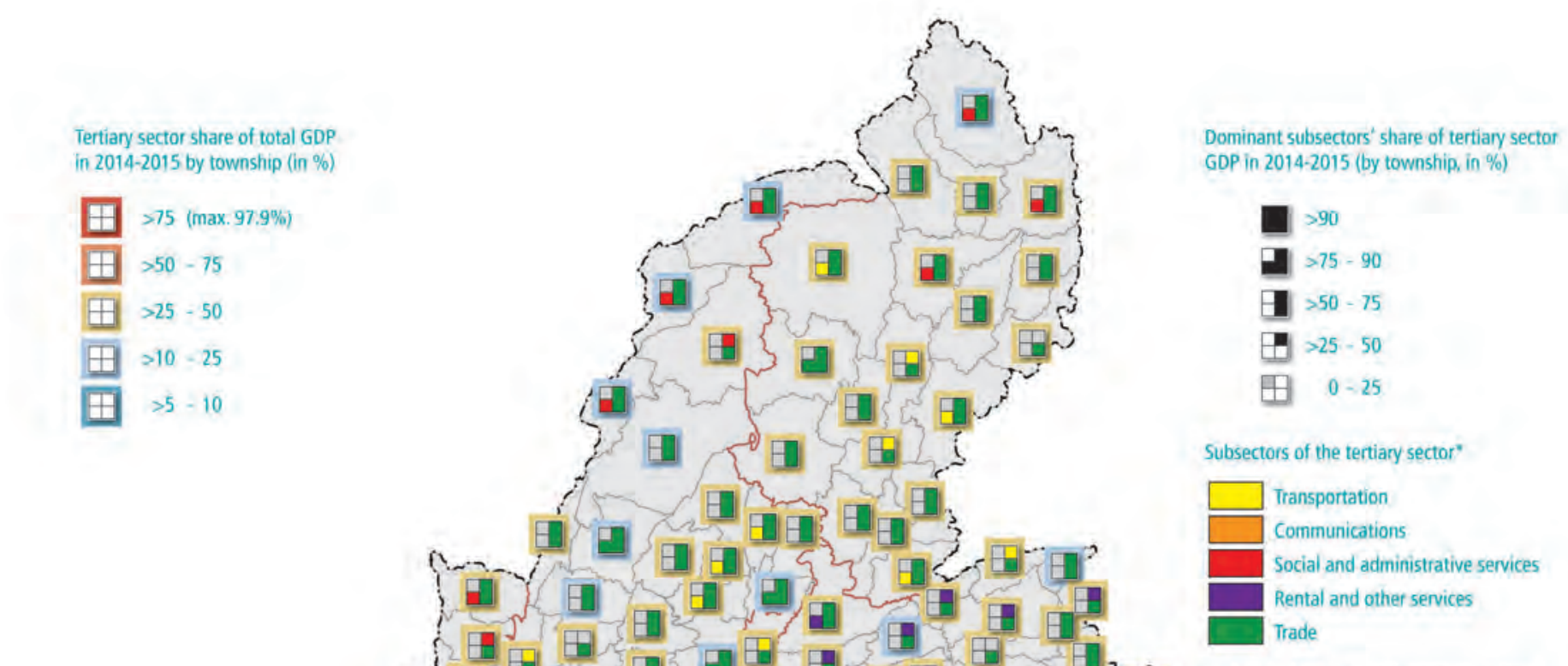

Social and administrative services

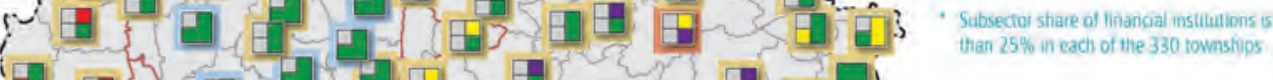
i

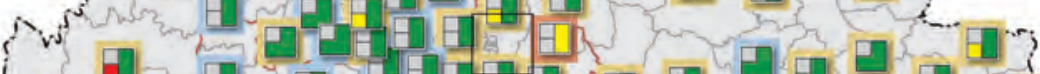

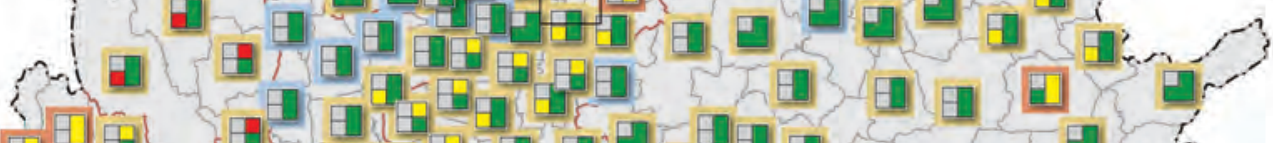
开国

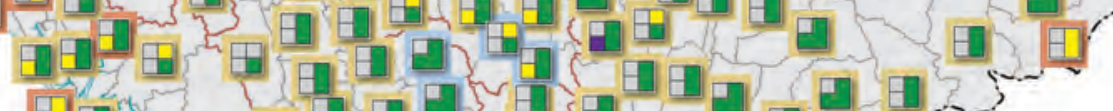
由l

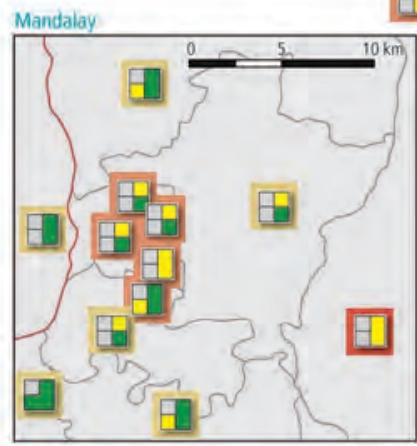
a 0

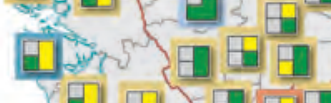
$\{$ a 3$\}$ I)

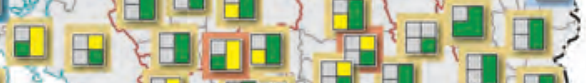

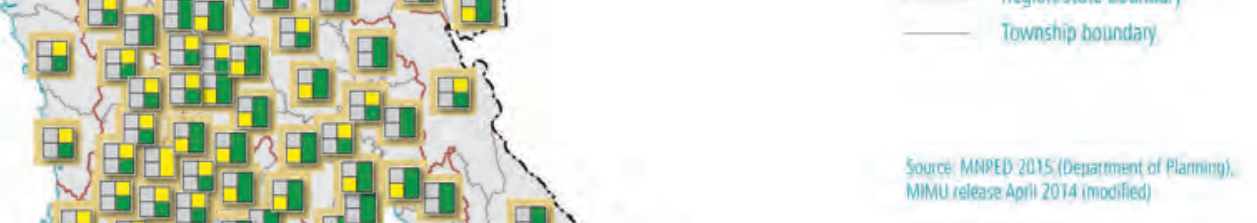

Nay Pyi Taw
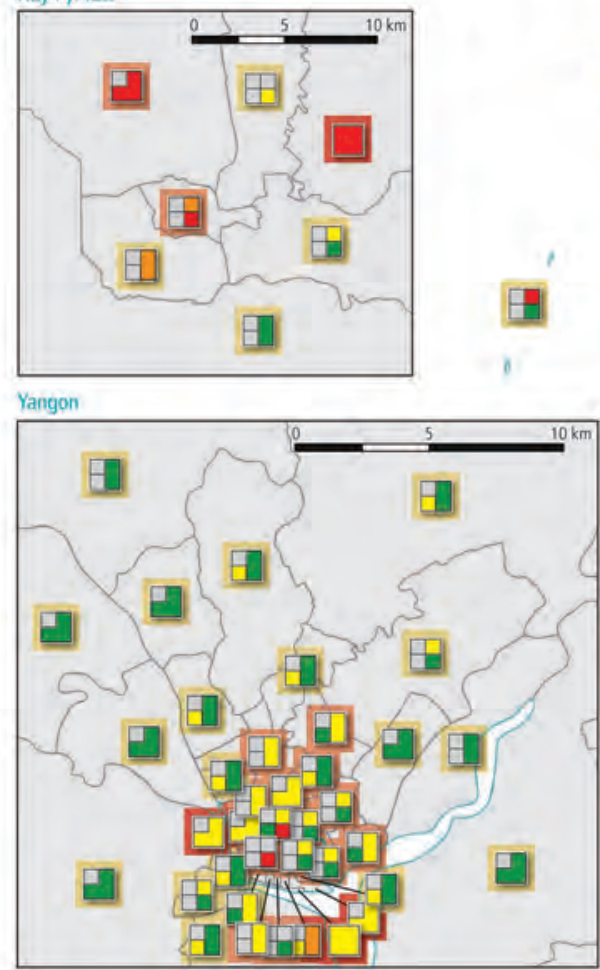

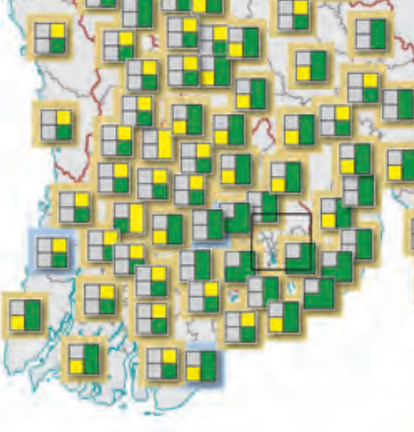

国

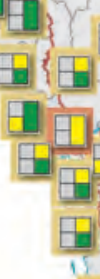

Source MAPED 2015 (Depratment of
MiMU release Apili 2014 imodified)

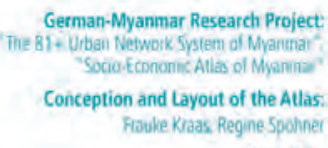
Copyright: Instute of Geography, Universily of Cologne. Germany
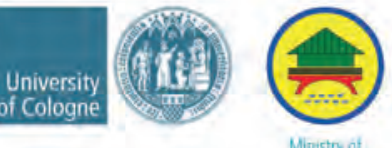

Ministry of

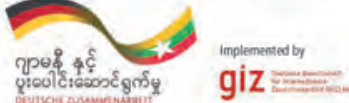

(2)

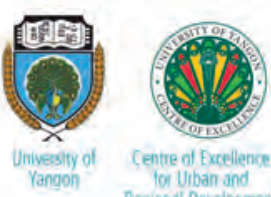

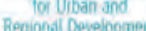




\section{TOURISM DEVELOPMENT}

Tourism plays a particularly important part in the country's economic development, although it is not regionally identifiable in the GDP earnings of the townships. As a result of both growing domestic tourism and a significant increase in tourism from abroad, it is one of the most strongly growing economic sectors in Myanmar as well as an important earner of foreign currency.

Myanmar has experienced rapid growth in tourism demand, particularly since 2011, and is beginning to diversify its range of tourism products and services. The country offers immense potential for tourism development, with an abundance of cultural and natural heritage, the genuine hospitality of its people and, at least for the moment, the exotic appeal of a hitherto 'unexplored' country (at least viewed from a foreign perspective). This is flanked by rising incomes in its Asian neighbours, with an accompanying surge in investment and interest in foreign travel.

Its eminent religious and cultural sites, the lively traditions of the country's many ethnic groups and the great diversity of its natural and cultural assets offer immense potential for tourism development. These primary assets are enhanced by increasingly diversified secondary tourism resources. Numerous hotels and restaurants, mainly in the mid to upper price segment, have opened recently and international hotel investors are entering the market. The offering in the formal and informal souvenir trade is expanding and the range of tourism or tourism-related services is also increasing. A Tourism Master Plan was published in 2013 (MoHT 2013b).

Although the pre-colonial visits by explorers and missionaries cannot be described as 'tourism' in the narrower sense, the images and impressions that they conveyed attracted growing numbers of investors and merchants, paving the way for the initial phase of early tourism development during the British colonial period. This led to the emergence of international tourism - primarily for the purpose of culture, education, adventure and hunting and mainly targeted at the elites - towards the end of the 19th century. After the country gained its independence in 1948, however, the length of time that international visitors could feasibly remain in the country and their freedom to travel were initially limited by the impacts of conflict and civil war. Travel was then further constrained by the nationalisation of industries and the policy of autarky and isolation from 1962.

It was not until the introduction of a marketoriented economy after 1988 that a second phase of tourism development could begin. This took place in 1996 with the launch of the 'Visit Myanmar Year' marketing campaign, the systematic objective of which was to encourage more openness to tourism in general and to facilitate the expansion of a small number of centres, specifically the classic 'quadrangle' comprising Yangon, Bagan, Mandalay and Inle Lake (Kraas/Zin Nwe Myint 2015). However, the country's poor transport and supply infrastructure and hence its inaccessibility meant that there was virtually no tourism development in its peripheral regions. A distinct seasonality (high season: November to midApril, before the start of the monsoon) additionally limited opportunities for tourism development. A system of obligatory currency exchange, unrealistically high exchange rates and the impacts of the sanctions were further impediments.

A third phase of tourism development began with a rapid increase in visitor numbers triggered by the current transformation process (Kraas/Häusler 2016). In 2015, the number of domestic tourists reached 2.5 million, with weekend pilgrimages or visits to family accounting for most of this activity. According to official statistics, Myanmar hosted around 800,000 foreign visitors in 2010, and this increased to more than one million in 2012 and approximately 4.6 million in 2015. However, these figures, published by the Ministry of Hotels and Tourism (MoHT), are of only limited reliability as they include day-trippers from neighbouring countries who crossed the border for the purpose of trade or to visit family (Myanmar Times, 19.1.2015). Out of 


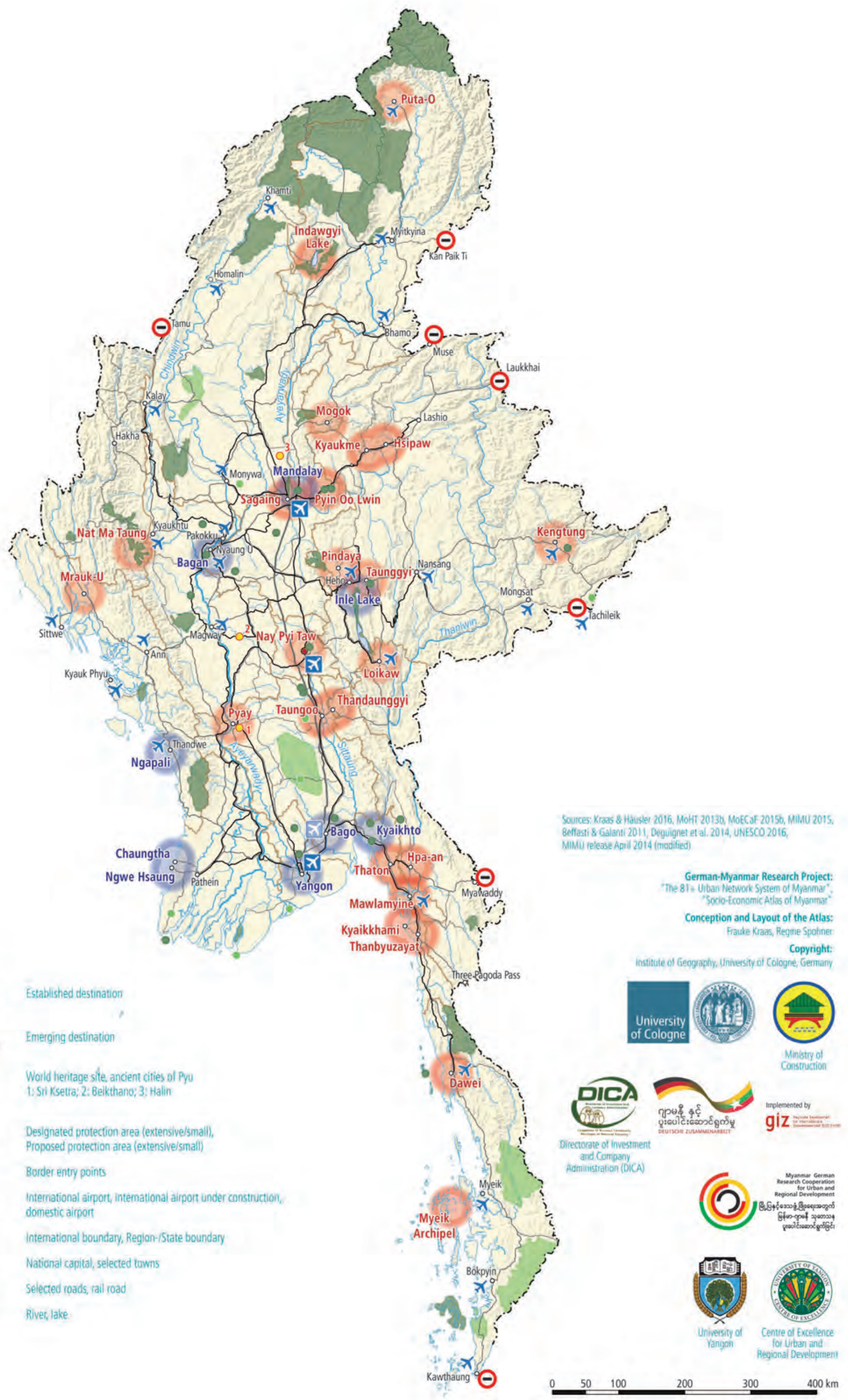


around one million international arrivals, some 500,000 incoming visitors described themselves as 'Foreign Individual Travellers' (FITs) or as 'Package Tour' tourists. Most of the rest were travelling on business or visiting family. The Shwedagon Pagoda, Yangon's landmark and main attraction, was visited by half a million tourists, while other key destinations, which mainly attract Westerners and the Japanese, report visitor numbers of around 250,000, suggesting that a figure of around 500,000 'real' tourists (i.e. for leisure purpose) is realistic; more precise statistics are not available.

\section{TOURISM CENTRES AND REGIONS}

Myanmar has a number of well-established centres of international tourism whose significant religious, cultural and historical sites have attracted visitors for decades (Kraas/Häusler 2016). They include the area around the archaeological site of Bagan - dating back to the 9th century, with its pagodas, which extend across an area of more than $36 \mathrm{~km}^{2}$ (Kyaw Lat 2010) - and ancient royal capitals like Bago, Dagon, Taungoo and Mandalay. Inle Lake, surrounded by $1500 \mathrm{~m}$ high mountains, is another classic element of any tourist programme; here, the diversity of the natural and cultural assets is the main attraction. The floating gardens of Inle Lake are a unique feature of the horticultural landscape here: these 'islands' or floating garden beds are anchored to the floor of the lake and, with the application of earth, plants and algae as a soil substrate, are used for the cultivation of vegetables and flowers on the lake itself (Wilhelmy 1986, Nilar Aung 2013). The constant availability of water enables these crops to be grown all year round. For local people, most of whom live in simple houses on stilts at the water's edge, seasonal tourism provides an additional source of income alongside farming, fishing and crafts.

A number of new tourist destinations, most with a specialised offer, are also emerging (Hudson 2016). The inscription of the three Pyu Ancient Cities - Halin, Beikthano and Sri Ksetra (politically significant from around 200
BC to $700 \mathrm{AD})$ - on the UNESCO World Heritage List in July 2014 generated fresh impetus for cultural, historical and heritage tourism (Su Su/Win Kyaing 2016, Moe Ommar Lwin 2017). New seaside resorts are emerging, such as Ngapali, Chaung Tha and Nwe Hsaung at the Indian Ocean. A new destination is also Mrauk-U (Zin Nwe Myint 2009, 2011 and 2014, Zin Nwe Myint/Khin Myo Hla 2009).

Around Yangon and Mandalay, there is growing demand for resorts for weekend tourism, which is becoming increasingly popular with Myanmar's middle class and elite and the expanding international expatriate community. As a result, in the former colonial hill stations - i.e. towns located at higher altitudes with cooler temperatures, where the British would seek refuge from the summer heat or monsoon rains - such as Kalaw and Pyin Oo Lwin, but also in the mountain regions around Taunggyi, Hsipaw and Lashio (Shan State) and Kho $\mathrm{Nu}$ Msung (Chin Daai language) or Nat Ma Taung (Myanmar language) or Mt Victoria (British) respectiveley, a tourism segment which specialises in summer retreats, golf and hiking is developing, in some cases based around newly constructed weekend accommodation and second homes. Early signs of tourism development can also be discerned in the mountain regions, e.g. around Mogok and Kyatpyin and the former Thandaunggyi hill station (Naw Paw Thaw Thaw 2016), which for many years were accessible to foreign nationals only with special permission. In the region around Kyaikhtiyo, Thaton, Mawlamyine (Lusby/Eow 2015), Hpa-an and Kyaikkhami, there is a strongly expanding weekend tourism segment, mainly attracting domestic tourists and centred around visits to religious sites. However, there are also signs of a nascent nature-based and cultural/heritage tourism sector aimed at international visitors. Following the completion of a transnational highway and the opening of the international border crossing between Myawaddy/Myanmar and Mae Sot/Thailand in August 2014, the border region is an emerging new destination, especially for tourists from Thailand. 
Infrastructures in the peripheral mountain areas in Sagaing Region (including Nagaland), Chin State and Kachin State are still underdeveloped for the most part, with the result that these areas are still largely inaccessible; this also applies to the far south of the country with the Myeik (Mergui) Archipelago and Kawthaung. There are initial signs of a basic tourism infrastructure emerging in Hakha and Falam (Kraas/Zin Nwe Myint/Khin Khin Soe 2016), at Indawgyi Lake (Kraas/Zin Mar Than 2016, Zin Mar Than/Kraas 2016, Zin Mar Than 2017), around Myitkyina and in the Puta-O and Machanbaw basin.

\section{FUTURE OPTIONS}

Future developments in Myanmar's tourism industry should take into account innovations and trends in the broader regional context of growing tourism competition in Southeast Asia, especially since the current value of Destination Myanmar's 'exotic novelty' is likely to decline with time. For example, as nature tourism based around the unique selling point of national parks and nature reserves develops, this natural potential - and hence the appeal and value of these assets - will decline with growing tourism demand and use. Spiritual and mediation-based tourism (increasingly tailored to the specific needs of foreign visitors) is also enjoying a surge in popularity but it too could well lose some of its originality and authenticity as international demand for a certain type and quality of accommodation and food, but also international values, take hold. Secondly, national and international tourism is likely to continue to diversify in relation to both supply and demand: wellness, sport and medical tourism (e.g. in and around Taunggyi), meetings, incentives, conferences and events (MICE) tourism (in or close to the major cities), educational/summer course tourism (in regional centres with better education infrastructure relative to the surrounding area) and cross-border and trade-related tourism (e.g. in Tachileik, Kengtung, Tamu and Myawaddy) point to the opportunities for highly diversified regional segmentation, and, in some cases, growing specialisation of the tourism potential. And lastly, against the background of Myanmar's burgeoning international engagement, it is clear that not only will new investors contribute to a more diversified tourism offering, e.g. by introducing newer, lowbudget but also high-end price segments into the market, but also that new customers will want to see their specific expectations and demands fulfilled, which could potentially include a de facto separation of guests based on nationality (which has long been the standard practice in neighbouring countries). It is often said that 'tourism destroys the very assets on which the industry itself depends and thus destroys itself', and there is a fear that this may soon hold true for Myanmar. This risk can only be mitigated with carefully crafted strategies and sustainable, systematic planning and development processes, based on the principle of fairness and involving a wide range of decision-makers and stakeholders.

Important changes lead to a responsible tourism policy and a policy on community involvement (MoHT 2012, 2013a). Positive signals exist from the government about the need to implement sustainability principles in the tourism sector (Häusler 2014, Häusler/Baumgartner 2014, MCRB/HSF 2015a, b).

Frauke Kraas and Zin Nwe Myint 


\section{SOCIAL DEVELOPMENT: HOUSEHOLD INFRASTRUCTURE, EDUCATION AND HEALTH}

138 HOUSEHOLD INFRASTRUCTURE

139 MAIN SOURCE OF LIGHTING AND AVAILABILITY OF MOBILE PHONES

140 EDUCATION AND EDUCATION SYSTEM

141 PROPORTION OF PERSONS WITH EDUCATION

143 NUMBER OF PERSONS WITH EDUCATION

145 EDUCATION LEVEL

147 HIGHER EDUCATION: UNIVERSITIES, DEGREE COLLEGES, COLLEGES

149 HIGHER EDUCATION: SUBJECTS AND NUMBER OF STUDENTS

155 SUBJECTS, NUMBERS OF STUDENTS AND STUDENT-TEACHER RATIO

156 HEALTH AND HEALTH SYSTEM

157 REGIONAL HEALTH CENTRES

159 SUBREGIONAL HEALTH CENTRES

161 HOSPITALS AND DOCTORS

163 MIDWIVES 


\section{HOUSEHOLD INFRASTRUCTURE}

The regional distribution of the availability of essential household infrastructure - first, the main sources of lighting and second, the proportion of households with mobile phones - is informative as it demonstrates the general level of infrastructure available to households and allows basic conclusions to be drawn about the extent of regional inequalities. Furthermore, lighting and mobile phones are both important preconditions for the socio-economic development of the households - e.g. lighting in the evenings allows children to learn or complete their homework; mobile phones allow social contacts to be maintained or negotiations with business partners to be undertaken.

There are large countrywide disparities in the provision of households with electricity for lighting. This basic infrastructure is provided to almost all households in the inner-city districts of Yangon, Mandalay and Nay Pyi Taw, although it is common knowledge that temporary power cuts are also frequent in these areas. Otherwise, high percentages of households with electricity for lighting are found only in Myitkyina, several regional cities and a few townships along the eastern border; in the central lowland of Myanmar $25-50 \%$ of all households have access to electricity for lighting. Considerable supply deficits are revealed by the household information for large parts of the rural region, the mountainous regions of Chin, Kachin, Shan and Kayin States, and the Tanintharyi Region. With less than 5\% of all households accessing electricity for lighting, the greatest supply deficits are found in large areas of Rakhine State and Nagaland, in the central Shan State and in the townships of Yebyu, Dawai and Thayetchaung.

The situation concerning the availability of mobile phones is similar: almost all the households in the inner city areas of Yangon, Mandalay and Nay Pyi Taw are apparently supplied. In reality, however, several people in one household share a phone while other individuals have access to a number of phones. This gives the impression of full coverage, but it is actually a statistical effect. In many regional cities and in several of the border regions of the country more than half the population owns a mobile phone. Large parts of Chin, Kachin, Shan and Kayin States and of the Sagaing and Tanintharyi Regions are characterised by severe undersupply. The greatest deficits exist in Rakhine State, in the south of Chin State, in large parts of the Sagaing Region including Nagaland, in parts of the eastern Shan State and in the east of Kayin State.

These obvious regional disparities represent a series of other inequalities in the supply of important infrastructure. They are important in terms of (1) national justice and the realisation or guarantee of household-related development opportunities, (2) countrywide regional solidarity, countering processes of marginalisation, and (3) preventing or reducing migration, especially in the wider areas of Yangon and Mandalay, as this could impact development there. The question of national justice and solidarity is therefore relevant to decision-making about whether priority is given to continuing to privilege the most populated regions or to reducing disparities by allowing the mountainous and minority regions to catch up on development - or whether a reconciliation of interests will be found.

Frauke Kraas and Aye Aye Myint 


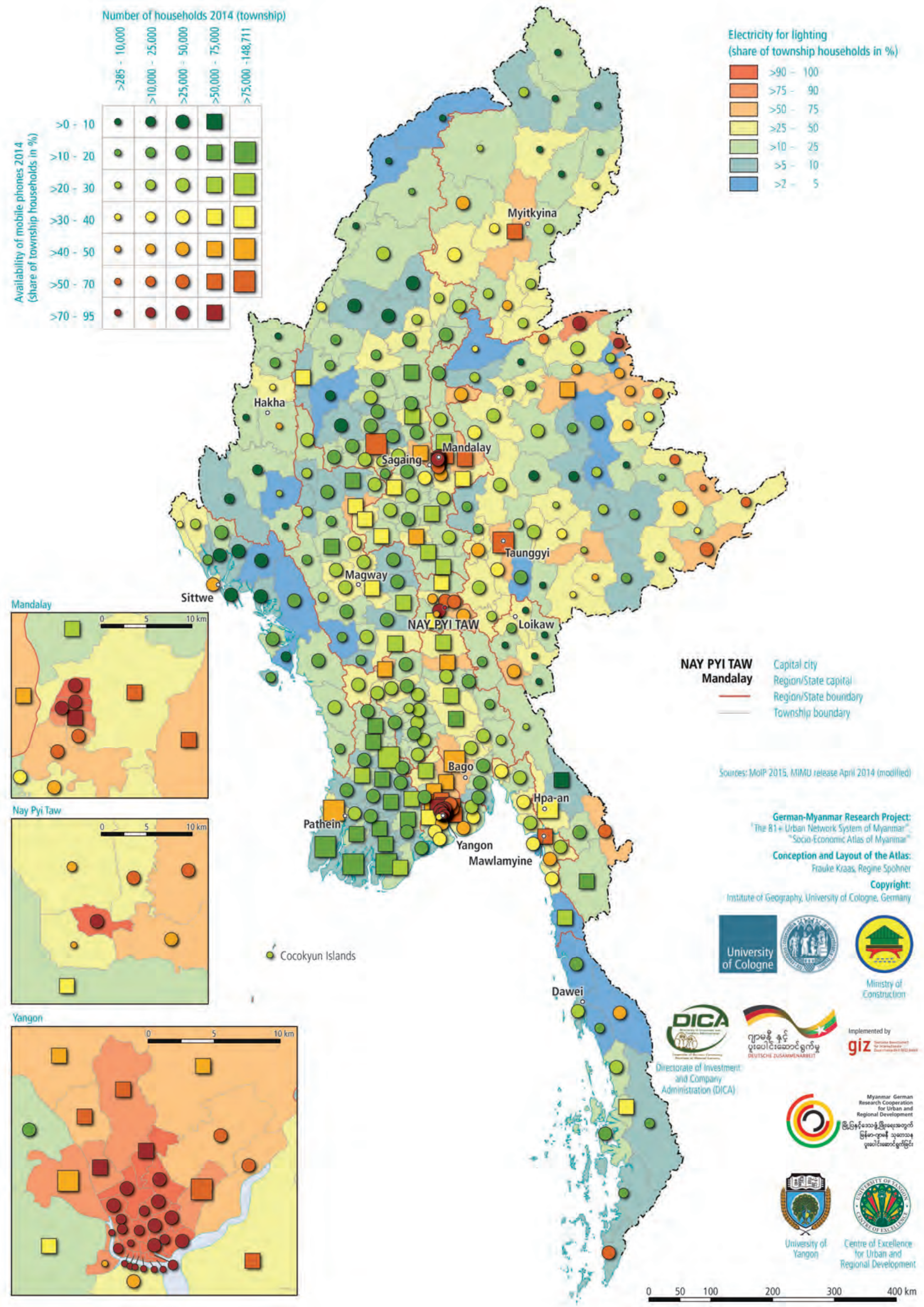




\section{EDUCATION AND EDUCATION SYSTEM}

\section{EDUCATION IN PRE-COLONIAL AND COLONIAL TIMES}

Education has a long tradition in Myanmar, closely linked to its Buddhist heritage. In the area of present-day Myanmar - and its earlier predecessors - education has been established since at least the 11th century (Furnivall 1943, Cheesman 2003: 48). Prior to the establishment of a centrally administered national education system in the mid-19th century by the British colonial government of Burma, a traditional education system run by the Buddhist monks was thus already in existence. In the 19th century the literacy rate seems to have been comparable to that of Europe, and possibly even higher (Hillman 1946: 527); figures indicate that in 1886 the literacy rate was $85 \%$ (Ministry of Education 2009, cited by Gärtner 2011b: 7). A considerable proportion of children, far more boys than girls, received instruction in reading, writing and recitation in Buddhist monastic schools, where they were also fed and put to work. The importance of the monastic schools extended far beyond the provision of education: 'This system ensured widespread literacy, mitigated class distinctions by bringing rich and poor together and opened even to the poorest prospects of advancement to the highest posts. Although its primary function was to perpetuate among successive generations the principles of Buddhism, it was one cause for the stability and permanence of Burmese civilization' (Furnivall 1957: (h), cited by Gärtner 2011b: 2).

Under colonial rule, an education system on the British model was established in parallel to the traditional system; from 1890 onwards the Education Department sought to ensure universal schooling (Cheesman 2003: 52/53). In creating a local educational elite the main aim was to provide trained administration officials for British services; the system also resulted in a deliberate indigenisation of the administration by giving children of collaborating village headmen preferential access to the schools (Hillman 1946, Tin Cung 2011: 88/89). The founding of the first missionary schools in Mawlamyine, Yangon and Mandalay - by such denominations as the Lasallian Christian Brothers, the Methodists and the Anglicans marked the emergence of higher education provision for the new elites, mainly in the cities. Education policy was also applied as an instrument of colonialism in the country's mountainous and peripheral regions with a view to converting people from their former beliefs to Christianity. The establishment of a health system and targeted regional development measures were tied in with this endeavour. The level of educational provision and opportunity improved for girls specifically (Chie Ikeya 2008).

The foundations of the higher education system were also laid during the British period. Rangoon College was founded in 1878; between 1904 and 1920 it was known as Government College and affiliated to the University of Calcutta (Hillman 1946: 530). As a result of the Rangoon University Act of 1920, Rangoon University was formed from the merger of Rangoon College and Judson College; it eventually combined six colleges.

After the end of the Japanese occupation, during which schools and universities were repeatedly closed and re-opened but eventually forced to a standstill (Hillman 1946: 532), the British government re-established the education system in 1945 under the newly founded Ministry of Education. After independence efforts focused on facilitating access to education for all sections of the population - an endeavour that in the face of significant financial 

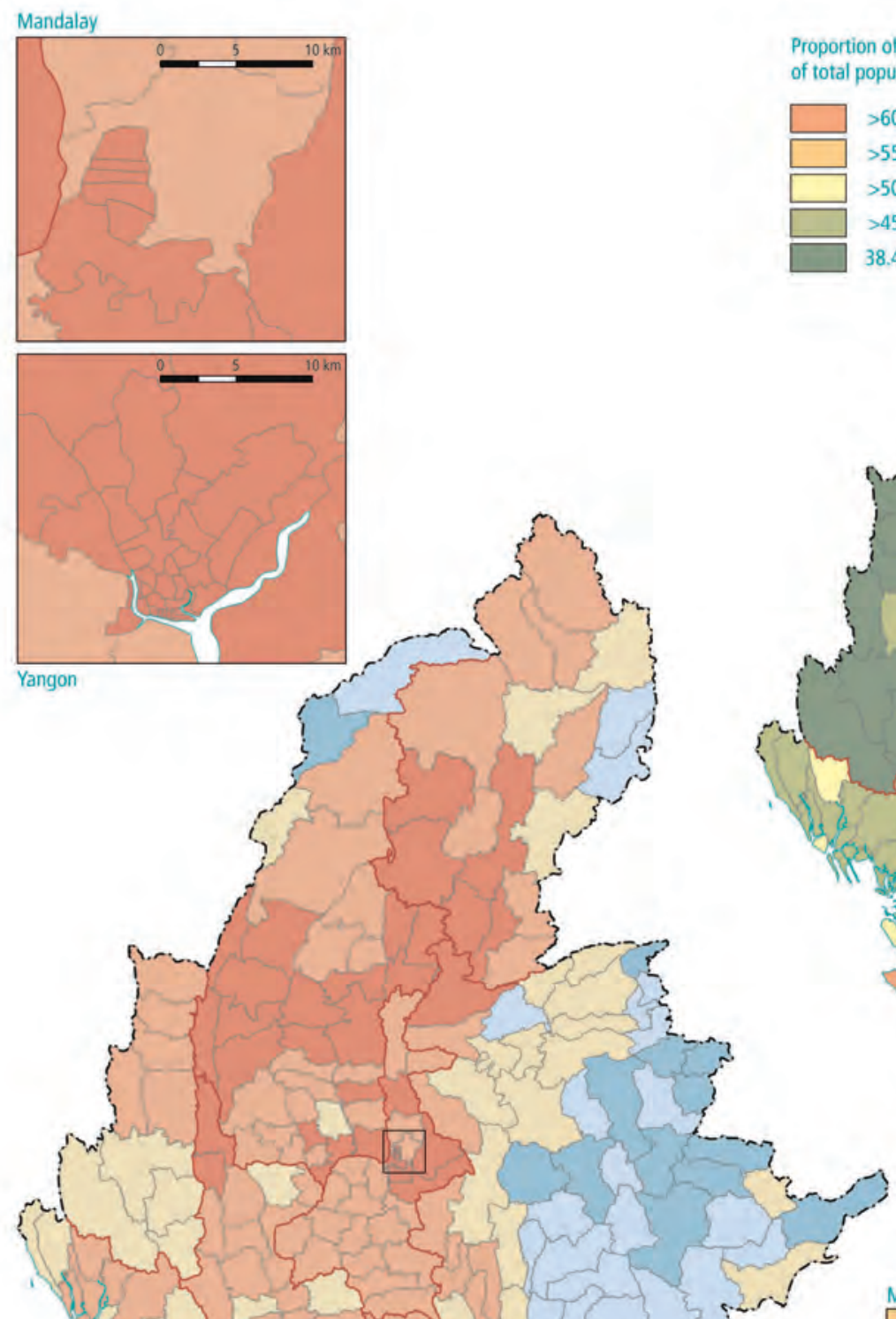

Proportion of persons with primary or higher education in the population aged 25 years and older 2014 by township (in \%)

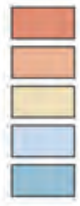

$$
\begin{array}{r}
>90-98.8 \\
>75-90 \\
>50-75 \\
>25-50 \\
9,5-25
\end{array}
$$

\section{Sources: Moip 2015, MiMU release April 2014 (modified)}

German-Myanmar Research Project:

The 81+ Uriban Meftwork System of Myanmar". "Socio-Economic Atlas of Myannar"

Conception and Layout of the Atlas:

Frovike Kraas, Regine Spohnes

Copyright:

Insitute of Geography, University of Cologne, Germany
Proportion of persons aged 25 years and older of total population 2014 by township (in \%)
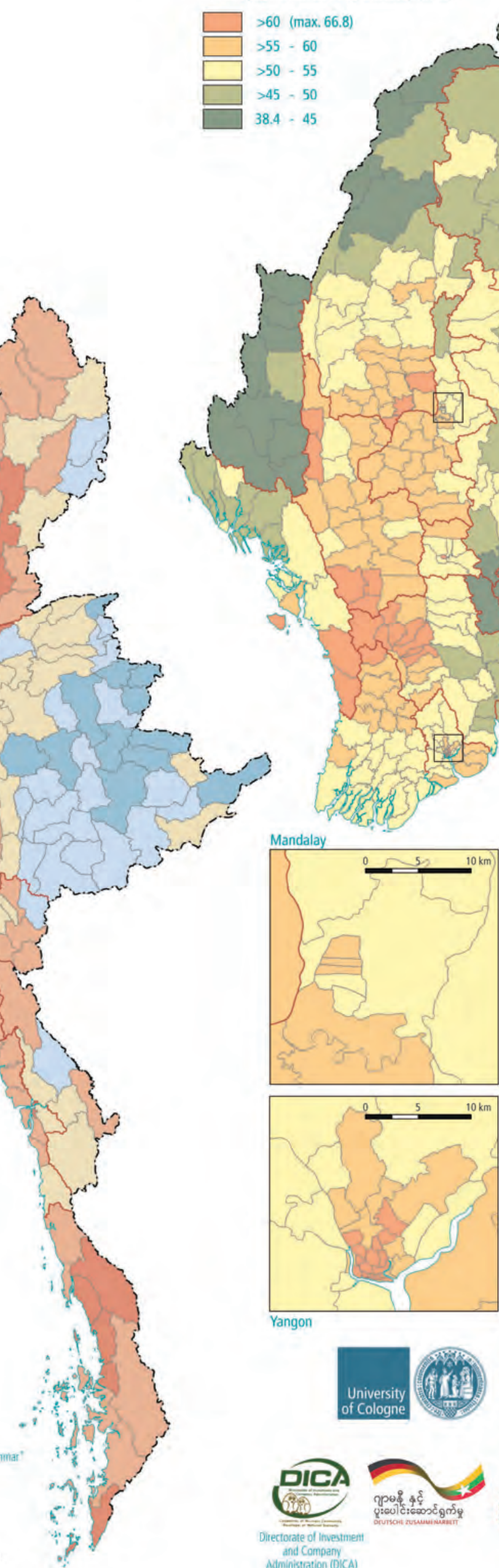
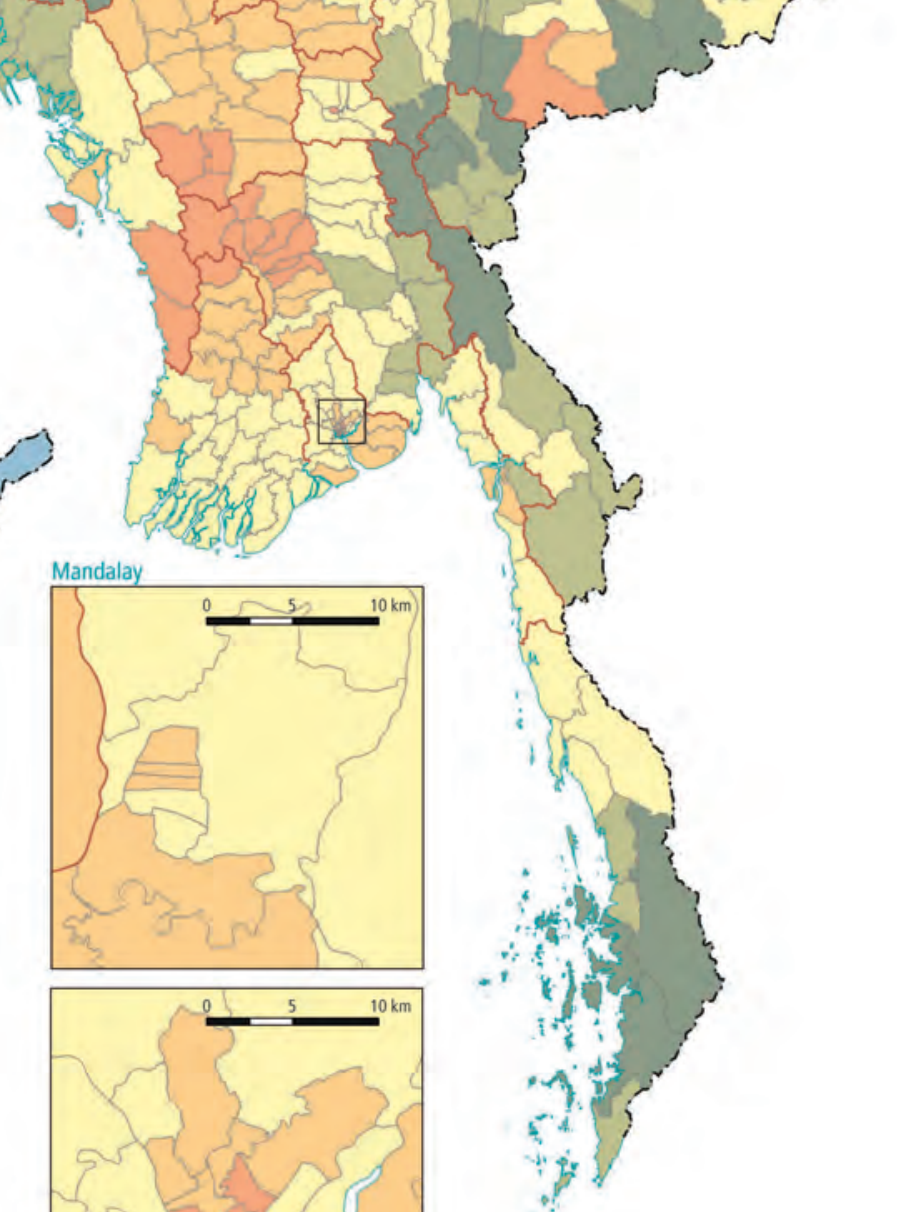
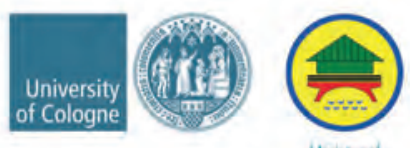

Monisty of
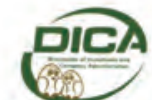

Directorate of investme

and Company

Administration (DICA)

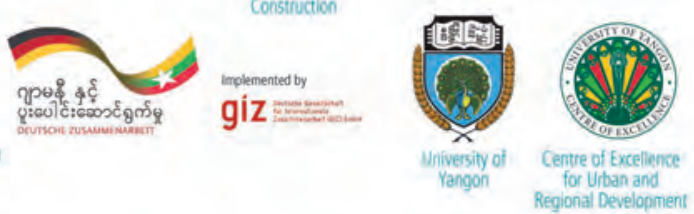


difficulties and political unrest was ultimately unsuccessful, especially in the peripheral regions. The Welfare State New Educational Plan of 1953 attempted to bring the school system under central control, but the private schools - including the mission schools - remained independent. In 1958 Mandalay Intermediate College was promoted to university status.

Following the coup d'état by General Ne Win in 1962, the education system was nationalised, the missionary schools closed, and English banned as a language of instruction. 'The Burmese Way to Socialism', which had ultimately arisen from an anti-colonial stance, resulted in the state taking control of the education system. In 1964 numerous departments - including economics and medicine - were split off from the universities and became separate institutions. In 1970 some private schools, catering mainly for the well-off, were permitted to re-open (Gärtner 2011b: 5).

Nationwide resistance against the government and the mismanagement and under-provision for which it was responsible, its disregard of election results and its crushing of the protest movement (which had been strongly supported by students) led between 1988 and the early years of the 21 st century to a temporary closure or in some cases 'resting' of the universities and relocation of the institutions to the urban peripheries. During this period teaching was often limited to short courses. The students were subsequently taught on new, predominantly smaller campuses outside the cities until they obtained their degree. The universities of Yangon and Mandalay took only post-graduate students. Between 1993 and 2004 the Universities of Culture in Yangon and Mandalay, the Theravada Buddhist Missionary University in Yangon, the Myanmar Maritime University in Thilawa and the Myanmar Aerospace Engineering University in Meiktila were newly established. From 1994 onwards the universities of Yangon and Mandalay were allowed to train $\mathrm{PhD}$ students; this authorization to hold examinations was later extended to a small number of other institutions, including the Yangon Institute of Economics and the Maritime University.

\section{THE CURRENT EDUCATION SYSTEM}

Today there is a system of national mandatory education under the 30-Year Long- Term Education Development Plan, which was implemented in 2001/02. The system requires pupils aged between six and sixteen to complete eleven years of schooling, consisting of five years of primary schooling (one year of kindergarten followed by four years of elementary school), four years of middle school and two years of high school leading to a school-leaving examination to qualify for university attendance from age 16 upward. In 2014/15, 187,327 primary, 69,212 middle and 28,817 high school teachers were teaching in 36,410 primary, 4,860 middle and 3,134 high schools. 5,166,317 pupils were being taught in primary, 2,542,830 in middle and 730,866 in high schools (MNPED 2015: 104).

To this day, monastic education plays a major role in providing schooling, mainly for children from underprivileged social groups and in remote and sparsely populated regions (Cheesman 2003, Lorch 2007 and 2008, Pyi Phyo Kyaw 2015, Lall 2016). Officially 12,111 novices and 5,571 nuns together with 115,658 boys and 85,767 girls were being taught at primary school level in the country's monastic schools; the number of primary schools was put at 972, of which 208 - the majority - were in the Mandalay Region, 134 in the Yangon Region and 121 in the Ayeyarwady Region. Middle schools - a total of 557 nationwide - were attended by 10,458 novices, 5,844 nuns, 29,879 boys and 23,454 girls. Myanmar also has two monastic high schools, both in the Mandalay Region, attended by 3,455 boys and 2,025 girls (all figures: 2014/15; MNPED 2015: 113/114). Monastic education is needed because although attending a public school is free of charge in principle, school uniforms, books and other materials still have to be purchased. This poses a problem for many parents in rural regions specifically. The values of education, knowledge and reason are highly prized in Buddhism, and consequently, the population in general - often not just parents and grandparents but also the extended family and the village community - will concentrate all disci- 
Number of persons $>25$ years with primary* or higher ** education level 2014 by township *...
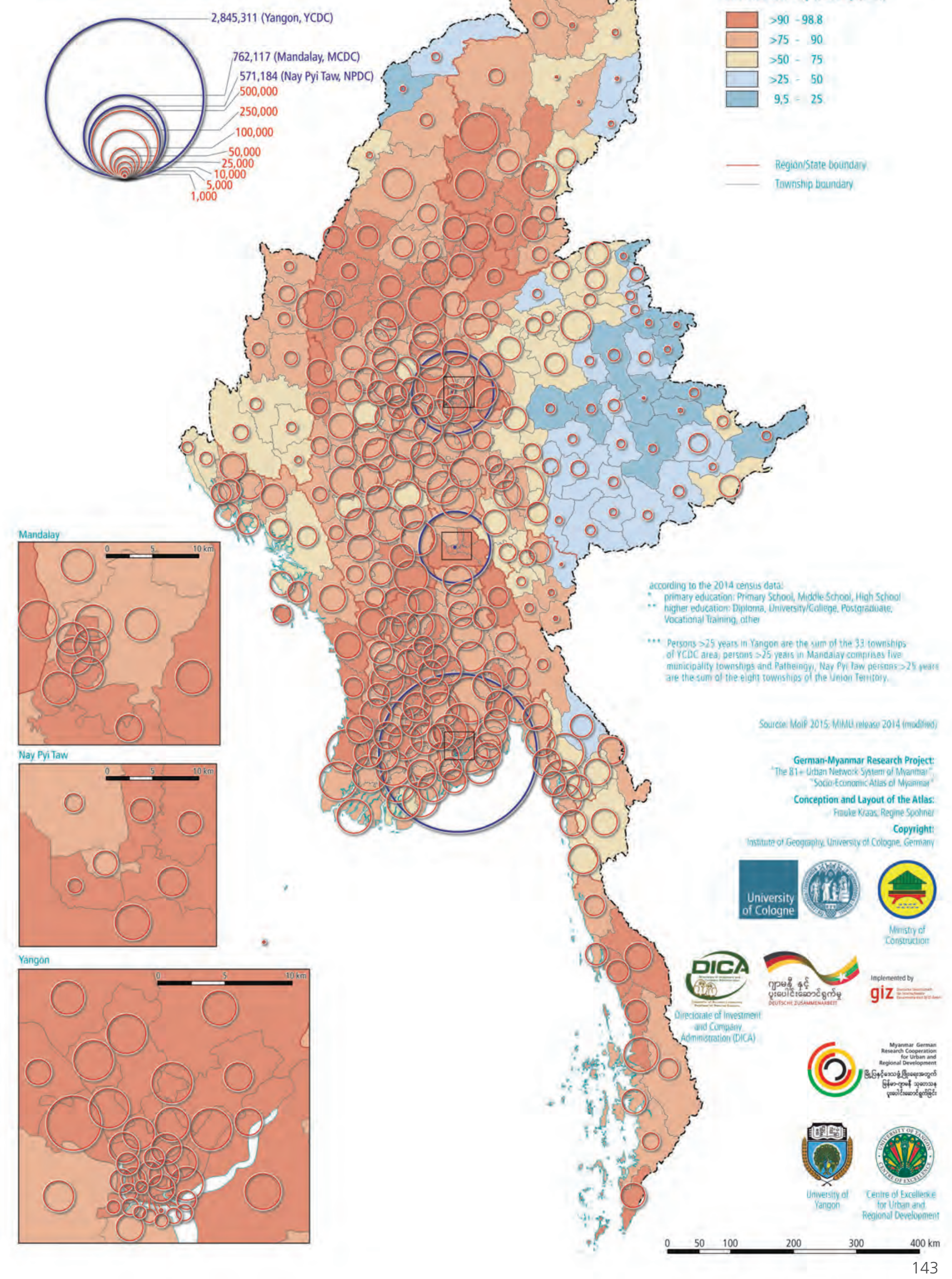

Nay Pyi Taw
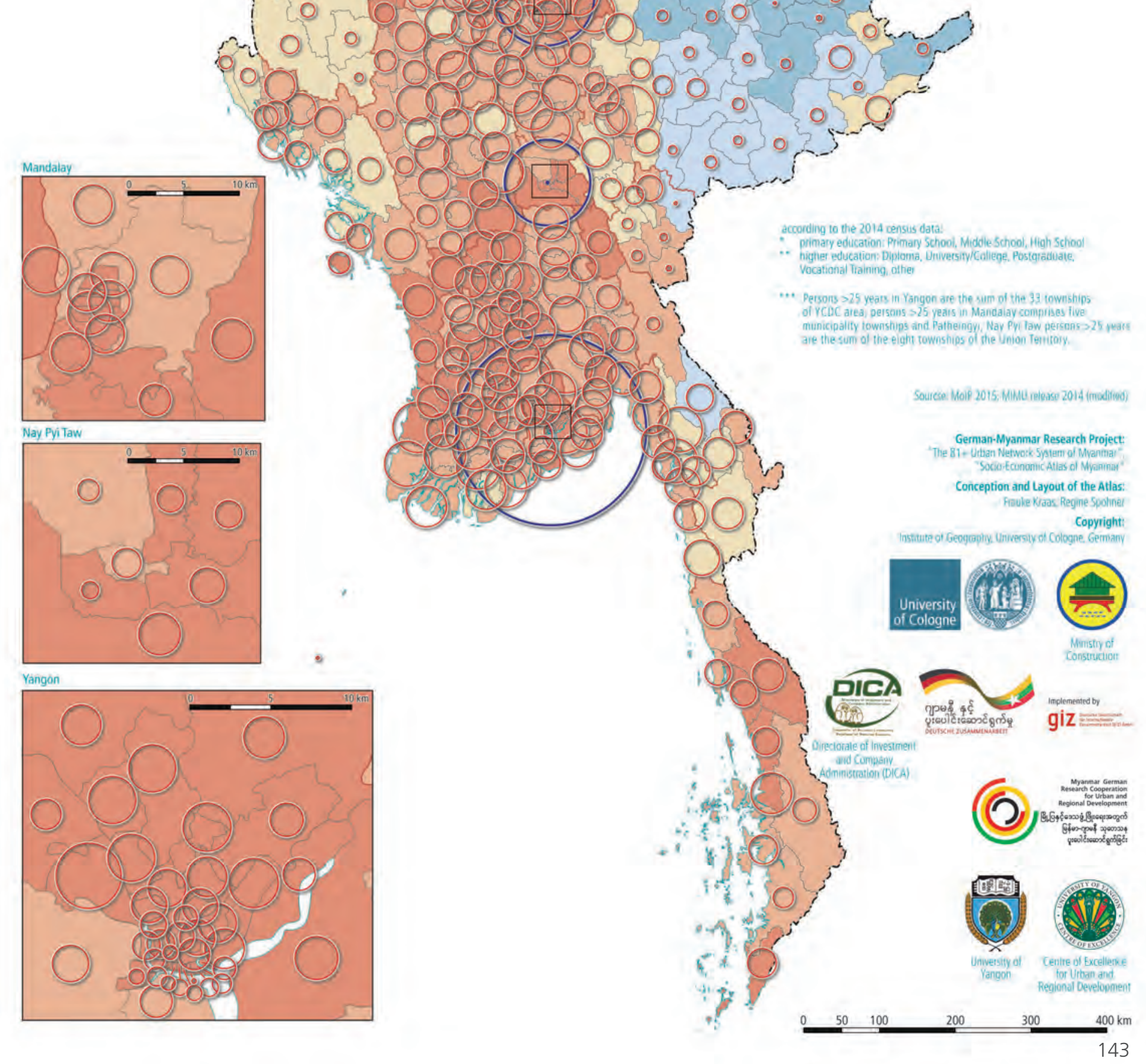

Proportion of persons with primary or higher education in the population aged 25 years and older 2014 by township (in \%)

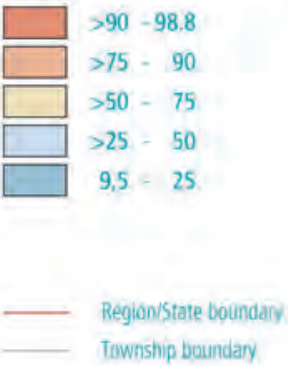


plinary efforts and economic resources in support of schooling. But despite private donations the monastic schools are ultimately underfunded (Lorch 2008), and as soon as they receive some support from the state, private donations fall (Pyi Phyo Kyaw 2015).

Similarly, education outside the governmental school system plays a key role in the predominantly Christian communities in the minority and mountainous regions (Lorch 2008: 164167): many churches and church communities support and finance primary and secondary education. In rural regions, children - mainly in the 9th and 10th years of schooling - are sent to special tuition schools in the nearest large town or more distant cities so that they can be specifically prepared for the matriculation examinations. The high costs of this represent an enormous burden for many families in rural areas, since only a few children obtain scholarships.

The realities of school life in Myanmar have therefore to be understood against the background of the traditional system coexisting with a public system that has been reoriented after each change of political regime: Buddhism attaches great value to recitation, the verbatim repetition and retention of religious texts. Both under colonial rule and during the socialist period and martial law, a prime concern was the deliberate instrumentalisation of education for the purpose of instilling each system's values. Societal hierarchies, obedience, discipline and knowledge priorities were bolstered through the ministerial administration, teachers, curricula, norms and practices. A complex web of interdependencies became established and hierarchies were reinforced. Education and schooling were already being instrumentalised in pre-colonial times and this intensified during the colonial era (Cheesman 2003). Sometimes this instrumentalisation occurs in the context of religious missionary work, for example via the 'NaTaLa' (National Races Youth Development Training Schools) schools in border regions and the Christian mission schools.

Provision of education and healthcare is inadequate in many rural areas; some places are without infrastructure of any sort (Lorch 2008: 155). Where there is no government education, community-based schools step in; the teachers often have no formal education (Lorch 2008: 162-163). Class size varies between up to $40 \mathrm{pu}-$ pils in the cities and up to 60 in rural areas. Although the official statistics quote 28 (primary school), 37 (middle school) and 25 (high school) pupils per teacher (2014/15; MNPED 2015: 108), the reality is often quite different: in rural areas and in primary education, classes of up to 100 pupils are by no means uncommon. Many pupils leave school after a few years because their parents can no longer finance their education. Although the literacy rate is officially stated to be $94 \%$, functional literacy is therefore estimated in some sources to be $53 \%$ (Taylor/Pederson 2005, cited in Gärtner 2011b: 1).

Lessons are teacher-centred, with teachers asking questions to which the textbooks contain the answers (Lall 2016). The relevant correct passages are read aloud by the pupils, copied out again at home, and most importantly, learned by heart ('rote learning') so that correct answers can be given in the written examinations. In urban (not many rural) areas, the extensive learning material is covered quickly and without much discussion, with the result that pupils often require extra tuition in the afternoons and/or evenings. This is offered by the same teachers - in return for payment (Lall 2008 and 2016, Lorch 2008). Pressure on the pupils intensifies from the tenth grade onwards because the decisive 'matriculation' exam takes place at the end of the eleventh grade, and the pass grade in this examination is the basis for decisions about admission to university and the subject options that can be chosen. For revision purposes, from the ninth grade onwards pupils are assigned 'guides', i.e. pupils from higher grades, who mainly teach the memorisation techniques and strategies for efficient exam preparation; again, they require payment. The high schools with the best reputations select their pupils according to their scores at the end of the ninth grade; parents are expected to make substantial donations to the school and these are used to improve the equipment. 


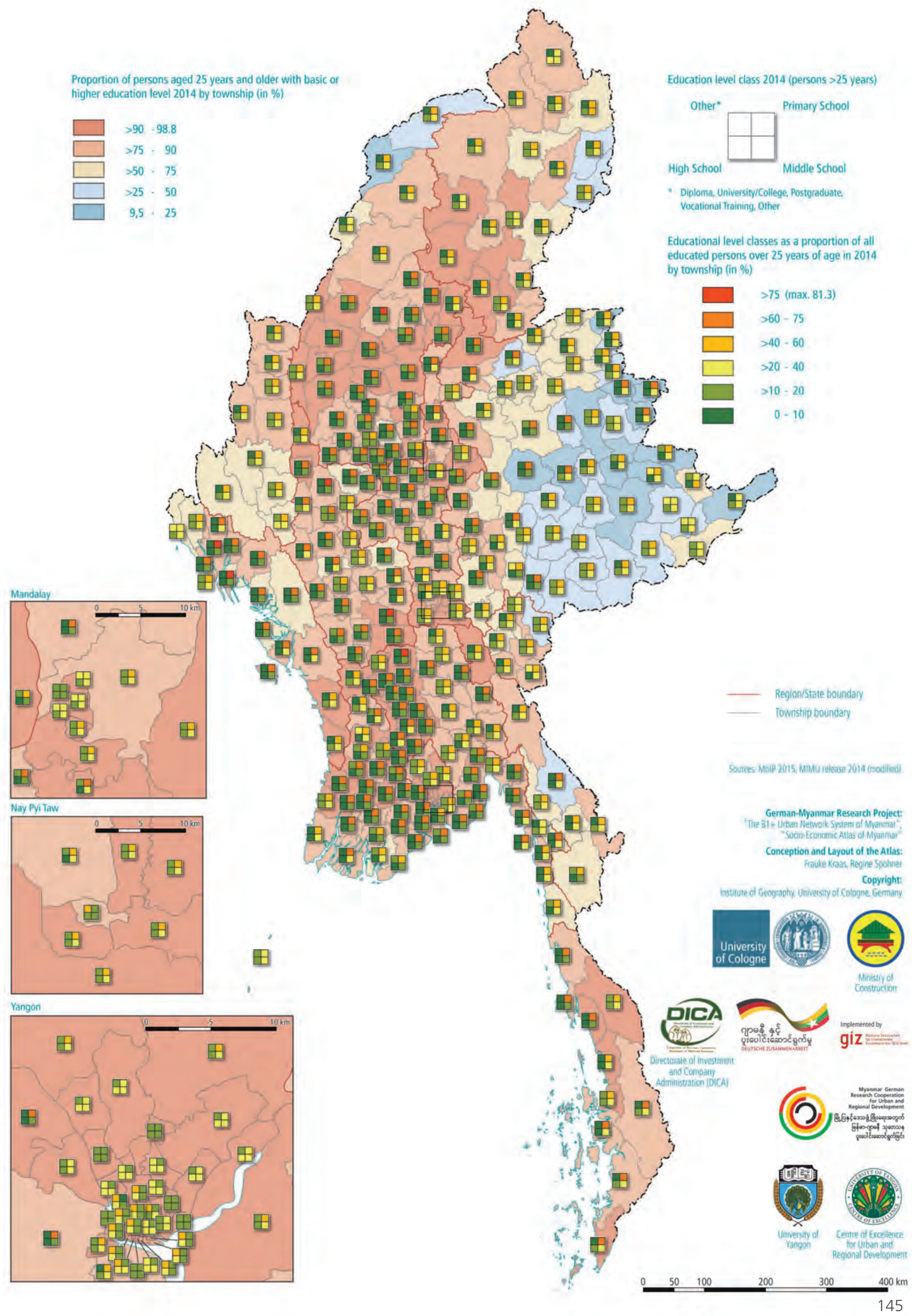


Compulsory subjects taught in public high school are Myanmar, English (reintroduced from 1981) and mathematics. In addition, pupils choose between a science track (including chemistry, physics and biology) or the humanities (including geography, history and economics). The grade point average achieved in the university entrance examination (the 'matriculation') determines which subjects can be studied at university (once the entrance examination has been passed).

In the minority areas, the problems of their peripheral location and hence of financing and ensuring comprehensive educational provision are exacerbated by additional ethnic and linguistic issues. While the importance of the Myanmar language as a national unity language is regarded from a national perspective as crucial for national integration, many minority group leaders see it as paternalistic and an obstacle to the strengthening of cultural and linguistic identity. Alongside the importance of Myanmar as a lingua franca, a good command of it is virtually essential for professional advancement in higher positions. Critics point out that learning Myanmar has disadvantages for the minorities, since it means that they must learn an additional language and leaves insufficient time for thorough learning of their mother tongues and dialects. The minorities' Culture and Literature Committees usually assume responsibility for basic language teaching, often on the basis of informal volunteer-led weekend or summer school education (Lorch 2008: 168/169, Thein Lwin 2007 and 2011). The teachers - who as a result of the usual transfer and promotion system are regularly transferred to other parts of the country, but who often do not want to be transferred to the minority areas and are therefore undermotivated - are often neither adequately qualified nor pedagogically prepared for the particular requirements of teaching in minority areas.

Alongside the predominantly public schools that are governed by the Ministry of Education, there are numerous private schools, especially in the cities; the number is estimated at about 100 (Gärtner 2011b: 13); many concentrate on the primary school sector, while some even rely on volunteer work (Lall 2008: 137/138). A normal teaching day in private schools begins between 8 and 9 a.m. and is a full day, continuing until 3 or 4 p.m. While school fees are charged for teaching and meals, more time is devoted to covering the material to be taught, which avoids additional 'tuition' costs. Furthermore, in peripheral regions there

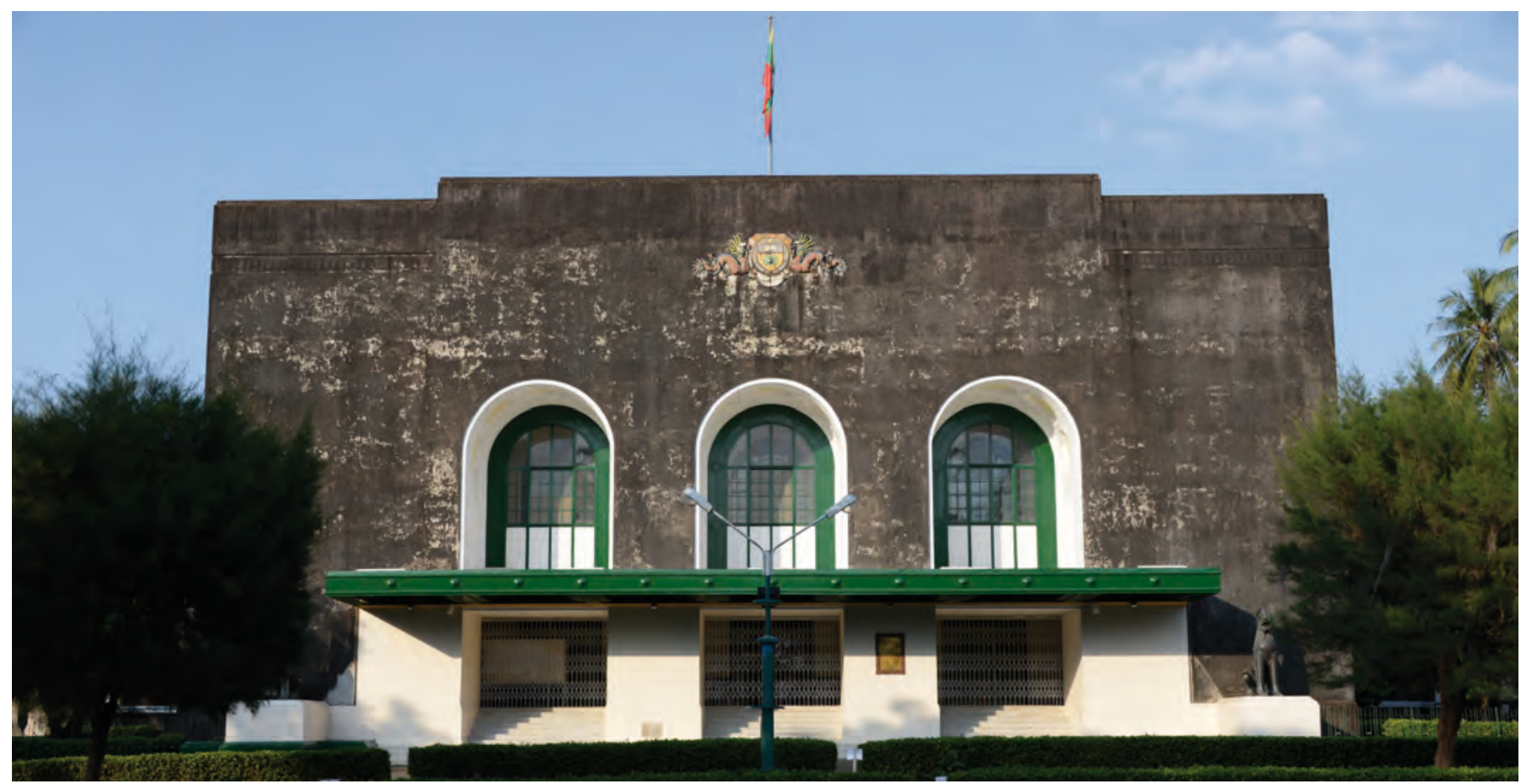


Higher education 2015: type and subject
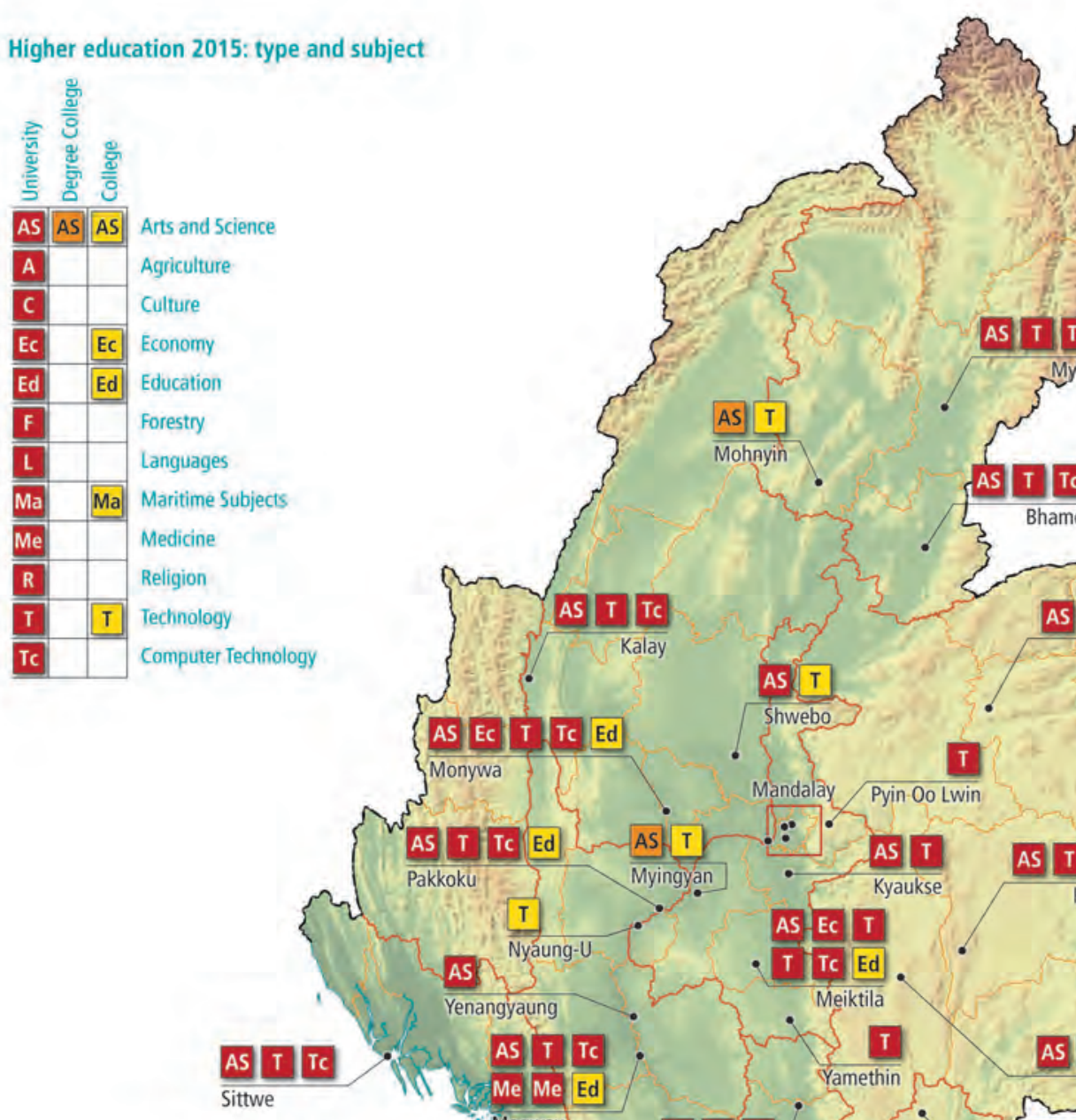
are private boarding schools for the surrounding region. These provide ninth and tenth grade pupils with full-day intensive training over a period of several months so that they attain good matriculation scores. The private schools - some of them now in foreign ownership - charge high fees, are not subject to any accreditation or quality control, devise their own curricula and are not licensed for the matriculation. Some private schools officially registered in the nearest related government high school so their students can sit for the government matriculation exam and their scores are recognized by the government. Other private schools are not registered in government high schools. Their main purpose is often to prepare pupils for study at a foreign university.

\section{REGIONAL DIFFERENTIATION}

The results of the 2014 Census reveal a very high rate of school education: nationally the proportion of the population who have received primary or more advanced education is usually more than $75 \%$. In major parts of Shan State, however, the proportion is less than $25 \%$, and in the peripheral parts of Kachin State and Nagaland it is less than 50\%. Similar deficiencies in the completion of education (with percentages between 50 and 75\%) occur in the remaining areas of Shan State, in southern Chin
State and in parts of Rakhine State, Kayah State and Kachin State (MoIP 2015). A similar picture of geographical distribution emerges in relation to the absolute number of school leavers with primary and more advanced education: at township level there is a clear concentration in urban areas - especially in Yangon, Mandalay and Nay Pyi Taw. However, if one considers the regional distribution of the percentages of the population with primary and more advanced education categorised into four qualification levels - i.e. primary, middle and high school and other (including in particular diploma, university/college, postgraduate and vocational qualifications) - a more nuanced picture emerges. In the central lowlands, especially in Yangon and Mandalay and their wider environs, the high percentages of the population with primary school qualifications combined with the low percentages with high school and other higher (including university) qualifications indicate that there is a not insignificant bipolarity of qualification levels: the proportions of the population with on the one hand basic and on the other hand higher educational qualifications are high. By contrast, it is interesting to observe that in the minority and mountainous areas (clearly noticeable in Shan State and Chin State), alongside a comparatively high proportion of the population with primary school qualifications there is also

University of Taunggyi: Convocation Hall and Campus

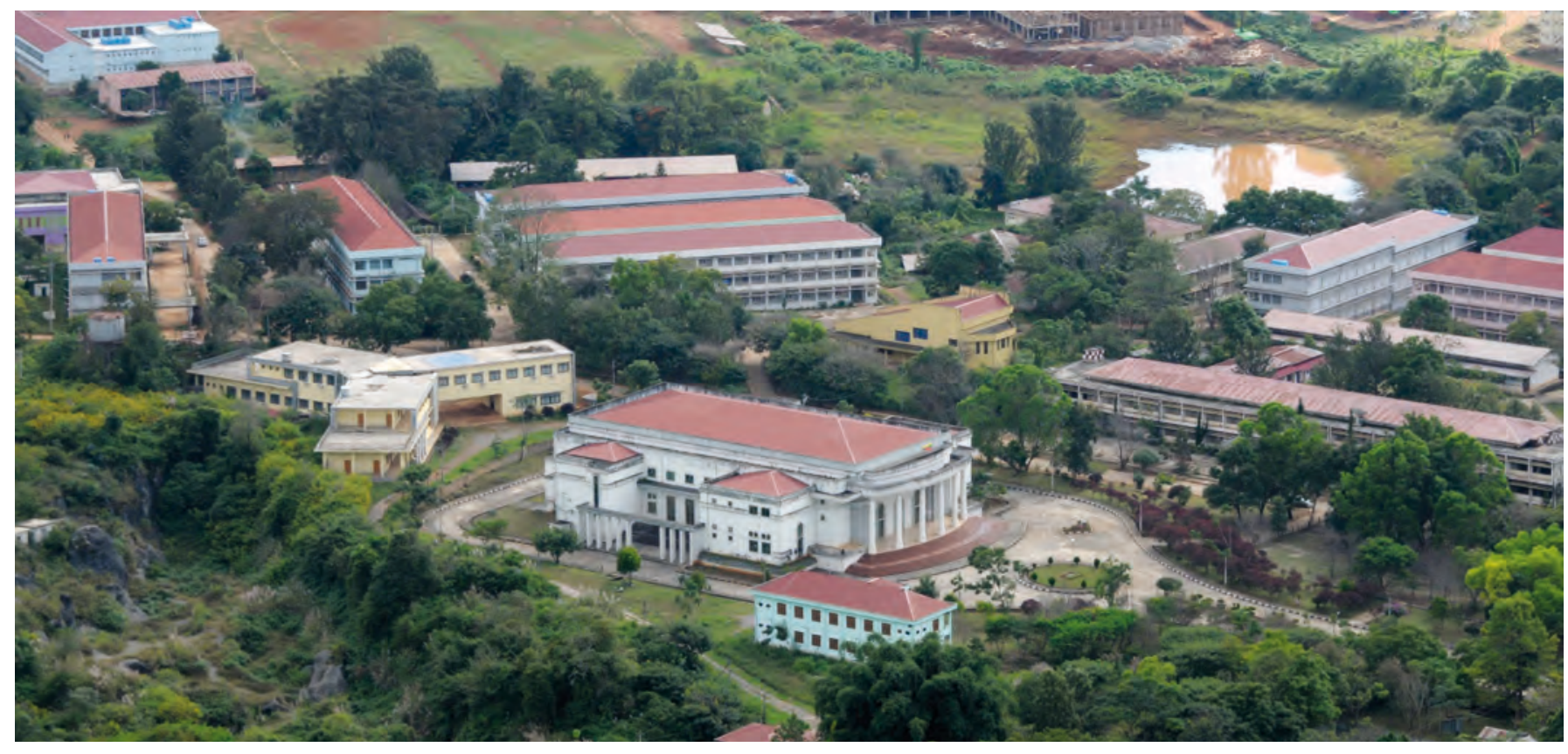


Number of students 2015 (total of town/city)

University of Distance Education

(Yangon, Mandalay)

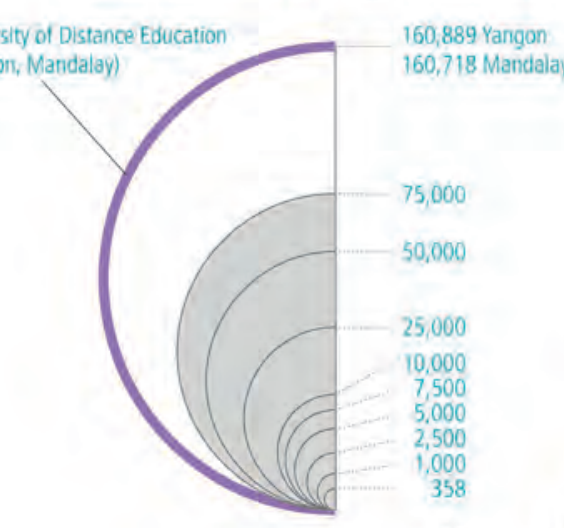

(1) 
by comparison with the national average a relatively large proportion of the population with high school and higher educational status. As expected, an 'urban effect' is also apparent: within the townships of Yangon, Mandalay and Nay Pyi Taw the percentages of the population with higher educational qualifications are above average.

The literacy rate is very high overall for a developing country, being $89.5 \%$ for the population on average $(92.6 \%$ of men, $86.9 \%$ of women; MoIP 2015). Considerable regional differences are found, however; for example, the rate in Yangon is around $96.6 \%$ compared to only $64.6 \%$ in Shan State. On national average, the rates for men are slightly above those for women; the lowest disparity between the genders amounts to 2.5\% (in Yangon) while the highest is $16.6 \%$ (in Chin State) (Kraas/Spohner 2015).

\section{HIGHER EDUCATION}

After ten years of school education, students entering the colleges and universities are still very young. In consequence, Bachelor degree courses are at a level roughly equivalent to that of international high schools. However, the education system is currently undergoing a process of transition leading to a Kindergarten+12-year course of education prior to university entrance.

In recent years - despite all the shortcomings highlighted in the literature (Lall 2008 and 2016, Lorch 2007 and 2008) - there have been significant changes and improvements in the field of higher education. The number of higher education institutions (i.e. universities, degree colleges and colleges) in the country has risen steadily from 32 (1988) to the most recent figure of 171 (2016; MOE 2017: 35). New colleges and universities have been opened even in peripheral parts of the country (for example most recently in Hakha/Chin State). Both historically and in terms of current leading roles in research and teaching, the University of Yangon - the country's top university - and the University of Mandalay are the peak educational institutions. In all, 653,475 students are registered at universities, degree colleges and colleges in Myanmar (2015; figures from the Ministry of Education). The University of Distance Education, with 306,987 enrolments, is the largest institution (2014/15; MNPED 2015: 119); it was formed from precursor institutions in 1992 and has two hubs, one for Lower Myanmar in Yangon (160,889 students in

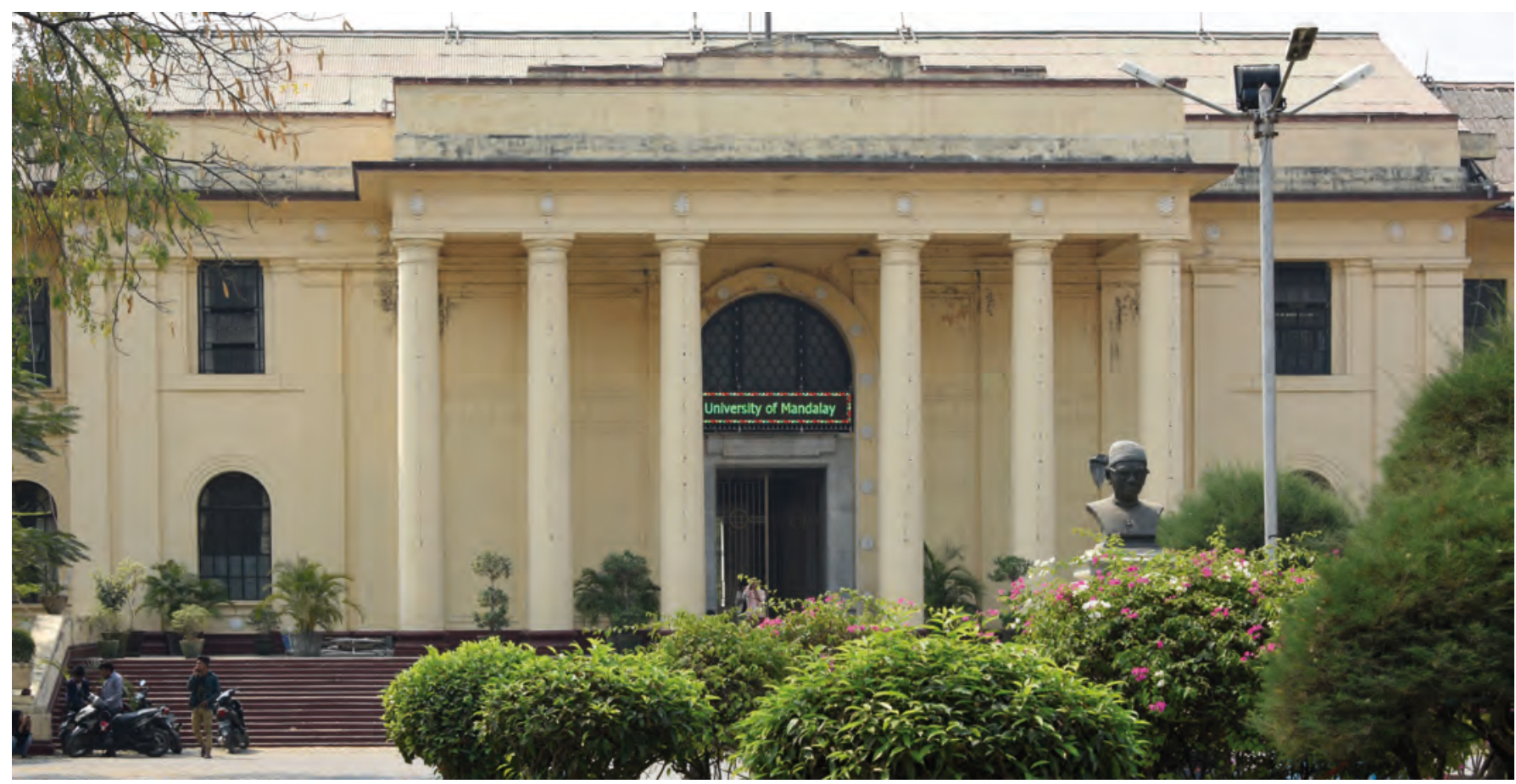


2015), the other for Upper Myanmar in Mandalay (160,718 students; both figures: Ministry of Education). The country's next-largest universities are Dagon University with 17,738 students, Yadanabon University with16,497 and the University of Monywa with 10,390 students (2015; figures: Ministry of Education).

The country's universities, degree colleges and colleges are widely dispersed across the regions: in each state or region there is at least one public university or college (Chin State was the last, acquiring Hakha Education College in 2017; before that it had only private colleges). Regionally, Yangon and Mandalay dominate the higher education scene: each has a number of universities, degree colleges and colleges. In addition, important trans-regional higher education locations are Monywa, Meiktila, Sagaing, Pakkoku, Magway, Taunggyi, Taungoo, Pyay, Pathein and Mawlamyine. The universities at Kalay, Myitkyina, Lashio, Dawai and Myeik provide regional Bachelor courses. There are also military training institutions, for example in Yangon, Nay Pyi Taw and Pyin Oo Lwin.

With regard to the range of subjects offered, the majority of universities offer subjects from the arts and sciences; at the same locations there are often also technological universities, which were under the control of the Ministry of Science and Technology before it merged with the Ministry of Education. Full universities have up to 20 departments; the majority offer a range of subjects that focuses on 12-14 disciplines. Institution-specific analysis reveals that there are also specialised universities, especially in the fields of medicine, economics and languages. These were or are often under the control of particular ministries such as the Ministry of Health, the Ministry of Forestry, the Ministry of Agriculture or the Ministry of Defence. Teacher training is provided via a number of education colleges that are dispersed throughout the country. Currently there are only a few universities that have close international links or stand out for their research achievements on any large scale.

\section{EDUCATION - BEYOND THE LEARNING CONTENT}

Myanmar has a developed and functioning multi-stage education system that is regionally widely dispersed and diversified and that over the decades has undoubtedly expanded and developed further. Efforts have been made to establish an education system that is accessible for all sections of the population and that is not polarised by a split between the government and private sectors and divided into 'class societies'; during the last two decades there has also been no lack of attempts to adapt the education system to international standards (Gärtner 2011b: 16). However, since the early 1960 s the education system has been increasingly eroded by political diktat, repeated restructuring and financial difficulties. It suffers as a result of little or no infrastructure replacement, the low pay of teachers and managers, limited international relationships and poor management and monitoring of quality standards. The situation is exacerbated further by the 'no failure' policy introduced in the mid-2000s and the preferential treatment of some groups that is inherent in the system.

However, Myanmar's education system also has a series of structural peculiarities - which can be found in similar forms in other Asian countries. These must be taken into account in any comprehensive further development of the education sector (MOE 2017). The following are the main structural challenges that reflect the shortcomings of the system and are in need of reform (as comprehensively addressed in the new National Education Strategy Plan (MOE 2017; see also Kraas 2016a):

1 Teacher training and teachers' pay: be1 cause of tight education budgets, the training of teachers usually takes the form of two-year intensive training programmes, for which the courses are heavily subscribed. Practical teaching experience is often gained by 'learning by doing'. Since monthly salaries are very low in comparison to the private sector, in the vast majority of cases only women choose the teaching profession. Tuition classes that are provided outside the normal teaching 
system and are paid for separately are a widespread source of additional income for school and university teachers (though one has to distinguish: not all teachers are offering tuition).

2

School accessibility and equipment: most schools are in one- or two-storey buildings with simple school benches and blackboards; in peripheral regions the pupils often sit on raffia mats. If not within walking distance, transportation to school must be organised by parents. This can mean long and difficult journeys, particularly in the rainy season. Even many universities that in the last ten years have been the subject of enormous infrastructure improvements (large, modern teaching and institute buildings, new accommodation for teaching staff and in some cases students) do not necessarily have technical equipment or an adequate electricity supply.

3 Teaching, learning and instructional volving rote learning and recitation of material are the standard practices; little time is scheduled for discussions or pupil presentations, although in recent years the Ministry has recommended and encouraged their introduction (student-centred teaching methods).
4 Costs of education: being the key to later professional success, education is valued highly - and significant amounts are spent on it. However, it is only possible to quantify the actual costs of educational success in any given instance by scrutinising them more closely: even though school attendance is free of charge, substantial costs are incurred - not just for school uniforms, books and materials (since 2016 books, material and school uniforms are free of charge in primary schools; MOE 2017: 36) but for other factors such as transport, tuition and social obligations which many families find unaffordable. The problem of the additional costs that parents have to pay for tuition is often explained as an answer to the problem of the low salaries of teaching staff, but it is more complex than this: 'Tuition as way of life apparently resulted from the coincidence of freedom for business in the framework of market economy and unsufficient salaries, and it can be overcome only in the course of overall socio-economic development' (Gärtner 2011b: 14). Tuition is a problem that is largely inherent in the system: many good students pay for their studies through tuition; when over the years they have acquired a good reputation as an effective tutor, many of them - attracted by the prestige, the good source of income and the freedoms of self-de-

University of Mawlamyine

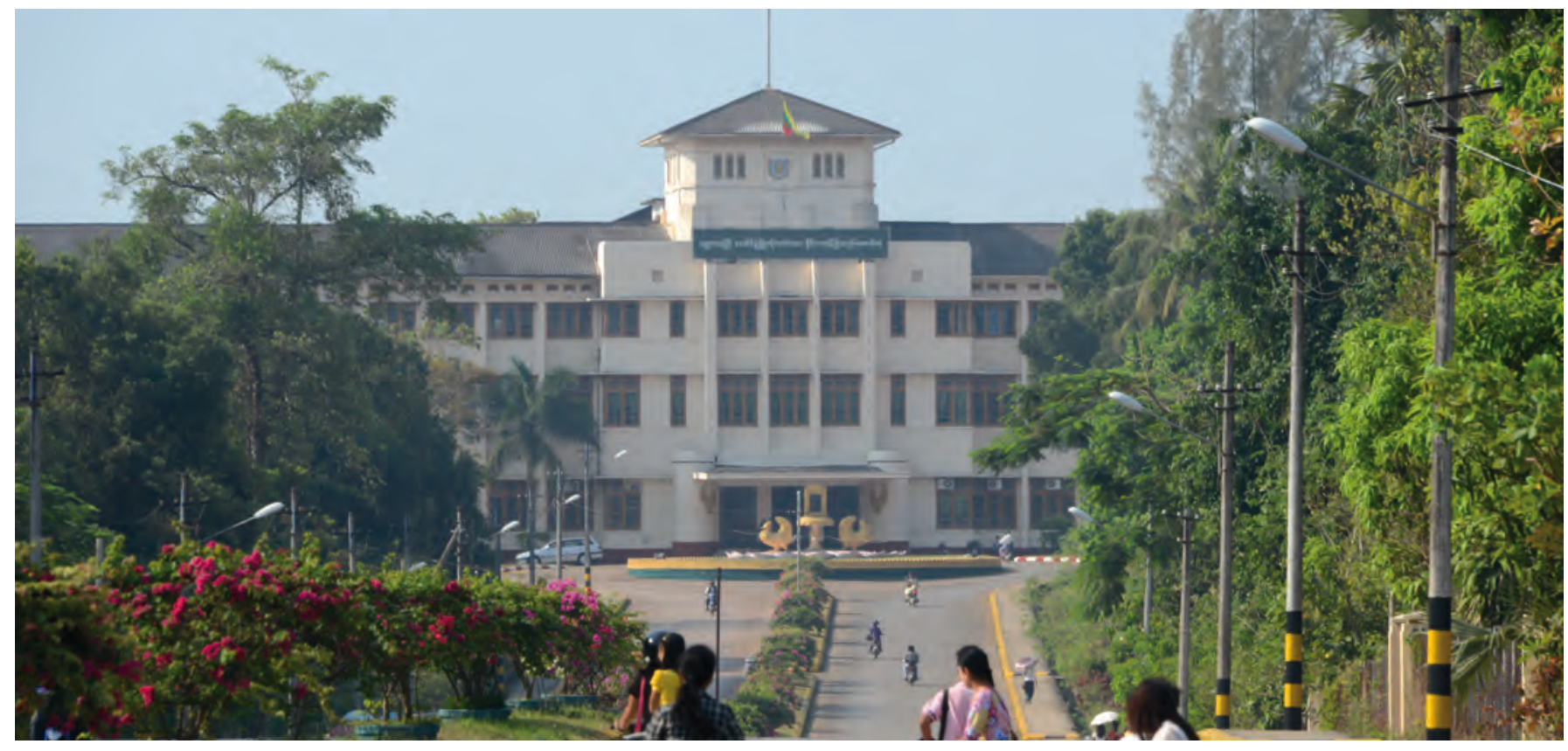


termined teaching - set up schools of their own that become a sort of parallel learning institution in their own right. They thus become employers and legitimise themselves on the basis of their own success. As far as university education is concerned, many families are unable to afford it for their children - partly on account of the relatively high costs of enrolment but largely because of the additional amounts that must be found for accommodation, food, study materials and direct and indirect payments for supervision and examination services. The potential loss of income during the course must also be taken into account.

5 Education as a complex system of inter3 twined practices: families have to invest a great deal of money in (notably: good quality) education. Children are under an obligation, once they are established in successful careers, to repay these investments to their parents, either financially or in the form of care-giving (not as obligation but as practise).

Education merits recognition: but a different kind of currency is also in use in the education system; namely, esteem and prestige. Teachers from all levels of education are highly esteemed personalities. They are shown deep respect, not just on special occasions like the annual 'saya gadaw pwe' gatherings, where pupils honour their teachers and present them with gifts. For the teacher-pupil relationship is a bond that is more than merely functional: teachers give guidance over a lifetime; their advice is sought after. To the same extent that teachers demonstrate accountability for their pupils education, pupils are deemed to owe lifelong recognition to good teachers, who are often cared for by a fraternity of former pupils in their old age.

In future there will, in addition to the abovementioned challenges, be a number of issues to be addressed in connection with specific training - such as vocational training and capacity development in the field of social work (Buzzi/ Hayes/Mullen ca. 2012, Costello/Taik Aung 2015). Another issue requiring attention is the provision of life-long training, especially in view of the fact that training requirements and levels will change as the country develops and the system must be able to adapt promptly. International trends indicate that this calls for cooperation between the different stakeholders in the education system, namely the government, teachers, parents and pupils (Lall 2016, Metro 2016). However, platforms for such exchange are as yet few and far between. So far the focus has been on changing the mindset of teachers and students. The role of teachers is vital: they 'have great potential to act as agents of change. Teachers are, however, as a group, highly conservative and traditionalist, and tend to resist change' (Han Tin 2008: 115; see also Metro 2016).

One of the crucial issues concerns the basic orientation of the future education system whether it will involve significantly improving and strengthening the public education system or place a greater emphasis on the promotion of private education. While the former can in the medium to long term promote equal access to education and fair distribution of educational opportunities, supporting 'edu-business' with the involvement of the private sector can lead to more rapid development and faster opening up of the international education market (Lall 2008), but does so in a manner that favours a small educational and economic middle and upper class and disadvantages or even excludes the broad majority of the population.

Educational migration is becoming increasingly important. Many parents decide to move from the countryside to the city in order to take advantage of the better facilities for education and healthcare and an anticipated wider range of employment opportunities: 'some rural families have shifted towards urban areas because of the belief - real or imagined - that more job opportunities exist in the cities' (Han Tin 2008: 116). International educational migration, too, is becoming more important and is no longer only for the upper classes and the growing economic middle classes.

Frauke Kraas, Aung Kyaw and Nay Win Oo 


\section{HIGHER EDUCATION: SUBJECTS, NUMBERS OF STUDENTS AND STUDENT-TEACHER RATIO}

\begin{tabular}{|c|c|c|c|c|c|c|c|}
\hline \multicolumn{2}{|l|}{ Ayeyarwady } & & \multirow{2}{*}{$\begin{array}{l}66 \\
67\end{array}$} & \multirow{2}{*}{$\begin{array}{l}\text { Mandalay Education College } \\
\text { University of Medicine }\end{array}$} & \multicolumn{3}{|l|}{ Shan } \\
\hline Bogale & 167 Bogalay Education College & & & & Kengtung & 151 & Kengtung University \\
\hline \multirow[t]{3}{*}{ Hinthada } & 163 Hinthada University & & 68 & University of Dental Medicine & & 152 & Technological University \\
\hline & 164 Technological University & & 69 & University of Nursing & & 153 & Computer University \\
\hline & 165 Computer University & & 70 & University of Medical Technology & Lashio & 154 & Lashio University \\
\hline \multirow[t]{3}{*}{ Ma-ubin } & 166 Ma-ubin University & & 71 & University of Pharmacy & & 155 & Technological University \\
\hline & 168 Technological University & & 72 & University of Iraditional Medicine & & 156 & Lashio Education College \\
\hline & 169 Computer University & & 73 & Mandalay Technological University & & 157 & Computer University \\
\hline Myaungmya & 160 Myaungmya Education College & & 74 & University of Computer Studies & Pinlon & 148 & Panglong University \\
\hline \multirow[t]{4}{*}{ Pathein } & 158 Pathein University & & 75 & Technological University & & 149 & Technological University \\
\hline & 159 Pathein Education College & & 77 & Computer University & & 150 & Computer University \\
\hline & 161 Technological University & & 81 & National University of Arts and Culture & Taunggyi & 143 & University of Taunggyi \\
\hline & 162 Computer University & & 82 & Co-operative College & & 144 & Taunggyi Education College \\
\hline \multicolumn{2}{|l|}{ Bago } & \multirow{8}{*}{ Meiktila } & 85 & Mandalar College & & 145 & Technological University \\
\hline Bago & 42 Bago University & & 86 & State Pariyatti Sasana University & & 146 & Computer University \\
\hline \multirow[t]{4}{*}{ Pyay } & 46 Pyay University & & & Meiktila University & Tanintharyi & & \\
\hline & 47 Pyay Education College & & 88 & Meiktila University of Economics & Dawei & 34 & Dawei University \\
\hline & 48 Pyay Technological University & & 90 & Meiktila Education College & & 35 & Dawei Education College \\
\hline & 49 Computer University & & 91 & Myanmar Aerospace Engineering University & & 36 & Technological University \\
\hline \multirow[t]{4}{*}{ Taungoo } & 41 Taungoo University & & 92 & Technological University & & 37 & Computer University \\
\hline & 43 Taungoo Education College & & 94 & Computer University & Myeik & 38 & Myeik University \\
\hline & 44 Technological University & Myingyan & 65 & Myingyan Degree College & men & 39 & Technological University \\
\hline & 45 Computer University & & 76 & Government Technological College & & 40 & Computer University \\
\hline \multicolumn{2}{|l|}{ Kachin } & Nyaung-U & 83 & Lacquerware Technology College & Yangon & & \\
\hline \multirow[t]{3}{*}{ Bhamo } & 7 Banmaw University & Pyinmana & 95 & University of Forestry & Yangon & 108 & University of Yangon \\
\hline & 8 Technological University & & 96 & Yezin Agricultural University & & 109 & Yangon University of Economics \\
\hline & 9 Computer University & & 97 & University of Veterinary science & & 110 & Yangon University of Education \\
\hline \multirow[t]{2}{*}{ Mohnyin } & 2 Mohnyin Degree College & Pyin 0o Lwin & 84 & $\begin{array}{l}\text { Technological University } \\
\text { (Yatanarpon Cyber City) }\end{array}$ & & 111 & Yangon University of Distance Education \\
\hline & 5 Govemment Technological College & Yamethin & 98 & Technological University & & 112 & Dagon University \\
\hline Myitkyina & 1 University of Myitkyina & Mon & & & & & Yangon University of Foreign Languages \\
\hline & 3 Myitkyina Education College & Mawlamvine & & & & 115 & West Yangon University \\
\hline & 4 Technological University & Mawlamyine & 99 & Mawlamyine University & & 116 & National Management College (NMC) \\
\hline & 6 Computer University & & 100 & Mawlamyine Education College & & 117 & Yankin Education College \\
\hline Kayar & & Thaton & $\begin{array}{l}101 \\
102\end{array}$ & $\begin{array}{l}\text { Technological University } \\
\text { Computer University }\end{array}$ & & 119 & Thingangyun Education College \\
\hline Loikaw & 10 Loikaw University & Rakhine & & & & 120 & University of Medicine (1) \\
\hline & 11 Technological University & Rakhine & & & & 121 & University of Medicine (2) \\
\hline & 12 Computer University & Kyaukpyu & 105 & Kyaukphyu Education College & & 122 & University of Dental Medicine \\
\hline Kayin & & Sittwe & 103 & Sittwe University & & 123 & University of Nursing \\
\hline Hpa-an & 13 Hpa-an University & & 106 & Technological University & & 124 & University of Medical Technology \\
\hline & 14 Hpa-an Education College & & 107 & Computer University & & 125 & University of Pharmacy \\
\hline & 15 Technological University & Toungup & 104 & Taung Goke College & & 126 & University of Public Health \\
\hline & 16 Computer University & Sagaing & & & & 127 & Yangon Technological University \\
\hline & io compuler universily & Kalay & 17 & Kalay University & & 128 & West Yangon Technological University \\
\hline Mlagway & & & 18 & Technological University & & 129 & University of Computer Studies \\
\hline Magway & 50 University of Magway & & 19 & Computer University & & 130 & University of Computer Studies (Bahan) \\
\hline & 52 Magway Education College & Monywa & 21 & University of Monywa & & 135 & National University of Arts and Culture \\
\hline & 53 University of Medicine & & 22 & Monywa University of Economics & & 138 & International Theravada Buddhist Missionary \\
\hline & 54 University of Community Health & & 26 & Monywa Education College & & & University \\
\hline & 55 Technological University & & 27 & Technological University & & 139 & State Pariyatti Sasana University \\
\hline & 56 Computer University & & 30 & Computer University & & 140 & Nationalities Youth Resource Development \\
\hline Pakokku & 57 Pakokku University & Sagaing & 20 & Sagaing Institute of Education & & & Degree College \\
\hline & 58 Pakokku Education College & & 24 & Sagaing University & & 142 & Myanmar Mercantile Marine College \\
\hline & 59 Technological University & & 25 & Sagaing Education College & Hlegu & 118 & Hlegu Education College \\
\hline & 60 Computer University & & 29 & Technological University & & 137 & Co-operative College (Phaunggyi) \\
\hline Yenangyaung & 51 Yenangyaung Degree College & & $\begin{array}{l}29 \\
31\end{array}$ & University of Co-operative & Hmawbi & 132 & Technological University (Hmawbi) \\
\hline Mandalay & & & 32 & The University for Development of the & Thanlyin & 114 & East Yangon University \\
\hline Kyaukse & 89 Kyaukse University & & & National Races of the Union & & 131 & Technological University (Thanlyin) \\
\hline & 93 Technological University & & 33 & Nationalities Youth Resource Development & & 136 & University of Co-operative (Thanlyin) \\
\hline Mandalay & 61 University of Mandalay & & & Degree College & & & Myanmar Maritime University \\
\hline & 62 Mandalay University of Foreign Languages & Shwebo & 23 & Shwebo University & & & \\
\hline & 63 Mandalay University of Distance Education & & 28 & Government Technological College & & & \\
\hline & 64 Yadanabon University & & & & & & \\
\hline
\end{tabular}




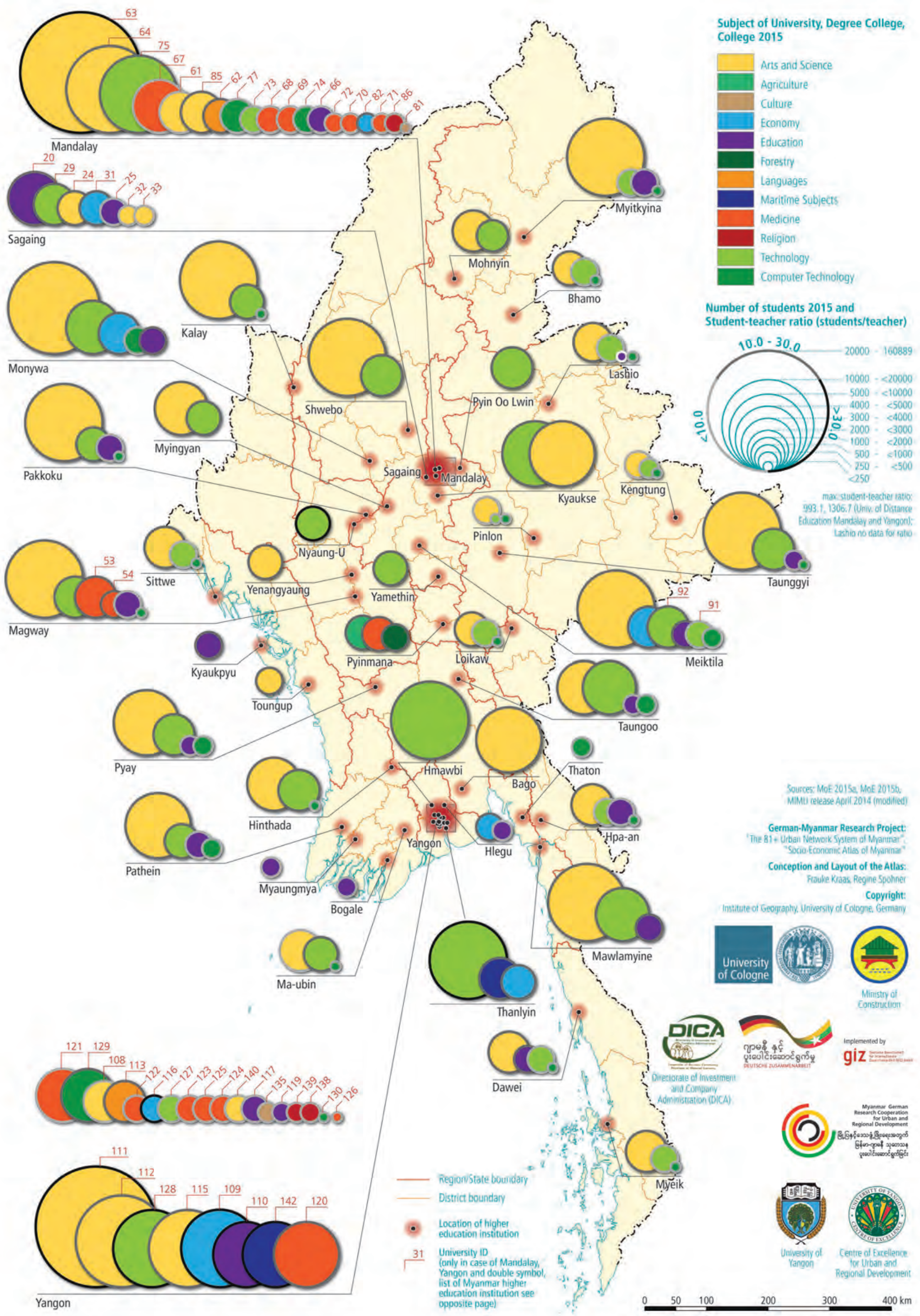




\section{HEALTH AND HEALTH SYSTEM}

\section{DEVELOPMENT OF THE HEALTH SYSTEM}

Myanmar's traditional health system underwent profound change during the British colonial period: 'indigenous practitioners trained in the Ayuvadic tradition were deprived of status and credibility and replaced by medicine from the colonial authorities' (Than Tun Sein et al. 2014: 32). But under the British, the first medical facilities and hospitals were built, hygiene and sanitation standards were introduced and vaccination programmes were established to protect the population from epidemics. The measures focused mainly on the towns and cities: coverage rarely extended to rural areas. After independence in 1948, the Pyidawtha Plan therefore specifically targeted health care for all population groups; the emphasis was on tackling endemic and epidemic diseases and reducing maternal and child mortality. After 1962 wide-ranging reform of the health sector and nationalisation of the health care system - including the previously private hospitals - significantly reduced the regional disparities in provision. However, investment and service provision declined after 1988, resulting in increasing erosion of services. Fundamental improvement in health care services was not achieved until after 2011 (on the five phases of development of the health system: Than Tun Sein et al. 2014: 32-36). Myanmar currently spends between just $2.0 \%$ (2001) and $2.4 \%$ (2011) of GDP on health, which places it among the Southeast Asian countries with the lowest expenditure on health care; only $1 \%$ of the population is insured under the social security scheme (Than Tun Sein et al. 2014: 61).

\section{LIFE EXPECTANCY, BIRTH AND FERTILITY RATES, MORBIDITY AND MORTALITY}

Life expectancy has risen from 55.0 years (1980; 56.5 for women and 53.7 for men) to 61.9

Yangon General Hospital

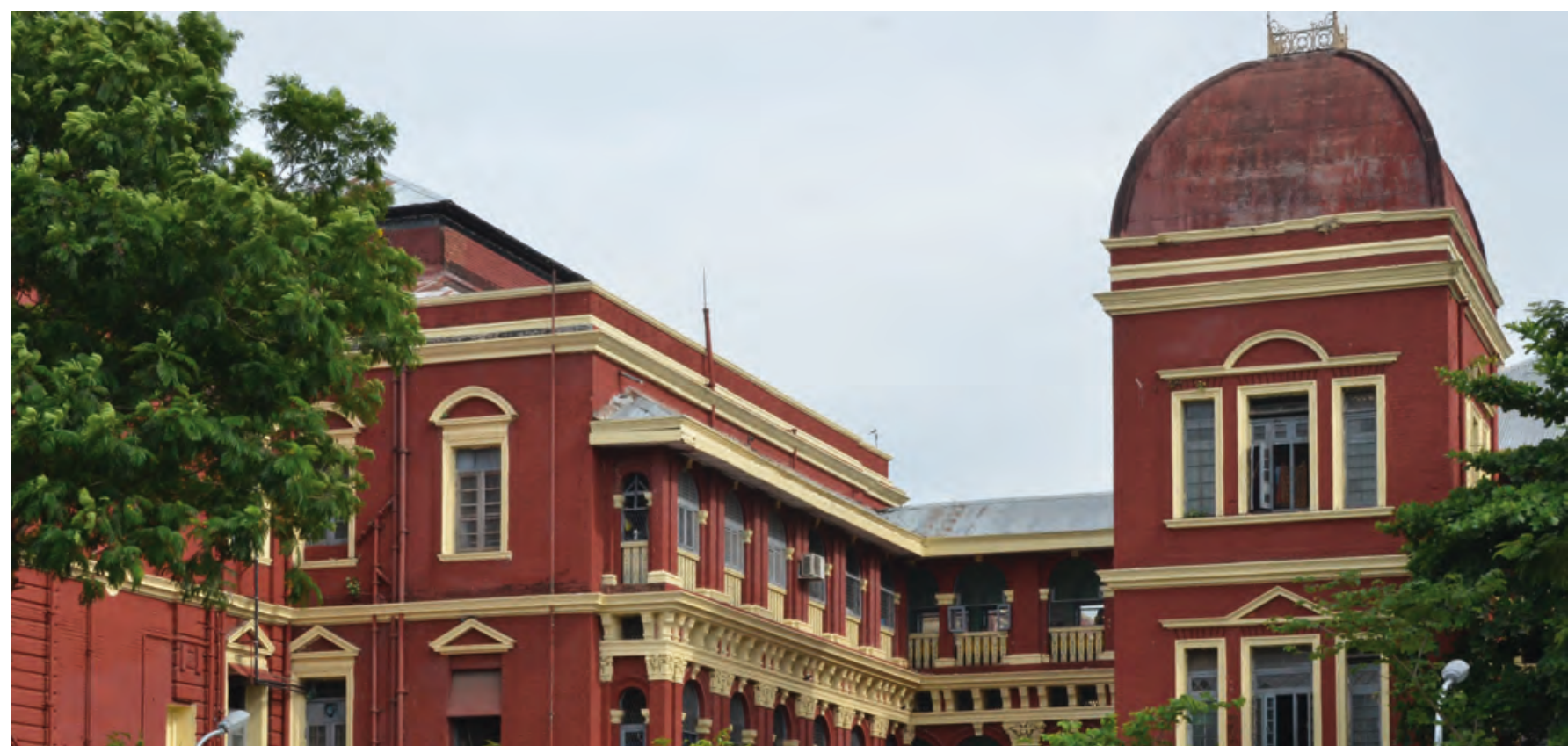



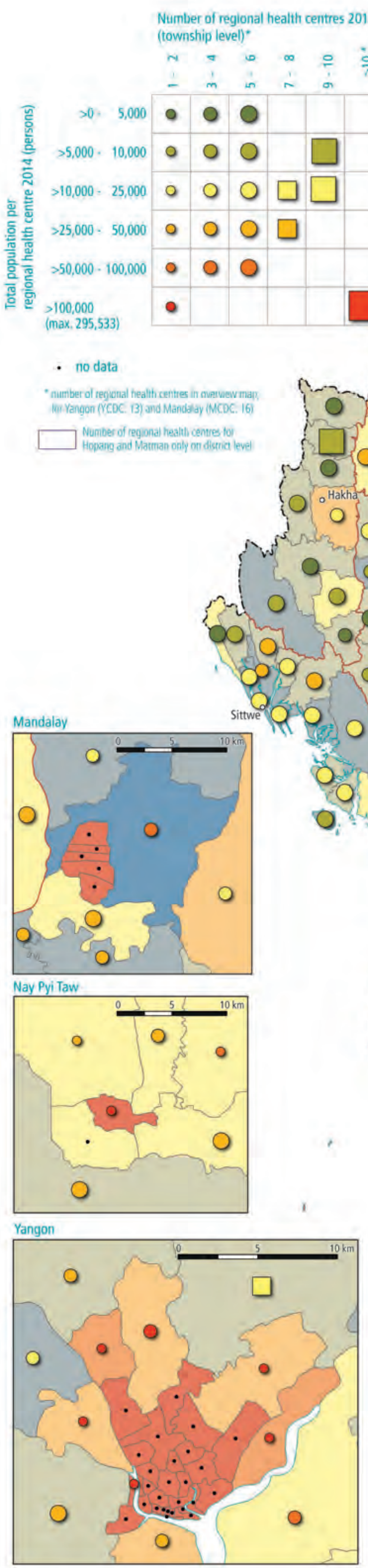

Urban population 2014

(share of township population in \%)

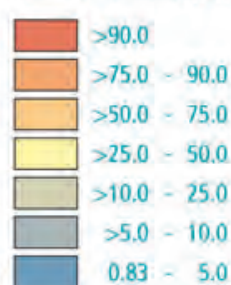


years $(2000 ; 63.3$ for women, 60.5 for men; Than Tun Sein et al. 2014: 15). According to the 2014 census, the crude birth rate was 18.9 per 1,000 population, with annual population growth of $0.89 \%$ in the period between 2003 and 2014. The total fertility rate has fallen from 6.1 (1965) to 2.3 (2015); in 2015 regional differences ranged from 1.7 in Yangon Region and 1.9 in Mandalay Region, 2.1 in Magway Region and 2.3 in Sagaing Region to 3.4 in Kayin State and 4.4 in Chin State (2015; MoHS 2016: 9, Nyi Nyi Latt et al. 2016: 124).

Mortality rates - especially infant and child mortality - are declining (infant mortality rate: 1990 - 47.0 per 1,000 live births, 2005 45.1). Of all under-five deaths, $87 \%$ occur in rural areas; infant mortality constitutes $73 \%$ of child mortality, and $70 \%$ of the infants who die do so in the first three months of life (all figures from Than Tun Sein et al. 2014: 24). Undernutrition and malnutrition in children is widespread, especially in rural areas, as in anaemia in women and children (MoHS 2016: 21-27).

Smallpox, leprosy, trachoma, poliomyelitis and iodine deficiency disorders have been eradicated in recent decades (Than Tun Sein et al. 2014: 110). Non-communicable diseases (NCDs) - principally cardiovascular diseases, malignant neoplasms and respiratory diseases - are the cause of around $40 \%$ of deaths; this percentage has been rising for some years. Among infectious and parasitic diseases, tuberculosis, diarrhoeal diseases and HIV/AIDS are the main causes of death (Than Tun Sein et al. 2014: 16). Despite considerable success in tackling malaria in recent years, the disease is still a major problem as a cause of sickness and death ( $8.1 \%$ of total mortality): $71 \%$ of the population live in malaria risk areas, $29 \%$ of them in high-risk areas. Changes in land use, environmental change, migration (in connection with land development, mining and road construction in peripheral areas), artemisinin resistance and vector adaptation encourage the spread of the disease (2008; Than Tun Sein et al. 2016: 21). Plasmodium falciparum is responsible for $68 \%$ of malaria cases and Plasmodium vivax for $23 \%$ (WHO 2012). Arsenic contamination of groundwater occurs in some parts of the country, including a number of townships in the Ayeyarwady Region (Mukherjee et al. 2006: 152).

The top five causes of disability-adjusted life years (DALY) are lower respiratory tract infections, tuberculosis, diarrhoeal diseases, HIV/ AIDS and stroke; the significance of ischaemic heart disease, road injury and cirrhosis of the liver is also increasing (Than Tun Sein et al. 2014: 16). The top five risk factors are dietary risks, tobacco smoking, household air pollution from solid fuels, high blood pressure and high blood sugar (IHME 2010, quoted after

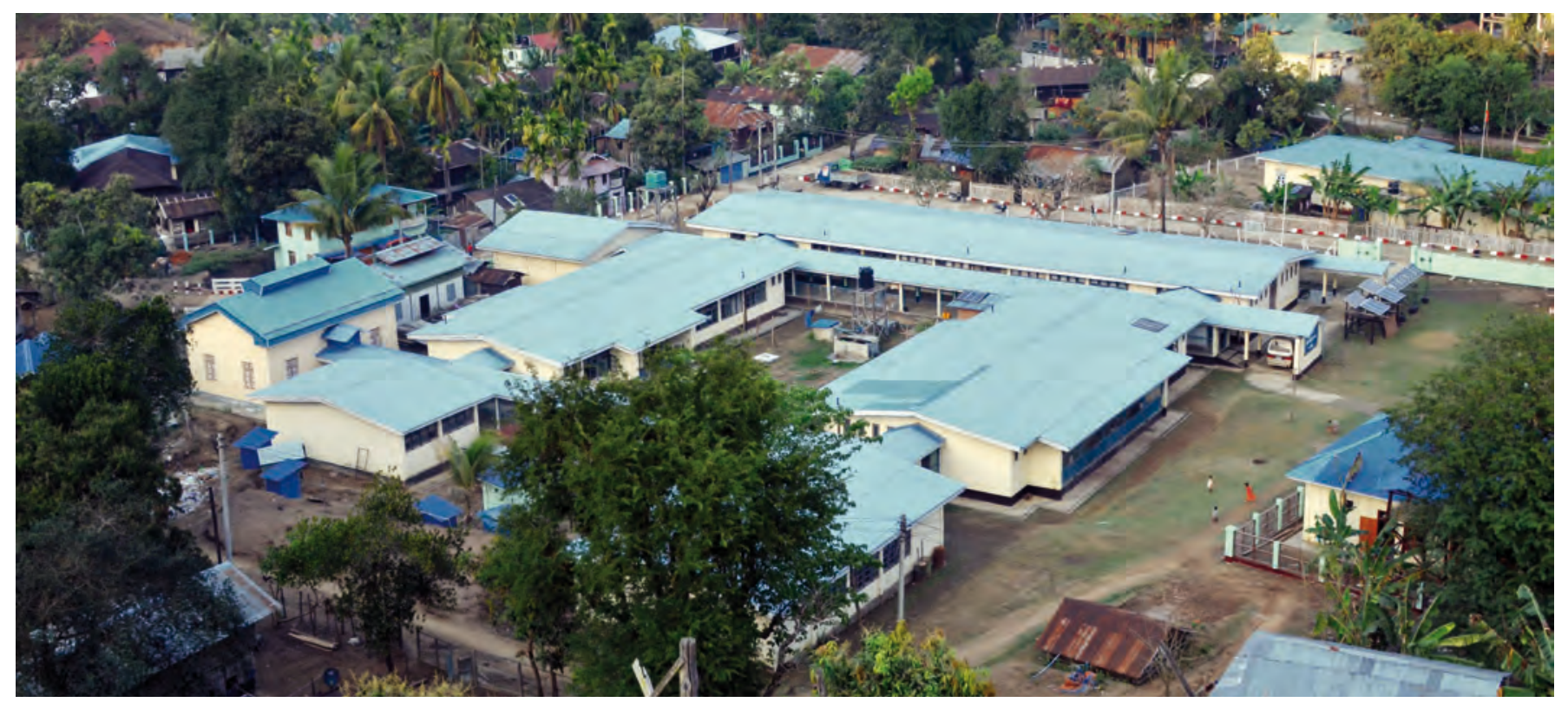




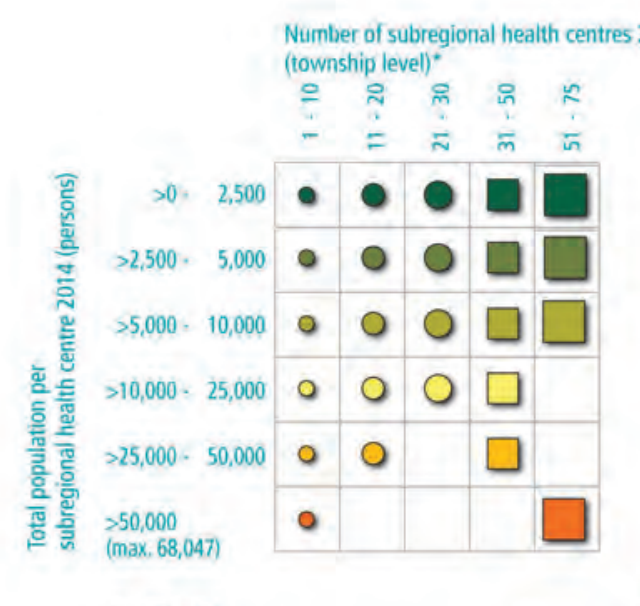
2014
$\sqrt{2}+2$

- no data

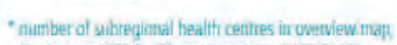
Fey Yangon (YCDC. B) and Mandiday (NCDC. 16)

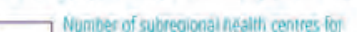

Hoparg and Matman only on dismia level

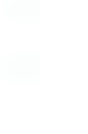


Than Tun Sein et al. 2014: 18). The use of alcohol and drugs - including to an increasing extent amphetamine-type stimulants (ATS) gives rise to significant problems, especially for the male population and in rural, peripheral and mining areas where the range of employment opportunities is limited; in addition, new, frequently young consumers in urban areas are turning to methamphetamines (Blickman 2011).

\section{HEALTH-RELATED INFRASTRUCTURE}

Health care is delivered via dual channels: there is a public and a private health system. Of the country's 32,861 doctors, 14,050 work in the state service and 18,811 in the private service. In addition there are 3,413 dental surgeons, 32,609 nurses, 22,258 midwives, 1,033 indigenous medical practitioners and 4,980 veterinary doctors (2014/15; MoPF 2016: 38). Primary health care coverage is relatively comprehensive and is provided through regional and sub-regional health centres (RHCs/sub-RHCs), the majority of which were built between 1970 and 1990. Their availability, number and distribution in the parts of the country is based largely on the focal points of population. In the mountainous areas there is therefore a large number of facilities for a relatively small population, in order to ensure that the centres and sub-centres can be accessed even in areas with little transport infrastructure.
For the country as a whole, there are 61 doctors, 100 nurses and 7 midwives within the public health care system per 100,000 population, which places Myanmar below the ASEAN average (Nyi Nyi Latt et al. 2016: 128). The country has 1,056 public hospitals with a total of 56,748 beds, including two general hospitals with more than 2,000 beds, 55 regional/state/ district hospitals with 200-500 beds and 330 township hospitals with 25-100 beds for curative and rehabilitative services. Facilities are distributed virtually countrywide, but the majority - including specialist clinics and by far the highest doctor-hospital ratios - are to be found in Yangon, Nay Pyi Taw, Mandalay and a few regional cities. The 2,199 facilities for preventive and public health services include 348 maternal and child health centres and 1,684 rural health centres. There are also 16 traditional medicine hospitals and 243 traditional medicine clinics (all figures: MoH 2014: 142-151). In the urban centres there is one midwife for more than 10,000 people; in the rural areas - especially in the more inaccessible parts of the country - the ratio is significantly higher. All the statistics quoted exclude the medical facilities operated by various ministries (such as the Ministry of Defence, the Ministry of Mines and the Ministry of Energy) for the use of employees and their families (Nyi Nyi Latt et al. 2016).

Medical Store at a Hospital

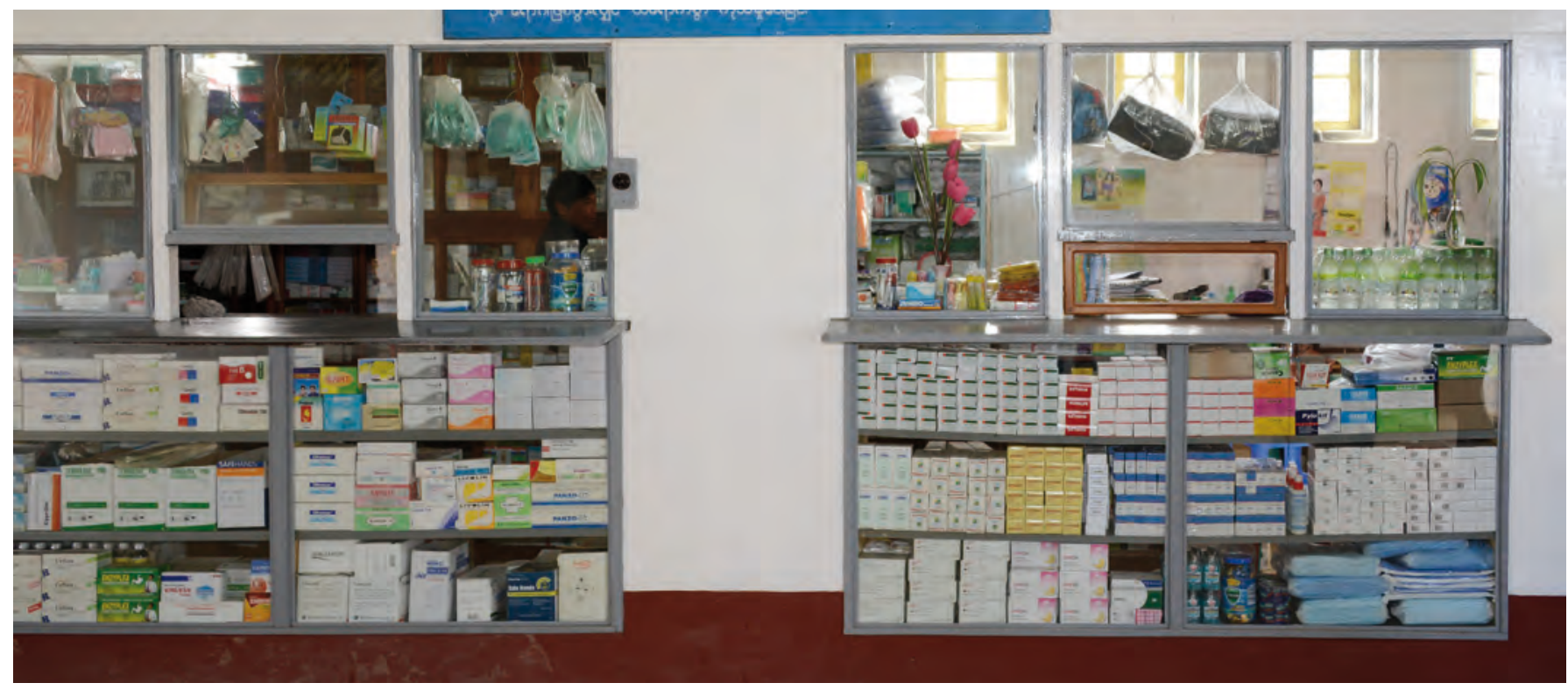




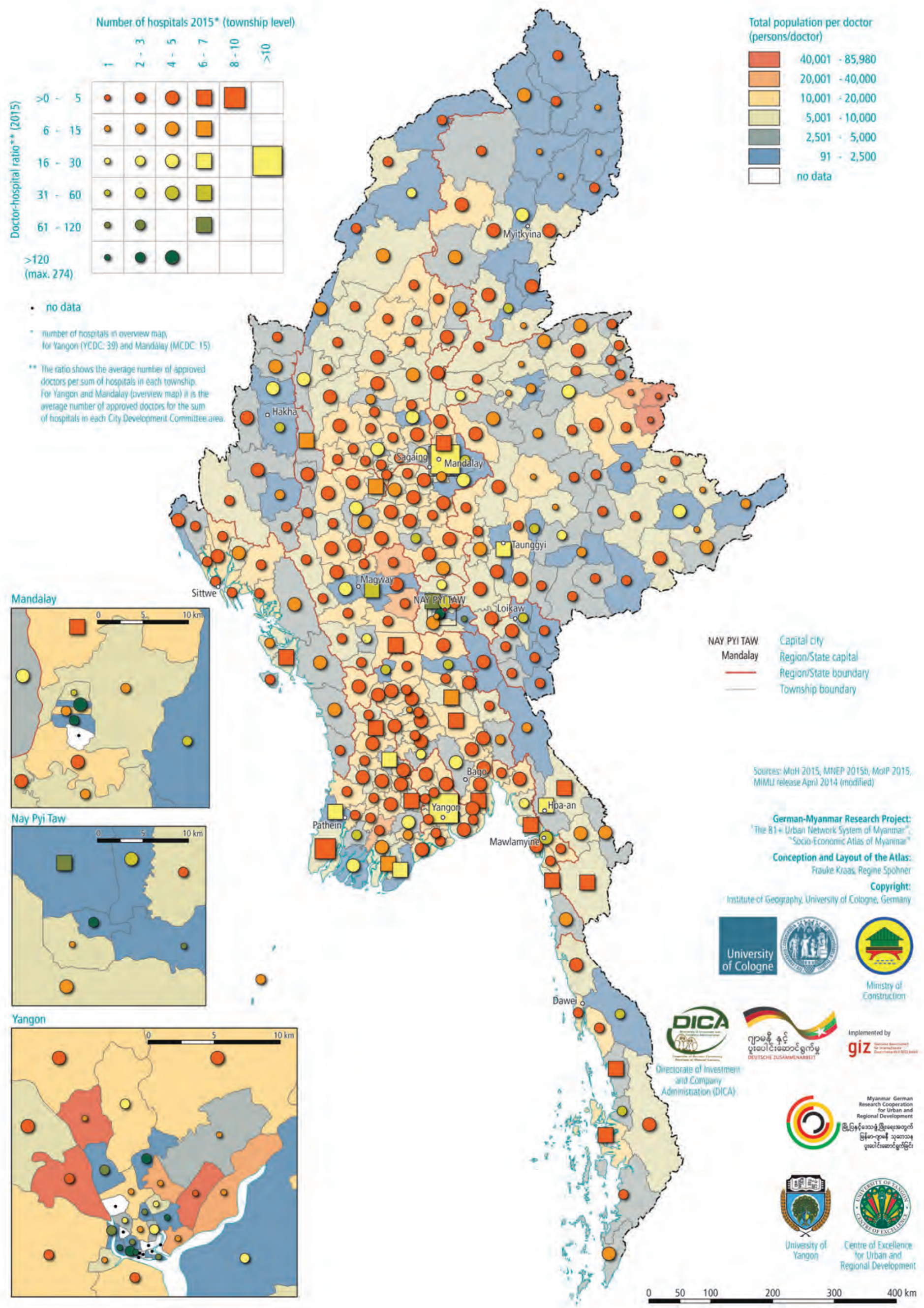


The availability of statistics relating to private medical facilities is limited; statistical analysis of the health infrastructure must therefore be treated with caution. Ni Nyi Latt et al. (2016: 126) quote figures for the country as a whole of 193 private hospitals, 201 specialist clinics, 3,911 private general clinics and 776 private dental clinics. The number of private medical institutions has been rising rapidly in the last few years, especially in the cities; frequently owned by foreign providers, they are often outposts of major hospitals in neighbouring Asian countries. In places where public health care provision is not comprehensive and there are no commercial private providers, communitybased organisations and religious communities step in, usually in support of charity-oriented initiatives. Traditional medicine is important, especially in rural areas: nationwide 6,963 private traditional practitioners are registered (2014; Nyi Nyi Latt et al. 2016: 125) and there are also many healers who practice informally.

The public and private health care systems overlap in that many doctors working in public health care institutions also provide services in private institutions outside their official working hours, in order to boost their salaries and have access to better equipment (dual practice in off-hours). In cases of serious illness and when transport and treatment can be funded, patients are transferred to hospitals in other countries - usually hospitals in Thailand or Singapore that meet international standards and have specific specialist expertise.

A particular problem is the care of the sick and elderly when the family has no social security system in place (Knodel/Bussarawan 2016). With 2,898,000 members of the population aged over 65 , the national dependency ratio is 8.8 , but in some regions it is significantly higher - e.g. in Magway Region it is 10.9, in Rakhine State 10.7 and in Mon State 10.4 (MoPF 2016: 19).

\section{FINANCE AND TRAINING}

The funding of health care services presents a major problem. Household out-of-pocket payments (OOP) are extremely high at 75\% (Than
Tun Sein et al. 2014: 70). This means that patients must pay most, if not all, of the costs of diagnosis and treatment themselves, including the costs of drugs and hospital stays. Around a third of households cannot afford these costs or must borrow money and sell property to do so, thereby often driving the family into poverty and debt. Charities and donations from relatives, friends, neighbours and religious communities play an important part in meeting the costs of treatment.

Training is provided in 15 medical universities and 46 nursing and midwifery training schools; in addition, the military has its own training centres (Nyi Nyi Latt 2016: 128). Many doctors complete at least part of their training abroad; since they can often earn more money in the countries in which they train, this not infrequently results in the emigration of medical workers.

\section{CHALLENGES IN THE HEALTH SYSTEM}

The greatest challenge in improving the health system is that of reducing health inequities in relation to the availability of and access to health services across the country. In the light of the Constitution of the Republic of the Union of Myanmar of 2008 (Article 367: 'Every citizen shall ... have the right to health care'), this means that there is a particular need to improve provision for poor and disadvantaged population groups, minorities and the inhabitants of conflict-affected and hard-to-reach-areas in the peripheral and mountainous regions. In addition, adequate funding of health care provision must be ensured and the expansion of a basic social security system encouraged (Than Tun Sein et al. 2014: 155-170). An approach based solely on the support of foreign donors is beset with difficulties: 'Challenges emerge when donor funding is managed by nonstate actors through numerous parallel programmes often not in line with government policy priorities and not sustainable in the long term' (Than Tun Sein et al. 2016: 61; see also Morrison et al. 2013: 9).

Frauke Kraas and Zin Mar Than 


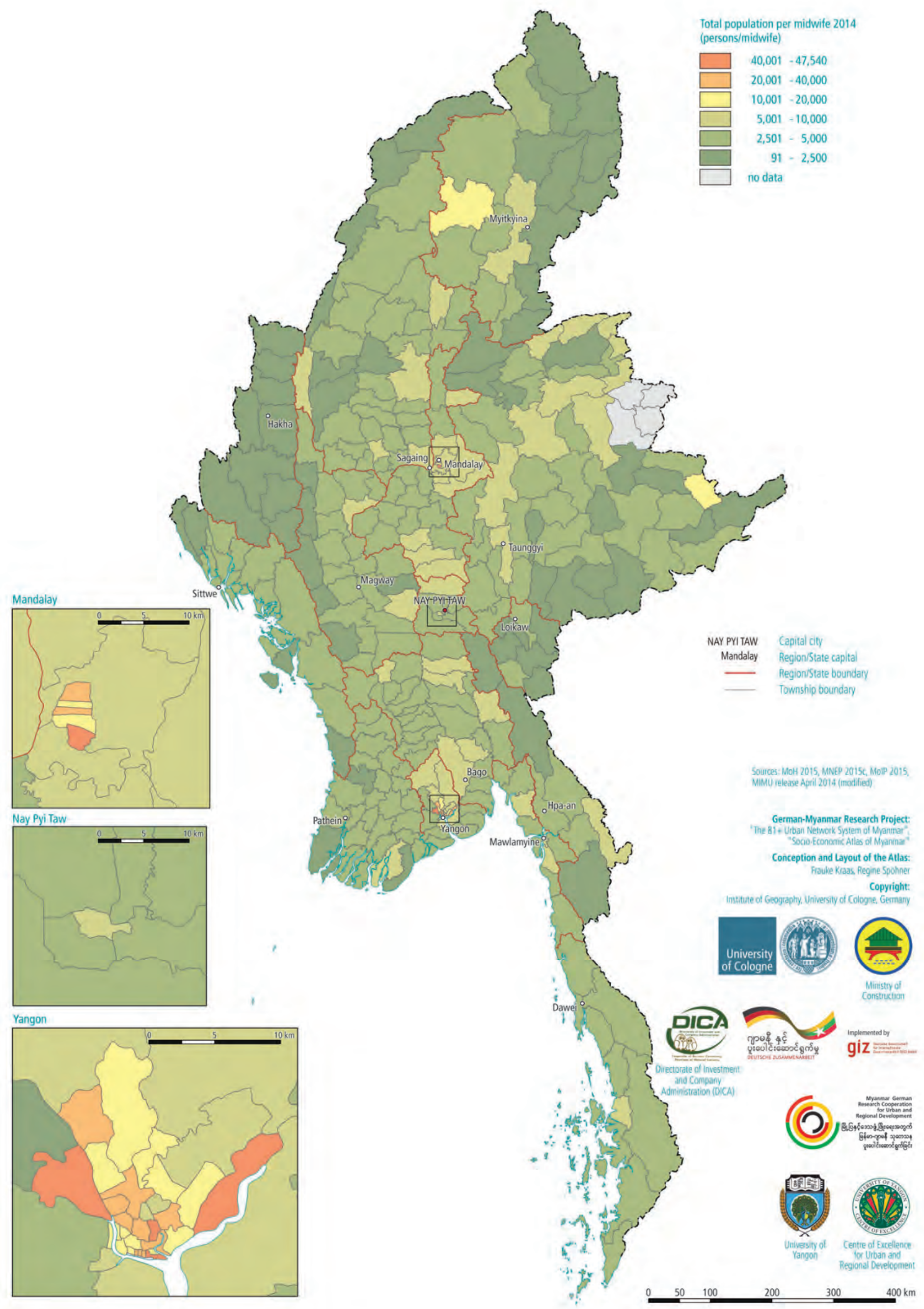




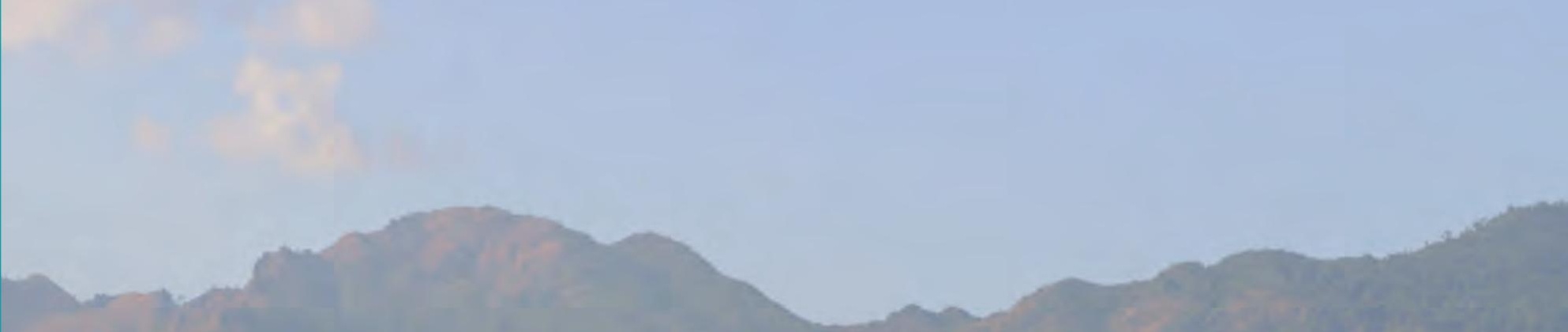

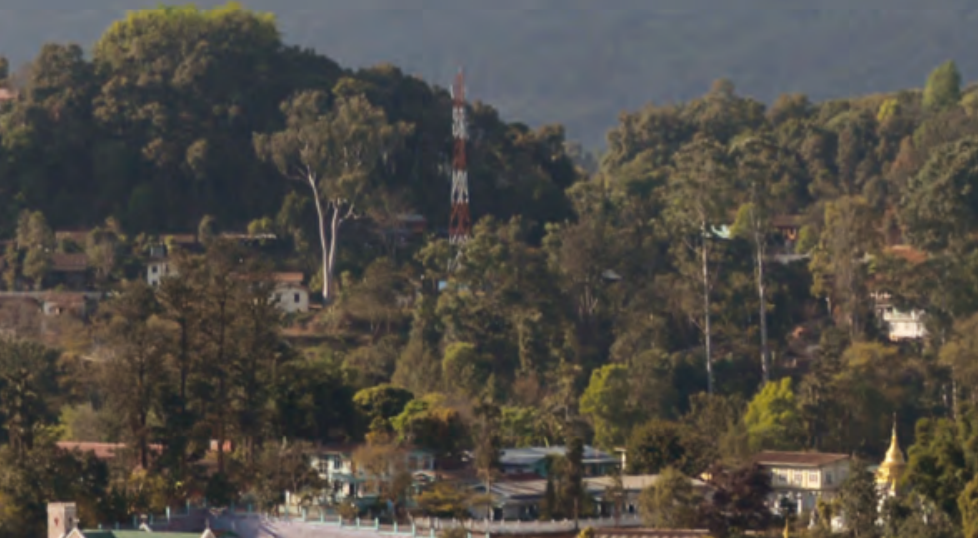
(1)

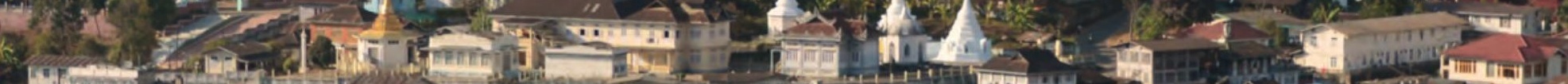

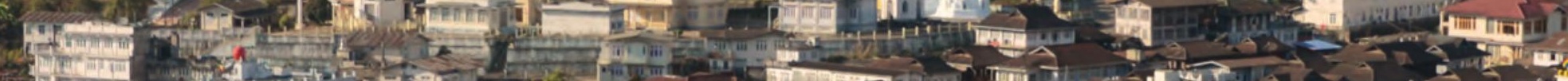

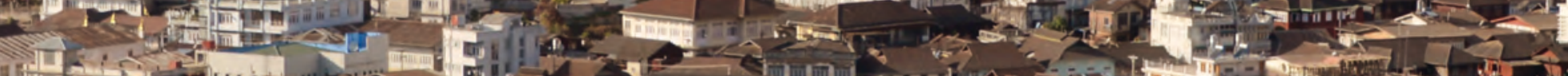
40 . W. के

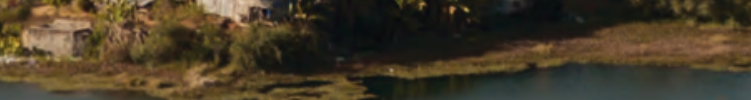
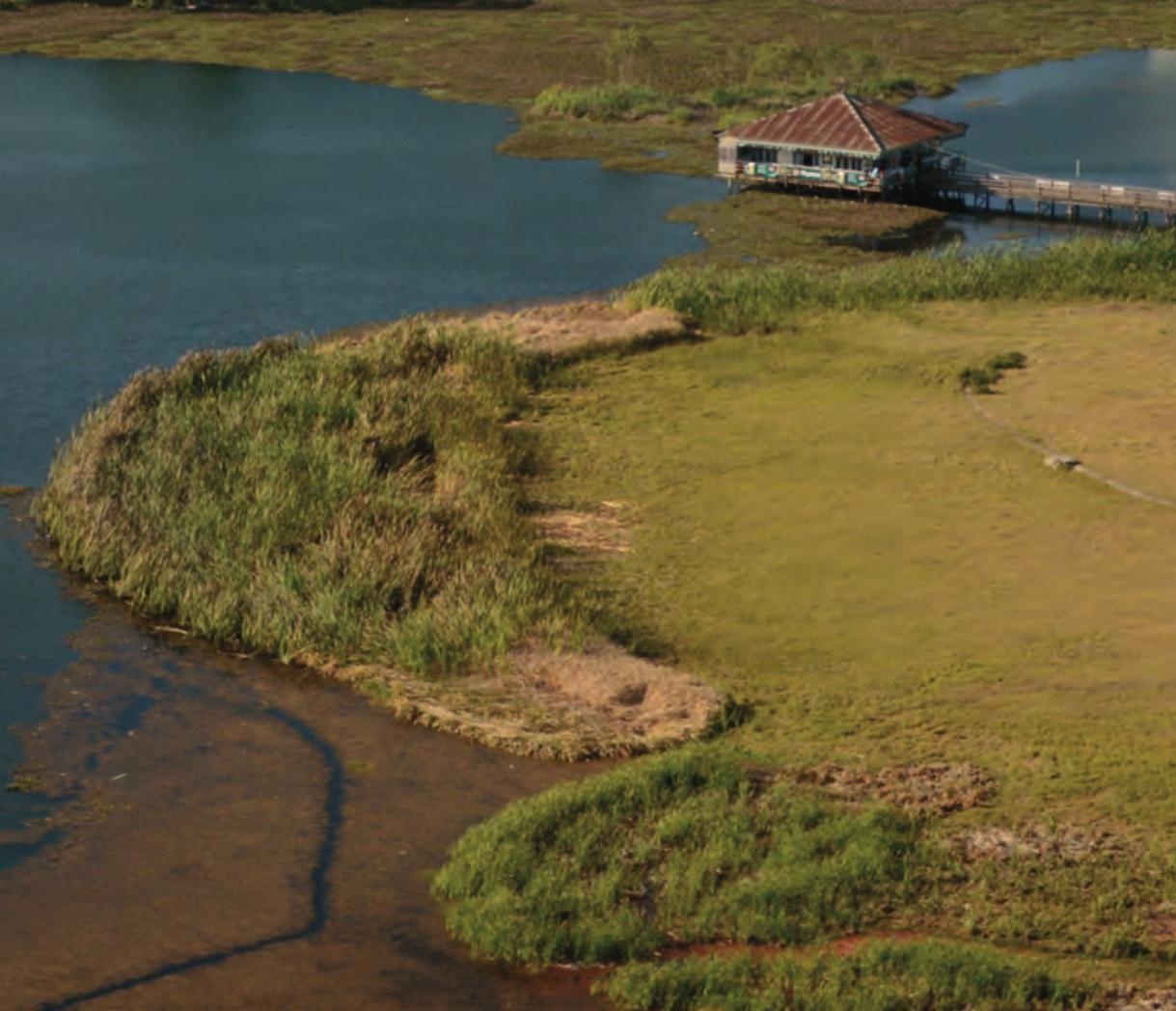


\section{REFERENCES}




\section{REFERENCES}

- Adas, M. (1974): The Burma Delta: Economic Development and Social Change on an Asian Rice Frontier, 1852-1941. Madison.

- ADB (Asian Development Bank) (2012a): Myanmar in Transition. Opportunities and Challenges. Manila.

- ADB (Asian Development Bank) (2012b): Myanmar: Transport Sector Initial Assessment. Manila.

- ADB (Asian Development Bank) (2012c): Myanmar: Energy Sector Initial Assessment. Mandaluyong City. (https://www.adb.org/sites/ default/files/institutional-document/33719/ files/myanmar-energy-sector-assessment. pdf, download September 2015)

- ADB (Asian Development Bank) (2012d): Myanmar - Energy Sector Initial Assessment. Manila (http://www.themimu.info/ sites/themimu.info/files/documents/ Report_Energy_Sector_Initial_Assessment_ ADB_2012.pdf, download October 2015)

- ADB (Asian Development Bank) (2013): New Energy Architecture: Myanmar.

- ADB (Asian Development Bank) (2016): Basic Statistics 2016. Manila.

- Allen, L. (1984): Burma. The Longest War. 1941-1945. London.

- AMA (Association of Myanmar Architects) (2012): 30 Heritage Buildings of Yangon. Inside the City that Captured Time. Chicago.

- Amine, M., Steckhan, H., S. Silvestrini (2016): Baseline Report for the German-Myanmar Programme on Sustainable Economic Development. German Institute for Development Evaluation (DEval). Bonn.

- Anderson, J. (1876): Mandalay to Momien. A Narrative of the Two Expeditions to Western China of 1868 and 1875 under Colonel Edward B. Sladen and Colonel Horace Browne. Reprint 2009. Bangkok.

- Andrus, J. R. (1947): Burmese Economic Life. London.
- Ardeth Maung Thawnghmung (2003): The SocioEconomic Impacts of Rice Policies Implementation in Rural Burma/Myanmar. Sojourn 18 (2): 299-321.

- Arino, O., Perez, R., Julio, J., Kalogirou, V., Defourny, P., F. Achard (2010): GLOBCOVER 2009. ESA-iLEAPS-EGU Earth Observation for LandAtmosphere Interaction Science. 3rd - 5th November, Frascati, Italy, SP-688, short paper, 3 pp, hdl:10013/epic.39889.d001

- Aung Kyaw, Ye Ye Than, Moe Moe, Kay Thi Aung (2013): Geographical analysis on the variation in agricultural technology diffusion among the farmers near Taungoo University. Journal of the Myanmar Academy of Arts and Science VI (6): 177-193.

- Aung Kyi (2006): Identification of Pulling Factors for Enhancing the Sustainable Development of Diverse Agriculture in Myanmar. CAPSA Working Paper No. 91. UN-ESCAP. Bangkok.

- Aung-Thwin, M., M. Aung-Thwin (2012): A History of Myanmar since Ancient Times. Traditions and Transformations. London.

- Aung Tun Thet (1989): Burmese Entrepreneurship. Creative Response in the Colonial Economy. Beiträge zur Südasienforschung. SüdasienInstitut Universität Heidelberg 126. Stuttgart.

- Aung Win (2006): Housing Situation in Megacity Yangon. In: Kraas, F., H. Gaese, Mi Mi Kyi (Eds.): Megacity Yangon: Transformation processes and modern developments. Southeast Asian Modernities 7. Berlin: 154-158.

- Avibase (2016): Avibase - the world bird database. http://avibase.bsc-eoc.org/, accessed: 22.11.2016

- Ba Shwe (2012): Economic Conditions of Rakhine under British Rule (1860-1886). PhD Thesis, Department of History, University of Yangon.

- Bannert, D., Lyen, A. S., Than Htay (2011): The Geology of the Indoburman Ranges in Myanmar. Geologisches Jahrbuch, Reihe B 101. Hannover.

- Beffasti, L., V. Galanti (Eds.) (2011): Myanmar Protected Areas - Contact, Current Status and Challenges. Milano.

- Belton, B., Aung Hein, Kyan Htoo, L. Seng Kham, U. Nischan, T. Reardon, D. Bougthon (2015): 
Aquaculture in Transition. Value Chain Transformation, Fish and Food Security in Myanmar. International Development Working Papers 139. Michigan.

- Bender, F. (1983): Geology of Burma. Beiträge zur regionalen Geologie der Erde 16. Stuttgart.

- Berlie, J. A. (2008): The Burmanization of Myanmar's Muslims. Bangkok.

- Beveridge, M. C. M., D. C. Little (2002): The history of aquaculture in traditional societies. In: B. A. Costa-Pierce (Ed.): Ecological aquaculture. Oxford: 3-29.

- Bhagwat, T., Hess, A. Horning, N., Thiri Khaing, Zaw Min Thein, Kyaw Moe Aung, Kyaw Htet Aung, Paing Phyo, Ye Lin Tun, Aung Htat Oo, Neil, A., Win Myo Thu, Songer, M., LaJeunesse Connette, K., Bernd, A., Huang, Q., Connette, G., P. Leimgruber (2017): Losing a jewel - Rapid declines in Myanmar's intact forests from 2002-2014. PLOS ONE (Public Library of Science) https://doi.org/10.1371/journal.pone.0176364

- Blickman, T. (2011): Amphetamine Type Stimulants and Harm Reduction. Experiences from Myanmar, Thailand and Southern China. Drug Policy Briefing 37. Amsterdam.

- Blower, J., Paine, J., Ohn Saw Hahn, H. Sutter (1991): Burma (Myanmar). In: Collins, N. M., Sayer, J. A., T.C. Whitmore (Eds.): The Conservation Atlas of Tropical Forests: Asia and the Pacific. London: 103-110.

- Bounthavy Sisouphanthong, C. Taillard (2000): Altas de a République Démocratique Populaire Lao. Les structures territoriales de développement économique et social. Paris.

- Boyle, J. (1990): Railroad to Burma. Sydney.

- Brown, I. (2005): A colonial economy in crisis. Burma's rice cultivators and the world depression of the 1930s. London.

- Burney, H. (1842): On the Population of the Burman Empire. Journal of the Statistical Society of London 4 (4): 335-347.

- Buzzi, C., M. Hayes, M. Mullen (ca. 2012): Education in Transition: A Preliminary Study of Capacity Development for Civil Society Actors in Burma/Myanmar. Institute for Human Rights and Peace Studies. Mahidol University. Bangkok. http://www.burmalibrary.org/docs13/Education_ in_Transition-IHRP-red.pdf (accessed: 22.2.2016)

- Carey, P. (Ed.): (1997): Burma. The Challenge of Change in a Divided Society. Oxford.

- Cernea, R. F. (2007): Almost Englishmen. Baghdadi Jews in British Burma. Lanham.

- Chang, W.-C. (2014): Beyond Borders. Stories of Yunnanese Chinese Migrants of Burma. Ithaka.

- Charles Maung Bo (2015): Toward a Future of Justice, Peace, and Development in Myanmar: A Christian Perspective. Review of Faith \& International Affairs 13 (4), Special Issue SI: 91-94.

- Chakravarti, N. R. (1971): The Indian Minority in Burma. The Rise and Decline of an Immigrant Community. Oxford.

- Charney, M.W. (2009): A History of Modern Burma. Cambridge.

- Chen, J., Liao, A., Cao, X., Chen, L., Chen, X., He, C., Han, G., Peng, S., Lu, M., Zhang, W., Tong, X., J. Mills (2014): Global Land Cover Mapping at 30m Resolution: a POK-based Operational Approach, ISPRS Journal of P\&RS, DOI: 10.1016/j. isprsjprs.2014.09.002. www.globallandcover.com

- Cheng, S.-H. (1968): The Rice Industry of Burma 1852-1940. Singapore.

- Cheesman, N. (2003): School, State and Sangha in Burma. Comparative Education 39 (1): 45-63.

- Cheesman, N., Skidmore, M., T. Wilson (Eds.) (2010): Ruling Myanmar. From Cyclone Nargis to National Elections. Singapore.

- Cheesman, N., Skidmore, M., T. Wilson (Eds.) (2012): Myanmar's Transition. Openings, Obstacles and Opportunities. Singapore.

- Cheng, S.-H. (1968): The Rice Industry of Burma 1852-1940. Singapore.

- Chhibber, H. L. (1933): The Physiography of Burma. London.

- Chhibber, H. L. (1934a): The Geology of Burma. London.

- Chhibber, H. L. (1934b): The Mineral Resources of Burma. London. 
- Chhor, H., Dobbs, R., Hansen, D. N., Thompson, F., Shah, N., L. Streiff (2013): Myanmar's moment: Unique opportunities, major challenges. McKinsey Global Institute. New York (http://www.mckinsey. com/insights/asia-pacific/myanmars_moment, accessed: 25.12.2016)

- Chie Ikeya (2008): The Modern Burmese Woman and the Politics of Fashion in Colonial Burma. The Journal of Asian Studies 67 (04): 1277-1308.

- Chit So (1999): Industrial Development and Reforms in Myanmar. In: Kiryu, M. (Ed.): Industrial Development and Reforms in Myanmar. ASEAN and Japanese Perspectives. Bangkok: 123-156.

- Chit Win, Kean, T. (2017): Communal Conflict in Myanmar: The Legislature's Response, 2012-2015. Journal of Contemporary Asia 47 (3), Special Issue SI: 413-439.

- Constitution of the Republic of the Union of Myanmar (2008). Nay Pyi Taw.

- Corbett, G. B., J. E. Hill (1992): Mammals of the Indomalayan Region: A Systematic Review. London.

- Corlett, R. T. (2005): Vegetation. In: Gupta, A. (Ed.): The Physical Geography of Southeast Asia. Oxford: 105-119.

- Costello, S., Taik Aung (2015): Developing social work education in Myanmar. International Social Work 58 (4): 582-594.

- Cummins, P. R. (2007): The potential for giant tsunamogenic earthquakes in the northern Bay of Bengal. Nature 449: 75-79.

- David Thang Moe (2017): Exclusion and Embrace: A Theology of Breaking Boundaries and Building Bridges Between Christianity and Buddhism in Myanmar. Exchange - Journal of Missiological and Ecumenical Research 46 (2): 103-128.

- Das, P. (2014): Status of India's Border Traded. Strategic and Economic Significance. IDSA Occasional Paper 37. New Delhi.

- Davis, J. H. (1960): The Forests of Burma. Gainesville.

- Davies, J., Sebastian, A. C., S. Chan (2004): A Wetland Inventory for Myanmar. Ministry of the Environment, Japan. Tokyo.
- Deguignet, M., Juffe-Bignoli, D., Harrison, J., MacSharry, B., Burgess, N., N. Kingston (2014): 2014 United Nations List of Protected Areas. UNEP-WCMC: Cambridge (download: 10.03.2016).

- DMH (Department of Meteorology and Hydrology) et al. (2009): Hazard Profile of Myanmar. Bangkok.

- Dumarcay, J., M. Smithies (1995): Cultural Sites of Burma, Thailand, and Cambodia. Oxford.

- Duval, Y. (2008): Economic Cooperation and Regional Integration in the Greater Mekong Subregion (GMS). UN-ESCAP Trade and Investment Division, Staff Working Paper 02/08. Bangkok.

- Earthrights International (2008): China in Burma: The Increasing Investment of Chinese Multinational Corporations in Burma's Hydropower, Oil and Natural Gas, and Mining Sectors. Updated: September 2008. (https://www. earthrights.org/sites/default/files/publications/ China-in-Burma-update-2008-English. pdf, download September 2015)

- Egreteau, R., F. Robinne (Eds.) (2016): Metamorphosis. Studies in Societal and Political Change in Myanmar. Singapore.

- Ericsson (2012): The potential economic impact of mobile communications in Myanmar. http:// www.ericsson.com/res/docs/2012/myanmarreport-2012-13nov.pdf (accessed: 27.12.2016)

- ESCAP (Economic and Social Commission for Asia and the Pacific) (1996): Geology and Mineral Resources of Myanmar. New York.

- Fan, H. (2011): China's 'Look South': ChinaMyanmar Transport Corridor. Ritsumeikan International Affairs 10: 43-66.

- FAO (Food and Agriculture Organization of the United Nations) (2000): Forest Cover Mapping and Monitoring with NOAA-AVHRR and other Coarse Spatial Resolution Sensors. Forest Resources Assessment Programme, Working Paper 29. Rome.

- FAO (Food and Agricultural Organization of the United Nations) (2005): Agricultural Atlas of the Union of Myanmar. Myanmar Agriculture Sector Review. Rome. 
- FAO (Food and Agriculture Organization) (2006): Global Forest Resources Assessment 2005. Progress Towards Sustainable Forest Management. Rome.

- FAO (Food and Agriculture Organization) (2015): Global Forest Resources Assessment 2015. Desk reference. Rome.

- FAO (Food and Agriculture Organisation) (2016): FishStatJ database (accessed: 28.11.2016). http:// www.fao.org/fishery/statistics/software/ fishstatj/en

- Fife, E. (Ed.) (2014): Myanmar: Telecoms Last Frontier. Honolulu. (Pacific Telecommunications Council Broadband Reports 2)

- Findlay, R., Park, C.-Y., J.-P. A. Verbiest (2015): Myanmar: Unlocking the Potential. A Strategy for High, Sustained, and Inclusive Growth. ADB Economic Working Paper Series 437. Manila.

- Florento, H., M. I. Corpuz (2014): Myanmar: The Key Link between South Asia and Southeast Asia. ADBI Working Paper 506. Tokyo: Asian Development Bank Institute. http://www.adbi.org/ working-paper/2014/12/12/6517.myanmar.key. link.south.southeast.asia/ (accessed: 27.9.2016)

- Fong-Sam, Y. (2012): The Mineral Industry of Burma. USGS 2010 Minerals Yearbook. Washington.

- Fong-Sam, Y. (2016): The Mineral Industry of Burma. USGS 2013 Minerals Yearbook. Washington.

- Frasch, T. (1996): Pagan. Stadt und Staat. Beiträge zur Südasienforschung, Südasien-Institut Universität Heidelberg 172. Stuttgart.

- Frasch, T. (2002): Coastal Peripheries during the Pagan Period. In: Gommans, J., J. Leider (Eds.): The Maritime Frontier of Burma. Exploring Political, Cultural and Commercial Interaction in the Indian Ocean World, 1200-1800. Amsterdam: 59-78.

- Fraser-Lu, S. (1994): Burmese Crafts. Past and Present. Kuala Lumpur.

- Fraser-Lu, S. (2000): Burmese Lacquerware. Bangkok.

- Fritz, H.M., Blount, C.D., Swe Thwin, Moe Kyaw Thu, Nyein Chan (2009): Cyclone Nargis storm surge in Myanmar. Nature Geoscience 2 (7):

448-449.

- Fujita, K., F. Mieno, I. Okamato (Eds.) (2009): The Economic Transition in Myanmar after 1988. Market Economy versus State Control. Kyoto CSEAS Series on Asian Studies 1. Singapore, Kyoto.

- Furnivall, J. S. (1943): Educational Progress in Southeast Asia, IPR Inquiry Series. New York.

- Furnivall, J. S. (1948): Colonial Policy and Practice. A Comparative Study of Burma and Netherlands India. New York.

- Furnivall, J. S. (1957): An Introduction to the Political Economy of Burma. Rangoon.

- Gärtner, U. (2011a): Nay Pyi Taw - the reality and myths of capitals in Myanmar. In: Grabowsky, V. (Ed.): Southeast Asian historiography unravelling the myths: essays in honour of Barend Jan Terwiel. Bangkok: 258-267.

- Gärtner, U. (2011b): Education in Myanmar. A Concise Abstract of Educational Policy. Passauer Beiträge zur Südostasienkunde. Working Papers 15. Passau.

- Gaese, H., Kraas, F., Mi Mi Kyi (Eds.) (2005): Sustainability in Rural and Urban Environments. Proceedings of the First German-Myanmar Workshop in Yangon/Myanmar, 17-21 November 2003. Cologne.

- Ganesan, N., Kyaw Yin Hlaing (Eds.) (2007): Myanmar. State, Society and Ethnicity. Singapore.

- Gibson, T., James, H., L. Falvey (Eds.) (2016): Rohingyas. Insecurity and Citizenship in Myanmar. Songkhla.

- Goeres, J., White, N., C. Tun (2013): Myanmar the next Asian telecommunications Greenfield? Deloitte Southeast Asia Ltd. https://www2. deloitte.com/content/dam/Deloitte/sg/ Documents/technology-mediatelecommunications/sg-tmt-Myanmar-next-Asiantelecommunications-greenfield.pdf (accessed: 03.01.2017)

- Golloch, A. (2014): Handwerkskunst in Myanmar (Burma). Mit traditioneller Technik zu Meisterwerken. Aachen. 
- Government of Burma (1952): Pyidawtha. The New Burma. Rangoon.

- Grant, W.J. (1942): The New Burma. London.

- Gravers, M. (Ed.) (2007): Exploring Ethnic Diversity in Burma. NIAS studies in Asian topics 39. Copenhagen.

- Gravers, M. (2013): Spiritual Politics, Political Religion, and Religious Freedom in Burma. Review of Faith \& International Affairs 11 (2): 46-54.

- Gravers, M., F. Ytzen (Eds.) (2014): Burma/ Myanmar - Where Now? Copenhagen.

- Grundy-Warr, C., E.W.S. Yin (2002): Geographies of Displacement: The Karenni and the Shan across the Myanmar-Thailand Border. Singapore Journal of Tropical Geography 23 (1): 93-122.

- Gupta, A. (1996): Erosion and sediment yield in Southeast Asia: a regional perspective. Proceedings of the Exeter Symposium. IAHS Publication no. 236: 215-222.

- Gupta, A. (2005): The Physical Geography of Southeast Asia. Oxford.

- Häusler, N. (2014): Nachhaltiger Tourismus in Myanmar: Erste wichtige Schritte? In: Köster, U., Trong, P.L., C. Grein (Hg.): Handbuch Myanmar. Berlin: 293-303.

- Häusler, N., C. Baumgartner (2014): Myanmar on its Way to Responsible Management: The Important Role of Stakeholder Dialogues. In: Wohlmuther, C., W. Wintersteiner (Eds.): International Handbook on Tourism and Peace. Klagenfurt: 181-198.

- Han Tin (2008): Myanmar education: challenges, prospects and options. In: Skidmore, M., T. Wilson (Eds.): Dictatorship, Disorder and Decline in Myanmar. Canberra: 113-126.

- Harlow, G. E., A. Bender (2013): A study of ruby (corundum) compositions from the Mogok Belt, Myanmar: Searching for chemical fingerprints. American Mineralogist 98: 1120-1132.

- Hauff, M. von (2007): Economic and Social Development in Burma/Myanmar. The Relevance of Reforms. Marburg.

- Hauff, M. von (2016): Industrial Zone Planning according to the Requirements of Sustainable
Development. In: Kraas, F., Mi Mi Kyi, Win Maung (Eds.) (2016): Sustainability in Myanmar. Southeast Asian Modernities 15. Wien: 265-276.

- Hedley, P. J., Bird, M. I., R. A. J. Robinson (2010): Evolution of the Irrawaddy Delta region since 1850. Geographical Journal 176: 138-149.

- Hemley, G., J. A. Mills (1999): The beginning of the end of tigers in trade? In: Seidensticker, J., S. Christie, P. Jackson (Eds.): Riding the Tiger. Tiger Conservation in Human Dominated Landscapes. Cambridge: 217-229.

- Hennig, T. (2016): Damming the transnational Ayeyarwady basin. Hydropower and the waterenergy nexus. Renewable and Sustainable Energy Reviews 65: 1232-1246.

- Hesmer, H. (1975): Leben und Werk von Dietrich Brandis 1824-1907. Begründer der tropischen Forstwirtschaft. Förderer der forstlichen Entwicklung in den USA. Botaniker und Ökologe. Abhandlungen der Rheinisch-Westfälischen Akademie der Wissenschaften 58. Opladen.

- Heymann, J., E. Löffler (1997): Mangrove degradation in the Ayeyarwady Delta, Myanmar. Petermanns Geographische Mitteilungen 141 (5/6): 291-306.

- Hillman, O. (1946): Education in Burma. The Journal of Negro Education 15 (3): 526-533.

- Hlaing Maw Oo (alias) Maw Oo Hock (2006): Heritage Conservation in Transforming Yangon into a Sustainable Megacity. In: Kraas, F., H. Gaese, Mi Mi Kyi (Eds.): Megacity Yangon: Transformation processes and modern developments. Southeast Asian Modernities 7. Berlin: 199-215.

- Hla Naing, Fuller, T. K., Sievert, P. R., Randhir, T. O., Saw Htoo Tha Po, Myint Maung, Lynam, A. J., Saw Htun, Win Naing Thaw, Than Myint (2015): Assessing large mammal and bird richness from camera-trap records in the Hukaung Valley of Northern Myanmar. Raffles Bulletin of Zoology 63: 376-388.

- Hla Tun Aung (2003): Myanmar. The Study of Processes and Patterns. Yangon: National Centre for Human Resource Development, Publishing Committee, Ministry of Education. 
- Holliday, I. (2011): Burma Redux. Global Justice and the Quest for Political Reform in Myanmar. Hong Kong.

- Hpone-Phyo Kan-Nyunt, Karampelas, S., Link, K., Kyaw Thu, Kiefert, L., P. Hardy (2013): Blue Sapphires from the Baw Mar Mine in Mogok. Gems \& Gemology 49 (4): 223-232.

- Hudson, S. (2016): Let the journey begin (again): The branding of Myanmar. Journal of Destination Marketing Management 5 (4), SI: 305-313.

- Hudson, B., T. Lustig (2008): Communities of the past: A new view of the old walls and hydraulic system at Sriksetra, Myanmar (Burma). Journal of Southeast Asian Studies 39 (2): 269-296.

- Hudson, B., Nyein Lwin, Win Maung (2001): The origins of Bagan: New dates and old inhabitants. Asian Perspectives 40 (1): 48-74.

- Ibrahim, A. (2016): The Rohingyas. Inside Myanmar's Hidden Genocide. London.

- IHME (Institute for Health Metrics and Evaluation) (2010): GBD (Global Burden of Disease) profile: Myanmar. Seattle. http://www.healthdata. org/myanmar (accessed: 12.1.2017)

- International Crisis Group (2008): Burma/Myanmar after Nargis: Time to normalise aid relations. Asia Report 161. Brussels.

- James, H. (2003): Cooperation and community empowerment in Myanmar in the context of Myanmar agenda 21. Asian-Pacific Economic Literature 17 (1): 1-21.

- James, H. (2005): Governance and Civil Society in Myanmar: Education, Health and Environment. London.

- James, H. (2006): Security and Sustainable Development in Myanmar. Abingdon.

- James, H. (2010): Resources, Rent-seeking, and Reform in Thailand and Myanmar (Burma): the Economics-Politics nexus. Asian Survey 50 (2): 426-448.

- James, H., D. Paton (2015): Social Capital and the Cultural Contexts of Disaster Recovery Outcomes in Myanmar and Taiwan. Global Change, Peace \& Security 27 (2): 207-228.
- Jonsson, T. N. (2014): A case study on Internet freedom and responsibility investment in Myanmar's emerging Telecom scene. Master Thesis. Department of Theology. Uppsala Universitet.

- Kan Hla (1977): Pagan: Development and town planning. The Journal of the Society of Architectural Historians 36 (1): 15-29.

- Kan Zaw, Nu Nu Lwin, Khin Thida Nyein, Mya Thandar (2011): Agricultural Transformation, Institutional Changes, and Rural Development in Ayeyarwady Delta, Myanmar. In: Ponciano S. I. Jr., Intal, P. S. Jr., Oum, S., M. J. O. Simorangkir (Eds.): Agricultural Development, Trade and Regional Cooperation in Developing East Asia. Jakarta: 307-355.

- Kane, R.E., R.C. Kammerling (1992): Status of Ruby and Sapphire Mining in the Mogok Stone Tract. Gems \& Gemology 28 (3): 152-174.

- Kattelus, M. (2014): Myanmar under reform: Emerging pressures on water, energy and food security. Natural Resources Forum 38: 85-98.

- Kattelus, M., Rahaman, M. M., O. Varis (2015): Hydropower development in Myanmar and its implications on regional energy cooperation. International Journal for Sustainable Society 7 (1): 42-66.

- Keck, S. (2015): British Burma in the New Century, 1895-1918. Basingstoke.

- Keller P. C. (1983) The rubies of Burma: A review of the Mogok Stone Tract. Gems \& Gemology 19 (4): 209-219.

- Kermel-Torrès, D. (2004): Atlas de Thailande. Structures spatiales et développement. Paris.

- Khin Htun (2009): Myanmar Forestry Outlook Study. Working Paper No. APFSOS II/WP/2009/07. Bangkok.

- Khin Khin Han (2016): Rainfall Distribution and Variability in Myanmar. In: Kraas, F., Mi Mi Kyi, Win Maung (Eds.) (2016): Sustainability in Myanmar. Southeast Asian Modernities 15. Wien: 25-32.

- Khin Khin Soe (2008): Economic Development Processes of Kyauktan Township (1985-2006). PhD Thesis, Department of Geography, University of Yangon. 
- Khin Khin Soe (2016): Agri-Food Chain Analysis of Economic Development Processes of Kyauktan. In: Kraas, F., Mi Mi Kyi, Win Maung (Eds.) (2016): Sustainability in Myanmar. Southeast Asian Modernities 15. Wien: 229-249.

- Khin Khin Soe, Kraas, F., Yee Yee Than (2016): Economic Development Potentials of Sagaing Region: Perception on Crafts and Handicrafts of Sagaing Town. Taungoo University Research Journal 7 (1): 29-38.

- Khin Khin Soe, Yin Yin Lwin (2015): Analysis of Labour Productivity in Rubber Latex Extraction among Smallholder Rubber Farmers in the Kyarinnseikkyi Township, Kawkareik District, Kayin State. Journal of the Myanmar Academy of Arts and Science XIII (6): 351-367.

- Khin San Yu, Saw Thandar, Mint Myint Htay (2016): A Geographical Assessment of Urban Landuse Changes in Sittway Town. Journal of the Myanmar Academy of Arts and Science XIV (5): 265-279.

- Kipgen, N. (2013): Conflict in Rakhine State in Myanmar: Rohingya Muslims' Conundrum. Journal of Muslim Minority Affairs 33 (2): 298-310.

- Kipgen, N. (2015): Ethnic Nationalities and the Peace Process in Myanmar. Social Research: An International Quarterly 82 (2): 399-425.

- Kirchherr, J., Charles, K.J., M.W. Walton (2016): The interplay of activists and dam developers: the case of Myanmar's mega-dams. International Journal of Water Resources Development. DOI: 10.1080/07900627.2016.1179176

- Kirchherr, J., Matthews, N., Charles, K. J., M. J. Walton (2017): 'Learning it the Hard Way': Social safeguard norms in Chinese-led dam projects in Myanmar, Laos and Cambodia. Energy Policy, 102, 529-539. http://dx.doi. org/10.1016/j.enpol.2016.12.058

- Knodel, J., Bussarawan Teerawichitchainan (2017): Aging in Myanmar. Gerontologist 00 (00): 1-7.

- Kraas, F., M. Rivet (1996): Wirtschafts- und Sozialstruktur von Kambodscha, Laos und Myanmar. Unveröffentlichte Studie für die DEG Deutsche Investitions- und Entwicklungsgesell- schaft und das Bundesministerium für wirtschaftliche Zusammenarbeit und Entwicklung (BMZ). Bonn.

- Kraas, F. (1997): Unruhen in Myanmar/Birma. Politische, soziale und wirtschaftliche Hintergründe. Geographische Rundschau 49 (5): 315-318.

- Kraas, F. (2002): Angkor Wat und Pagan: Konflikte zwischen Schutz des Weltkulturerbes und Ferntourismus? In: Karrasch, H. et al. (Hg.): Ferntourismus: Potentiale, Konflikte, Nachhaltigkeitsanspruch. HGG-Journal 17. Heidelberg: 125-149.

- Kraas, F. (2004a): Zur Situation der Geographie an den Universitäten in Myanmar. Petermanns Geographische Mitteilungen 148 (5): 92-93.

- Kraas, F. (2004b): Global Change and Scientific Challenges. A call for integrative research in Myanmar. Journal of Yangon University 2004: 272-277.

- Kraas, F. (2007): Megacities and global change: key priorities. Geographical Journal 173 (1): 79-82.

- Kraas, F. (2009): Tsunami 2004 und Zyklon 'Nargis' 2008. Katastrophenbewältigung in den Küstenregionen von Myanmar. Geographische Rundschau 61 (12): 50-58.

- Kraas, F. (2014a): Naturraumpotentiale, Naturrisiken und Ressourcennutzung in Myanmar. In: Köster, U., Ph. Le Trong, C. Grein (Hg.): Handbuch Myanmar. Gesellschaft, Politik, Wirtschaft, Kultur, Entwicklung. Berlin: 60-67.

- Kraas, F. (2014b): Bevölkerungsentwicklung, Migrationsprozesse und Urbanisierungsdynamik in Myanmar. In: Köster, U., Ph. Le Trong, C. Grein (Hg.): Handbuch Myanmar. Gesellschaft, Politik, Wirtschaft, Kultur, Entwicklung. Berlin: 33-40.

- Kraas, F. (2014c): Tachileik/Myanmar und Mae Sai/ Thailand: Grenzstädte im Transformationsprozess. Thailand-Rundschau 27 (1): 18-23.

- Kraas, F. (2015): Agrarregionen Myanmars. In: Gerhard, U., Meier, G., Nüsser, M., Schmidt, S. (Hg.): GO EAST I Klima - Krisen - Kulturen. HGGJournal 29 (2014/2015). Heidelberg: 31-46.

- Kraas, F. (2016a): Bildungswesen und Schulalltag in Myanmar. Praxis Geographie 46 (3): 50-53. 
- Kraas, F. (2016b): Ökonomische Transformationen im Delta des Ayeyarwady/Myanmar. Geographische Rundschau 68 (7/8): 24-29.

- Kraas, F. (2016c): Rubine und Saphire: Zur Entwicklung der Bergbaustadt Mogok/Myanmar. In: Die Welt verstehen - eine geographische Herausforderung. Eine Festschrift der Geographie Innsbruck für Axel Borsdorf. Innsbrucker Geographische Studien 40: 95-118.

- Kraas, F. (2017): Die Städte Südostasiens. In: Heineberg, H.: Stadtgeographie. Grundriss Allgemeine Geographie. 5th, revised edition. Paderborn: 350-363.

- Kraas, F., H. Gaese, Mi Mi Kyi (Eds.) (2006): Megacity Yangon: Transformation processes and modern developments. Southeast Asian Modernities 7. Berlin.

- Kraas, F., N. Häusler (2016): Tourismusentwicklung in Myanmar. Geographische Rundschau 68 (9): 52-57.

- Kraas, F., Hlaing Maw Oo, R. Spohner (2014): Yangon Urban Heritage: 189 Listed Heritage Buildings. An annotated thematic map. Cologne, 2nd edition.

- Kraas, F., Hlaing Maw Oo, R. Spohner (2015): Mapping Yangon's Urban Heritage: Concept, Categories and Priorities. In: Avrami, E. (Ed.): Building the Future: The Role of Heritage in the Sustainable Development of Yangon. World Monuments Fund. New York: 50-59.

- Kraas, F., Hlaing Maw Oo, Zin Nwe Myint, R. Spohner (2015): Yangon's Urban Heritage: Reassessing the Historic Stages of Development. In: Avrami, E. (Ed.): Building the Future: The Role of Heritage in the Sustainable Development of Yangon. World Monuments Fund. New York: 24-31.

- Kraas, F., Mi Mi Kyi, Win Maung (Eds.) (2016a): Sustainability in Myanmar. Southeast Asian Modernities 15. Wien.

- Kraas, F., Mi Mi Kyi, Win Maung (2016b): Pathways to Sustainability. In: Kraas, F., Mi Mi Kyi, Win Maung (Eds.): Sustainability in Myanmar. Southeast Asian Modernities 15. Wien: 11-22.
- Kraas, F., R. Spohner (2015): Ergebnisse der Volkszählung 2014 in Myanmar. Geographische Rundschau 67 (12): 44-50.

- Kraas, F., Yin May, R. Spohner, Zin Nwe Myint (2014): Yangon: Phases of Urban Development and Expansion. Journal of the Myanmar Academy of Arts and Science XII (6): 125-137.

- Kraas, F., Yin May, Zin Nwe Myint (2010): Yangon/Myanmar: Transformation Processes and Mega-Urban Developments. Geographische Rundschau International 6 (2): 26-37.

- Kraas, F., Zin Mar Than (2016): Socio-economic developments in the Indawgyi Lake Area, Kachin State, Myanmar. Journal of the Myanmar Academy of Arts and Science XIV (5): 281-299.

- Kraas, F., Zin Nwe Myint (2015): Potentials for Sustainable Tourism Development in the Taunggyi Area, Myanmar. Journal of the Myanmar Academy of Arts and Science XIII (6): 237-254.

- Kraas, F., Zin Nwe Myint, Khin Khin Soe (2016): Urban Developments in Hakha and Falam, Chin State/Myanmar. Journal of the Myanmar Academy of Arts and Science XIV (5): 301-318.

- Kress, W. J., DeFilipps, E., Farr, R. A., Yin Yin Kyi (2003): A checklist of the Trees, Shrubs, Herbs, and Climbers of Myanmar. Department of Systematic Biology - Botany, National Museum of Natural History, Washington, DC.

- Kripalani, R. H., A. Kulkarni (1998): The relationship between some large scale atmospheric parameters and rainfall over Southeast Asia: a comparison with features over India. Theoretical and Applied Climatology 59: 1-11.

- KTAM Report (Knappen Tippets Abbett McCarthy Engineers) (1953): Economic and Engineering Development of Burma. Vol. 1: Introduction, Economics and Administration, Agriculture and Irrigation, Transportation. Vol. 2: Telecommunications, Power, Industry. Aylesbury/London.

- Kudo, T. (1999): Industrial Policy in Myanmar. Lessons from the Past. In: Kiryu, M. (Ed.): Industrial Development and Reforms in Myanmar. ASEAN and Japanese Perspectives. Bangkok: 209-238. 
- Kudo, T. (2009a): Location Advantages and Disadvantages in Myanmar: The Case of Garment Industry. IDE Discussion Paper 203. Chiba.

- Kudo, T. (2009b): Industrial Policies and the Development of Myanmar's Industrial Sector in the Transition to a Market Economy. In: Fujita, K., F. Mieno, I. Okamato (Eds.): The Economic Transition in Myanmar after 1988. Market Economy versus State Control. Kyoto CSEAS Series on Asian Studies 1. Singapore, Kyoto: 66-102.

- Kudo, T., K. Odaka (2016): Post-colonial Industrialisation in Myanmar. In: Odaka, K. (Ed.): The Myanmar Economy. Its Past, Present and Prospects. Tokyo: 155-193.

- Kumar, K. A., H. Achyuthan (2006): A Record of Palaeo-Tsunami in the Indian Ocean. Marine Geodesy 29: 253-263.

- Kyauktan TPDC (Township Peace and Development Council) (2006): Regional Facts and Figures Kyauktan Township Peace and Development Council, Yangon. (in Myanmar)

- Kyaw Lat (2010): Art and Architecture of Bagan and Historical Background. Yangon.

- Kyaw Min Htun, Nu Nu Lwin, Tin Htoo Naing, Khine Tun (2011): ASEAN-India Connectivity: A Myanmar Perspective. In: Kimura, F., S. Umezaki (Eds.): ASEAN-India Connectivity: The Comprehensive Asia Development Plan, Phase II, ERIA Research Project Report 2010-7. Jakarta: 151-203.

- Kyaw Nyunt Lwin, Khin Ma Ma Thwin (2005): Birds of Myanmar. Bangkok.

- Kyaw Yin Hlaing, Taylor, R.H., Tin Maung Maung Than (Eds.) (2005): Myanmar. Beyond Politics to Societal Imperatives. Singapore.

- Lall, M. (2008): Evolving Education in Myanmar: the interplay of state, business and the community. In: Skidmore, M., T. Wilson (Eds.): Dictatorship, Disorder and Decline in Myanmar. Canberra: 127-149.

- Lall, M. (2016): Understanding Reform in Myanmar. People and Society in the Wake of Military Rule. London.

- Lasi Bawk Naw (2007): Traditions, Beliefs and Practices: Links with Nature Conservation in Kachin State. Yangon.
- Lateef, F. (2009): Cyclone Nargis and Myanmar: A wake up call. Journal of Emergencies, Trauma and Shock 2 (2): 106-113.

- Latham, J.,Cumani, R., Rosati, I., M. Bloise (2014): GLC-SHARE (Global Land Cover SHARE). FAO. Rome

- Le Dain, A.Y., Tapponier, P., P. Molnar (1984): Active faulting and tectonics of Burma and surrounding regions. Journal of Geophysical Research 89 (B1): 453-472.

- Lehner, B., G. Grill (2013): Global river hydrography and network routing: baseline data and new approaches to study the world's large river systems. Hydrological Processes 27 (15): 2171-2186. (data of river network and drainage basins on http://www.hydrosheds.org, download October 2015)

- Lehner, B., Verdin, K., A. Jarvis (2008): New global hydrography derived from spaceborne elevation data. Eos, Transactions, AGU, 89 (10): 93-94. (data of river network and drainage basins on http:// www.hydrosheds.org, download October 2015)

- Leider, J. (2012): 'Rohingya', Rakhaing and the Recent Outbreak of Violence - A Note. Burma Studies 89/90: 8-11.

- Leider, J. (2014): Rohingya: the name, the movement and the quest for identity. In: Myanmar Egress, Myanmar Peace Centre (Eds.): Nation Building in Myanmar. Yangon.

- Leimgruber, P., Kelly, D. S., Steininger, M. K., Brunner, J., Müller, T., M. Songer (2005): Forest Cover Change Patterns in Myanmar (Burma) 19902000. Environmental Conservation 32: 356-364.

- Leimgruber, P., Zaw Min Oo, Myint Aung, Kelly, D.S., Wemmer, C., Senior, B., M. Songer (2011): Current Status of Asian Elephants in Myanmar. Gajah 35: 76-86.

- Leonard, J.B. (1985): City Profile Rangoon. Cities 2 (1): 2-13.

- Li, Y. (2017): Chinese in Colonial Burma. A Migrant Community in A Multiethnic State. Cambridge Imperial and Post-Colonial Studies Series. New York.

- Lian H. Sakhong (2007): Christianity and Chin Identity. In: Gravers, M. (Ed.): Exploring Ethnic 
Diversity in Burma. NIAS studies in Asian

topics 39. Copenhagen: 200-226.

- Lintner, B. (1994): Burma in Revolt. Opium and Insurgency Since 1948. Boulder.

- Liu, F. J., Huang, C., Pang, Y., Li, M., Song, D.-X., Song, X.-P., Channan, S., Sexton, J. O., Jiang, D., Zhang, P., Guo, Y., Li, J. F., J. R. Townshend (2015): Assessment of the three factors affecting Myanmar's forest cover change using Landsat and MODIS vegetation continuous fields data. International Journal of Digital Earth. http:// dx.doi.org/10.1080/17538947.2015.1111451

- Lockwood, A.N. (1958): The Burma Road to Pyidawtha. 32. International Conciliation 518. o.0.

- Lorch, J. (2007): Myanmar's civil society - a patch for the national education system? The emergence of civil society in areas of state weakness. Südostasien aktuell 3/2007: 54-88.

- Lorch, J. (2008): The (re)-emergence of civil society in areas of state weakness: the case of education in Burma/Myanmar. In: Skidmore, M., T. Wilson (Eds.): Dictatorship, Disorder and Decline in Myanmar. Canberra: 151-176.

- Lucas, A., V. Pardieu (2014): Mogok Expedition Series. Part 1: The Valley of Rubies. Part 2: The Expedition, the Mines, and the People. Part 3: The Market and the Stones. http://www. gia.edu/gia-news-research-expedition-to-thevalley-of-rubies-part-1, http://www.gia.edu/ gia-news-research-expedition-to-the-valley-ofrubies-part-2, http://www.gia.edu/gia-newsresearch-expedition-to-the-valley-of-rubies-part-3.

- Lusby, C., K. Eow (2015): Tourism Development in a New Democracy: Residents' Perceptions of Community-based Tourism in Mawlamyine, Myanmar. Journal of Tourism and Recreation 2 (1): 23-40.

- Maung Aung Myoe (2011): In the Name of PaukPhaw. Myanmar's China Policy Since 1948. Singapore.

- Maung Maung Kha (1945): Forecasting the coastal rainfall of Burma, Quarterly Journal of the Royal Meteorological Society 71 (307-308): 115-128.

- Maung Maung Aye (2010): Tropical Cyclone 'Nargis': The worst natural disaster to strike the southern Ayeyarwady River Delta of Myanmar in early May 2008. In (translated from Myanmar): Research Journal of the 500 Year Anniversary of the Establishment of Kaytumadi (Taungoo) Palace and Town. Taungoo: 360-379.

- Maung Thein, Than Myint, Soe Thura Tun, Tint Lwin Swe (2009): Earthquake and Tsunami Hazard in Myanmar. Journal of Earthquake and Tsunami 3 (2): 43-57.

- Maung Thein, Tint Lwin Swe (2006): The Seismic Zone Map of Myanmar (Revised version). Myanmar Earthquake Committee, Myanmar Engineering Society. Yangon.

- May Thu Naing (2014): Geographic Study of Quality of Life in Layshi Township, Naga Land in Myanmar. Journal of the Myanmar Academy of Arts and Science XII (6): 265-291.

- McCormack, G., H. Nelson (Eds.) (1993): The Burma-Thailand Railway. Chiang Mai.

- MCRB (Myanmar Centre for Responsible Business), HSF (Hanns-Seidel-Foundation) (2015a): Community Involvement in Tourism. Nay Pyi Taw. http://www.myanmar-responsiblebusiness. org/news/community-involved-tourism. html (download 04.06.2016)

- MCRB (Myanmar Centre for Responsible Business), HSF (Hanns-Seidel-Foundation) (2015b): Human Rights and Tourism. Nay Pyi Taw. http:// www.myanmar-responsiblebusiness.org/ news/tourism-myanmar-needs-more-localinvolvement.html (download 17.01.2016)

- Mehm Ko Ko Gyi, Saw Win (1997): Sustainable Forest Management. In: Savage, Victor R., Lily L. I. Kong (Eds.): Environmental Stakes. Myanmar and Agenda 21. Singapore: 176-186.

- Messerli, P., Heinimann, A., Epprecht, M., Phonesaly Souksavath, Thiraka Chanthalanouvong, N. Minot (Eds.) (2008): Socio-Economic Atlas of the Lao PDR - an Analysis based on the 2005 Population and Housing Census. Bern and Vientiane.

- Metro, R. (2016): Students and Teachers as Agents of Democratization and National Reconciliation in Burma: Realities and Possibilities. In: Egreteau, R., F. Robinne (Eds.): Metamorphosis. Studies in 
Societal and Political Change in Myanmar. Singapore: 209-233.

- MGMA (Myanmar Garment Manufacturers Association) (2015): MGMA Members: Company, Investment/Company Type, No of workers release July 2015. Unpublished document.

- Mi Mi Kyi (2005): Rural Sustainability in Myanmar. In: Gaese, H., Kraas, F., Mi Mi Kyi (Eds.): Sustainability in Rural and Urban Environments. Proceedings of the First German-Myanmar Workshop in Yangon/Myanmar, 17-21 November 2003. Cologne: 75-97.

- MIMU (Myanmar Information Management Unit) (2015): P-code table release August 2015 (www.themimu.info, download August 2015)

- MIMU (Myanmar Information Management Unit) (2016): Baseline data release June 2016 (www.themimu.info, download July 2016)

- Min Naing (2000): National Ethnic Groups of Myanmar. Yangon.

- Min Thein (2016): Research and Development of Sustainable Myanmar Spirulina Biotechnology. In: Kraas, F., Mi Mi Kyi, Win Maung (Eds.) (2016): Sustainability in Myanmar. Southeast Asian Modernities 15. Wien: 251- 263.

- Mizuno, A. (2016): Economic Relations Between Myanmar and China. In: Odaka, K. (Ed.): The Myanmar Economy. Its Past, Present and Prospects. Tokyo: 195-224.

- MNPED (Ministry of National Planning and Economic Development) (1995): Economic Development of Myanmar. Yangon.

- MNPED (Ministry of National Planning and Economic Development, Central Statistical Organisation) (2015): Myanmar Statistical Yearbook 2015. Nay Pyi Taw.

- MNPED (Ministry of National Planning and Economic Development) (2015a): GDP per sector by township - 2013-2014 and 2014-end of March 2015. Unpublished document.

- MNPED (Ministry of National Planning and Economic Development) (2015b): List of approved doctors and nurses per townships under the Department of Medical Care-05.08.2015. Unpublished document.
- MNPED (Ministry of National Planning and Economic Development) (2015c): No. of midwives per township. Unpublished document.

- MoAl (Ministry of Agriculture and Irrigation Department) (2013): Myanmar Agriculture at a Glance. Nay Pyi Taw.

- MoAl (Ministry of Agriculture and Irrigation) (2015): Paddy Cultivation and Production Data according to the Regions/States, Districts, Townships: 2011-2012/2012-2013/2013-2014. Unpublished document.

- MoC (Ministry of Construction) (2016a): The 367 towns of Myanmar, 2014. Unpublished document.

- MoC (Ministry of Construction) (2016b): List of towns of Myanmar with Urban Population 1973, 1983 and 2014; Classification of towns. Unpublished document.

- MoE (Ministry of Education) (2009): Development of Education in Myanmar. Nay Pyi Taw.

- MoE (Ministry of Education) (2015a): No of Students and Teachers for 169 institutions of higher education in Myanmar 2015. Unpublished document.

- MoE (Ministry of Education) (2015b): List of Universities, Degree Colleges and Colleges under Respective Ministry. Unpublished document.

- MoE (Ministry of Education) (2017): National Education Strategic Plan 2016-21. Nay Pyi Taw.

- Moe Kyaw (2009): Flow Chart Approach to Industrial Cluster Policy in Yangon. In: Kuchiki, A., S. Uchkawa (Eds.): Research on Development Strategies for CLMV Countries, ERIA Research Project Report 2008-5. Jakarta: 113-118.

- Moe Ommar Lwin (2017): Heritage Tourism in Pyay and its Vicinity. PhD Thesis. Department of Geography, University of Yangon.

- MoECaF (Ministry of Environmental Conservation and Forestry) / MoHT (Ministry of Hotels and Tourism) (2015a): Myanmar. Ecotourism Policy and Management Strategy for Protected Areas 2015-2025. Nay Pyi Taw.

- MoECaF (Ministry of Environmental Conservation and Forestry) (2015b): List of protected 
Areas System in Myanmar (20-2-2015).

Unpublished document.

- MoEP (Ministry of Electric Power) (2013): Hydropower Generation Enterprise. (http://www. youbuyfrance.com/medias/press/ hpge_9_7_2013_28_34.pdf, download September 2015)

- MoEP (Ministry of Electric Power) (2015a): Publicprivate partnership development in Thermal Power Generation. Nay Pyi Taw.

- MoEP (Ministry of Electric Power) (2015b): List of salient features of On-Going Projects. Unpublished document.

- MoF (Ministry of Forestry, Survey Department) (2004): Union of Myanmar, Scale 1: 5000000, 2004 Calender. Yangon.

- MoF (Ministry of Forestry) (2005): National Action Programme of Myanmar to combat Desertification in the Context of United Convention to combat Desertification (UNCCD). Yangon. http:// www.unccd.int/ActionProgrammes/ myanmar-eng2005.pdf

- $\mathrm{MoH}$ (Ministry of Health) (2014): Health in Myanmar. Nay Pyi Taw.

- MoH (Ministry of Health) (2015): List of Hospitals, Rural Health Centers and Sub Rural Health Centers. Unpublished document.

- MoHRA (Ministry of Home and Religious Affairs) (1984): The 1983 Population Census Report, Burma: Immigration and Manpower Department. Rangoon.

- MoHS (Ministry of Health and Sports), ICFI (ICF International) (2016): Myanmar Demographic and Health Survey 2015-16: Key Indicators Report. Nay Pyi Taw, Rockville.

- MoHT (Ministry of Hotels and Tourism) (2012): Responsible Tourism Policy. Nay Pyi Taw.

- MoHT (Ministry of Hotels and Tourism) (2013a): Policy on Community Involvement in Tourism (CIT). Nay Pyi Taw.

- MoHT (Ministry of Hotels and Tourism) (2013b): Myanmar Tourism Master Plan 2013-2020. Nay Pyi Taw.
- MolCT (Ministry of Information Communication Technology) (2015): List of tower for Ooredoo, Telenor and MPT per township. Unpublished document.

- Moilanen, I., S.S. Ozhegov (1999): Mirrored in Wood. Burmese Art and Architecture. Bangkok.

- MolP (Ministry of Immigration and Population) (2015a): The 2014 Myanmar Population and Housing Census. Highlights of the Main Results. Census Report Volume 2-A. Nay Pyi Taw.

- MolP (Ministry of Immigration and Population) (2015b): The 2014 Myanmar Population and Housing Census. States and Region Reports. Census Report Volume 3 (A-N). Nay Pyi Taw.

- MolP (Ministry of Immigration and Population) (2015c): The 2014 Myanmar Population and Housing Census. The Union Report. Census Report Volume 2. Nay Pyi Taw.

- MoLF (Ministry of Livestock and Fishery) (2015): Number of fish farm, shrimp farm, crab farm per township. Unpublished document.

- MoPf (Ministry of Planning and Finance) (2016): Myanmar Statistical Yearbook 2016. Nay Pyi Taw.

- MoLIP (Ministry of Labour, Immigration and Population) (2016a): Thematic Report on Population Dynamics. Census Report Volume 4-E. Nay Pyi Taw.

- MoLIP (Ministry of Labour, Immigration and Population) (2016b): Thematic Report on Migration and Urbanization. Census Report Volume 4-D. Nay Pyi Taw.

- MoLIP (Ministry of Labour, Immigration and Population) (2016c): The Union Report: Religion. Census Report Volume 2-C. Nay Pyi Taw.

- Moore, E. (2004): Ancient Knowledge and the Use of Landscape. Walled Settlements in Lower Myanmar. In: Ministry of Education (Ed.): Traditions of Knowledge in Southeast Asia. Part I. Proceedings of the Traditions of Knowledge in Southeast Asia Conference, 17-19 December 2003. Myanmar Historical Commission. Yangon: 1-27.

- Moore, E., San Win (2007): The Gold Coast: Suvannabhumi? Lower Myanmar Walled Sites of the First Millennium A.D. Asian Perspectives 46 (1): 202-232. 
- Moore, E., San Win, Pyiet Phyo Kyaw (2016): Water Management in the Urban Cultural Heritage of Myanmar. TRaNS: Trans-Regional and -National Studies of Southeast Asia 4 (2): 283-305.

- Moore, E., Swe Than (2006): Early walled sites of Dawei: Thagara and Mokti. In: Bacus, L. Glover, I., V. Piggott (Eds.): Uncovering Southeast Asia's Past - Selected papers from the Tenth Biennial Conference of the European Association of Southeast Asian Archaeologists: 271-282.

- Morrison, S. J., RADM T. Cullison, M. Hiebert, T. Summers, L. Hammergren (2013): Rehabilitating Health in the Myanmar Transition. Center for Strategic and International Studies. Washington.

- Moseley, Chr., R. E. Asher (Eds.) (1994): Atlas of the World's Languages. London.

- Mukherjee, A., M. K. Sengupta, M. A. Hossain, S. Ahamed, B. Das, B. Nayak, D. Lodh, M. M. Rahman, D. Chakraborti (2006): Arsenic Contamination in Groundwater: A Global Perspective with Emphasis on the Asian Scenario. Journal of Health Population and Nutrition 24 (2): 142-163.

- Mullen, M. (2016): Pathways that changed Myanmar. London.

- Murty, T. S., M. Rafiq (1991): A tentative list of tsunamis in the Marginal Seas of the North Indian Ocean. Natural Hazards 4: 81-83.

- Mya Than (2005): Myanmar in ASEAN. Regional Cooperation Experience. Singapore.

- Mya Than, A. Rajah (1996): Urban Management in Myanmar: Yangon. In: Rüland, J. (Ed.): The Dynamics of Metropolitan Management in Southeast Asia. Singapore: 225-252.

- Mya Than, J. L. H. Tan (Eds.) (1990): Myanmar Dilemmas and Options. The Challenge of Economic Transition in the 1990s. Singapore.

- Myat Mon (2010): Burmese labour migration into Thailand: governance of migration and labour rights. Journal of the Asia Pacific Economy 15 (1): 33-44.

- Myat Thein (2004): Economic Development of Myanmar. Singapore.

- Myers, N., Mittermeier, R. A., Mittermeier, C. G., Fonseca G. A. B., J. Kent (2000): Biodiversity hotspots for conservation priorities. Nature 403 (6772): 853-858.

- Myint (2010): Myanmar Economy. A Comparative View. Stockholm. http://www.esocialsciences. org/Download/repecDownload. aspx?fname=A201221510128_20.pdf\&fca tegory=Articles \&Ald=4783\&fref $=$ repec

- Myint (2012): Myanmar and the FDI Issue. Unpublished article. Yangon.

- Myint Aung, Khaing Khaing Swe, Thida Oo, Kyaw Kyaw Moe, Leimgruber, P., Allendorf, T., Duncand, C., C. Wemmer (2004): The environmental history of Chatthin Wildlife Sanctuary, a protected area in Myanmar (Burma). Journal of Environmental Management 72: 205-216.

- Myint Aung (2007): Policy and practice in Myanmar's protected area system. Journal of Environmental Management 84: 188-203.

- Myint Thida, Hla Yin Nu (2015): Effects of Paddy Cultivation on Economy of Farmers in Hmawbi Township, Yangon Region. Journal of the Myanmar Academy of Arts and Science XIII (6): 369-385.

- Myo Myo Myint, R. Rasiah, K. Singaravelloo (2015): Globalization of industrialization and its impact on clothing workers in Myanmar. Journal of the Asia Pacific Economy 20 (1): 100-110.

- Naing Oo (1989): Urbanization and Economic Development in Burma. Sojourn 4 (2): 233-260.

- Nam, K.-Y., Cham, M. R., P. Rodelio Halili (2015): Power Sector Development in Myanmar. ADB Economics Working Paper Series No. 460, October 2015. Manila.

- Nang Mya Han (2016): Public Awareness Creation for the Sustainable Development of Tanintharyi Coastal Urban Areas. In: Kraas, F., Mi Mi Kyi, Win Maung (Eds.) (2016): Sustainability in Myanmar. Southeast Asian Modernities 15. Wien: 155-187.

- Nature News (2008): Forest clearance boosted power of cyclone Nargis, Nature, 453: 270.

- Naw Paw Thaw Thaw (2015): Potential Coffee Cultivation Areas in Thandaunggyi Township. Journal of the Myanmar Academy of Arts and Science XIII (6): 285-304. 
- Nesbit, R. C. (2009): The Battle for Burma. Barnsley.

- Nilar Aung (2007): Supply of Vegetables for Yangon City. PhD Thesis, Department of Geography, University of Yangon.

- Nilar Aung (2013): Sustainable Development of Floating Garden Cultivation in Inlay (Inle). Journal of the Myanmar Academy of Arts and Science XI (6): 333-349.

- Nishizawa, N. (1991): Economic Development of Burma in Colonial Times. IPSHU Research Report Series No. 15. Hiroshima.

- Nixon, H., Joelene, C., Kyi Phyar Chit Saw, Tet Aung Lynn, M. Arnold (2013): State and Region Governments in Myanmar. Yangon.

- Nwe Yin Min, Myint Thida, Khin Aye Mu, Thida Lwin (2016): Agriculture in Climate Change Risk Area: Case Study of Myingyan Township. Journal of the Myanmar Academy of Arts and Science XIV (5): 349-363.

- Nyi Nyi (no date): Geology of Burma. Unpublished collection of articles. Yangon.

- Nyi Nyi (2013): Levels, Trends and Patterns of Internal Migration in Myanmar. Ministry of Immigration and Population. The Republic of the Union of Myanmar. Nay Pyi Taw.

- Nyi Nyi Latt, Su Myat Cho, Nang Mie Mie Htun, Yu Mon Saw, Myat Noe Htin Aung Myint, F. Aoki,

J.A. Reyer, E. Yamamoto, Y. Yoshida, N. Hamajima (2016): Healthcare in Myanmar. Nagoya Journal of Medical Science 78: 123-134.

- Nyo Me Htwe, G. R. Singleton, Aye Myint Thwe, Yee Yee Lwin (2010): Rodent population outbreaks associated with bamboo flowering in Chin State, Myanmar. In: Singleton, G. R. Belmain S. R., Brown, P. R., B. Hardy (Eds.): Rodent outbreaks: ecology and impacts. Los Banos: 79-98.

- Nyo Nyo Aung (2008): Community Structure of Waterbirds in Indawgyi Wetland Bird Sanctuary of Kachin State. PhD Thesis. Department of Zoology, University of Yangon.

- O'Connor, S. (1907): Mandalay and other Cities of the Past in Burma. Reprint 1996. Bangkok.
- Odaka, K. (Ed.) (2016): The Myanmar Economy. Its Past, Present and Prospects. Tokyo.

- OECD (Organisation for Economic Co-operation and Development) (2014a): OECD Investment Policy Reviews: Myanmar 2014. http:// dx.doi.org/10.1787/9789264206441-en

- OECD (Organisation for Economic Co-operation and Development) (2014b): Multi-dimensional Review of Myanmar. Volume 2: In-depth Analysis and Recommendations. OECD Development Pathways. http://dx.doi.org/10.1787/ 9789264220577-en

- Ohnmar Htway, J. Matsumoto (2011): Climatological onset dates of summer monsoon over Myanmar. International Journal of Climatology 31 : 382-393.

- Okamoto, I. (2008): Economic Disparity in Rural Myanmar. Transformation under Market Liberalization. Singapore.

- Pearn, B. R. (1939): A History of Rangoon. Rangoon.

- Pearson, R., K. Kusakabe (2012): Burmese migrant women factory workers: Thailand's hidden workforce. London.

- Perry, P. J. (2007): Myanmar (Burma) since 1962: the Failure of Development. Farnham.

- Pyi Phyo Kyaw (2015): Foundations of criticality: applications of traditional monastic pedagogy in Myanmar. Contemporary Buddhism 16 (2): 401-427.

- Pyi Soe Aung, Adam, Y. O., Pretzsch, J., R. Peters (2014): Distribution of forest income among rural households: a case study from Natma Taung national park, Myanmar. Forests, Trees and Livelihoods. Published online: DOI: 10.1080/14728028.2014.976597

- Rao, M., Saw Htun, Platt, S. G., Tizard, R., Poole, C., Than Myint, J. E. M. Watson (2013): Biodiversity conservation in a changing climate: A review of threats and implications for conservation planning in Myanmar. AMBIO 42: 789-804.

- Richell, J. L. (2006): Disease and Demography in Colonial Burma. Copenhagen. 
- Rieffel, L., J. W. Fox (2013): Too Much, Too Soon? The Dilemma of Foreign Aid to Myanmar/ Burma. Nathan Associates. Arlington.

- Rivet, M. (2000): Stadtentwicklung von Yangon. Bedeutung der Persistenz kolonialer Strukturen für die aktuelle Entwicklung der Hauptstadt Myanmars/Birmas. Dissertation Universität Bonn. http://hss.ulb.uni-bonn.de:90/ulb_bonn/ diss_online/ math_nat_fak/2000/rivet_manuela.

- Roberts, J. (2016): Mapping Chinese Rangoon. Place and Nation among the Sino-Burmese. Seattle.

- Rogers, B. (2012): Burma. A Nation at the Crossroads. London.

- Roy, S. N., S. Kaur (2000): Climatology of monsoon rains of Myanmar (Burma). International Journal of Climatology 20: 913-928.

- Sai S. W. Latt (2013): Managing migration in the Greater Mekong Subregion: Regulation, extralegal relation and extortion. Singapore Journal of Tropical Geography 34: 40-56.

- Saito, T., L. K. Kiong (1999): Statistics on the Burmese Economy. The 19th and 20th Centuries. ISEAS Data Paper Series. Sources for the Economic History of Southeast Asia 7. Singapore.

- San San Hmwe, Moe Sanda Oo, Mie Mie Than (2016): Ecological Aspects of Sambhur Cervus unicolar and Hog Deer Axis porcinus in the Hlawga Wildlife Park: Implications for Conservation and Management. In: Kraas, F., Mi Mi Kyi, Win Maung (Eds.) (2016): Sustainability in Myanmar. Southeast Asian Modernities 15. Wien: 33-49.

- San Thein (2012): Industrial Readjustment in Myanmar: Agro-industrial Preparedness for Integration with the AEC. In: Ueki, Y., Teerana Bhongmakapat (Eds.): Industrial Readjustment in the Mekong River Basin Countries: Towards the AEC, BRC Research Report No. 7, Bangkok Research Center, IDE-JETRO, Bangkok.

- Satake, K., Than Tin Aung, Y. Sawai, Y. Okamura, Kyaw Soe Win, Winn Swe, Chit Swe, Tint Lwin Swe, Soe Thura Tun, Maung Maung Soe, Thant Zin Oo, Saw Htwe Zaw (2006): Tsunami heights and damage along the Myanmar coast from the December 2004 Sumatra-Andaman earthquake. Earth Planet and Space 58 (2): 243-252.
- Saw Yu May (2015): An Assessment of Climate Change and its Impacts on Agriculture of Taunggyi Township. Journal of the Myanmar Academy of Arts and Science XIII (6): 305-327.

- Schissler, M., Walton, M. J., Phyu Phyu Thi (2017): Reconciling Contradictions: Buddhist-Muslim Violence, Narrative Making and Memory in Myanmar. Journal of Contemporary Asia 47 (3), Special Issue SI: 376-395.

- Schmidt, C. (2012): As isolation ends, Myanmar faces new ecological risks. Science 337: 796-797.

- SCW (Save Cambodia's Wildlife) (2006): Atlas of Cambodia: National Poverty and Environment Maps. Phnom Penh.

- Seekins, D. M. (2005): The State and the City: 1988 and the Transformation of Rangoon. Pacific Affairs 78 (2): 257-275.

- Seng Aung (2016): Urban Environmental Issues: Urban Growth and its Impact on Natural Ecosystems in Hukawng Valley, Kachin State, Northern Myanmar. In: Kraas, F., Mi Mi Kyi, Win Maung (Eds.) (2016): Sustainability in Myanmar. Southeast Asian Modernities 15. Wien: 361-370.

- Settlement and Land Records Department (2013): Annual Report. Nay Pyi Taw.

- Simpson, A. (2013): Challenging hydropower development in Myanmar (Burma): cross-border activism under a regime in transition. The Pacific Review 26 (2): 129-152.

- Singer, N.F. (1995): Old Rangoon. City of the Shwedagon. Gartmore.

- Skidmore, M. (Ed.): (2005): Burma at the Turn of the 21 st Century. Honolulu.

- Smith, M. (1993): Burma. Insurgency and the Politics of Ethnicity. London².

- Smith, M., A. Allsebrook (1994): Ethnic Groups in Burma. Development, Democracy and Human Rights. London.

- Soe Min (2008): Land use and land capability of Taunggyi and Ayethayar: mainly emphasized on Geology and Geotechnical points of view. Journal of the Myanmar Academy of Arts and Science VI (5): 31-58. 
- Soe Min (2009): Analysis on recharge area of ground water resources for Taunggyi City. Journal of the Myanmar Academy of Arts and Science VII (6): 21-31.

- Soe Win, Marlar Myo Myint (1998): Mineral Potential of Myanmar. Resource Geology 48 (3): 209-218.

- South, A. (2008): Ethnic Politics in Burma. States of conflict. London.

- Spate, O. H. K. (1941): Beginnings of Industrialization in Burma. Economic Geography 17 (1): 75-92.

- Spoorenberg, T. (2013): Demographic Changes in Myanmar since 1983: An Examination of Official Data. Population and Development Review 39 (2): 309-324.

- Spoorenberg, T. (2014): Provisional results of the 2014 census of Myanmar: The surprise that wasn't. Asian Population Studies, DOI: 10.1080/17441730.2014.972084.

- Stamp, L. D. (1924): The Vegetation of Burma from an Ecological Standpoint. Rangoon.

- Steinberg, D. I. (2001): Burma: The State of Myanmar. Washington, D.C.

- Steinberg, D. I. (2006): Turmoil in Burma; Contested Legitimacies in Myanmar. New York.

- Steinberg, D. I. (2013): Burma/Myanmar: What Everyone Needs to Know. New York.

- Steins, N. A., Bosma, R., Taal, K., Bolman, B., Bink, E., van den Dop, H., Dekker, A., Vrolijk, C., Numan, J., Spek, G, W. van den Pijl (2015): Capacity building for sustainable aquaculture and fisheries development in Myanmar. Den Haag.

- Storz, H.-U. (1967): Birma. Land, Geschichte, Wirtschaft. Schriften des Instituts für Asienkunde Hamburg 21. Wiesbaden.

- Su Su, Win Kyaing (2016): 2,000 Years of Urban Continuity in Sri Ksetra-Pyay. In: Kraas, F., Mi Mi Kyi, Win Maung (Eds.) (2016): Sustainability in Myanmar. Southeast Asian Modernities 15. Wien: 307-318.

- Sun, Y. (2012): China's Strategic Misjudgement on Myanmar. Journal of Current Southeast Asian Affairs 31 (1): 73-96.
- Taylor, R. H., M. Pederson (2005): An independent report for the European Commission. Unpublished document.

- Taylor, R. H. (2007): British Policy towards Myanmar and the Creation of the 'Burma Problem'. In: Ganesan, N., Kyaw Yi Hlaing (Eds.): Myanmar. State, Society and Ethnicity. Singapore: 70-95.

- Taylor, R. H. (2009): The State in Myanmar. London.

- Taft, L., M. Evers (2016): A review of current and possible future human-water interactions in Myanmar's river basins. Hydrology and Earth System Sciences Discussions, DOI: 10.5194/ hess-2015-516. http://www.hydrol-earth-syst-scidiscuss.net/hess-2015-516/hess-2015-516.pdf

- TCG (Tripartite Core Group: Government of the Union of Myanmar, Association of Southeast Asian Nations, United Nations) (2008a): Post Nargis Joint Assessment (PONJA). o.O.

- TCG (Tripartite Core Group: Government of the Union of Myanmar, Association of Southeast Asian Nations, United Nations) (2008b): Post-Nargis Periodic Review I. o.O.

- Than Than Htay (2012): Geography of Myanmar. Yangon University of Distance Education, Department of Higher Education. Yangon.

- Than Than Nwe (1998): Yangon: The Emergence of a New Spatial Order in Myanmar's Capital City. Sojourn 13 (1): 86-113.

- Than Than Thwe (2004): Regionalised Population Forecast for the Union of Myanmar. PhD Thesis, University of Stuttgart.

- Than Tun (2010): A Modern History of Myanma (1752-1948). Yangon.

- Than Tun Sein, Pyone Myint, Nilar Tin, Htay Win, San San Aye, Than Sein (2014): The Republic of the Union of Myanmar Health System Review. Health Systems in Transition 4 (3). Geneva.

- Thanong Leelawatanasuk, Wilawan Atichat, Tay Thye Sun, Boontawee Sriprasert, Jirapit Jakkawanvibul (2014): Some Characteristics of Taaffeite from Myanmar. The Journal of Gemmology 34 (2): 144-148. 
- Thant Myint-U (2001): The Making of Modern Burma. Cambridge.

- Thant Myint-U (2011): Where China Meets India. Burma and the New Crossroads of Asia. London.

- Thaw Tar Min, Fife, E., E. Bohlin (2014): Consumer demand for the mobile Internet in a greenfield emerging market: The case of Myanmar. 20th ITS Biennial Conference, Rio de Janeiro, Brazil, 30.11.-03.12.2014: The Net and the Internet - Emerging Markets and Policies. (accessed: 22.12.2016: http://hdl.handle.net/10419/106868)

- Thein Lwin (2007): Education and Democracy in Burma: Decentralization and Classroom-Level Educational Reform. International Forum for Democratic Studies, July 10, 2007, Washington DC. http://www.thinkingclassroom.org/ uploads/4/3/9/0/43900311/8._education_ and_democracy_in_burma,_2007. pdf (accessed: 21.4.2017)

- Thein Lwin (2011): Languages, Identities, and Education - in Relation to Burma/Myanmar. Shan Herald Agency for News 15. http://www. thinkingclassroom.org/uploads/4/3/9/0/ 43900311/2._dr._thein_lwin_language_ article_english_15thoct11.pdf (accessed: 21.4.2017)

- Thomson, C. N. (1995): Political Stability and Minority Groups in Burma. The Geographical Review 85 (3): 269-285.

- Tin Cung (2011): Impact of British Colonial Administration on Chin Hills (1896-1948). PhD Thesis, Department of History, University of Yangon.

- Tin Maung Maung Than (2007): State Dominance in Myanmar: The Political Economy of Industrialization. Singapore.

- Tin Soe (2004): Myanmar in Economic Transition: Constraints and Related Issues Affecting the Agriculture Sector. Asian Journal of Agriculture and Development 1: 57-68.

- Tordoff, A. W., Baltzer, M. C., Fellowes, J. R., Pilgrim, J. D., P. F. Langhammer (2012): Key Biodiversity Areas in the Indo-Burma Hotspot: Process, Progress and Future Directions. Journal of Threatened Taxa 4 (8): 2779-2787.
- Tun Aye (1999): Industry in Yangon. In: Kiryu, M. (Ed.): Industrial Development and Reforms in Myanmar. ASEAN and Japanese Perspectives. Bangkok: 157-172.

- Tun Lwin (2002): The Climate Changes over Myanmar during the Last Five Decades. Water Resources Journal (United Nations, Economic and Social Commission for Asia and the Pacific, ESCAP Ser. C) 212: 95-106.

- Tun Yin (1993): Wild Mammals of Myanmar. Yangon.

- UN (United Nations) (1996): Geology and Mineral Resources of Myanmar, Atlas of the Mineral Regions of the ESCAP Region. United Nations Economic and Social Commission for Asia and the Pacific, Vol. 12. New York.

- UNDP (2013) Accelerating Energy Access for All in Myanmar. United Nations Development Programme, Myanmar. (http://www.ch.undp.org/ content/dam/myanmar/docs/Accelerating $\% 20$ energy \%20access\%20for\%20all\%20in\%20 Myanmar.pdf, download September 2015)

- UNFPA (United Nations Population Fund) (2013): http://countryoffice.unfpa.org/myanmar/2013/07/ 12/7329/funding/ (accessed: 12.07.2013)

- UNFPA (United Nations Population Fund) (2015): Press Conference REleaseDAta. http:// countryoffice.unfpa.org/myanmar/2015/05/29/ 12209/census_results_highlight_myanmar_rsquo_ s_development_needs/

- UNISDR (United Nations International Strategy for Disaster Reduction) (2009): 2009 UNISDR Terminology on Disaster Risk Reduction. Geneva. http://www.unisdr.org/files/7817_ UNISDRTerminologyEnglish.pdf

- USDA (United States Department of Agriculture) (2015): Foreign Agricultural Service. Southeast Asia: 2015\&16 Rice Production. https://www. pecad.fas.usda.gov/highlights/2015/06/ Southeast_Asia/Index.htm (accessed: 30.4.2017)

- Vigny, C., Socquet, A., Rangin, C., Chamot-Rooke, N., Pubellier, M., Bouin, M.-N., Bertrand, G., M. Becker (2003): Present-day crystal deformation around Sagaing Fault, Myanmar. Journal of Geophysical Research 108, ETG 6-1-10. 
- Vu, T. L., C. Taillard (1993): An Atlas of Vietnam. Dynamiques du territoire series 13 . Paris.

- Walinsky, L. J. (1962): Economic Development in Burma: 1951-1960. New York.

- Walaiporn Tantikanangkul, A. Pritchard (Eds.) (2016): Politics of Autonomy and Sustainability in Myanmar. Change for New Hope ... New Life? Communication, Culture and Change in Asia 1. Singapore.

- Webb, E. L., Phelps, J., Friess, D. A., Rao, M., A. D. Ziegler (2012): Environment-friendly reform in Myanmar. Science 336 (6079): 295-295.

- Webb, E. L., Jachowski, N. R. A., Phelps, J., Friess, D. A., Thand, M. M., A. D. Ziegler (2014): Deforestation in the Ayeyarwady Delta and the conservation implications of an internationally engaged Myanmar. Global Environmental Change 24: 321-333.

- Weigelt, U. (2005): Birmas Lackkunst in deutschen Museen. Münster.

- Wilhelmy, H. (1986): 'Schwimmende Gärten'. Eine Intensivform tropischer Landwirtschaft. In: Hofmeister, B., F. Voss (Hg.): Beiträge zur Geographie der Kulturerdteile. Festschrift zum 80. Geburtstag von Albert Kolb. Berliner Geographische Studien 20. Berlin: 59-96.

- Woodthorpe, R.G. (1873): The Lushai Expedition. 1871-1872. London.

- World Bank (2014): Myanmar. Ending poverty and boosting shared prosperity in a time of transition. A systematic country diagnostic. Yangon.

- Wyss, M. (2008): Estimated Human Losses in Future Earthquakes in Central Myanmar. Seismological Research Letters 79 (4): 520-525.

- Yee Yee Than, Thida Shwe (2016): Geographical Study of Cheroot Industry in Bago. Journal of the Myanmar Academy of Arts and Science XIV (5): 243-263.

- Yegar, M. (1972): The Muslims of Burma. A Study of a Minority Group. Schriftenreihe des SüdasienInstituts der Universität Heidelberg. Wiesbaden.

- Yhome, K. (2015a): The Burma Roads: India's Search for Connectivity through Myanmar. Asian Survey 55 (6): 1217-1240.
- Yhome, K. (2015b): From 'Look East' to 'Act East': What it means for India's Northeast? Eastern Quarterly 11 (I/II): 18-29.

- Yi Yi Cho (2016): Current Situations of Paddy Cultivation in Dawei Township. Journal of the Myanmar Academy of Arts and Science XIV (5): 317-330.

- Yin May (1962): Greater Rangoon: A Study in Urban Geography. Unpublished Master Thesis, Department of Geography, University of Rangoon.

- Yin May (1999): Urbanization in Myanmar. Unpublished working paper. Department of Geography, University of Yangon.

- Yin May (2006): Strategies for Improved Quality of Life in Yangon City. In: Kraas, F., H. Gaese, Mi Mi Kyi (Eds.): Megacity Yangon: Transformation processes and modern developments. Southeast Asian Modernities 7. Berlin: 141-153.

- Yule, H. (1858): A Narrative of the Mission Sent by the Governor-General of India to the Court of Ava in 1855. Reprinted: Kuala Lumpur 1968.

- Zaw Latt Tun, Zin Nwe Myint (2007): A Preliminary Study on Intra-Urban Public Transport of Sittway: A case of motorcycle taxies. Journal of Myanmar Academy of Arts and Sciences V (6): 265-276.

- Zhao, H., M. Yang (2012): China-Myanmar Economic Corridor and its Implications. East Asian Policy 4: 21-32.

- Zin Mar Than (2017): Socio-Economic Development of Indawgyi Lake, Myanmar. Urban and Regional Development in Myanmar 1. Stuttgart.

- Zin Mar Than, F. Kraas (2016): Sustainable Development of the Indawgyi Lake Area, Kachin State/Myanmar. In: Kraas, F., Mi Mi Kyi, Win Maung (Eds.) (2016): Sustainability in Myanmar. Southeast Asian Modernities 15. Wien: 347-360.

- Zin Nwe Myint (1998): Geographical Study of the Urban Growth of Yangon City. Unpublished Master Thesis, Department of Geography, University of Yangon.

- Zin Nwe Myint (2004): Towards Sustainable Urban Development of Yangon City: Woodfuel Utilization. PhD Thesis, Department of Geography, University of Yangon. 
- Zin Nwe Myint (2006a): Woodfuel Uses: A Distinct Phenomenon in Megacity Yangon, Myanmar. In: Kraas, F., Gaese, H., Mi Mi Kyi (Eds.): Megacity Yangon: Transformation processes and modern developments, Southeast Asian Modernities 7. Berlin: 261-284.

- Zin Nwe Myint (2006b): Environmental Problems of Yangon City: Establishment of Industrial Zones. In: Kraas, F., Gaese, H., Mi Mi Kyi (Eds.): Megacity Yangon: Transformation processes and modern developments, Southeast Asian Modernities 7. Berlin: 217-236.

- Zin Nwe Myint (2009): Preliminary Investigation on Tourist Industry of Mrauk-U, Rakhine State. Journal of Myanmar Academy of Arts and Science VII (6): 127-144.

- Zin Nwe Myint (2011) Host Perceptions on Tourism Development of Mrauk-U, Rakhine State. Journal of the Myanmar Academy of Arts and Science IX (6): 175-194.

- Zin Nwe Myint (2014): Heritage, Culture and Tourism Development of Mrauk-U: Perception of Local Community. In: Cultural Traditions, 2014 SEAMEO Regional Centre for History and Tradition, Yangon: 1-20.

- Zin Nwe Myint (2016): Drivers of Cultural Tourism in Mrauk-U, Myanmar. In: Kraas, F., Mi Mi Kyi, Win Maung (Eds.) (2016): Sustainability in Myanmar. Southeast Asian Modernities 15. Wien: 319-345.

- Zin Nwe Myint, Khin Myo Hla (2009): Preliminary Investigation on Tourist Industry of Mrauk-U, Rakhine State. Journal of Myanmar Academy of Arts and Sciences VII (6): 127-144.

- Zin Nwe Myint, Saw Yu May, Zin May Oo, F. Kraas (2016): Economic Development Potential of Mrauk-U, Rakhine State. Journal of the Myanmar Academy of Arts and Science XIV (5): 331-347.

\section{GEO DATA}

- CGIAR-CSI (Consultative Group on International Agricultural Research - Consortium for Spatial Information): SRTM 90m Digital Elevation Database v4.1 (http://srtm.csi.cgiar.org, download June 2014)
- DOC/NOAA/NESDIS/NCEI (National Centers for Environmental Information, National Environmental Satellite, Data and Information Service, National Oceanic and Atmospheric Administration, U.S. Department of Commerce): ETOPO1 1 Arc-Minute Global Relief Model. (http://www.ngdc.noaa.gov/mgg/global/ global.html, accessed: August 2016)

- FAO AQUASTAT Geo-referenced database on dams in Southern and Eastern Asia (http:// www.fao.org/nr/water/aquastat/dams/ index.stm, accessed: September 2015)

- GLC-SHARE (Global Land Cover SHARE) v1.0. FAO: Global Land Cover Share Database (2013). (http://www.fao.org/geonetwork/srv/en/ metadata . show ?uuid=ba4526fd-cdbf-4028a1bd-5a559c4bff38\&currTab=distribution, download June 2015)

- GlobCover 2009 v2.3: Global Land Cover Map (period January-December 2009). (http://due. esrin.esa.int/page_globcover.php, download zipfile and description/validation report May 2016)

- Google Earth Pro

- HydroSHEDS: River Network (RIV) and Drainage Basins (BAS). (http://hydrosheds.cr.usgs.gov/ dataavail.php, download October 2015)

- MIMU (Myanmar Information Management Unit) (2014): GIS resources/GIS datasets - administrative boundary datasets release April 2014 (www. themimu.info, download September 2014)

- MIMU (Myanmar Information Management Unit) (2012): GIS resources/GIS datasets town location release February 2012 (www. themimu.info, download September 2014)

- MODIS Land Cover: MODIS data product MCD12Q1, Version 5.1, in the IGBP classification of land cover types 2001-2012. (ftp:// ftp.glcf.umd.edu/glcf/Global_LNDCVR/ UMD_TILES/, download March 2015)

- MODIS VCF 2010: MODIS Vegetation Continuous Fields 2010. (http://www.landcover.org/ data/vcf/, download March 2015), citation: DiMiceli, C. M., M. L. Carroll, R. A. Sohlberg, C. Huang, M. C. Hansen, and J. R. G. Townshend (2011): Annual Global Automated MODIS Vegetation Continuous Fields (MOD44B) 
at $250 \mathrm{~m}$ Spatial Resolution for Data Years Beginning Day 65, 2000 - 2010, Collection 5 Percent Tree Cover, University of Maryland.

- NASA LP DAAC 2014: MODIS Land Cover (MCD12 Q1 V051), NASA EOSDIS Land Processes DAAC, USGS Earth Resources Observation and Science (EROS) Center, Sioux Falls, South Dakota (https://lpdaac.usgs.gov), accessed: May, 2016

- NASA WorldView: MODIS 2014-02-01 True Color (https://worldview.earthdata.nasa.gov, download July 2015)

- Natural Earth (2015): Large scale dataset 1:10 million (www.naturalearthdata.com, download April 2015)

- Oak Ridge National Laboratory 2014: LandScan Global Population Dataset 2013, sample Myanmar, Oak Ridge, Tennessee

- OpenStreetMap Myanmar, download via extract.bbbike.org May 2016

- USGS (U.S. Geological Survey): Landsat Archive - Landsat 8 OLI (https://earthexplorer.usgs.gov, access from January 2014 until May 2016)

- USGS-NEIC (U.S. Geological Survey-National Earthquake Information Center) 2016: ANSS Comprehensive Earthquake Catalog (ComCat). (http://earthquake.usgs.gov/data/comcat/، download September 2016)

- WorldClim 2015: Global weather stations. (https://databasin.org/datasets/15a31dec689b 4c958ee491ff30fcce75, download July 2015)

\section{MAPS}

- MoAl (Ministry of Agriculture and Irrigation, Survey Department) (2004-2008): Topographic Maps 1:250.000 und 1:50.000

- DLCA (Digital Logistic Capacity Assessment) (2016): Myanmar. (http://dlca.logcluster.org/display/ public/DLCA/Myanmar, assessed June 2016)

- JICA (Japanese International Cooperation Agency) (2014a): Myanmar's National Transport Master Plan. (https://www.jica.go.jp/information/ seminar/2014/ku57pq00001nep1r-att/ kf20140813_01_01.pdf, accessed: September 2016)
- JICA (Japanese International Cooperation Agency) (2014b): Project for Comprehensive Urban Transport Plan of the Greater Yangon (YUTRA). (https://www.jica.go.jp/english/news/field/2014/ c8h0vm00008wqgw0-att/YUTRA.pdf, accessed: September 2016)

- MIA (Myanmar Industries Association) (2015): Map of Yangon Industrial Zones (Yangon Industrial Zone Index). (http://myanmarindustries. org/index.php/zones/industrial-zones/yangonindustrial-zones, accessed: May 2015)

- MoC (Ministry of Construction) (2015a): List of infrastructure project and future/envisaged development project (name of bridge, length and cost per region) (June 2015). Unpublished document.

- MoC (Ministry of Construction) (2015b): Map of future urban and regional development planning in the context of National Urban System Plan. Unpublished document.

- MoC (Ministry of Construction) (2015c): Map of roads managed by regional government \& ministry of construction per each regions. Unpublished document.

- MoC (Ministry of Construction) (2015d): Selected maps of Myanmar Transportation Master Plan. Unpublished document.

- MoECaF (Ministry of Environmental Conservation and Forestry) (2015): Map of bird sanctuary, elephant range, mountain park, national park, nature reserve, protected area, wildlife park. In: MoECaF (Ministry of Environmental Conservation and Forestry)/MoHT (Ministry of Hotels and Tourism) (2015): Myanmar. Ecotourism Policy and Management Strategy for Protected Areas 2015-2025. Nay Pyi Taw.

- MoEP (Ministry of Electric Power) (2015a): Hydropower Resources in Myanmar. Existing Hydropower Station and On-going Hydropower Projects. Unpublished map.

- MoEP (Ministry of Electric Power) (2015c): Maps and information of electrification projects per each regions. Unpublished maps.

- MolCT (Ministry of Information Communication Technology) (2015): Map of telecommunication 
infrastructure (number of tower per region) Unpublished map.

- MoRT (Ministry of Rail Transportation) (2015a): Map of rail network per state/division. Unpublished map.

- MoRT (Ministry of Rail Transportation) (2015b): List and maps of infrastructure projects and future/ envisaged development projects implemented by foreign loan/grant. Unpublished document.

- Myanmar Mining Risk Map (2015), http:// tractus-asia.com/wp-content/uploads/2015/04/ Website-Blogs-Project-Mining-Risk-2015-04-23. jpg, accessed: October 2015)

- Myanmar: Oil and Gas Blocks Map. Parami Energy, published in Wynne, A. (2015): Still sunny, but clouds are brewing. Drilling Contractor: Features, Global and Regional Markets, January/February, The Offshore Frontier, Jan. 28, 2015. (http:// www.drillingcontractor.org/still-sunny-but-cloudsare-brewing-2-32673, accessed: 17.10.2015)

- Seismic zone map of Myanmar. In: DMH (Department of Meteorology and Hydrology) et al. (2009): Hazard Profile of Myanmar. Bangkok.

- Tectonic map of Myanmar and surrounding area (www.sagaingfault.info)

- Tractus (2015a): Myanmar Mining Risk Map. (http://tractus-asia.com/myanmar-miningrisk-map/, accessed: October 2015)

- Tractus (2015b): Yangon industrial zone and infrastructure map. Yangon, Myanmar infrastructure and industrial activity. (http://tractusasia.com/wp-content/uploads/2015/05/ Regional-IZ-Project-Rangoon-Amcham-A4-01. png, download May 2015).

- UN-UNECE (United Nations-United Nations Economic Commission of Europe) (2016): Code for Trade and Transport Locations (UN/LOCODE) (MM) Myanmar. (https:// www.unece.org/fileadmin/DAM/cefact/ locode/mm, accessed: June 2016)

- YCDC (Yangon City Development Committee) (2009): The Map of Yangon, Myanmar. Street Directory. Yangon.
- YCDC (Yangon City Development Committee) (2015): Yangon City Zone Map. Unpublished document.

\section{INTERNET SOURCES}

- Amante, C., Eakins, B.W. (2009): ETOPO1 1 ArcMinute Global Relief Model: Procedures, Data Sources and Analysis. NOAA Technical Memorandum NESDIS NGDC-24. National Geophysical Data Center, NOAA. DOI: 10.7289/V5C8276M, accessed: August 2016.

- Arakan Rivers (2015): Status of Hydropower Plants (www.arakanrivers.net, accessed: September 2015)

- Burma Rivers Network (2015): Status reports of several power plant projects. (www. burmariversnetwork.org, accessed: MaySeptember 2015)

- Dapice, D. (2016): To Build or Not to Build? Designing Sustainable Hydro for Federalism in Myanmar. Harvard Kennedy School Ash Center. Prepared for Proximity Design, Myanmar. (http:// ash.harvard.edu/files/ash/files/20160219_ to_build_or_not_to_build_designing_ sustainable_hydro_projects_in_myanmar_eng. pdf?m=1456347698, download September 2016)

- Holsen, B. N. (2014): The urgent power need in Myanmar. NABS Bangkok, Yangon April 2014 (http://norway-asia.com/wp-content/uploads/ 2014/05/140428-11-Holsen.pdf, download September 2015)

- International Rivers (2015): Southeast Asia Salween Dams. (https://www.internationalrivers.org/ campaigns/salween-dams, accessed: June 2015)

- IUCN: Protected Areas Categories. (https:// www.iucn.org/theme/protected-areas/about/ protected-areas-categories, accessed: July 2015)

- Jarvis, A., H. I. Reuter, A. Nelson, E. Guevara (2008): Hole-filled SRTM for the globe Version 4. available from the CGIAR-CSI SRTM $90 \mathrm{~m}$ Database (http://srtm.csi.cgiar.org).

- MoHT (Ministry of Hotels and Tourism): Tourism Statistics. http://www.myanmartourism.org/ images/tourism-statistics (download 04.06.2016) 
- NRGI (National Resource Governance Institute) (2015): Could natural Resource Revenue Sharing help secure peace in Myanmar? (http://www. resourcegovernance.org/blog/could-naturalresource-revenue-sharing-help-secure-peacemyanmar, accessed: December 2015)

- Salween Watch (2013): Current Status of Dam Projects on Burma's Salween River. (https://www. internationalrivers.org/sites/default/files/attachedfiles/english-salween.pdf, download May 2015)

- Simmance, A. (2013): Environmental Flows for the Ayeyarwady (Irrawaddy) River Basin, Myanmar. Unpublished document. UNESCO-IHE Online Course on Environmental Flows.

- Snider, E. (2012): Electrical Industry of Burma/ Myanmar On-Line Compendium. 4th edition, April 2012. (http://www.burmalibrary.org/docs2/ELECBurma-4th-edition.pdf, (download September 2015)

- Sourcewatch (2015): Proposed coal plants in Myanmar. (http://www.sourcewatch.org/ index.php/Category:Proposed_coal_plants_ in_Myanmar, accessed: September 2015)

- The World Bank Group: Climate Change Knowledge Portal. (http://sdwebx.worldbank.org/ climateportal/index.cfm?page=country_ historical_climate\&ThisRegion=Asia \&Thi sCCode=MMR, accessed: May 2015)

- Than Tun (2015): Exploration \& Development Updates and Opportunities. (Presentation on www.slideplayer.com/slide/10310851, accessed: September 2016)

- The Nature Conservancy, WWF, University of Manchester (2016): Improving hydropower outcomes through system-scale planning: an example from Myanmar. Prepared for the United Kingdom's Department for International Development. Arlington, Virginia, USA. (https:// thought-leadership-production.s3.amazonaws. com/2016/05/09/13/53/29/e26cf10b-9a56-463d97fc-0309b1fde0d6/System-Scale\%20Planning_ Myanmar_Report.pdf, download October 2016)

- Watkinson, I., Soe Thura Tun, K. Atakan: The Sagaing Fault, Myanmar (Burma). (www. sagaingfault.info, accessed: June 2016)
- www.protectedplanet.net/country/MM: Myanmar dataset of protected areas (download July 2015)

- World Heritage Center (WHC): World Heritage List. (whc.unesco.org/en/list, accessed: June 2016).

\section{NEWSPAPER ONLINE ARCHIVES}

- The New Light of Myanmar

- Eleven Myanmar

- Myanmar Times

- Mizzima

- Democratic Voice of Myanmar

- The Irrawaddy 


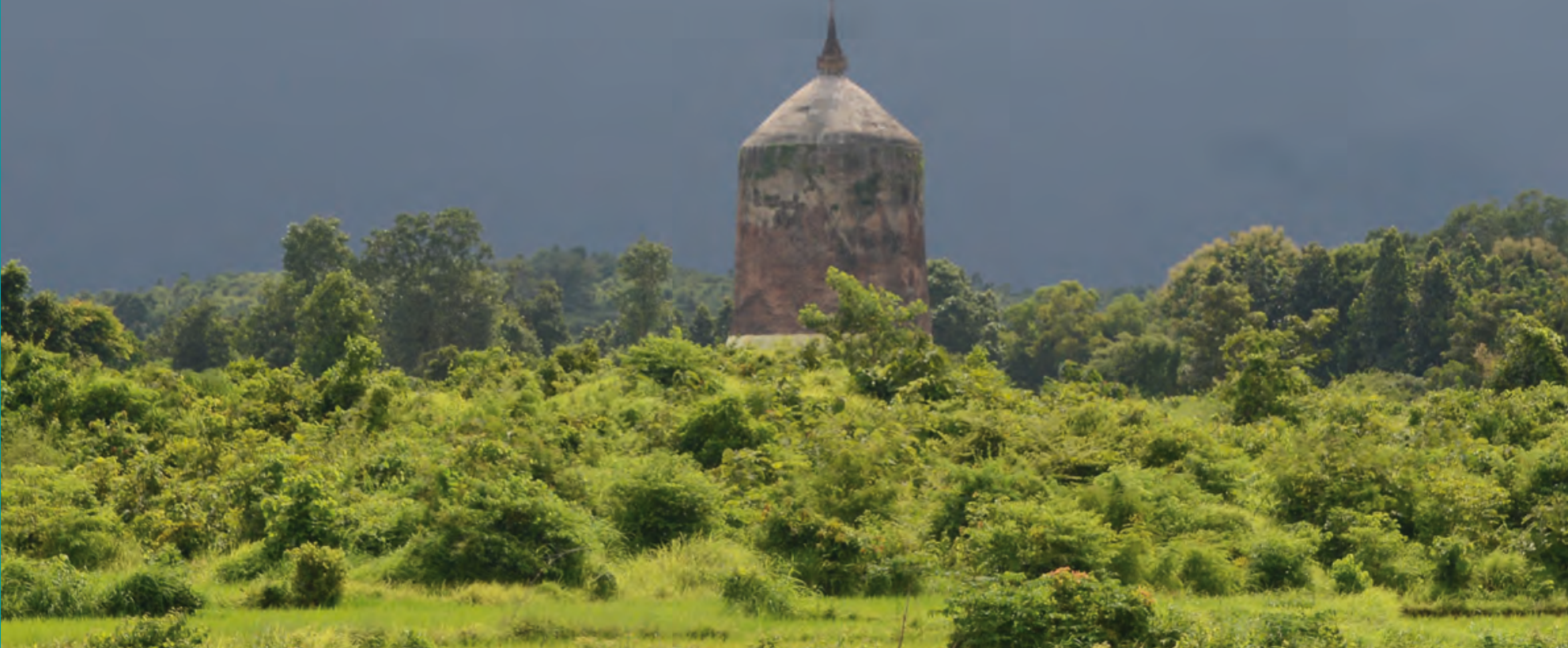

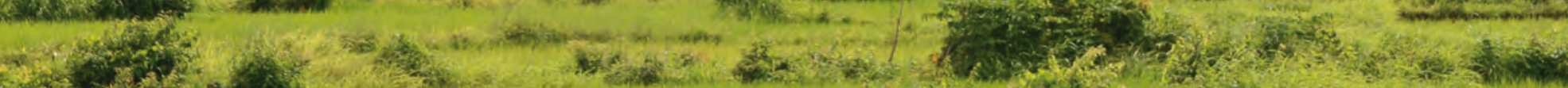

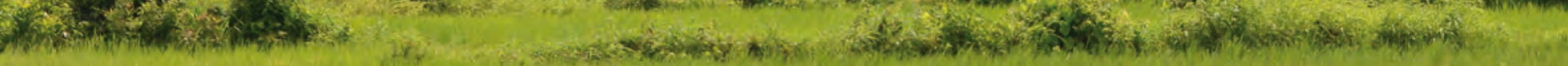
whang 


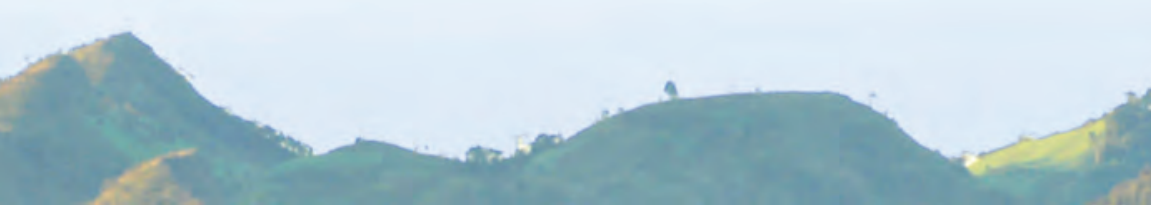

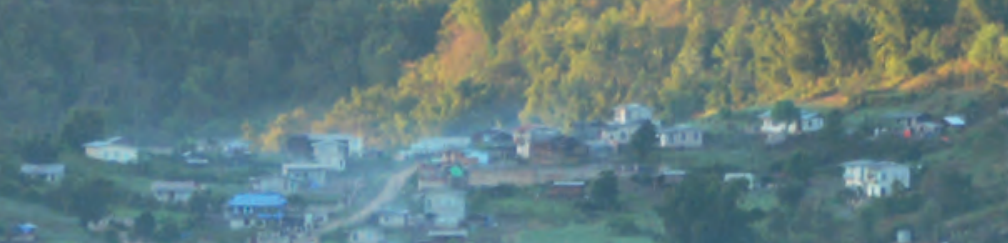

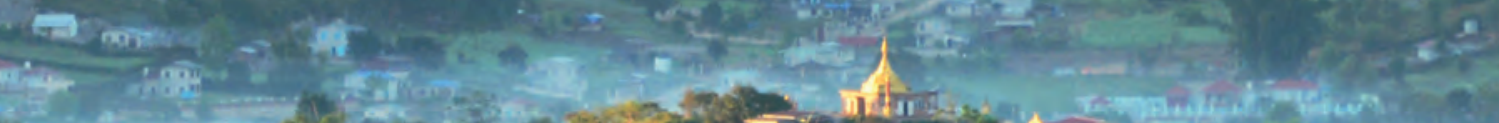

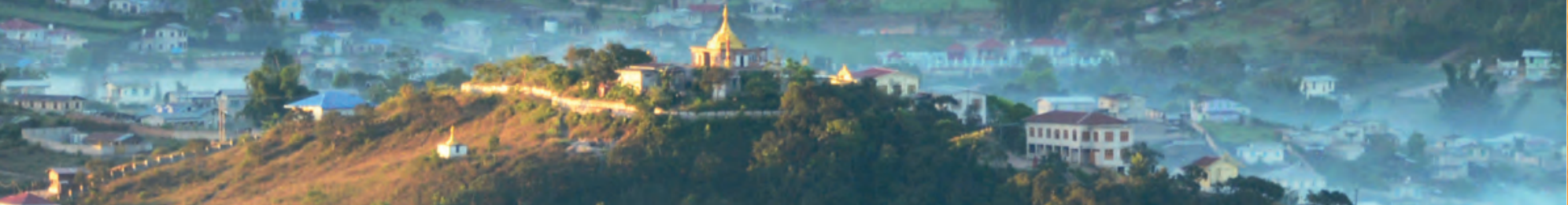

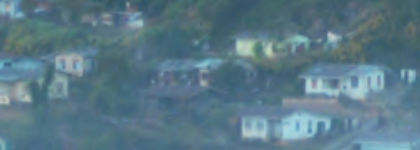

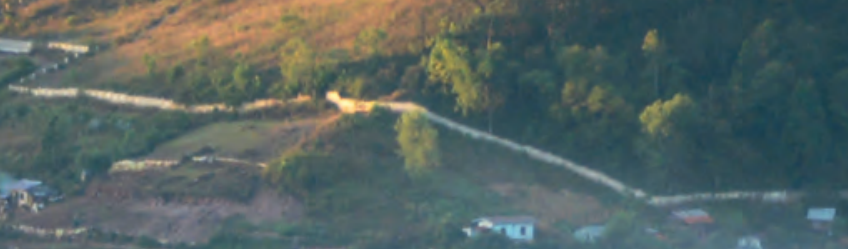

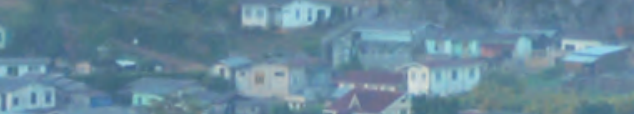
(6)

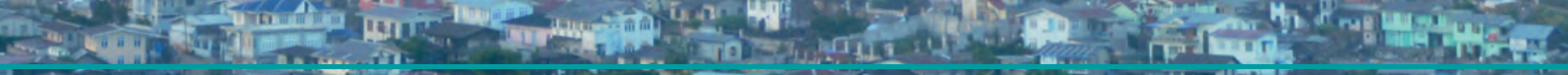
Till

Institute of Geography,

University of Cologne, Germany

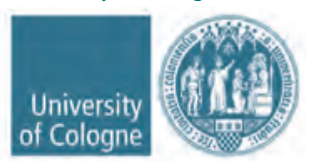

Ministry of Construction y Pyi Taw, Myanmar

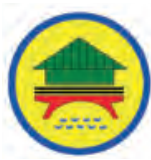

Franz Steiner Verlag

ISBN 978-3-515-11623-7

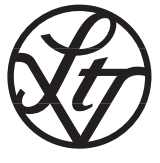

9 783515116237

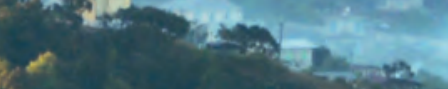

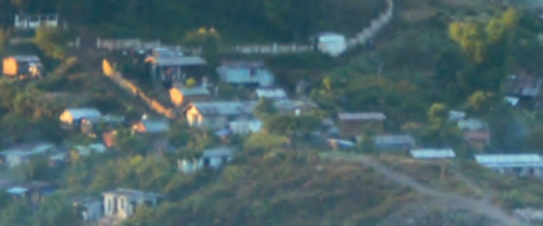

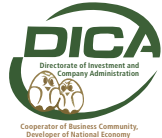

Directorate of Investment Administration (DICA)

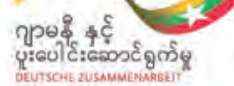

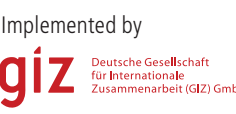
(2) 